\title{
POLICY ADVISORY CAPABILITY IN PAPUA NEW GUINEA'S CENTRAL GOVERNMENT: EVALUATION, IMPLICATIONS AND LESSONS
}

A thesis submitted to the Victoria University of Wellington in fulfilment of the requirements for the degree of Doctor of Philosophy in Public Policy

By

Lawrence L. Sause

School of Government

Victoria University of Wellington

2008 


\begin{abstract}
There has been mounting criticism (generally associated with the "weak state thesis") of the inability of the Papua New Guinea (PNG) public service to discharge its various policy formulation and implementation tasks. Such criticisms tend to be generalised in nature. Information about performance and the operational deficiencies of specific departments and policy domains derived from scholarly research has been sparse. Against this background, and using as a measure key elements of capability from the development administration literature, this study examines the state of policy advisory capability in three key central agencies within the PNG central government; identifies key constraints on the agencies' ability to provide comprehensive and reliable advice; and then proposes policy intervention measures aimed at strengthening capability.
\end{abstract}

The agencies play a very influential and significant role in the government advisory machine and comprise the Department of Finance and Treasury (DF\&T), the Department of Prime Minister and National Executive Council (DPM\&NEC) and the Department of Personnel Management (DPM). Analysis is primarily based on the responses from the policy staff of the lead policy units in each department. Such responses have been gauged using a questionnaire survey and in-depth interviews in early and late 2002 in Port Moresby.

This study shows that the problems affecting policy advisory capability are, in most cases, pervasive and systemic. Such a loss in capability tends to arise from a variety of interlocking (and often interwoven) problems from both the political and the administrative and organisational dimensions within which policy advice is developed and delivered.

On a broader level, the weakening of policy advisory capability raises important implications for the organisation and delivery of quality and timely advice. In particular, there is a risk that policy issues will not be comprehensively assessed taking into account the available evidence, views of parties concerned and, most important, the implications arising from various policy options provided to ministers and the National Executive Council (NEC) (cabinet). There is, therefore, a risk of ministers and NEC being ill advised on policy issues. This, in turn, may affect the executive branch's effectiveness in policymaking. The deterioration in the policy advisory capability of the three key agencies also gives rise to doubts about whether the three agencies can effectively maintain their key functions of control, monitoring 
and oversight and policy coordination across the PNG public service. There is a risk of the centre of the PNG government losing its ability to control and steer the government machine.

This conclusion is consistent with the existing anecdotal evidence of a deteriorating capability of the PNG public service and, to some extent supports the weak state thesis advanced in the literature. This study on the ground of three key agencies demonstrates, however, that the political environment is not the only cause of weak performance by the PNG public service. That is a function of a variety of interlocking political and administrative and organisational capability factors. An improvement in policy advice capability in PNG will require attention to the several systemic factors identified in the study. Using insights from the policy transfer literature this study shows that policy lessons from other jurisdictions could be drawn on to improve capability in policy advice in PNG.

This thesis was completed in January 2004 and finally submitted in April 2008. 
To my parents

Joseph Whazighembe and Clara Psirighas Sause 


\section{Acknowledgements}

This thesis would not have been completed without the support and encouragement of a large number of individuals and organisations. It is virtually impossible to name all of them here. Firstly, my appreciation and thanks to the People and Government of New Zealand for having sponsored me and my family during the period of my studies in New Zealand. And to the Victoria International staff especially Bronwyn Pollock (former staff) and Jay Neill, my sincere thanks for all your help.

To my supervisors, Professor Claudia Scott and Mr. John Martin, I owe a large debt of gratitude for their guidance and supervision of my PhD work. Their constant support and encouragement to finalise the corrections from the examiners is highly appreciated. John Martin brought also a deep personal commitment to help me finish this project - thank you John. I am also grateful to many other people in Wellington and the School of Government. In particular, I wish to acknowledge the support and friendship of Associate Professor Robert Gregory, Dr. Karen Baehler (who commented on the initial drafts of the survey questionnaire), the academic and administrative staff of the School of Government, the staff of the Papua New Guinea High Commission in New Zealand led by the High Commissioner, Her Excellency Lucy Bogari, and many Masters and PhD colleagues.

In Papua New Guinea, the assistance of the departmental heads of the Departments of Finance and Treasury, Prime Minister and National Executive Council and Personnel Management is acknowledged. I am especially grateful to the staff of respective policy units in the above departments who have provided valuable data both in the survey and the interviews. A special thanks goes to the heads of policy units and 25 policy staff involved in the survey and 23 others who were interviewed.

To those individuals who helped me with the necessary logistical arrangements, Chris Kalebo, Damien Horiambe, Raga Kila and Anthony Yauieb, thank you. My appreciation is also due to many friends and colleagues who have given me constant encouragement. I am especially grateful to Kindin and Leah, David Kavanamur, Henry Okole, Elly Kinkin, Daniel Aloi, Billy Nuegu, Casper Periwanga, Lucas Michael, the Donigis, David Jones, Brian Sam, Roger Kilembe, and my brothers, Michael and Alfred, for their constant encouragement.

To my wife, Maureen and my two children, Brent and Scott, my deepest appreciation and thanks for bearing with me and your never-ending love, support and 
encouragement. Finally to my parents, Joseph and Clara Sause, who were never educated but taught me the virtue of being educated and worked hard to give me an education, my profoundest thanks and appreciation.

The views and opinions expressed in this thesis are entirely my own and should not be attributed to the above people or organisations.

\section{Lawrence Sause}

Port Moresby

April 2008 


\section{List of Abbreviations}

\begin{tabular}{|c|c|}
\hline AS & Assistant Secretary (PNG) \\
\hline ANAO & Australian National Audit Office \\
\hline APS & Australian Public Service \\
\hline AusAID & Australian Agency for International Development \\
\hline FAS & First Assistant Secretary (PNG) \\
\hline BVF & Best Value Framework (UK) \\
\hline CACC & Central Agencies Coordination Committee (PNG) \\
\hline CCMA & Code of Conduct for Ministerial Advisers \\
\hline CCMD & Canadian Centre for Management Development \\
\hline CIDA & Canadian International Development Agency \\
\hline CMPS & Centre for Management and Policy Studies (UK) \\
\hline CPRN & Canadian Policy Research Network \\
\hline DFID & Department for International Development (UK) \\
\hline DF\&T & Department of Finance \& Treasury (PNG) \\
\hline DPM & Department of Personnel Management (PNG) \\
\hline DPM\&NEC & Department of Prime Minister \& National Executive Council (PNG) \\
\hline DS & Deputy Secretary (PNG) \\
\hline EPU & Economic Policy Unit, Department of Finance \& Treasury (PNG) \\
\hline FAS & First Assistant Secretary (PNG) \\
\hline HDI & Human Development Index \\
\hline $\mathrm{ICT}$ & Information and Communication Technology \\
\hline ND\&GS & $\begin{array}{l}\text { National Development \& Government Service, Department of Prime } \\
\text { Minister \& National Executive Council (PNG) }\end{array}$ \\
\hline NEC & National Executive Council (Cabinet) (PNG) \\
\hline NPM & New Public Management \\
\hline NSO & National Statistics Office (PNG) \\
\hline NZAID & New Zealand Agency for International Development \\
\hline OECD & Organisation for Economic Cooperation and Development \\
\hline OLPLLG & Organic Law on Provincial \& Local-Level Governments 1995 (PNG) \\
\hline PFMA & Public Finance Management Act 1995 (PNG) \\
\hline PIU & Performance Innovation Unit (UK) \\
\hline PMR & Policy Management Review (Australia) \\
\hline PNG & Papua New Guinea \\
\hline PSC & Public Service Commission (PNG) \\
\hline PSMA & Public Service Management Act 1995 (PNG) \\
\hline
\end{tabular}


PSRMU Public Sector Reform Management Unit, Department of Prime Minister and National Executive Council (PNG)

PRI Policy Research Initiative (Canada)

SCMC Salaries, Conditions \& Monitoring Committee (PNG)

SOI Statement of Intent (New Zealand)

SP\&D Strategic Policy \& Development Branch, Department of Personnel Management (PNG)

SSC State Services Commission (New Zealand)

UNDP United Nations Development Programme

UK United Kingdom 


\section{Table of Contents}

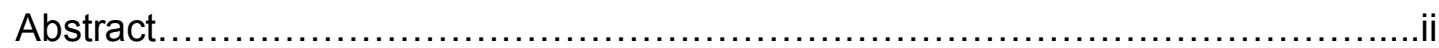

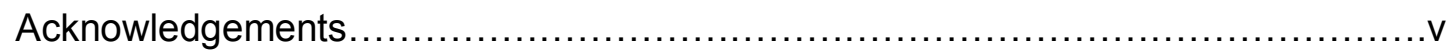

List of Abbreviations...............................................................

\section{Part I: Introduction and Background}

Chapter One: Introduction ....................................................................

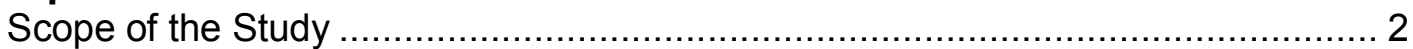

Key Concepts and Definitions ...................................................................... 3

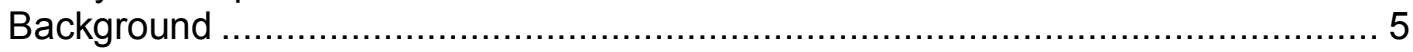

Problems of Administrative Capability in Developing Countries........................ 7

Experience of Papua New Guinea............................................................. 9

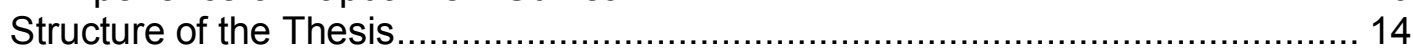

Chapter Two: The Papua New Guinea Public Service and the

Organisation of Policy Advice .............................................................16

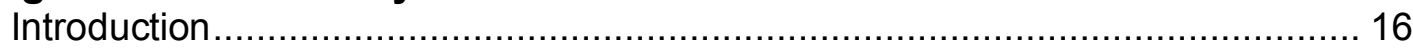

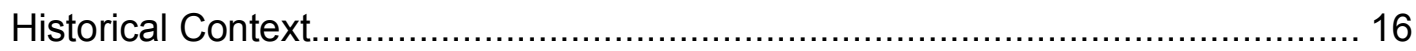

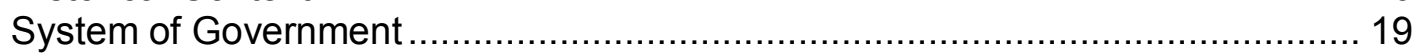

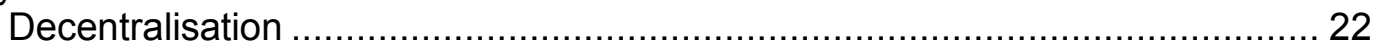

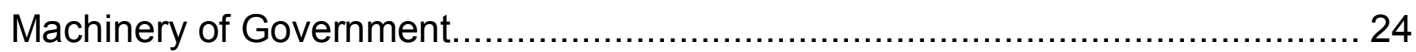

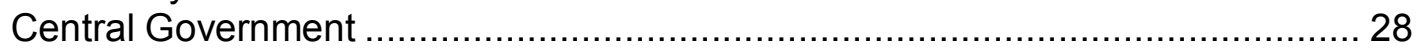

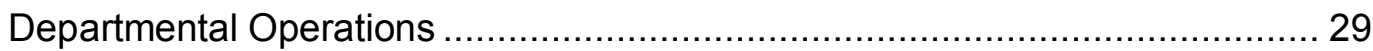

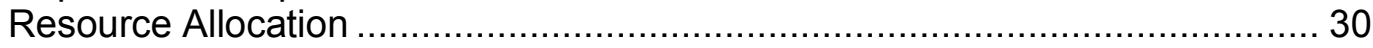

Organisation of Policy Work within Departments.............................................. 34

Vertical and Horizontal Arrangement of Policy work ..................................... 36

The Role of the CACC............................................................................ 40

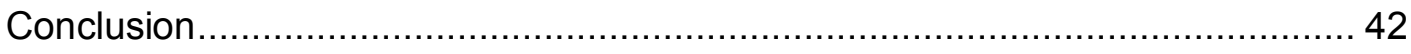

Chapter Three: The Dynamics of Policy Advice....................................44

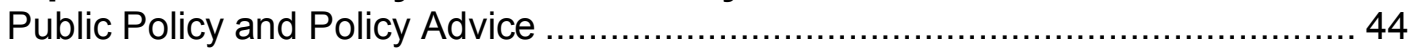

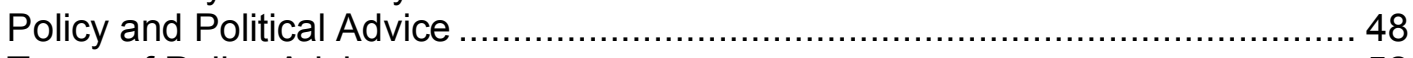

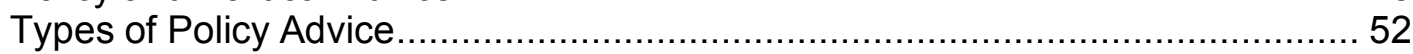

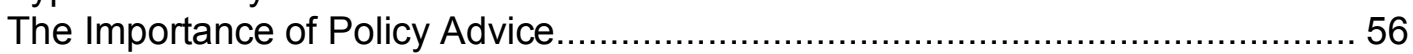

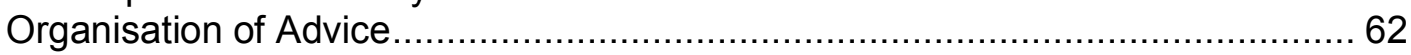

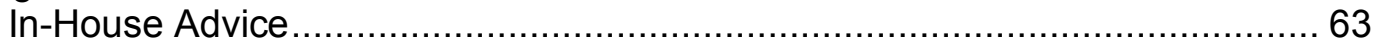

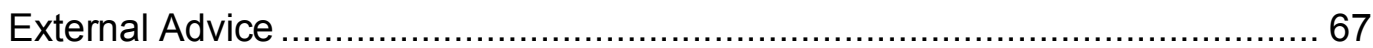

Improving Policy Advisory Capability: International Trends and Issues ...............6 68

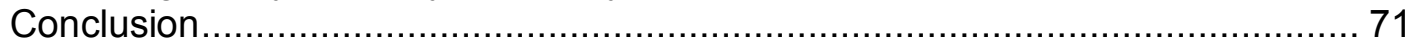

Chapter Four: Policy Transfer and Lesson Drawing ............................74

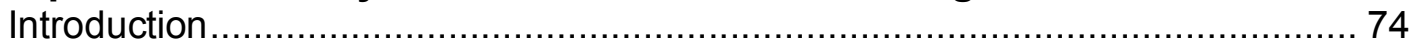

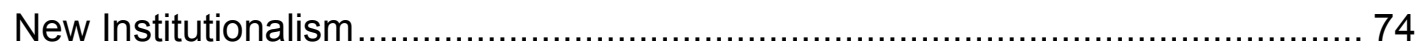

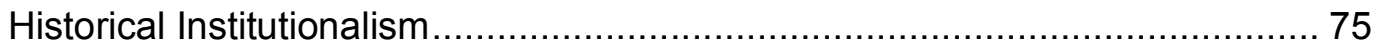

Rational Choice Institutionalism ......................................................... 76

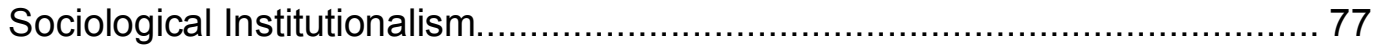

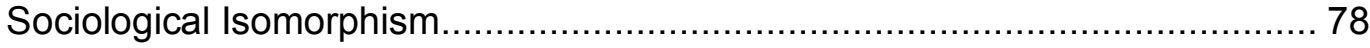

New Institutionalism and Policy Transfer ................................................. 82

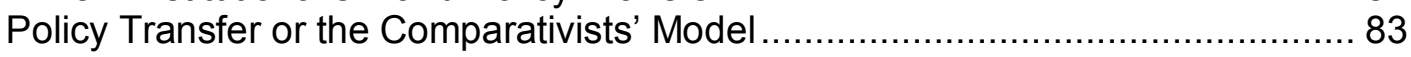

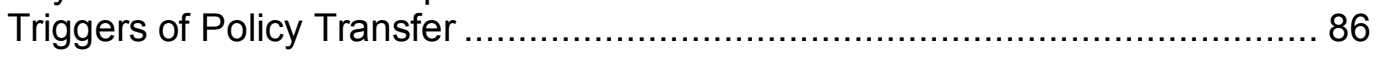




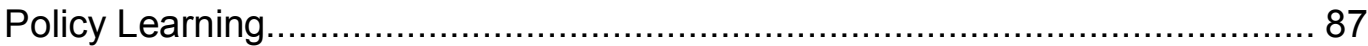

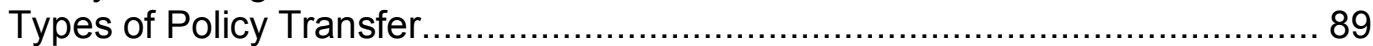

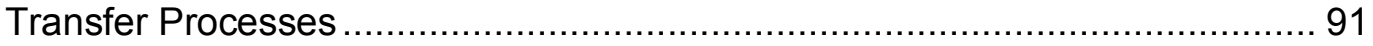

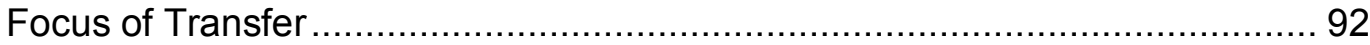

Policy Transfer and Policy Failure .......................................................... 92

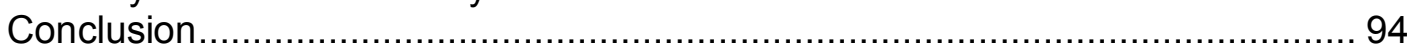

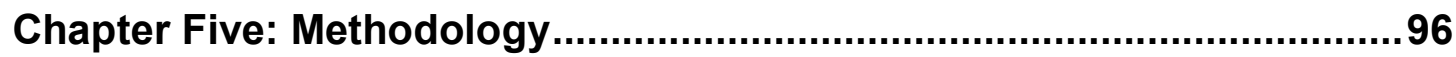

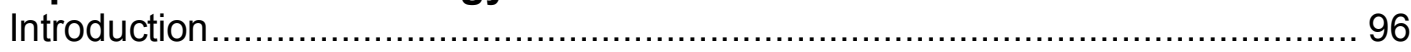

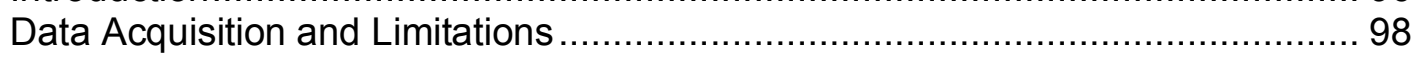

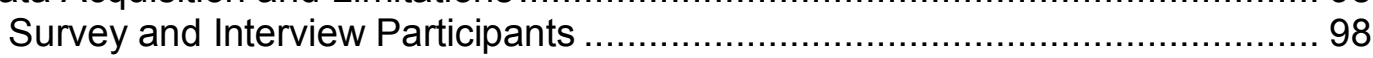

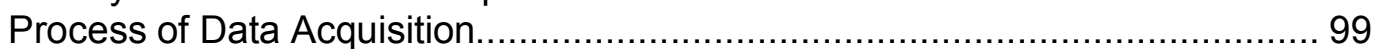

Difficulties and Limitations................................................................. 99

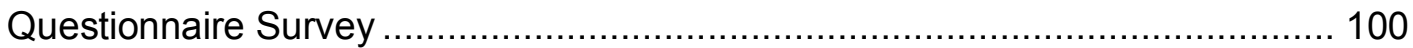

Summary Data of the Survey .............................................................. 102

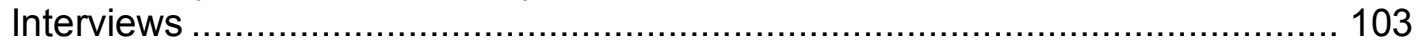

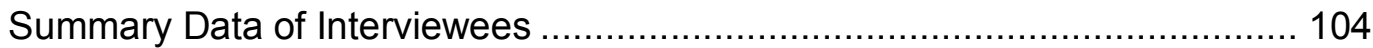

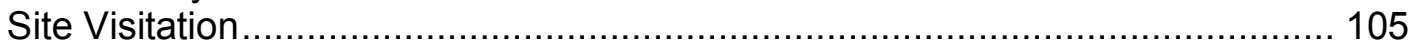

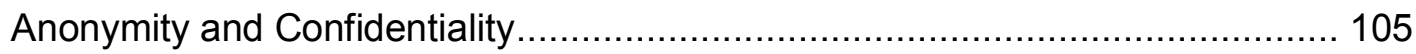

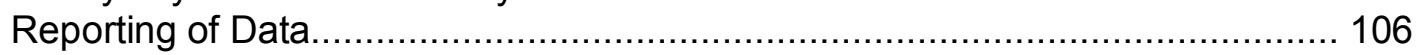

Chapter Six: Department of Finance \& Treasury (DF\&T).......................108

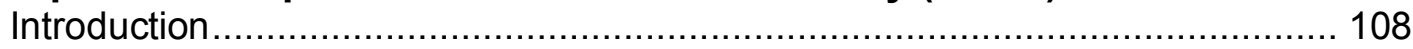

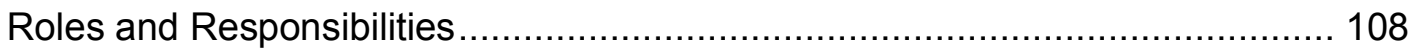

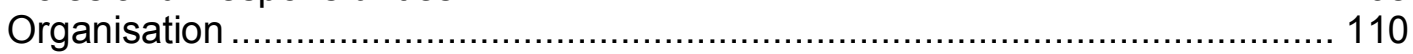

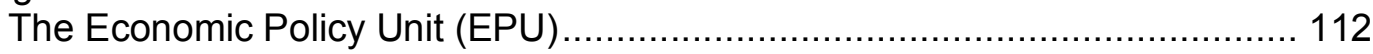

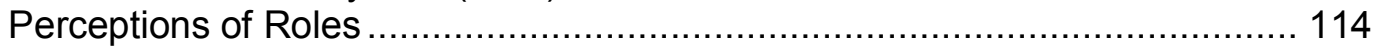

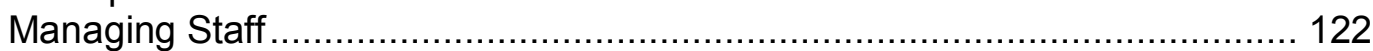

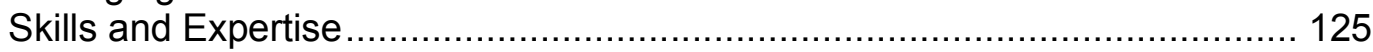

Developing Knowledge and Skills ..................................................... 127

Facilities for High Quality Policy Work .................................................... 131

Organisation of Policy Work .................................................................... 135

External Context of Policy Advice............................................................ 136

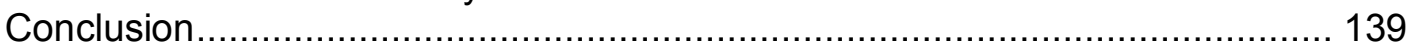

Chapter Seven: Department of Prime Minister and National Executive

Council (DPM\&NEC) ......................................................................140

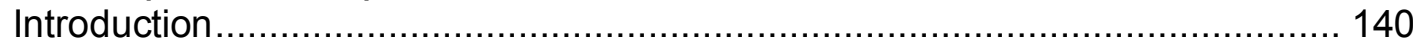

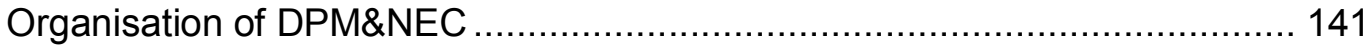

The Chief Secretary .................................................................. 142

The Department's Role in Policymaking ............................................... 144

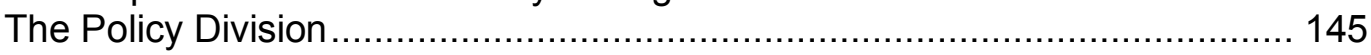

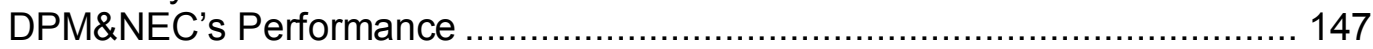

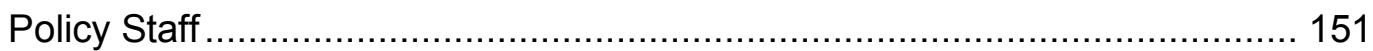

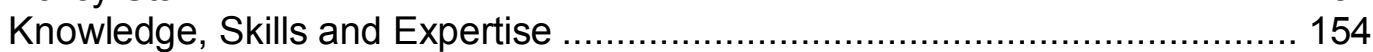

Developing Capability through Training .................................................... 156

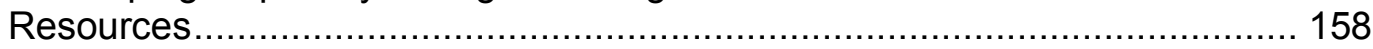

Planning and Organisation of Work ...................................................... 161

Political and External Factors ............................................................. 162

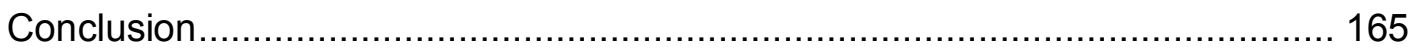

Chapter Eight: Department of Personnel Management (DPM)...............167

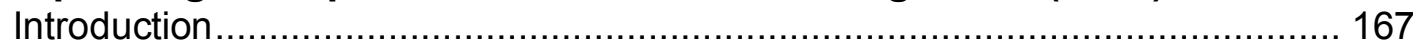

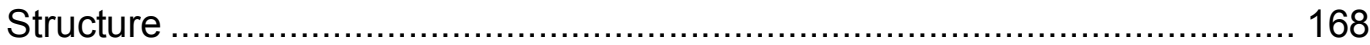

Functions of the Department ........................................................ 170 


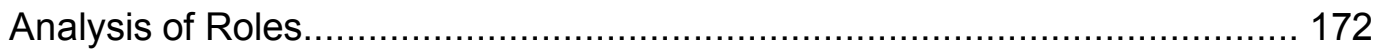

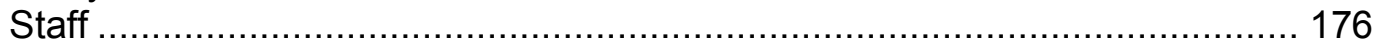

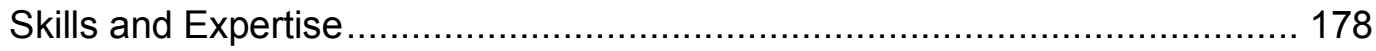

Knowledge and Skills Development ................................................... 179

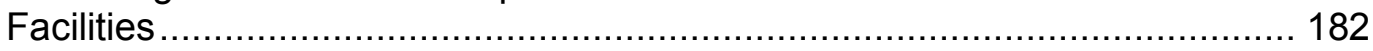

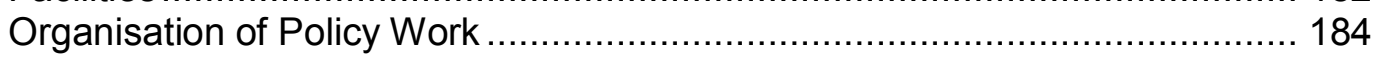

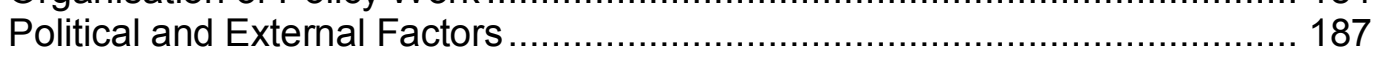

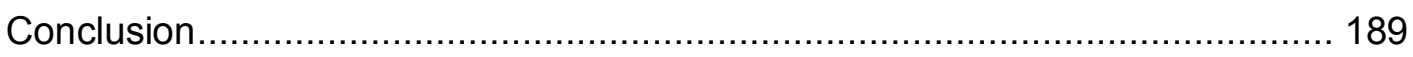

Chapter Nine: Evaluating the Status of Policy Advice ..........................191

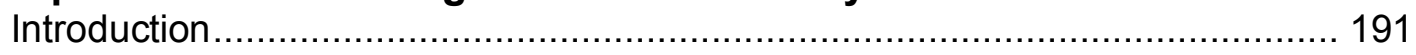

Evaluating the Central Features of Policy Advice.......................................... 191

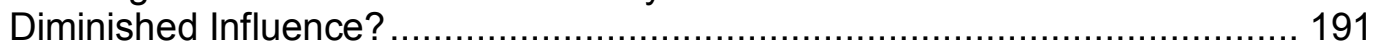

The Context for Organising Policy Advice ............................................... 194

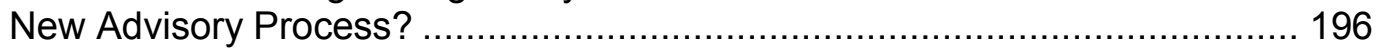

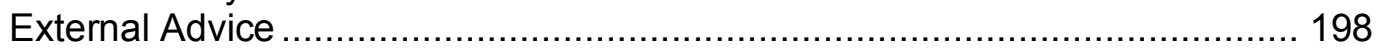

Tensions between Political and Policy Advisers ......................................... 199

Tensions surrounding Westminster Conventions...................................... 201

Ministerial Direction of Departments ..................................................... 202

Lack of Strong Ownership Interest by Ministers and Government .................. 203

Short-term Policy Cycles .......................................................................... 204

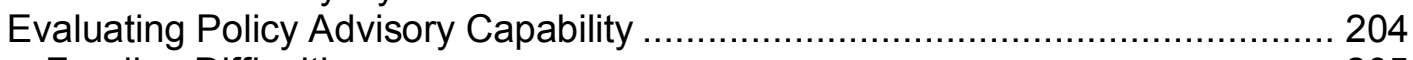

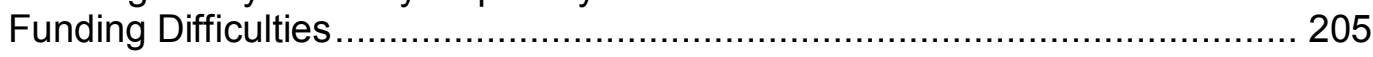

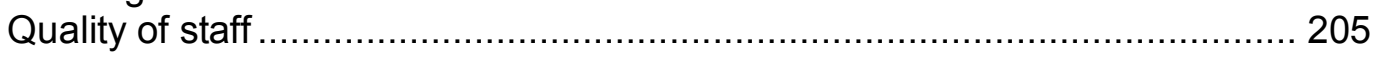

Level and Quality of Resources....................................................... 208

Organisation and Management of Policy Advisory Work ............................. 208

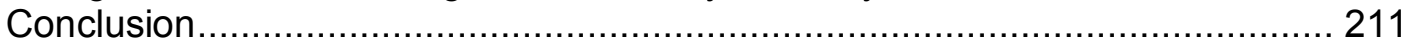

Chapter Ten: Strengthening Policy Advisory Capability — Some Policy

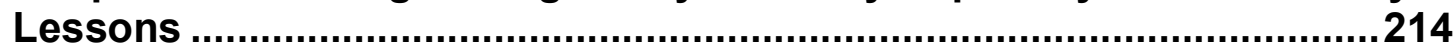

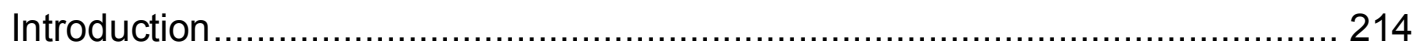

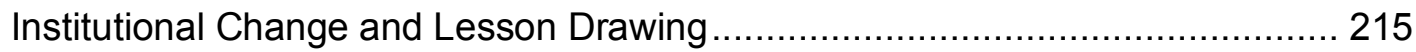

Lesson Drawing Process ......................................................................... 217

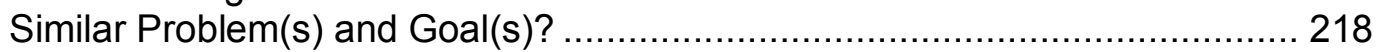

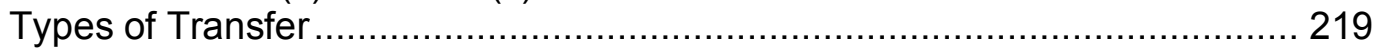

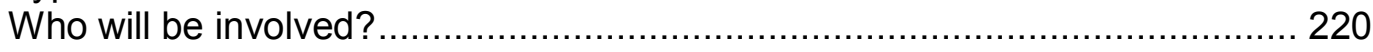

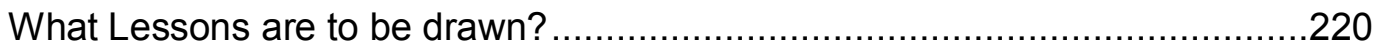

Applying Policy Lessons: Broader Considerations ........................................221

Policy Awareness and Policy Learning ....................................................221

Managing the Change Process ........................................................224

Extending the Scope of the Multiple Provider Arrangement.........................227

Stronger Policy Intervention Measures at the Political Level..........................231

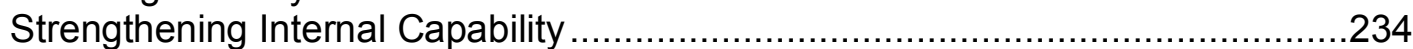

Building Effective Managerial Systems..................................................234

Strengthening Staff Competence ..........................................................237

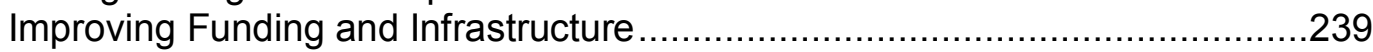

Establishing Best Practice in Policy Advice ...............................................244

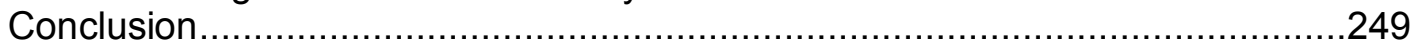

Chapter Eleven: Conclusion ................................................................251

The Weak State, Capability and Rational Analysis.......................................256

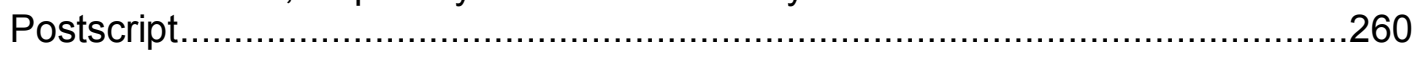

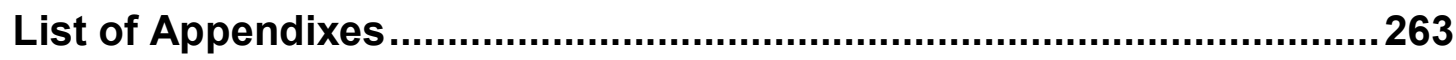

Appendix 1: Political Map of Papua New Guinea .........................................263 


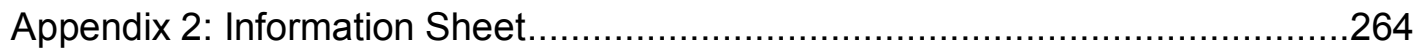

Appendix 3: Questionnaire Survey..............................................................266

Appendix 4: Sample of Interview Request Letter ......................................272

Appendix 5: Interview Consent Form ....................................................273

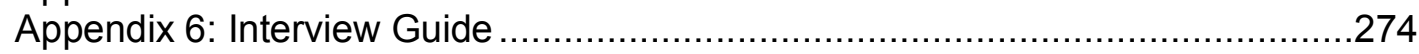

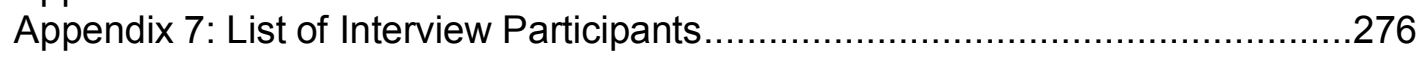

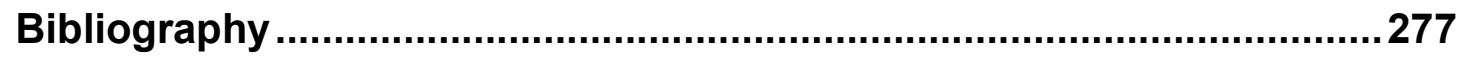




\section{List of Tables}

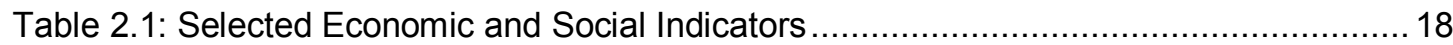

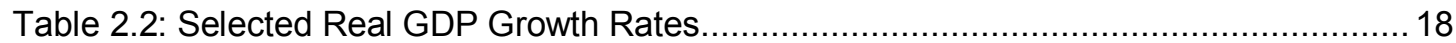

Table 2.3: The Organisation of the Government Machinery ......................................... 25

Table 2.4: Key Categories in Estimates Formulation .................................................... 31

Table 2.5: Financial Allocation to Departments, 1999-2003 (Millions of Kina) ......................33

Table 2.6: Salaries and Wages versus Operations \& Investments (Millions of Kina) ...............33

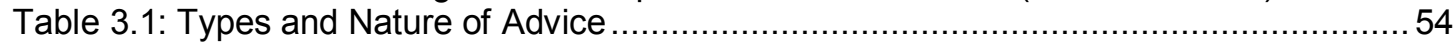

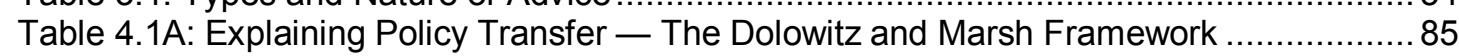

Table 4.1B:Explaining Policy Transfer — The Dolowitz and Marsh Framework .................... 85

Table 5.1 Selected Categories of Staff by Position and Grade ...................................... 101

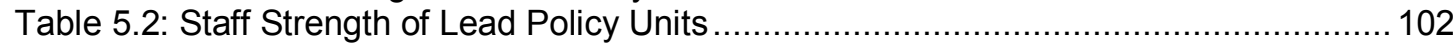

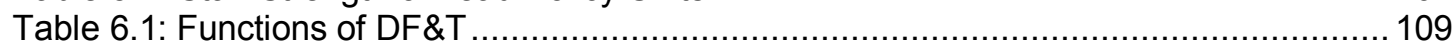

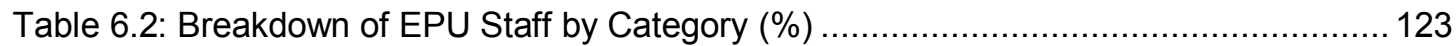

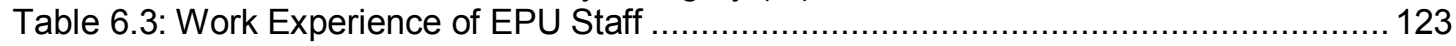

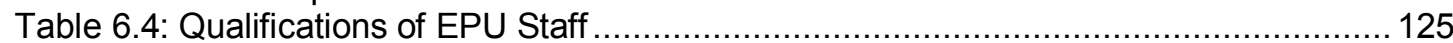

Table 6.5: Selected Expenditure Items 1999-2002, DF\&T (in K'000) ................................... 133

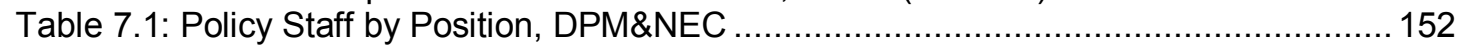

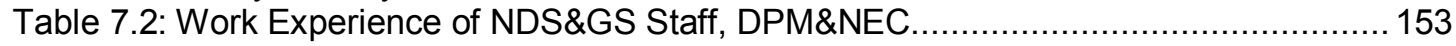

Table 7.3: Selected Expenditure of DPM\&NEC, 1999-2001 (in K'000) .............................. 160

Table 8.1: Breakdown of Staff by Major Category, SP\&D (\%)........................................... 176

\section{List of Figures}

Figure 2.1: Administrative Relationships in the PNG Public Service ...................................26

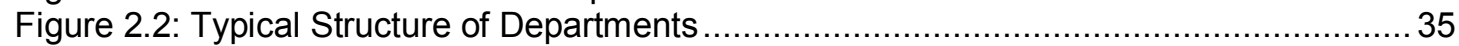

Figure 2.3 CACC in Vertical and Horizontal Policy Formulation ....................................... 41

Figure 3.1: Policy as Problem Solving and Policy Advice .............................................4 4

Figure 3.2: Sharpe's Four-Level Policy Framework ........................................................ 53

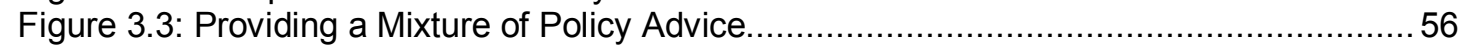

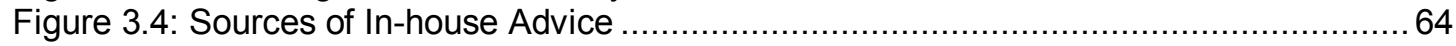

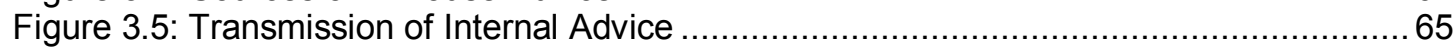

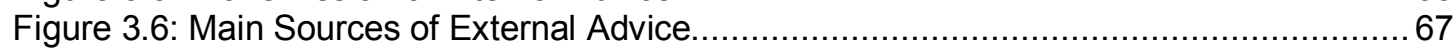

Figure 4.1: Policy Learning and Prospective Evaluation in Policy Transfer .......................... 89

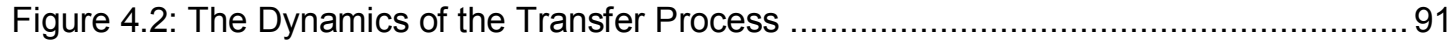

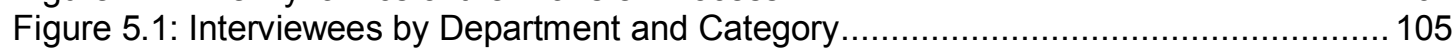

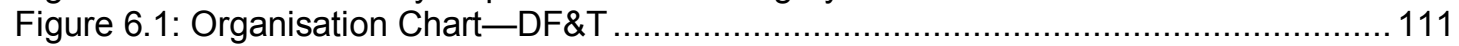

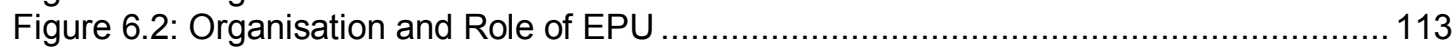

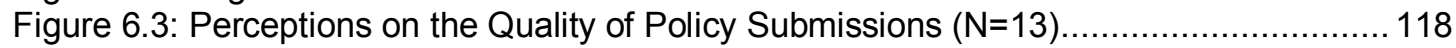

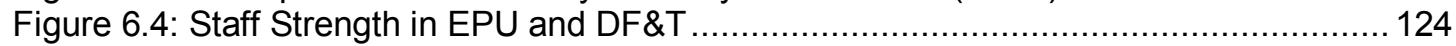

Figure 6.5: Spread of Qualification by Major Category, EPU …....................................... 126

Figure 6.6: Estimated Distribution of Funding to Training, DF\&T 1998-2002 (\%) ................. 130

Figure 6.7: Distribution of Funding to Capital Formation, DF\&T (\%) ................................. 133

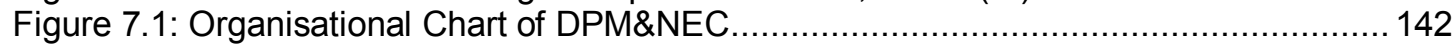

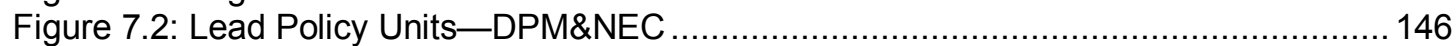

Figure 7.3: Distribution of Qualification by Major Category, NDS\&GS (\%) ........................... 155

Figure 7.4: Selected Financial Distribution to Training by Years, DPM\&NEC (\%) ............... 157

Figure 7.5: Practice of Ministerial Responsibility, DPM\&NEC (\%) ................................... 164

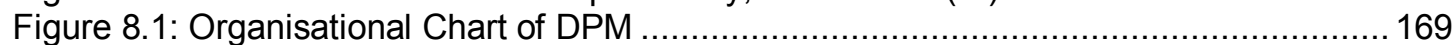

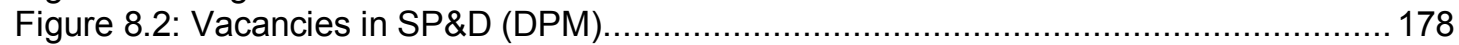

Figure 8.3: Distribution of Qualifications by Major Category, SP\&D (\%).......................... 178

Figure 8.4: Investment in Training and Skills Development 1999-2002, DPM (\%)............... 180

Figure 8.5: Selected Funding to Capital Formation 1999-2002, DPM (\%)......................... 184

Figure 8.6: Perceptions on Organising and Planning Policy Advice, DPM (\%) .................... 185 


\section{Chapter One: Introduction}

Problems in the polity and governance of Papua New Guinea (PNG) have led some observers to see PNG as a "weak state" (Dinnen et al, 1997; Dinnen, 2001; Curtain, 2000, 2002, Denoon, 2002; Reilly, 2002; Windybank and Manning, 2003; Hughes, 2003). For example, Dinnen (2001: 5) in his recent study of law and order in PNG says:

For many observers, Papua New Guinea is a classic example of a weak state.... Its institutional shortcomings are manifested in its limited capacity to maintain public order, to deliver government services and to implement policy decisions.

To some extent this perception about PNG is part of a broader analysis of the inability of the state and its administrative machinery, the public service, in developing countries to deliver effective governance and public services to the citizens. Such analyses, for example, can be found in the work of Mann (1984 cited in Polidano, 2000) and Migdal (1988). According to Mann, "infrastructural power" - that is, the ability of the state to penetrate society and see that its decisions are carried out - in many developing countries is either weak or lacking. Migdal sees it in another context, namely in "social control". He is concerned about the ability of governments to "regulate social behaviour" so that the state can maintain its authority. According to Migdal, the problem of social control, widespread in many developing countries, weakens state capacity.

Similar comments were made about PNG by Denoon (2002). Although he did not characterise PNG as a weak state, his analysis of PNG's parliamentary system as "completely unstable" and "a bureaucracy that cannot deliver public services either to the countryside or reliably to the towns" demonstrates some of the basic characteristics of a weak state.

Judgements of PNG's social, economic and political upheavals appear to be supported by the country's recent history (see, for example, Ghai, 1997; Windybank and Manning, 2003; Sause and Aloi, 2003). However, many such assessments appear to have originated from anecdotal and prima facie evidence. Furthermore, general accounts of politics and government highlighting a deteriorating capability of the PNG state are often used as bases for analysing the problems of the PNG public service. But, such analyses are often problematic. Little attention is given to the performance of departments and agencies in specific policy domains and they do not 
emerge from in-depth accounts of the contextual problems confronting departments and agencies within central government. Important questions need to be asked about the operations and management of departments and agencies in the PNG public service. What constraints do departments and agencies in PNG public service face? More specifically, do particular tasks encounter specific constraints? How do such constraints affect a department's effectiveness in carrying out those tasks? What measures should be taken to strengthen a department's capability to perform those tasks? This study attempts to answer some of these questions in respect of the three central agencies. ${ }^{1}$

\section{Scope of the Study}

Generally, this study is mounted against the perceived weakness of the PNG state and the public service's inability to effectively discharge its various functions. More specifically, it is spurred by the need to understand how departmental effectiveness in specific policy domains is constrained by various capability problems and how such constraints might be addressed. This thesis is specific, assessing the capability to provide quality and timely policy advice of the Department of Finance \& Treasury (DF\&T), Department of Prime Minister and National Executive Council (DPM\&NEC) and the Department of Personnel Management (DPM). It goes beyond the general inferences (and extrapolations) often made about the problems of the PNG public service by attempting to explain why and how performance in policy advice in these three agencies has been poor. Using the views and perceptions of policy officials ${ }^{2}$ drawn from a survey and in-depth interviews, key constraints are identified and their impact highlighted. Policy lessons are then drawn from the experiences of developed Westminster jurisdictions in order to reinvigorate the agencies' capabilities. This is done using the theoretical insights of the policy transfer or lesson drawing literature.

Three essential questions remain the primary focus of the thesis, viz:

a) Has policy advisory capability weakened in each agency and, if so, how?

\footnotetext{
1 The dearth of detailed studies of the working of the internal processes of executive institutions is not confined to PNG or even developing countries. For example, in the case of the UK, Rhodes notes, "There are enormous gaps in our knowledge of the key actors and institutions in British government. We cannot do simple things like describing the work of ministers of state, permanent secretaries and their departments" (Rhodes, Preface to Weller et al., 1997).

${ }^{2}$ In this thesis, "official" and "policy staff" will be used interchangeably.
} 
b) What are the key constraints faced by the three agencies in organising and supplying quality and timely policy advice?

c) How can the capability of the three agencies in organising policy advice be strengthened?

\section{Key Concepts and Definitions}

\section{Policy Advice}

The study primarily focuses on in-house advice organised and supplied by professional public servants as opposed to outside or external advice. Policy advice is essentially a recommended course of action aimed at addressing or tackling a given policy issue(s) provided by policy advisers to public authorities. In this study, policy advice is viewed as an outcome of a rational activity and/or process that takes place in departmental domains - in this case, within the three central agencies and is shaped by the political context within which it is provided.

The organisation and supply of advice may not necessarily follow the pattern often depicted in the literature, for instance in proceeding through the stages of the policy cycle (Hogwood and Gunn, 1984; Howlett and Ramesh, 1995; Parsons, 1995; Bridgman and Davis, 1998). Despite this, policy analysts and advisers follow a more or less rational process when analysing issues and submitting policy advice to policy clients. Confronted with issues, or when advice is requested by policy clients such as ministers and cabinet, policy analysts and advisers gather and collect relevant evidence and information; they diagnose the issue by examining its causes and effects; they use various rational methods of analysing the issues, some highly quantitative; they propose options, supporting such options with information and evidence considered to be relevant; and they provide advice in a given timeframe to decision-makers.

There are broad criteria that are widely accepted as defining quality and timely policy advice. The common benchmarks are that advice should be rigorous, relevant, evidence-based and timely (SSC, 1992; 1999; Waller, 1996; UK Cabinet Office, 2000; Office of the Provincial Auditor, 2001; Sanderson, 2002; Butterworth and Horne, 2003). It is also commonly accepted that although the provision of quality and timely policy advice depends on a robust process of analysis - i.e., how policy issues are analysed and the manner in which different policy options are formulated - more fundamentally it depends on the capability (comprising various elements) of 
both the policy officials and the agencies that tender advice (SSC, 1999a; UK Cabinet Office, 2000; Bhatta, 2002; Sanderson, 2002). ${ }^{3}$

\title{
Capability
}

At the day -to -day level, "capacity or "capability" is used interchangeably. ${ }^{4}$ Generally both concepts refer to the "ability, talent or competency" of personnel and organisations to effect or do something (Cohen, 1995: 409). Within the context of policy advice capability refers to "the ability to structure the decision-making process, coordinate it throughout the government, feed informed analysis into it..." and provide quality and timely advice to those to whom advice is given (Polidano, 2000: 810).

There are a range of interlocking factors that determine the capability of personnel and organisations. Furthermore there are different views on exactly what these factors are. This thesis follows the approach of the World Bank:

\begin{abstract}
The meaning and scope of capacity building can, however, be ambiguous. If narrowly defined as the provision of training and materials to build skills within organisations, capacity building is only part of the challenge of reforming public institutions... When more broadly defined to include reforms of incentives and institutions as well as
\end{abstract}

\footnotetext{
${ }^{3}$ Various ways of improving the process of analysis in policy advice have been proposed in the literature (see, for example, SSC, 1992; 1999; Waller, 1996; Sanderson, 2002). Virtually all the prescriptions improving analysis are based on the rational model of policymaking, recommending logical steps policy advisors should observe or follow when analysing issues (see for example, SSC, 1992; Butterworth and Horne, 2003: 220). However, the overemphasis on improving rational analysis tends to gloss the reality in many developing countries where a lack of capability in both personnel and organisations is a key problem. It is contended in this study that a focus on improving the process of analysis alone is unlikely to improve the quality and timeliness of policy advice. In the first place, important consideration should be given to improving capability of personnel and departments who provide policy advice.

${ }^{4}$ Although the two concepts are often used interchangeably, some scholars attempt to draw a fine line between the two concepts, arguing that there is a difference between "capability" and "capacity". For example, according to Franks (1999: 52), "capability refers to the knowledge, skills and attitudes of the individuals, separately or as a group, and their competence to undertake the responsibility assigned to them. Capacity, on the other hand, refers the overall ability of individuals or groups and the organisations combined to actually perform the responsibilities". Franks argues that this "depends on the capabilities of the people but also on the overall size of the tasks, the resources which are needed to perform them and the framework (organisational and institutional arrangements) within which they are discharged". It is argued in this thesis that the two concepts overlap and that the notion of "ability" or "competence" of individuals and organisations to effectively undertake their tasks remains central to each. In this thesis the term "capability" is used throughout and refers to the second definition, "capacity," offered by Franks (also see SSC, 1999, 1999a for a similar usage of the term).
} 
strengthening skills and resources...capacity building is synonymous with the concept of institutional development (World Bank, 2000a: 13).

Following the World Bank's approach, "capability" in policy advice is conceptualised broadly to be dependent on a variety of organisational elements including staffing, other resources, the process of organising policy work and the wider political environment in which departments and agencies in the public service operate.

\section{Background}

Central agencies - defined here as those few departments responsible for maintaining leverage and control over the public sector, and hence having an overriding influence at the centre of government — play a pivotal role in policymaking in both developing and developed Westminster countries (see Davis, 1997; Weller et al., 1997). The power and influence of each central agency varies, depending on factors that are unique to the central agency and the characteristics of the polity in individual countries. For example, Boston et al. (1996a: 125), attribute, inter alia, the strength of the New Zealand Treasury (NZT) to special characteristics such as the powerful and determined finance ministers who have been responsible for the NZT; the absence of a powerful prime minister's department which could provide countervailing advice on economic and financial matters; and the depth of the department's knowledge-base especially in neo-classical and organisational economics (see also McKinnon, 2003).

Generally, however, central agency functions are similar across both the developed and developing Westminster jurisdictions. First, and as mentioned by Davis (1997), central agencies are part of the "core executive" essentially responsible for "coordinating central government policies" while at the same time "acting as final arbiters of conflict between different parts of the government machine" (Rhodes, 1995: 12).

Second, they are "control agencies" (Boston, 1992: 89; Norman, 2002) because of their role in maintaining conformity and coherence in various policy guidelines and 
standards on a diverse range of policy and management issues. ${ }^{5}$ In performing such a role, they also scrutinise the performance of line departments and agencies. In some central agencies the control and steering roles are empowered by specific statutes, defining the manner and extent in which control is to be exerted. Financial statutes, for instance the Public Finance Act 1989 in New Zealand, or the Public Finance (Management) Act 1995 in PNG, are examples of enabling legislation which empowers central agencies such as the respective Treasuries to maintain control (for example, see Chapman, 1997). In other cases central agencies are responsible for "policy development" and "monitoring" (Campbell and Szablowski, 1979), implying that they initiate and develop overarching policies that have broad implications for the operations of government, as well as being responsible for ensuring their success.

Third, the powerful roles assumed by central agencies elevate them to a strategic position where they are able to exercise formidable influence over the policymaking process. Strategic positioning is therefore another defining feature of central agencies that cannot be matched by other departments and agencies within the public service. Being positioned at the apex of policymaking coupled with the strong links they have with politicians ensures that central agencies' input to the policymaking process can proceed without obstruction. This is evident in several ways. First, the Prime Minister is normally the ministerial head of a key central agency, the Department of Prime Minister and Cabinet. There is therefore a solid link between the chair of cabinet, cabinet policymaking and the Prime Minister's department. Second, senior members of cabinet are usually portfolio ministers of key central agencies - a typical example would be the Minister of Finance. Third, it is normally the case that such ministers would also be members of important cabinet committees and therefore a direct link between cabinet policymaking and their departments. In Britain, for example, the Chancellor of the Exchequer sits on many important committees and has a powerful influence in cabinet decision-making (Thain and Wright, 1995; Chapman, 1997). In PNG the Minister of Treasury and Finance is

\footnotetext{
${ }^{5}$ The concept of "control agencies" can be misleading especially when some central agencies have experienced some loss of control from managerial devolution in the new public management (NPM)-led reforms. For example, in New Zealand, the description "control" has given way to "central" when the State Services Commission lost its employer role across the public service and the Treasury ceded increased flexibility in financial matters to departments (see Scott, 2001; Norman, 2003). Nonetheless, in a wider sense used here "control" continues to denote a central agency function. This is especially the case in developing countries where central agencies retain much of their controlling power.
} 
a senior member of cabinet and sits on many important committees of cabinet. ${ }^{6}$ Fourthly, officials of central agencies (in most cases the departmental head) often have direct access to cabinet policymaking - a privilege not available to many other departments. Attending cabinet meetings to explain policy proposals emanating from departments or being used as resource persons in cabinet's deliberation of complex policy issues are two common ways in which central agencies are drawn directly into cabinet policymaking.

Finally, in some countries the power of central agencies is enhanced by the creation of high-powered advisory committees comprised exclusively of central agencies officials (see for example, Hennessy, 1986; Blackstone and Plowden, 1988; UK Cabinet Office, 2000; DPM\&NEC, 2000). Such committees are trusted by the government to carry out its various executive mandates and therefore are able to influence the operations of the government from the centre. As will be seen in Chapter Two, the Central Agencies Coordination Committee (CACC) within central government in PNG is an example.

\section{Problems of Administrative Capability in Developing Countries}

Although potentially central agencies have a lot of power over the process of policy advice, the positive use of that power depends on their capability to exercise it effectively. Central agencies with a strong administrative ability are more likely to utilise their power effectively, while weak central agencies may not utilise their power as effectively as they could. The latter appears to hold true for many central agencies in developing countries. Despite assuming powerful roles, attributable, at least in part to the many centralised controls placed in their hands and the close connection they have with the political executive, central agencies remain weak (Migdal, 1988; Polidano, 2000). Luke's (1990) analysis - one of the few focusing specifically on the policy role of central agencies in developing countries - highlights this problem. He observes that while central agencies are strategically positioned at the locus of power and therefore can influence policy, they are often in disarray and unable to play their roles effectively (Luke, 1990: 437). Confronted by a myriad of problems, they cannot effectively perform their key roles as agencies of the core executive and as key advisers to the government.

\footnotetext{
${ }^{6}$ In fact, during the tenure of the Morauta government, it has been common for the Prime Minister to combine both the finance and treasury and prime minister's portfolios.
} 
A pertinent issue, illuminated in Luke's analysis, with which many developing countries are grappling, pertains to weak administrative and organisational capability of their public service to maintain the operation of the government machine (Caiden and Wildavsky, 1974; World Bank, 1997; 2000a). The inability to manage effectively the civil service, poor implementation of policy, and inadequate delivery of critical services are often attributed to weak administrative capability both among key state institutions and individual departments of the public service (see Mutahaba and Balogun, 1992; Grindle, 1997; Polidano, 2000).

The lack of capability of the institutions of state and the inability of the public service machinery in developing countries to discharge their mandated tasks together with the need to reinvigorate flagging capability has become a central theme of scholarly analysis in the development administration literature spanning nearly three decades (see Brinkerhoff and Goldsmith, 1992; Mutahaba and Balogun, 1992; Rondinelli, 1993; Grindle and Hilderbrand, 1995; Grindle, 1997; Campos and Nugent, 1999; Klitgaard, 1995; World Bank, 1997; 2000; 2000a; Polidano, 2000). In particular, a lack of administrative capability was perceived to be a key cause of underdevelopment and was seen as a critical stumbling block to the future growth of developing countries (Turner and Hulme, 1997; World Bank, 1997). In Africa where the crisis of capability is most evident, it has been observed by some experts of the World Bank that "ethnic factionalism," "traditional ways of thinking" and "crises of capability" have plagued the continent with disastrous consequences (Easterly and Levine, 1997 in Sender, 1999: 90). This perception has forced many bilateral and multilateral agencies and international financial institutions (development agencies) to mount a variety of aid programmes aimed specifically at reducing existing capability gaps and strengthening the institutions of state and public services (see World Bank, 1997; 2000a; 2002).

Earlier efforts by development agencies focused primarily on improving capability through the transfer of physical and financial assets to many developing countries (Franks, 1989). However, the rapid deterioration of asset and infrastructure management made development agencies realise that necessary skills and expertise are needed if assets are to be effectively managed. As a result, subsequent efforts directed towards capability building placed a simultaneous emphasis on both transferring resources and on developing skills and expertise. However, this orientation too became problematic. It was found that institutional and organisational systems and processes, and the external political environment within which state 
institutions and public service organisations operate play a critical role in enhancing capability (Turner and Hulme, 1997; World Bank, 1997; 2000c). As a direct response, development efforts over the past decade have focused on improving systems and processes underpinning institutional and organisational operations, as well as on strengthening state and political institutions - broader governance issues (see World Bank, 1997; 2002). Despite these ongoing efforts, however, capability problems still present a formidable challenge in many developing countries, as is evident in the work by many development agencies (see for example, UNDP, 2001).

\section{Experience of Papua New Guinea}

As a developing country PNG faces similar capability problems to those highlighted above. Anecdotal evidence suggests that problems associated with the elements of capability mentioned above are present. There is a burgeoning literature on PNG and most of the publications make reference to capability problems in the public service. A good part of what is already written pertains to politics and governance issues, analysing how PNG's political system operates and the problems of governing associated with the "weak state" thesis. Such analyses for example, are illustrated by the writing of Dinnen (2001) cited earlier, Dorney (1990) on the workings of PNG's parliamentary democracy, Turner (1990) on the challenges facing PNG since independence, and more recently in a number of studies on electoral politics and state/society relations (Reilly, 1997, 1999, 2000, 2002; Larmour 2002).

Recent analyses of problems of governance and public administration have also appeared in the writings of Windybank and Manning (2003) and Hughes (2003) two analyses that received wide publicity in PNG. The assessment by Windybank and Manning, although focusing generally on the deterioration of the PNG state (and therefore the need for more robust support from Australia), raised important points about the capability of the PNG public service. They, for example, compared the dismal state of important public services such as health and education to the rest of the Asia Pacific region, implying that the deterioration of such services stems from the inability of the public service to maintain its role in service delivery, and that there is a need for PNG to catch up with the other countries in the region (Windybank and Manning, 2003: 3).

Some analyses tend to concentrate on a specific policy domain and a single department. This has been evident in recent studies concentrating on economic and fiscal issues in a single agency, the Department of Finance and Treasury (DF\&T), 
and the role of the elected government in managing the economy and the fiscal affairs of the state (see Duncan and Temu, 1995; Curtain, 2000; 2000a, 2002). Although drawing attention to some aspects of departmental capability, these analyses are usually limited to analysing the adverse consequences stemming from the inability of DF\&T or the government to manage the economy and public finances.

Some analyses of the public service do, however, give some direct attention to the capability problems of the public service. Numerous publications by the World Bank are illustrative. For example, in a 1995 Report the World Bank observed:

It was not so long ago that Papua New Guinea could take pride in its effective and expanding public services. During the self-government and early post-Independence period, primary schools and basic public facilities were constructed throughout the country. Enrolment rates were rising, while infant mortality declined. New roads were built. Old ones were maintained...National agencies helped set the direction and standards for these services...the budget was almost balanced and made prudent use of resource-based revenue... (World Bank, 1995: 1).

The same Report mounted a stinging critique of the public service's performance in the subsequent page:

Indicators suggest that there has been serious deterioration in the quality of many services. Recent studies have found an alarming spread of familiar diseases amid sharp decline in health services. In education, the attrition rate at the primary level is exceptionally high and rising. In infrastructure, expenditure for maintenance per kilometre has declined by 70 percent in less than a decade (World Bank, 1995: 2).

In addition, a few studies of specific sectors in PNG provide some useful information about the types of capability problems encountered in these sectors. In the health sector, Kolehmainen-Aitken (1992) notes that the health service has been severely undermined by a lack of concerted efforts to decentralise and properly manage health functions. Confused responsibilities, rivalry between provincial and national governments, shortage of funds, lack of planning capacity and the shortage of skilled manpower have all contributed to eroding the capacity of the department to deliver health services.

To be sure, the Department of Health has a better reputation than most agencies in the country. That does not mean, however, that it has escaped the woes associated 
with capability problems. Bennett and Mills' 1998 study involving institutional capacity in organising and managing contracts for clinical and ancillary health services across six countries - India (Bombay), Mexico, PNG, South Africa, Thailand and Zimbabwe - indicates a range of administrative problems in the Health Department in PNG.

While the study laid most of the blame on the Department of Finance, it notes that the Department of Health was partly to be blamed:

Problems commonly stemmed from quality specifications not being adequately written into contracts, so there were neither clear quality standards which should be achieved nor obvious measures of quality to use in monitoring...there were frequently weak incentives to monitor or use information. This predicament is particularly clear in the PNG case study (Bennett and Mills, 1998: 315).

At the provincial and district levels, similar capability problems are evident even though the Organic Law on Provincial and Local Level Governments (OLPLLG) passed in 1995 had envisaged an active provincial and district administration at the lower tier of governments. The underlying justification for the OLPLLG was to devolve political, administrative and fiscal responsibilities to provincial and local governments so that they could be more effective in policy formulation and implementation. However, after several years it was noted that health care has declined, fewer children now go to school, and infrastructure facilities (roads, bridges, airstrips and wharfs) are falling apart in many provinces (Sause and Kinkin, 1997; Leechor, 1997).

Falling public services are accompanied by the inability to maintain effective systems and processes of administration. In 2002, the Permanent Parliamentary Committee on Public Accounts noted with shock and dismay that since 1995, provincial governments have failed to account for K2.7 billion of public funds (The National, Wednesday, 25 September 2002). ${ }^{7}$ There were no audits; nor were financial statements furnished to the relevant national authorities. Provincial heads of the civil service and their treasurers were unable to tell the Committee about the causes, claiming that, "their main problem has been a lack of capacity within the provincial treasury offices to carry out audits as well as provide financial statements" (The

${ }^{7}$ Kina $(K)$ is the currency of Papua New Guinea. One hundred Toea is equivalent to One Kina $(\mathrm{K} 1.00)$ 
National, Wednesday, 25 September 2002). ${ }^{8} \quad$ Deficiencies of fiscal and administrative accountability continue to haunt departments and agencies at the centre as well, as revealed by the Auditor General in the same review.

The general perception from some of the analyses mentioned above appears to support the view that lack of capability is a pervasive problem for the country. Moreover, this view appears to be held at the ministerial level:

The quality of public sector management in PNG has deteriorated over the past decade. As strongly emphasised by the Government, poor governance is the root cause. The public sector's capacity for designing and implementing sound policies and to manage its responsibility has been eroded. A broad consensus has arisen that the situation must be reversed (Prime Minister, Sir Mekere Morauta quoted in the ADB News Release 192/01, 12 December 2001, p2).

A more precise account of the capability of the central agencies that are the subject of this study is contained in a recent official report by the government. The report (PSRMU, 2000) published by the Government's Public Sector Reform Management Unit within the Department of Prime Minister \& National Executive Council (DPM\&NEC) lists findings from a number of reviews on line departments' performance. It revealed, inter alia, that there is an "absence of clear understanding of what the key functions, roles and responsibilities of departments are; financial and operational relationships between line agencies and central agencies, especially Treasury \& Finance and Personnel Management are, inefficient and effective; and there is little long term policy development and planning" (PSMRU, 2000: 9). The report $(p, 9)$ noted that, "preliminary reviews into the DPM\&NEC, Treasury \& Finance and Personnel Management confirm that these problems are widespread". Thus, one could conclude that the three central agencies are facing the same capability problems as line departments.

\section{Sparse Knowledge of Public Service Operations and Capability}

General conclusions from assessments such as those mentioned above do not in themselves meet the demands of rigorous scholarly scrutiny - a key requirement for gaining a deeper, fuller understanding, of the capability problems confronting the PNG public service. A major drawback of some of the analyses mentioned above is

\footnotetext{
${ }^{8}$ See http://www.thenational.com.pg/0925/nation1.htm [25.09.2002] and http://www.thenational.com.pg/0925/nation2.htm [25.09.2002]
} 
that they are often cast widely, painting a broad picture of the PNG public service, without being department-specific. Some of the published literature on politics and governance cited above is illustrative. Furthermore, some aspects of PNG government have been studied more than others (e.g., elections and electoral polities, politics and governance, and macroeconomic management); some have received relatively little or no attention (e.g., departmental operations and management). For those areas which have been given less scrutiny, knowledge is sparse.

Secondly, there is often an emphasis on the problems created by a lack of capability of public service organisations without an equal emphasis on what has caused such a lack of capability. For example, the 1995 World Bank report mentioned earlier and the 2000 PSRMU report are illustrations. In the case of the World Bank, for example, the reduced level of education and health services suggests that departmental capability is lacking, but the report does not explain why and how capability has diminished and/or weakened. In the case of the PSRMU, one is told about the problems of capability, but the causes (and how these causes have come about) remain unclear.

A final deficiency in the literature on PNG governance and public administration is the failure to prescribe viable solutions for the problems encountered in the public service. Public service functions are diverse and in some cases, distinctive in terms of their nature and objectives. Such differences often require the adoption of specific intervention measures for each policy domain. Generalised policy intervention measures, though applicable in some instances, are often, therefore, unlikely to be adequate. Thus, in order to prescribe more effective policy intervention measures (policy solutions), it would be necessary to undertake studies in particular policy domains that will assist the comprehension of existing problems and the particular circumstances in which such problems have emerged. In this regard, the PNG public service has a long way to go.

Some of the problems discussed above can be found in the three central agencies analysed in the present study. In particular, no study is available that determines their level of capability, although anecdotal evidence does seem to indicate that their capability has been weakened in the last decade (PSRMU, 2000; Barry and Harris, 2002). Nor is there any published study that has examined the specific role of the three central agencies in policy advice in PNG. As a result there is very limited 
understanding of the policy advisory role of the three agencies and their capability. Yet the three agencies play a very significant and influential role in advising ministers and cabinet (National Executive Council) - indeed, more influential than any line department or agency.

The present study is designed to address the gaps in knowledge mentioned above. On a micro scale, it aims to contribute to a fuller understanding of the role the three central agencies play in organising and supplying policy advice and how this role is being constrained by capability problems. On a broader scale, it aims to contribute to the general literature on the constraints in capability building in developing countries by discussing the experience of the three PNG agencies.

\section{Structure of the Thesis}

The thesis has four main parts totalling eleven chapters. Part One contains the introductory and background material (Chapters One and Two). Chapter One (this chapter) briefly defines the scope of the study and provides the rationale upon which the study is mounted. Chapter Two offers an overview of the structure and operations of the PNG government and public service and aims to provide those unfamiliar with PNG with a broad knowledge of how policy advice in that country is shaped by political and administrative forces.

Part Two consists of Chapters Three and Four and offers a discussion of the relevant literature and theoretical framework. Chapter Three analyses the dynamics of policy advice, explaining the nature and types of advice and the systems and processes in which policy advice is organised and delivered. Chapter Four discusses the policy transfer and lesson drawing literature, showing how, why and where policy lessons are drawn and applied among different settings.

Part Three reports the main empirical investigation addressing the two key questions of the study - how is policy advice affected, and the key constraints on policy advice - and consists of Chapters Five, Six, Seven, Eight and Nine. Chapter Five explains the methodology used. Chapters Six, Seven, Eight and Nine discuss in detail the organisation of policy advice in each central agency and present the findings from the survey and interviews for each agency. Chapter Nine presents a broad evaluation of the study drawing on the analysis in the previous chapters. It evaluates the central features of organising policy advice within the three agencies, raises the implications 
arising from these features and then rehearses the key problems on policy advisory capability.

Part Four contains the policy lessons and conclusions and consists of Chapters Ten and Eleven. Chapter Ten addresses the final question of the study by discussing ways in which the policy advisory capability of the three agencies might be strengthened. Using the theoretical insights of the policy transfer and lesson-drawing framework, this chapter offers explanations of how particular lessons might apply to the three agencies, and what lessons and transfer techniques could be employed to reinvigorate policy advisory capability. A variety of lessons are considered for transfer using different transfer techniques. The final chapter, Chapter Eleven, contains the conclusion. This chapter briefly summarises the findings of the study and various policy implications arising from these findings. A particular emphasis is placed on the relationship between these findings and the weak state thesis as applied to PNG. Because of the significance and relevance of developments towards the end of 2003 (in the final weeks as this thesis was being completed) a brief Postscript noting these events has been added. 


\section{Chapter Two: The Papua New Guinea Public Service and the Organisation of Policy Advice}

\section{Introduction}

As noted in the preceding chapter, this study focuses on the provision of policy advice within three key central agencies in the Papua New Guinea (PNG) public service. In order to appreciate the analysis that follow in the subsequent chapters, especially Chapters Seven to Eleven, it is first necessary to examine in some detail the political and administrative context of PNG and the manner in which policy advice is organised within PNG's machinery of government. This chapter discusses the broader context in which policy advice takes place in the PNG public service. It examines the socio-economic and political context of the country, the system of government and the operations of the public service. It then focuses on how policymaking takes place, illuminating the way vertical and horizontal policy formulation is organised within departments, and between departments, powerful bureaucratic committees, ministers and cabinet.

\section{Historical Context}

PNG has five million people with a landmass of 462, 840 square kilometres and occupies the eastern half of the New Guinea mainland and a number of islands located around the main island of New Guinea (Appendix 1). In 1973 it gained selfgovernment, allowing for the first time an indigenous Chief Minister and an Assembly that was virtually indigenous in composition. ${ }^{9}$ This was subsequently followed by independence on 16 September 1975, terminating the UN Trust Territory responsibility (formerly League of Nations mandate) administered by Australia from 1921.

PNG has a rich history, having been discovered by the Portuguese and Spanish explorers in the sixteenth century and then annexed by Germany (German New Guinea) and Britain (British New Guinea) in the late 1800s. Germany annexed the northern half of New Guinea (German New Guinea) with several outer Islands (New Ireland, New Britain, and Bougainville), while Britain annexed the southern half (Papua) (it later relinquished control to Australia in 1906). After the outbreak of war in 1914, Australia took control of German New Guinea and formally took over its

\footnotetext{
${ }^{9}$ Except for a few expatriate Australians, for the first time in the history of Papua New Guinea, nearly all legislators in the First House of Assembly were indigenous Papua New Guineans.
} 
administration in 1921. Both parts then became known as the Territory of Papua and New Guinea and were governed by the Australian colonial administration. During the Second World War, the Territory came under two separate controlling authorities, the Japanese who had occupied the eastern coastline and the outlaying areas of the New Guinea Islands (largely the northern part of New Guinea), and Australians and the allied forces, who had occupied most of Papua (southern part of the Territory). For four long years a bitter war was waged in the Territory drawing many indigenous inhabitants to fight alongside the Australians and Americans. The Territory was subsequently entrusted to Australia by the United Nations to administer under the Papua and New Guinea Act, 1949, until political independence in $1975 .^{10}$

The physical geography of PNG is diverse with mountainous terrain, fast-flowing rivers, swamps, valleys, dense tropical jungle, and savannah grassland. Equally there is a large diversity in ethnic and tribal groupings, although all belong to the Negroid race called Melanesians. Perhaps this diversity is nowhere more reflected than in the diversity of the languages that are currently spoken. Apart from the common lingua franca of Motu and PNG Pidgin, there are 867 living languages in use, one third of the world's languages (Dorney, 1998).

PNG is endowed with much natural wealth not found in the other countries in the Pacific (see World Bank, 1998; 2000a). However, since the mid-1980s poverty and wealth disparity has increased, social and economic development has declined, and law and order problems have been on the rise (Levantis, 2000; Bank of Hawaii, 2001). Law and order, in particular, has posed a formidable challenge to policymakers in the country; it has impacted negatively on the growth of the private sector and stifled the inflow of new investments; its roots are complex, and the state's capacity to maintain effective policing has been weakened (Clifford et al, 1984; AusAID, 1999; World Bank, 2000; Dinnen, 2001).

PNG is ranked as a middle-income country, yet according to the UN Human Development Index (HDI) its social indicators are closer to those of low--income countries (see Table 2.1).

\footnotetext{
${ }^{10} \mathrm{~A}$ brief and/or concise political history of the Territory of Papua and New Guinea and Papua New Guinea can be solicited from Griffin et al., (1979), Papua New Guinea: A Political History; Nelson (1972), Papua New Guinea: Black Unity or Black Chaos? Dorney (1990) People, Politics and History since 1975.
} 
Table 2.1: Selected Economic and Social Indicators

\begin{tabular}{lclll}
\hline & $\begin{array}{l}\text { Gross national } \\
\text { product per } \\
\text { person } \\
(1997)\end{array}$ & $\begin{array}{l}\text { Human } \\
\text { development } \\
\text { index ranking } \\
(1999)\end{array}$ & $\begin{array}{l}\text { Life expectancy } \\
\text { (1997) }\end{array}$ & $\begin{array}{l}\text { Child mortality } \\
\text { rate** }\end{array}$ \\
\hline & US\$ $\$ 1997)$ \\
Papua New Guinea & 930 & 129 & years & no. \\
Vanuatu & 1340 & 116 & 58 & 112 \\
Solomon Islands & 870 & 118 & 65 & 50 \\
Fiji & 2460 & 61 & 70 & 28 \\
Indonesia & 1110 & 105 & 73 & 24 \\
Philippines & 1200 & 77 & 65 & 68 \\
& & 68 & 41 \\
\hline
\end{tabular}

* Out of 174 countries

** Death of children under 5 years of age per 1000 births

Sources: UN Human Development Report, 1999; World Bank Atlas, 1999.

According to the Government's principal economic adviser, "Despite recent economic and financial conditions, the economy's overall performance over the last few years has been poor" (Finance and Treasury, 2002: 3). With the exception of 1996 and 1999, the economy as measured by changes in gross domestic product (GDP) has actually declined each year since the mid1990s (Table 2.2).

Table 2.2: Selected Real GDP Growth Rates

\begin{tabular}{lllllllll}
\hline & 1995 & 1996 & 1997 & 1998 & 1999 & 2000 & 2001 & 2002 \\
\hline Real GDP Growth & $-3 \%$ & $8 \%$ & $-4 \%$ & $-3 \%$ & $8 \%$ & $-1 \%$ & $-3 \%$ & $-0.1 \%^{*}$ \\
\hline
\end{tabular}

* Forecast

Source: Treasury Economic Monitor, September 2002

Fiscal indicators demonstrate that there has been an expansion in government revenue and grants from donors, from K998 million in 1990 to K3, 219.4 million $^{11}$ in 2002 (Bank of PNG various sources; Finance and Treasury, 2002 Supplementary Budget). But successive governments have adopted an expansionary fiscal policy since the early 1990s (Mawuli, 2001; Curtin, 2000a) to a point where the country has successively incurred budget deficits apart from two budget surpluses in 1996 and 1997.

\footnotetext{
${ }^{11}$ This is a projected (revised) figure based on the 2002 Supplementary Budget handed down by the new Somare government when it came into office after the 2002 National Elections.
} 
Among other adverse economic conditions, fiscal management was especially bad in mid-1994 and later in 1999. In both periods the culmination was a cash crisis faced by the public sector and the near collapse of the economy. Poor fiscal management continues to haunt the government and the public sector even after a measure of general economic stability was restored in 2000. Among the many contributing factors have been ill-advised budget decisions made by politicians and a lack of expenditure control resulting in budget deficits that have reached an unsustainable level $^{12}$. Public debt has risen, from K1,1470 million in 1990 to K5,148 million in 2000 (Bank of Hawaii, 2002). This level of debt comprises overwhelmingly borrowings from external creditors (Governments of Australia and Japan, World Bank and the ADB), which according to the Department of Finance and Treasury (DF\&T), account for 97.7 percent of total debt (DF\&T, 2002 Supplementary Budget, Volume 1). Despite a slow revival of the economy (2001-2002), the immediate future is bleak at the time of writing this thesis. It has been estimated that output in key sectors (manufacturing, construction, wholesale and retail, and mining) would shrink in 2003 and 2004 (DF\&T, 2002: 3). In particular, it has been estimated that there would be a loss of revenue of K190 million from petroleum and mining in 2003, two of the government's biggest income earners. ${ }^{13}$

\section{System of Government}

The constitutional arrangements of PNG are contained in the National Constitution. ${ }^{14}$ PNG is a constitutional monarchy and has a parliamentary democracy based on the Westminster model ${ }^{15}$ with Queen Elizabeth II, the Queen of England, as its Head of

\footnotetext{
12 For example, the free education policy, which has seen the funding of all school fees by the government for several years (albeit now seen largely as a political gimmick), the Electoral Development Fund which provides K1 million to each 109 national politicians to fund electoral projects, and the constant pay rises for national politicians have been seen as examples of bad decisions (see Mellam and Aloi, 2003).

${ }^{13}$ See "Adjustments hit spending" on line at http://www.postcourier.com.pg/20021024/news06

14 See Goldering (1978) for an in-depth examination of the constitutional powers of the legislature, executive branch and the judiciary in PNG.
}

${ }^{15}$ The term "Westminster model" is in common currency in PNG and is used throughout this study. It denotes the origins of PNG's constitutional arrangements and, by emphasising the election of ministers from the legislature, differentiates these arrangements from, for example, a presidential system. It correctly suggests that, in respect of the executive government, power is concentrated in the cabinet and also that the public service system of PNG is within the category of countries which can loosely be described as "Westminster/Whitehall". But in practice PNG does not demonstrate some features of the textbook model: single party government, two party elections and a largely unwritten constitution (Miller, 2001:xviii). Also see Larmour (2002). 
State. Powers of the Head of State are ceremonial, inscribed in the constitution and performed by the Queen's representative, a Governor-General, who acts upon advice from the cabinet - or the National Executive Council (NEC), as it is called in PNG. PNG has a multi-party system with democratic elections held every five years. A government is formed after every election and it is expected to serve five years in office (see Dorney, 1990). The formal structure and institutions of government, including the organisation and operations of the public service, are an adaptation of the Whitehall model, a reflection of the influence of the previous administering authority, Australia.

Parliament is a single chamber comprising 109 members elected through the First Past the Post system and is the supreme law-making body. Governments remain in office so long as they command a majority in parliament on matters of confidence (including the annual budget). ${ }^{16}$ At present (2003) there are more than seven political parties represented in parliament; four of these usually support the present government of Michael Somare. In addition to its legislative role, the parliament exercises scrutiny of the executive government, which in accordance with the Westminster convention, is held responsible for the activities of government. All statutes including the key budgetary instrument, the annual Appropriation Bill, need the approval of a majority of the votes in the parliament. As in other Westminster systems, parliament uses a system of parliamentary committees to which have been delegated powers to examine virtually all matters that fall under the jurisdiction of parliament, to take appropriate action, and to report to parliament.

Separate from parliament are the two other branches of government, the judiciary and the executive ("the Government"), whose functions are sanctioned by the constitution. Parliament and the judiciary (through judicial review of executive actions) exercise 'checks and balances' on the executive. Since independence in 1975 the judiciary has maintained complete independence from the executive, administering the courts and enforcing the laws in an impartial manner. Significant among other institutions of government is the Office of the Ombudsman, which has recorded a remarkable performance since independence in holding political leaders and Constitutional Office Holders accountable to the Leadership Code ${ }^{17}$.

\footnotetext{
${ }^{16}$ Since independence, all governments have been coalitions.

17 The Leadership Code stipulates the duties and responsibilities of leaders (provincial and national legislators, departmental heads and heads of statutory bodies, constitutional office holders, and members of boards of governmental bodies) while holding public office.
} 
The Government of PNG (the executive arm) is responsible to parliament (and thus the citizens) for the day-to-day administration of the manifold activities carried out by departments and other public agencies. The National Executive Council (NEC), comprising ministers from the governing coalition, dominates the policymaking process within the government and also the business of parliament most of the time. Its role can be equated with the role played by cabinet in other Westminster jurisdictions.

The question of who actually dominates cabinet has been prominent in the literature on the Westminster system (for example, see Dunleavy, 1995a). Numerous models including that of prime ministerial government, cabinet government, and ministerial government have emerged in describing and assessing the operations of cabinet, especially in decision-making (Jones, 1975; Minogue and Biddiss, 1983; Rhodes, 1995). There is no general pattern across countries (James, 1992). The operations of the NEC demonstrate a strong resemblance to those of the cabinet model: key policy decisions are usually discussed and taken in a collegial manner within the confines of the cabinet (see Rhodes, 1995), as opposed to being taken, by contrast, by the prime minister alone (prime ministerial government) or individual ministers (ministerial governments). Generally, the Westminster convention of collective responsibility of cabinet is respected and underpins the operations of the NEC.

At the core of government, the NEC is very powerful and has always carried with it the government as a whole in key matters of policy. This power is underpinned by the fact that governments in PNG, although coalitions, have always commanded a parliamentary majority since the general elections of 1977 . Backed by that majority key policy measures such as the Appropriation Bill and statutes proposed by the government have in most cases been enacted by parliament with relative ease.

The NEC comprises the prime minister and other ministers with a membership ranging between 25 and 30 . At present (2003) there are 28 members, each drawn from four parties in the coalition government. ${ }^{18}$ The deputy prime minister is usually a member of the ruling party or the second largest party in the coalition. Senior ministers are also usually drawn from the largest parties in the coalition. The NEC is

\footnotetext{
${ }^{18}$ See http://www.thenational.com.pg/o814/nation5.htm for full listing of cabinet.
} 
serviced by a number of cabinet and high-powered official committees, who consider issues and advise cabinet on issues of policymaking. The Governor-General acting on advice from the Prime Minister appoints ministers and terminates their period in office. All ministers hold departmental portfolios for which, under the Westminster convention, they are responsible to parliament.

As already noted, since the formation of the first government after independence in 1977, all governments have been coalitions, formed by two or more political parties. None has survived a full term (Reilly, 1997; Chin, 2001) because of the shifting of allegiances of political parties between elections. The problems caused by shifts in party allegiances and the movement of independent members from one party to another has become so serious that parliament recently passed another organic law on the Integrity of Political Parties aimed at stabilising governments and restricting unnecessary party hopping (see The Organic Law on the Integrity of Political Parties and Candidates 2001; Reilly, 2002). The effectiveness of this law remains to be seen, but it is envisaged that it will bring about the much-needed stability that is required in the government.

\section{Decentralisation}

PNG has a three-tier system of government: the national government at the centre, provincial governments below the national government and local governments in districts. There are currently 20 provinces and 284 local councils (Edmiston, 2001). Each provincial government has a legislature (with members elected by First Past the Post voting $)^{19}$ a core executive (Provincial Executive Council) and a provincial administration headed by the provincial administrator. The provincial legislature enacts provincial laws; the political executive is responsible for policymaking and day-to-day operations of the government machine; and the provincial administration administers a range of public services within the province. Local bodies are also elected every five years.

Under the present system of decentralised government, the centre or national government retains considerable power and delegates or devolves responsibilities to governments and institutions at the lower levels. This is done through a variety of statutes and conventions, the most important being the Organic Law on Provincial and Local-Level Governments 1995 (OLPLLG), a form of constitutional law that can

\footnotetext{
${ }^{19}$ This will be replaced in 2007 with the Preferential Voting system.
} 
be only amended or repealed by a two-thirds absolute majority in the national legislature. ${ }^{20}$

Provincial governments exercise their power through provincial lawmaking in those areas that have been designated primarily provincial functions in the Organic Law (OLPLLG) and by formulating and executing policy in relation to these matters. Public services designated under the primarily provincial functions are delivered by the provincial governments' bureaucratic machinery, the provincial administration. Those that fall under national functions are delivered by the national government, although provincial and national governments often act in concert deciding which level of government should be responsible for particular activities where boundaries are unclear. In terms of lawmaking, although provincial legislatures can make provincial laws, national legislation takes precedence over any regulation imposed by provincial authorities in areas where a national statute already exists or in areas where there are no provincial laws.

Despite devolving greater responsibility and powers to provincial and local level governments, considerable power is still maintained at the centre. First, all members of the national parliament representing each electorate in a province are also members of the provincial legislature. In addition, a national member of parliament heads the Joint Provincial Planning and Budget Priorities Committee, the powerful committee responsible for determining provincial expenditure, and the provincial member is the Governor of the province. Thus, although by design the OLPLLG is supposed to devolve power to provinces and districts, significant policymaking power is still vested at the centre since the national members of parliament from the province retain considerable control over the way the provincial legislature operates.

Secondly, key statutes such as the Public Finance Management Act 1995, the Public Service Management 1995, and the Prime Minister Act 2002 vest controlling powers in the national government, particularly in central agencies. For example, decisions on staffing matters and terms and conditions of public service employment,

\footnotetext{
${ }^{20}$ Papua New Guinea has a long history of decentralised government. The Trust Territory prior to 1975 was effectively governed through District Commissioners in districts. The first Organic Law - Organic Law on Provincial Government 1977 - was enacted by Parliament in 1976. It was later repealed and replaced with the Organic Law on Provincial and LocalLevel Governments in 1995 on the grounds that the 1976 Organic Law did not provide for effective decentralisation of powers and functions to provinces and local councils. For a history of provincial governments see Ghai and Reagan (1986).
} 
reorganisations of departments, and appointments to senior positions within central and provincial departments are matters that come under the control of the Department of Personnel Management (DPM) - see Chapter Eight. Likewise, significant controls on budgetary matters pertaining to the allocation of public expenditure, financial review and reporting and financial accountability are maintained by the Department of Finance and Treasury (DF\&T) - see Chapter Six.

Thirdly, and most importantly, the national government commands a majority in parliament and therefore can ensure the passage of legislation that fundamentally affects the operation of the lower tiers of government. Finally, although the OLPLLG provides for additional sources of revenue to provinces and local government councils, provincial and local governments rely heavily on the national government for most of their budgetary needs through six main sources of grants. Through these grants the national government has overriding control of provincial and local activities and can withhold critical funding from provincial and local governments.

\section{Machinery of Government}

The machinery of government at the provincial and national levels comprises a wide range of public and semi-public organisations that are funded and controlled either directly or indirectly by the government. It comprises central government departments under direct ministerial control, provincial departments under the control of provincial government, and independent commissions, boards, and statutory authorities.

Broadly, the organisations at the centre can be categorised under two main headings: those in the core public service that come under direct ministerial control, and those that operate under statute and whose management usually falls under a board which reports to a minister. The PNG government has variously classified the public sector under three broad headings: national departments, statutory authorities and provincial departments (Table 2.3). 
Table 2.3: The Organisation of the Government Machinery

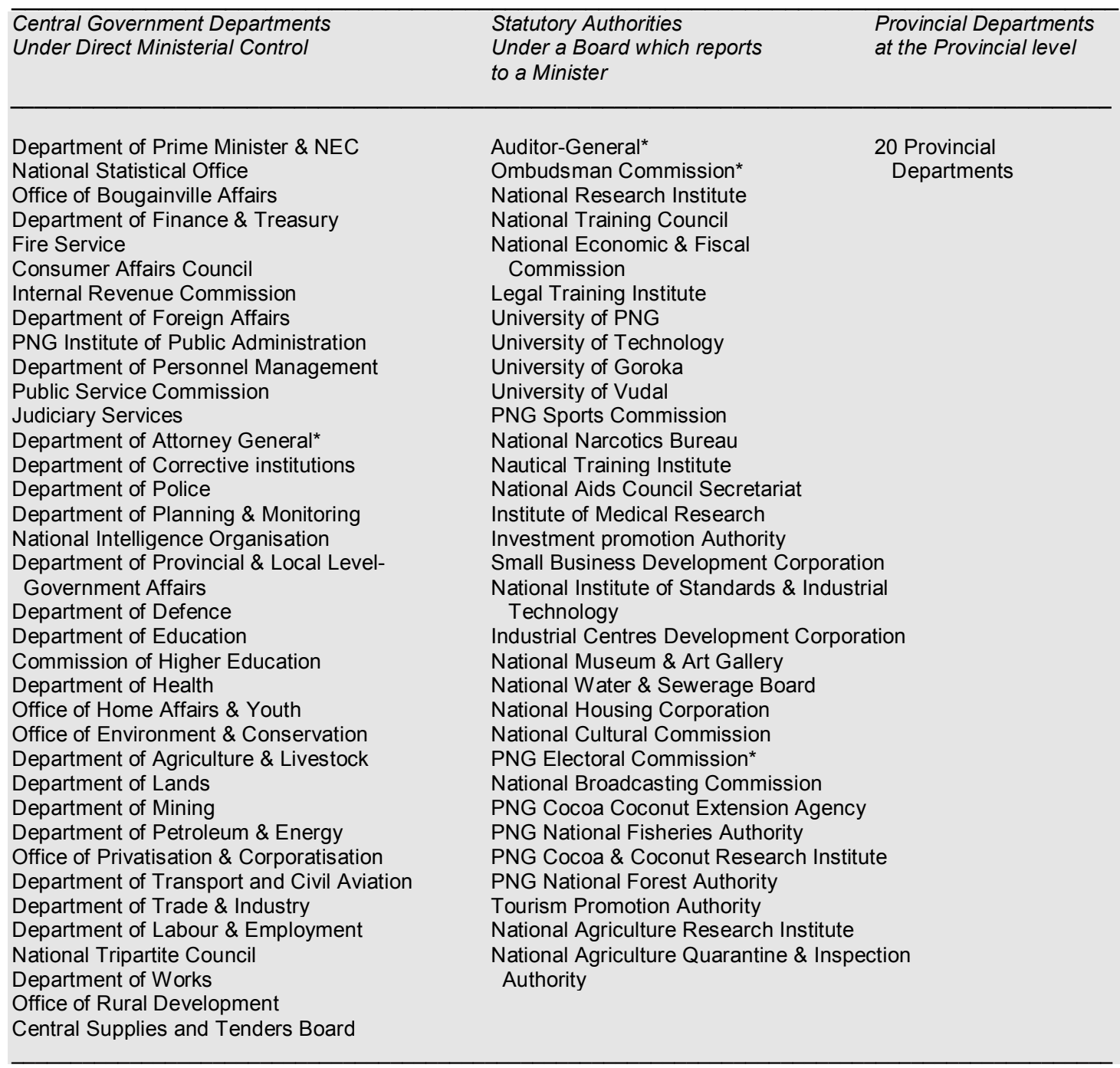

Table 2.3 does not include officers of the Parliament or the Governor-General, although they are classified under national departments. It also does not include state-owned enterprises (SOEs) owned by the national or provincial governments.

* Independent; established by the Constitution

Sources: Department of Finance \& Treasury, 2002 Budget, Volumes I \& II.

Although the government funds the statutory authorities, some may also raise their own revenue as part of the government's corporatisation and commercialisation effort (see Millett, 1993). Such revenues have, however, been small and as a result government continues to bear the large bulk of statutory bodies' operating costs.

Varying figures have been given as to the total number of personnel employed in central departments and agencies, and provincial administration (excluding statutory authorities). One source (Lasaro, 1998) suggests that there are 65,000 personnel working in the public service. Another indicates that there are 60,000 employed in 
central and provincial governments (Hughes, 2003). However, according to Curtin (2000:8), this figure is "bloated" as it includes 25,000 teachers and several thousands of police and army personnel. Curtin (2000:8) estimates that there around 31,000 public servants employed by national departments and provincial administrations. This number is indicative, as the government payroll has in recent years been inaccurate, thus posing problems for the Department of Personnel Management in establishing accurately who is employed.

Briefly, most line departments and agencies found within central government are replicated at the provincial level (provincial administration) (Figure 2.1).

Figure 2.1: Administrative Relationships in the PNG Public Service

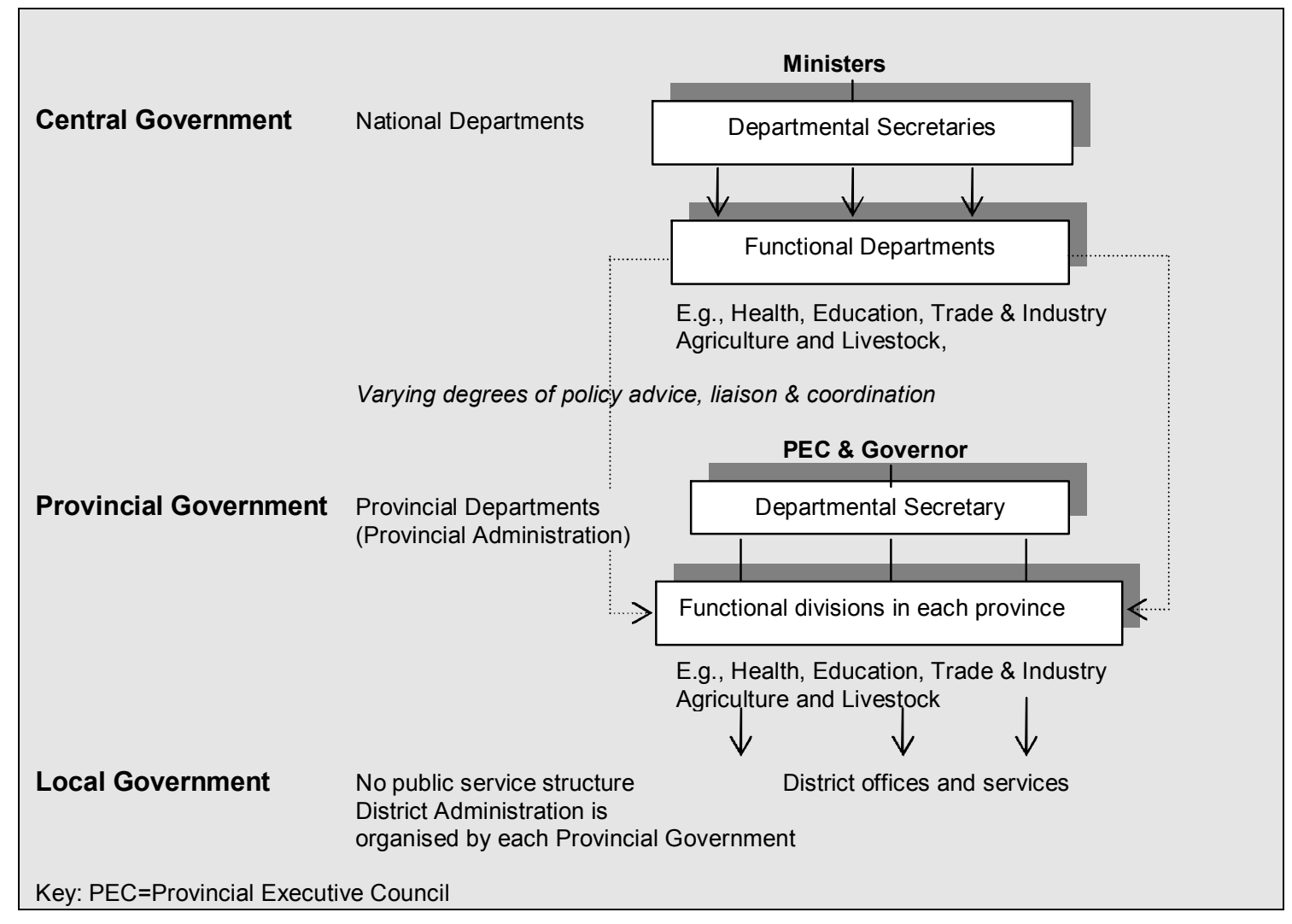

Source: Adapted and modified from Nicholson (1994).

As in central government, line departments and agencies within provinces are established on the basis of key functional responsibilities, such as health, education, primary industry and so forth, and are responsible for undertaking a variety of tasks in those functional domains. As mentioned earlier, the OLPLLG delineates responsibilities in functional domains between central government departments (national functions) and provincial administration (provincial functions). For example, 
in the health sector, the national Department of Health discharges those functions categorised as "national functions", while the provincial administration administers those that are designated as "provincial functions". The separation of responsibility covers both policy formulation and delivery (implementation). However, apart from certain delivery functions national departments are responsible for most aspects of long-range strategic planning (for instance in developing national plans for health or education). The provincial departments work within this national planning framework.

There are, however, fundamental differences in the reporting and accountability relationships, and the management, of central and provincial departments. Whereas central government departments and agencies come under direct ministerial control, such control in provincial administration is weak as there is no specific minister in charge of the provincial department (or more specifically "provincial division") at the provincial level. Secondly, the provincial administrator (who is the head of the provincial administration) is responsible and accountable to the Governor (who is the provincial member of parliament) and the Provincial Executive Council (provincial cabinet). Thus, the departmental head within central government has little control over the provincial administrator.

There is also a difference between central and provincial methods of appointing departmental heads. This has important implications for accountability. In the central government, all departmental heads are appointed and terminated by cabinet. The links of accountability between the departmental head and his or her minister and cabinet are therefore straightforward. Departmental heads report to their ministers who in turn report to cabinet. Thus, in circumstances of non-performance by the departmental head, the minister is the one who takes the matter to cabinet and cabinet decides whether it should terminate the appointment of the departmental head. There is, however, a different process in appointing and terminating provincial departmental heads (provincial administrators). This power rests with the NEC, but appointments and terminations are made on the recommendation of the Provincial Executive Council (PEC). Although provincial administrators are directly responsible to the PEC and their respective governors, these authorities have little power to sanction non-performing administrators (except for the power of suspension). The NEC at the centre retains that authority. This situation has made it difficult to enforce the accountability of provincial administrators. 
However, there are similarities. Public servants serving either central or provincial government are appointed under the Public Service Management Act and their terms and conditions of service are determined in accordance with the Act. Furthermore, the operations of provincial administrations are subject to the same financial management regulations as national departments. Thus, the disbursement of public finance and the subsequent financial reporting and accountability regimes apply equally to public servants in provinces and the central government.

\section{Central Government}

There are 36 national departments and agencies (Table 2.4) whose administration is subject to ministerial control. These departments are responsible for specific portfolios and perform a range of tasks. As in many other Westminster systems, departments are responsible for providing a range of policy advice to the minister and cabinet on matters that fall within the department's immediate portfolio and most also deliver services. Departments are also required to respond to the wishes of the minister on any matter that may not necessarily fall within a department's immediate portfolio but on which the minister or cabinet may require advice. Broadly, departments and agencies within central government can be demarcated into two classifications: ordinary line departments and agencies and central agencies.

At present there are thirty-one line departments and agencies and five central agencies. The central agencies include the three key departments studied in this thesis together with the departments of Attorney General and Provincial \& Local Government Affairs. These last two departments have specific functions: the former is responsible for all legal matters pertaining to the operations of government, and the latter monitors and coordinates the affairs of the lower tiers of government. Generally their focus is specific, confined to their immediate portfolios, rather than managing crosscutting policy issues and maintaining policy coordination.

By comparison, the responsibilities of the Departments of Prime Minister and National Executive Council (DPM\&NEC), Finance and Treasury (DF\&T), and Personnel Management (DPM) transcend other central government departments and agencies, provincial departments and statutory authorities. This status is underpinned by their extensive powers allowing them to exercise a range of centralised controls on matters of financial management, personnel management, 
policy coordination and strategic direction. ${ }^{21}$ For example, DPM controls conditions and employment of all public servants regardless of where they are, and approves all staff appointments up to and including deputy departmental secretaries (see Nicholson, 1994). It is also responsible for a wide range of machinery of government issues, including reorganising departments and strengthening departmental performance. (Chapter Eight is a detailed examination of the role and performance of DPM.) In the case of DF\&T - see Chapter Six - it controls budget allocations to all departments and provincial governments (including provincial administrations). DF\&T also has offices in provinces and districts (called provincial and district treasuries) that carry out treasury functions in these locations. Under the OLPLLG, provincial and district treasurers are required to be independent, reporting only to the Secretary of Finance at the centre and are required to maintain strong fiscal accountability in respect of the activities of provincial and local governments.

\section{Departmental Operations}

Virtually all departments and agencies are designed to undertake multiple functions combining both policy formulation and delivery. Furthermore, all the departments and agencies of the central government come under direct ministerial control and are managed by a departmental secretary who reports to a relevant portfolio minister. Under the constitution, the minister must be a politician (Member of Parliament) and a member of the NEC and represents his or her department within cabinet and in parliament.

As mentioned earlier, the operations and management of departments are determined largely by the Public Service Management Act 1995 (PSMA) and the Public Finance Management Act 1995 (PFMA). Under the PSMA, a departmental head is responsible for inter alia "the general working and efficient conduct of his or her Department" and is required to report to the Departmental Head of the Department of Personnel Management on the effective operation of his department (s24). Section 5 of the PFMA confers on the departmental head extensive responsibility for the financial management of the department. This includes proper record keeping of all accounts, proper authorisation of expenditure, efficient and effective utilisation of financial resources and the responsibility to provide the necessary financial record stipulating the use of funds in the manner and format

\footnotetext{
${ }^{21}$ The powers of the three agencies are derived from several overarching statutes including the Public Service Management Act 1995, Public Finance Management Act 1995 and the Prime Minister Act 2002.
} 
specified in the Act and relevant financial instructions. The Act (s25 (a-m)) also requires the departmental head to take responsibility (and be held accountable) for the use of all public funds in his or her department.

As with other countries in the Westminster model, departments are impacted by many conventions and traditions. These include, but are not limited to, the principle of ministerial responsibility, a career service that has largely remained unchanged, although this is slowly being modified by short-term contract employment; the nonpartisan and loyal stance of civil servants in discharging their duties and responsibilities; and, the principle of giving free and frank advice to political masters without fear and favour. Suffice to note that throughout the years since PNG became independent, most of these principles have been tested; some may appear to have been weakened. This has consequently led some observers to say that PNG's brand of parliamentary democracy is weak and stands in marked contrast to those of other Westminster democracies (see Dorney, 1990; Denoon, 2002; Reilly, 2002). This observation is debatable, at least by reference to other developing countries. Most of the Westminster principles have remained throughout the 27 years of independence, although there have been variations in practice in different times, giving rise to questions about the viability of parliamentary democracy in PNG. Equally, such Westminster characteristics as ministerial responsibility and career service tend to have evolved in different ways in other jurisdictions.

\section{Resource Allocation}

All departments including central agencies have an annual budgetary allocation appropriated by parliament. The budget process is complex but briefly involves departments submitting their budget estimates to the Department of Finance and Treasury (DF\&T). Departments then negotiate with DF\&T on estimates, within the guidelines set by NEC and the policy framework of government. Estimates are then sent for cabinet's deliberation. Once cabinet approves the budget estimates, the Appropriation Bill is formulated and sent to parliament for debate and approval. Allocations in the budget are input-based and built around key functions for which a department is responsible. A typical budget structure would include the identification of the key function, the objective of that function and then the items of expenditure ("Expenditure Items" or line items). The latter constitute the various inputs and their costs contributing to the discharge and/or maintenance of functional responsibilities. Current expenditure items (on functional responsibilities) are classified into four main groupings: salaries and allowances, goods and other services, capital formation and 
current transfers. Most functions usually have a mixture of expenditure items predominantly in the first three groups.

Table 2.4 shows the summary of expenditure items characteristic of a department's estimates using the example of the Department of Prime Minister and National Executive Council (DPM\&NEC).

Table 2.4: Key Categories in Estimates Formulation

DEPT. OF PRIME MINISTER AMD NATIONAL EXECUTIVE COUNCIL

Summary of Expenditure by Items (in Thousands of Kina)

\begin{tabular}{|c|c|c|c|}
\hline \multirow[b]{2}{*}{ Expenditure Items } & \multirow{2}{*}{\begin{tabular}{|l|} 
Actual \\
1999
\end{tabular}} & \multicolumn{2}{|c|}{ Appropriation } \\
\hline & & 2000 & 2001 \\
\hline CURRENT EXPENDITURE & $18,686.7$ & $19,179.1$ & $24,198.5$ \\
\hline $\begin{array}{l}\text { Personal Emoluments } \\
111 \text { Salaries and Allowances } \\
112 \text { Wages } \\
113 \text { Overtime } \\
114 \text { Leave Fares } \\
116 \text { Contract Officers Education Benefits }\end{array}$ & $\begin{array}{r}11550.5 \\
10,721.8 \\
461.6 \\
241.6 \\
115.6 \\
10.0\end{array}$ & $\begin{array}{r}10,948.5 \\
10,201.5 \\
540.6 \\
43.6 \\
162.8\end{array}$ & $\begin{array}{c}12,562.3 \\
11,570.2 \\
590 \\
212.2 \\
189.4\end{array}$ \\
\hline $\begin{array}{l}\text { Goods and Other Services } \\
121 \text { Travel and Subsistence Expenses } \\
122 \text { Utilities } \\
123 \text { Office Materials and Supplies } \\
124 \text { Operational Materials and Supplies } \\
125 \text { Transbort and Fuel } \\
126 \text { Administrative Consultancy Fees } \\
127 \text { Rental of Property } \\
128 \text { Routine Maintenance Expenses } \\
135 \text { Other Operational Expenses } \\
136 \text { Training }\end{array}$ & $\begin{array}{r}6,785.1 \\
634.9 \\
908.1 \\
140.0 \\
316.4 \\
353.6 \\
302.6 \\
67.4 \\
458.4 \\
3,603.6\end{array}$ & $\begin{array}{l}7,595.2 \\
1,050.0 \\
533.6 \\
214.5 \\
383.0 \\
436.0 \\
420.0 \\
63.0 \\
400.1 \\
3.745 .0 \\
350.0\end{array}$ & $\begin{array}{r}11.036 .2 \\
2,737.4 \\
944.4 \\
397.5 \\
388.4 \\
974.8 \\
1,406.5 \\
148.4 \\
1.134 .8 \\
2,604.8 \\
299.2\end{array}$ \\
\hline Current Transfers & 351.2 & 635.4 & 600.0 \\
\hline $\begin{array}{l}141 \text { Retirement Benefits, Pensions, } \\
\text { Gratuities and Retrenchment } \\
144 \text { Grants to Individuals and Non-Profit } \\
\text { Organisations }\end{array}$ & $\begin{array}{r}302.5 \\
48.7\end{array}$ & 635.4 & 600.0 \\
\hline $\begin{array}{l}\text { CAPITAL EXPENDITURE } \\
\text { Capital Formation }\end{array}$ & $\begin{array}{l}833.2 \\
833.2\end{array}$ & & $\begin{array}{l}2.112 .7 \\
2,112.7\end{array}$ \\
\hline $\begin{array}{l}221 \text { office Furniture and Equipment } \\
222 \text { Purchase of Vehicles } \\
225 \text { Construction, Renovation and Improvement }\end{array}$ & $\begin{array}{l}155.9 \\
463.4 \\
213,9\end{array}$ & & $\begin{array}{l}642.7 \\
620.0 \\
850.0\end{array}$ \\
\hline TOTAL & $19,519.9$ & $19,179.1$ & $26,311.2$ \\
\hline
\end{tabular}

Source: Department of Finance \& Treasury 2001 Budget, Volume 2 Part 1. 
The financial management of departments, however, suffers from a number of problems. One is that the focus of the budget does not encourage long-term budgetary planning. Because the budgets are annually based, departments are required to plan for those functions that can be accomplished in a year. This has inhibited many departments from making important long-term decisions on policies that extend over a number of years.

Development, and in some instances implementation, of strategic policy tends to be problematic given the short-tem focus of financial management. For example, in situations where long-term plans, for instance in health or education, have been developed, there are difficulties in implementation partly because these plans do not have the necessary financial support that would sustain implementation stretching over a number of years. Secondly, procedural compliance underpins virtually every aspect of financial management with little managerial freedom to utilise financial allocations in ways that can get the best possible outcome for a department. This has encouraged the uneconomical use of financial resources by departments because managers are forced to stick to routines and practices that add no value to the mission of the department. Moreover, the practice of giving back unspent funds to the Consolidated Revenue Fund (CRF) at the end of the fiscal year does not encourage departments to be cost-effective. Instead there is often a rush to spend the total allocation before the end of the financial year for fear that otherwise it will go back to the CRF.

Wider discrepancies can also be seen in the financial management of the public service. For example, there has been an uneven distribution of spending between national and provincial departments. National departments have been allocated disproportionately more financial resources than provincial departments (Table 2.5), although most public services (to 80 percent of PNG's population) are provided by provincial departments. It has been observed that the unbalanced nature of financial distribution favouring the national government and national departments tends to stifle much-needed funding for provincial departments which deliver basic public services to the majority of the PNG population (see Edmiston, 2002). 
Table 2.5: Financial Allocation to Departments, 1999-2003 (Millions of Kina)

\begin{tabular}{|c|c|c|c|c|c|}
\hline & 1999 & 2000 & 2001 & 2002 & 2003 \\
\hline $\begin{array}{l}\text { National Departments } \\
\text { (Percentage) }\end{array}$ & $\begin{array}{l}957.3 \\
(63)\end{array}$ & $\begin{array}{l}1,167.8 \\
(66.4)\end{array}$ & $\begin{array}{l}1,242.3 \\
(68)\end{array}$ & $\begin{array}{l}1,343.7 \\
(70.8)\end{array}$ & $\begin{array}{l}1,160.8 \\
(68)\end{array}$ \\
\hline $\begin{array}{l}\text { Provincial Departments } \\
\text { (Percentage) }\end{array}$ & $\begin{array}{l}556.9 \\
(37)\end{array}$ & $\begin{array}{l}591.1 \\
(33.6)\end{array}$ & $\begin{array}{l}588.6 \\
(32)\end{array}$ & $\begin{array}{l}555.5 \\
(29.2)\end{array}$ & $\begin{array}{l}545.5 \\
(32)\end{array}$ \\
\hline Total Government Allocation & $1,514.2$ & $1,758.9$ & $1,830.9$ & $1,899.2$ & $1,706.3$ \\
\hline
\end{tabular}

Source: Finance and Treasury Budget Documents (various); 2002 Supplementary Budget Volume 1

Nearly half the total government allocation to the national departments is attributable to salaries and wages. In provincial departments, more than three quarters of allocations are for salaries and wages. The supplementary budget for 2002, for example allocates K584.7 million (43.5 percent) for salaries and wages out of a total allocation of K1, 160.8 million for national departments; for provincial governments K456.7 million was allocated to salaries and wages (82.2 percent) out of a total allocation of K545.5 million (Finance and Treasury, 2002 Supplementary Budget Volume 1). Table 2.6 gives a selected summary of allocation to salaries and wages for 2001, 2002 and 2003. It demonstrates the "balance" left for operations and for maintaining key facilities after being "eaten-up" by salaries and wages.

Table 2.6: Salaries and Wages versus Operations \& Investments (Millions of Kina)

\begin{tabular}{|c|c|c|c|c|c|c|}
\hline & \multicolumn{3}{|c|}{ National Departments* } & \multicolumn{3}{|c|}{ Provincial Departments } \\
\hline & 2001 & 2002 & 2003 & 2001 & 2002 & 2003 \\
\hline Total Allocated & $1,242.3$ & $1,343.7$ & $1,160.8$ & 588.6 & 555.5 & 545.5 \\
\hline Salary Component & 539.5 & 584.7 & 574.7 & 419.8 & 456.7 & 447.3 \\
\hline Percentage of Total & $43.4 \%$ & $43.5 \%$ & $49.5 \%$ & $71.3 \%$ & $82.2 \%$ & $82 \%$ \\
\hline $\begin{array}{l}\text { Balance Remaining } \\
\text { Percentage of Total }\end{array}$ & $\begin{array}{l}702.8 \\
\mathbf{5 6 . 6 \%}\end{array}$ & $\begin{array}{l}759.0 \\
\mathbf{5 6 . 5 \%}\end{array}$ & $\begin{array}{l}586.1 \\
51.5 \%\end{array}$ & $\begin{array}{l}168.8 \\
29.7 \%\end{array}$ & $\begin{array}{l}98.8 \\
18.8 \%\end{array}$ & $\begin{array}{c}98.2 \\
18\end{array}$ \\
\hline
\end{tabular}

*Allocations to Offices of Parliament and the Governor-General are also included as they are included under the category of "Salaries \& Wages for National Departments" in the 2002 Supplementary Budget.

Source: Computed from Finance \& Treasury, 2002 Supplementary Budget Volume 1.

For national departments, the cost spent on or allocated for operations and investment per department would average around K18.48 million (2001), K19.97 (2002), K15.42 million (2003). Having mentioned that, operational and investment allocations to departments are uneven with priority social service departments (e.g., education and health) not surprisingly getting the biggest slice. Moreover, provincial 
departments have been affected the most because approximately three quarters of their budget is spent on salaries alone.

Effective spending by departments depends on how they (departments) set their priorities and allocate their financial resources accordingly. Departments may have a long-term vision for improving capability and correspondingly invest in assets that will enhance productivity. Management foresight plays a big role in this. Departments that are competently run and whose management recognises the need to invest in areas that matter are more likely to invest accordingly.

According to the Public Sector Reform Management Unit (PSRMU), in two recent reviews carried out by the PNG government on departmental operations it was found out that "there is little or no prioritisation of policy and functional needs prior to preparation of budget estimates", and there is "little long term policy development and planning within departments" (PSRMU, 2000: 9). Also, a major concern now is the frequent misuse of public funds either through misappropriation or from outright theft and fraud within departments (see Ombudsman Commission Reports, 1996, 1999; 2000 2000a).

\section{Organisation of Policy Work within Departments}

Usually departments are organised by divisions, with each division responsible for particular aspects of a department's portfolio. The most favoured type of arrangement has been to demarcate departments into two major areas consisting of operational matters on the one hand, and policy matters on the other, headed by respective Deputy Secretaries (DS). The operations division deals with internal matters of administration (for example, staffing, accounting, information technology and support services), while the policy division deals with the formulation, implementation, coordination and monitoring of policies directly under the department's portfolio. As in many organisations, the organisational scheme shapes the way functional responsibilities are discharged.

Figure 2.2 demonstrates the typical organisational structure of a department in PNG. The figure illustrates the type of reporting and accountability relationships that exist among key actors within the department and between the departmental head and the minister. 
Figure 2.2: Typical Structure of Departments

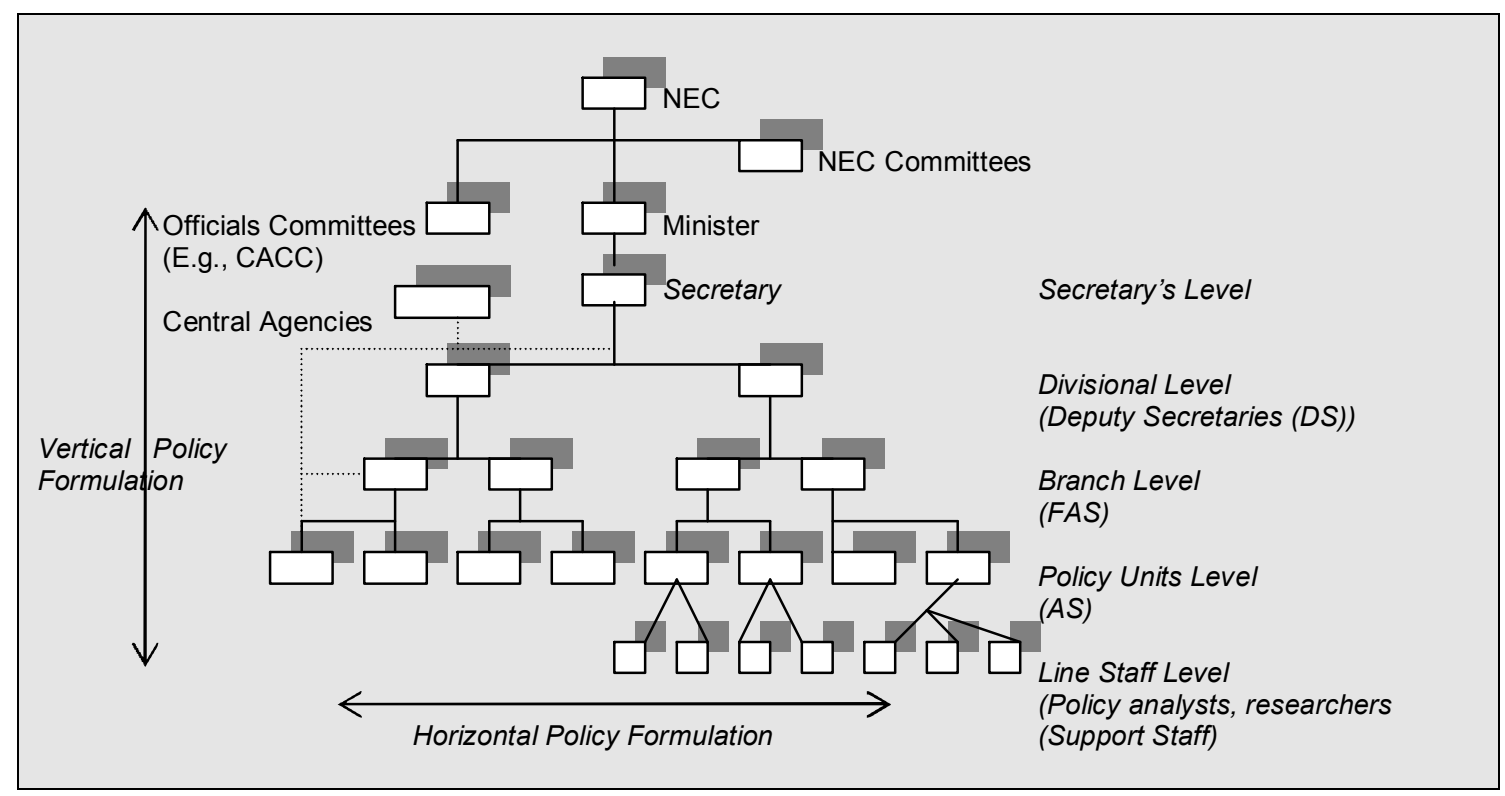

Divisions are made up of various branches that are likely to have a different policy focus - by subject - and are headed by First Assistant Secretaries (FAS), who report to the relevant Deputy Secretary. Each branch consists of a cluster of policy units and is usually headed by an Assistant Secretary (AS) who reports to the FAS. Policy units have a specialised policy focus and are manned by a number of policy staff including senior policy analysts, analysts, policy researchers and support staff. They vary in size across departments. Comparatively, policy units average between 10-15 staff. Some departments may have fewer staff numbers in their policy units, averaging about 10 or less in a policy unit.

The responsibilities placed upon departments and especially their policy units are very wide ranging. Policy units, for example, are responsible for analysing policy issues, liaising with clients - such as ministers and cabinet, central agencies, key officials' committees such as the Central Agencies Coordination Committee (CACC) and other stakeholders outside government - assessing policy propositions, formulating proposals, clarifying matters relating to the areas that come under the department's jurisdiction and then providing the necessary policy advice. Because of the combination of policy formulation and delivery in many departments, many policy units find themselves in situations where they are responsible for at least some aspects of implementation. Thus, they would be involved in additional responsibilities for monitoring and continuous refinement of policy using various 
intervention measures including policy coordination, evaluation, and reporting of ongoing progress and final outcomes.

\section{Vertical and Horizontal Arrangement of Policy work}

Organisational structures are important in shaping policy formulation and the tasks that are associated with it (Weller and Bakvis, 1997). The way a department is organised affects its mode of facilitating information, the decision-making processes and how policy tasks are carried out. For policy advice, structural arrangements are also significant in shaping the way advice is organised and tendered. In this section the arrangement of policy work within departments in PNG is described by reference to patterns identified in the literature about the generic policy process.

The main organisational arrangement, which is evident among departments in PNG as elsewhere, is the pyramidal hierarchical structure (see Self, 1977; Campbell and Szablowski, 1979). Such a structure is reflected in line staff rationally organising policy work and then reporting and accounting for their actions to those further up the hierarchical structure. In Weber's terms, work is a function of the superiorsubordinate relations (Perrow, 1986): superiors assign the tasks and subordinates execute the tasks following specified designated rules and process.

A more accurate depiction of what departments do in PNG is captured in the analysis of policy work carried out within a framework of vertical and horizontal dimensions (Pusey, 1991; Colebatch, 1998; Matheson, 2000). Matheson (2000: 44) calls this pattern "policy formulation on the vertical and horizontal axes". Colebatch (1998: 8789) says that the vertical and horizontal styles of policy involve a number of usual "processes" or patterns. For policy related work that runs vertically there are two basic patterns: (1) a downward flow of work delegated from superiors to subordinates; and (2) an upward flow of advice and completed work (Matheson, 2000: 45). Generally, the formulation and provision of policy advice follows such a pattern. For example, superiors do not necessarily engage in the analysis of policy work; subordinates down the line do. Once that is done, their work is pushed up the line to superiors to use for a variety of policymaking purpose.

Pusey (1991) characterises policymaking as "moving upwards", assuming that policy work (such as in the formulation of policy advice) technically starts with subordinates. This appears to be the case with departments in PNG. Policy officials within respective policy units do most of the policy work; they are expected to collect, 
synthesise and analyse a range of policy issues and then propose options. Although the process overlaps and in most cases is informal, the finished work is then sent up to the Assistant Secretary (AS) (unit heads) and the First Assistant Secretary (FAS) (branch heads). When they are satisfied, policy work can then be pushed upwards to the Deputy Secretary (DS) and the Departmental Secretary. Matheson's (2000:46) view of vertical policy formulation summarises the way policy work is done within government departments in PNG:

Once the groundwork on a policy issue has been completed it usually goes back 'up the line' to be inspected by superiors. They will make whatever modifications they see fit and perhaps pass it down for reworking. This process occurs at successive levels so that a briefing note written by a relatively junior officer may eventually rise to reach the minister's desk.

Analysis of policy carried out at the vertical angle, for example by Matheson (2000), makes reference to two quite distinct tasks of policy formulation and authorisation. Formulation entails processing and analysing policy work, which ultimately results in the proposition of relevant policy options, whereas authorisation denotes approval or legitimisation of the work done by bureaucratic superiors. Matheson (2000) observes, for example, that policy formulation within the Australian Public Service (APS) takes place at the Senior Officer and the AS levels, whereas authorisation begins at the FAS levels and above (ibid: 46 ).

Bureaucratic approval is necessary for a number of reasons. First, superiors, given their relatively long years of service and their progression through the bureaucratic ranks, would normally have an overarching and in-depth knowledge of issues which relate to the immediate concerns of their policy unit or department as well as those issues that are generic, having broader implications for the wider operations of government. According to Matheson (2000:46), "this enables them to assess fully the technical advice offered by subordinates by examining its wider technical and economic ramifications". Second, they understand better the wishes of political masters and can organise and synthesise policy work taking into account what politicians consider as important. Third, bureaucratic approval is an established aspect of the hierarchical mode of legitimisation, which requires that superiors up the hierarchy approve a set of work done below. Final approval of policy work in practice can be difficult to get if appropriate superiors do not give their stamp of approval as 
higher authorities are more likely to rely on the legitimisation of policy work by lower superiors they recognise than, say, from line staff.

The organisation of policy formulation and authorisation in PNG varies. Within a department line staff within policy units do most formulation work, but at different points in time both superiors and subordinates can also be involved in formulation. For example, it is not uncommon to find line staff within a policy unit working with their AS or FAS in formulating a policy proposal. In other instances, an AS or FAS may frame the skeleton of a proposal and allow line staff to undertake relevant research to complete the proposal. Authorisation is a different matter in that bureaucratic superiors do the authorisation work. Authorisation for operational policies (or advice for that matter) usually begins at the senior staff and AS levels without necessarily involving the FAS, although the general rule is to make the FAS aware of the developments in the policy work. Authorisation often depends on the nature of the policy worked on. Bigger policies which are politically important or which if adopted will have a significant impact on the entire government machine or the strategic intent of government often need approval at the higher end of the bureaucratic hierarchy (FAS, DS and Secretary levels).

Generally, operational policies are likely to be authorised at the lower levels of authority, for instance at the AS level, whereas substantive and strategic policies are expected to be authorised at the FAS, DS and secretary level. ${ }^{22}$ Most operational policies deal with what Simon (1996) calls programme decisions. Such decisions are routine and have often been dealt with before, hence lower-level superiors are more likely to be familiar with the issues. By contrast, most substantive and strategic policies are "unprogrammed"; they are new and are often complex. As a result they may need extensive research and analysis, or they may require a department to be forward-looking, formulating policies that encompass many years ahead as a direct response to the government's long-term anticipated outcomes.

The above pattern of policy work is also evident in the "vertical relationships" line departments have with the central agencies which are the focus of this study. For example, policy work emanating from a line department may be directed upward to a central agency for scrutiny or approval - a practice which is fairly common in other

\footnotetext{
${ }^{22}$ A definition of the nature of the different policies is discussed fully in the next chapter (Chapter Three).
} 
Westminster jurisdictions given the executive roles played by central agencies (Brown and Steel, 1978; Bakvis, 1997; Weller et al., 1997). The policy unit or perhaps the branch of a central agency may look at the work, assess it, and then give it back to the parent department for refinement. The process, as noted by Matheson above, continues until the parent or sponsoring department gets the policy work right. Formulating the budget serves as an example. In each annual budget round, departments submit their estimates to DF\&T. Preliminary work begins at the unit and branch levels of the line department. Once the department's estimates are formulated and agreed to, the department's finance branch is responsible for negotiating and liaising with DF\&T for their approval. If the estimates are unsatisfactory to DF\&T, they have to be brought back to the line department for reconsideration and reformulation. The estimates are resubmitted to DF\&T for consideration after they are finalised by the line department. In practice, the process of negotiation and refinement is an interactive one until agreement is reached with DF\&T.

Departments in the PNG public service also undertake policy work horizontally. Horizontal policy work is collaborative in nature and is evident in "intradepartmental, interdepartmental and intergovernmental" means of undertaking different policy tasks (Matheson, 2000: 49). The essence of horizontal policy work is that different actors and departments do not see their relations being underpinned by power and coercion - a feature of vertical relationships - but rather as equals. Such relationships involve negotiation, cooperation and continuing interaction among different actors. Actors see themselves as working towards a common goal or purpose and strive to achieve that by working across unit or departmental boundaries through cooperation.

For central agencies, there are specific reasons why the horizontal formulation of policy is salient. Central agencies are the locus of much horizontal policy work. This is evident in the regular consultations departments and agencies have with central agencies on a variety of policy matters. The relationship is one of cooperative action, engaged primarily to solicit the response and support of central agencies or in filtering and coordinating policy. In policy filtration, central agencies offer much needed advice in shaping and forming policies originating from departments. Also, given the strategic positioning and the degree of trust they have developed with the political executive, their input to departmental policy work ensures bureaucratic and political authorisation at later stages. In policy coordination, central agencies often play a lead role in bringing together the inputs of many departments, harmonising 
them and formulating policy responses to crosscutting issues. Asset specificity as defined by particular skills and expertise is another reason why departments often work across departmental lines with central agencies. Comparatively, many departments lack the analytic capability, the leadership skills necessary for developing policy and seeing it through, and the necessary political connection with influential ministers and cabinet. They therefore must solicit the assistance of central agencies to develop policy in their own jurisdictions.

\section{The Role of the CACC}

Over the last three years the Central Agencies Coordination Committee (CACC), established by the Prime Minister Act 2002, has become a dominant force in policy formulation within the PNG government machine. ${ }^{23}$ The committee comprises secretaries of all central agencies including the Chief Secretary and Secretary for DPM\&NEC, and the Secretaries for DF\&T, DPM, Attorney General \& Justice, and Provincial and Local-Level Government Affairs. The Chief Secretary is the chairperson. In his absence, the Secretary for DF\&T assumes the chairmanship. The committee was set up to strategise and formulate policy, coordinate government action within line departments and central agencies especially on strategic and crosscutting issues and act as a filter for screening and evaluating policy submissions that go into the NEC.

The establishment of the CACC stemmed from a perception that there was a lack of policy coherence and coordination from the centre, and especially from the concern that "financial and operational relationships between line agencies and central agencies, especially Treasury and Finance and Personnel Management are inefficient and ineffective" (PSRMU, 2000: 9). The CACC was therefore established as the vehicle to coordinate policy and to enhance relationships across government departments. CACC was also established to address a range of operational problems of line departments and agencies, which according to the PSRMU (ibid) received little attention from central agencies and therefore had "deepened administrative problems within departments" (ibid). The primary cause of these operational problems was attributed to a lack of monitoring and the subsequent relay of critical information, which would trigger the relevant central agencies to act in a timely fashion.

\footnotetext{
${ }^{23}$ The NEC decided to establish the CACC in early 2000 (NEC Decision No: 10/2000) (DPM\&NEC, 2000). In 2002 parliament enacted the Prime Minister Act giving the CACC more powers and made changes to the Public Service Management Act in order to give the CACC a range of powers over the operation of the machinery of government.
} 
The Committee carries out its work both vertically as well as horizontally, although being a powerful committee its involvement in the policy formulation process is largely vertical in nature (see Figure 2.3).

Figure 2.3 CACC in Vertical and Horizontal Policy Formulation

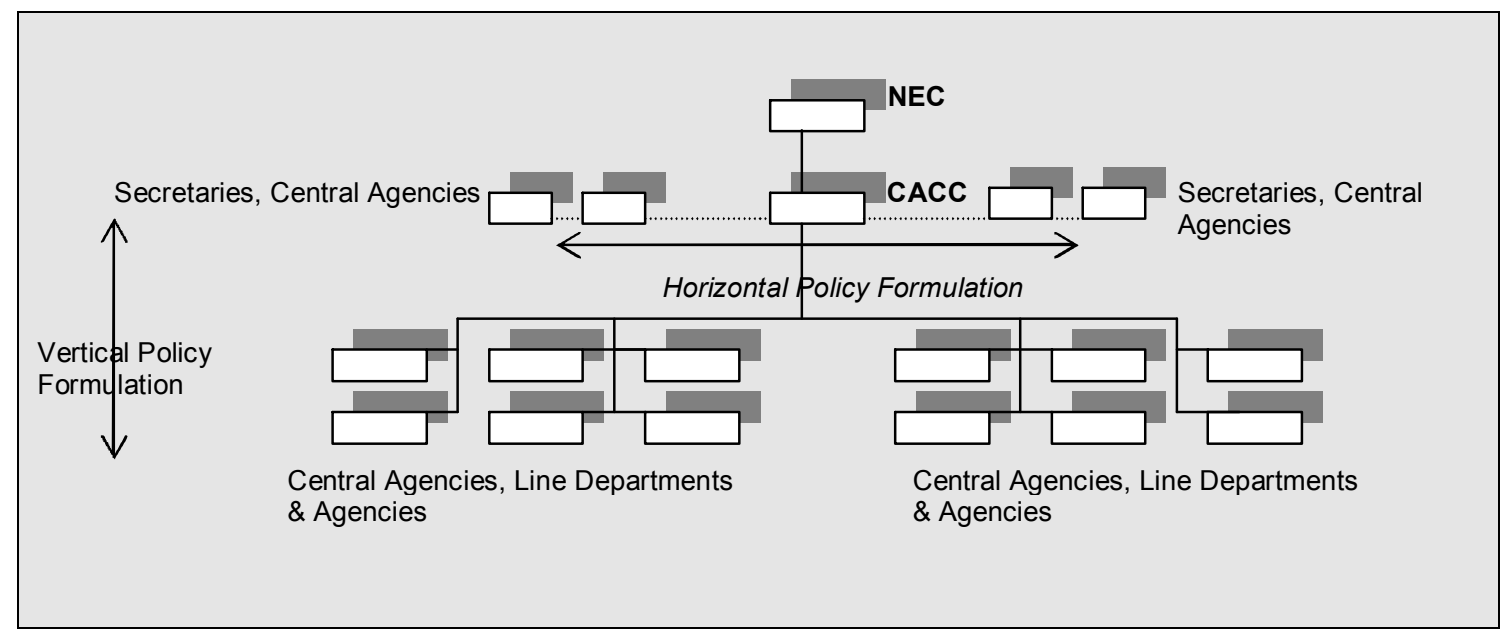

Vertically, almost all policy work produced by departments and agencies and aimed at going to NEC must now go through the CACC. In fact, the committee now advises cabinet on virtually all matters of substantive and strategic policy. Although the committee has a small secretariat that assists with various administrative tasks, it operates largely on the basis of the advice and assistance received vertically from central agencies. Submissions that go before it are either rejected - which means that departments have to rework them before resubmitting - or are accepted. Acceptance is accompanied by the recommendation of the committee, which is sent to the NEC for consideration.

Adopting these new roles has meant that the CACC is now a further layer of accountability above the central agencies, and plays a decisive role in determining departmental heads' tenure in office. Horizontally, CACC provides an avenue where its members can liaise and interact with one another about matters of policy. This horizontal interaction is significant and can be exercised at two levels. Individually, members can influence the formulation of policy at the cabinet level given their respective positions. For instance, being the chairman of the committee and given his strong connection with the Prime Minister and senior ministers, the Chief Secretary can influence decisional outcomes from the recommendation he makes to the Prime Minister and cabinet. Likewise the Secretary of DF\&T has a strong 
influence on fiscal policy given his close relationship with the Minister of Finance who is a senior member of cabinet and given his department's role in managing departmental expenditure. Collectively, the members can work as a group, considering policy issues and taking a collegial stand on policy issues when recommending policy proposals to the NEC.

The effectiveness of the CACC as the core nerve centre for vertical and horizontal formulation of policy remains to be seen in the long run. However, there is a real possibility that the multiple and many objectives of the CACC may swamp its key functions. Policy coordination at the centre, for example, may be sacrificed at the cost of taking on additional responsibilities of monitoring, evaluation and accountability. There may also be administrative as well as policy overload on the part of the committee, and the committee members may loose sight of their core responsibilities of administering their departments rather than running a committee.

\section{Conclusion}

Prevailing socio-economic and political conditions facing the public service in any political jurisdiction shape policy formulation and implementation roles of the public service (Midgal, 1988; Weiss and Hobson, 1995, Polidano and Hume, 1999; Brinkerhoff, 2000). Understanding how those conditions affect the operation of the public service is imperative in a study such as this. As a prelude to the detailed analyses later in the thesis, this chapter has discussed the context in which the PNG public service operates, and the way policy work is organised within departmental domains.

By comparison with many other developing countries, for instance in Africa where governments often crumble only to be replaced by either despots or military regimes, PNG's Westminster model of government has continued to function since political independence in 1975. Indeed, many aspects of democratic governance have taken root in PNG. Free elections, the use of the democratic process rather than force in changing governments, religious and political tolerance, and widespread civil rights including the freedom of speech and a free and vigorous press are aspects of democratic governance that have been maintained in PNG.

As in many developing countries, the public service machinery in PNG continues to be shaped by the political, socio-economic and administrative contexts in which it operates. Although there are opportunities for its robust development, external 
factors can also stifle the efficacy of the public service machinery (Brinkerhoff, 1991; 2000; Brinkerhoff and Goldsmith, 1992; Grindle, 1997). Despite the positive environmental factors mentioned above, the PNG public service continues to face serious problems in competently performing its tasks. As observed by Yash Ghai, a constitutional expert and long-time observer of PNG, "while the constitution and the institutions of government have survived since independence in 1975, almost none of the national goals have been achieved" (Ghai, 1997). A key issue noted in this chapter (and highlighted in Chapter One as a central concern of this study) is the declining capability of departments directly related, it will be argued, to prevailing political and administrative conditions: departments cannot effectively perform their functions because they lack the capability to do so. Prior to the commencement of the research for this study anecdotal evidence in PNG seemed to indicate that the quality of policy advice may have weakened as well as the standard of services delivered by the public sector. However, without hard evidence it is difficult to determine the extent and manner in which policy advisory capability might fall short of the required standard or the key constraints that undermine advisory capability. These issues will be considered in Chapters Six, Seven, Eight and Nine. 


\section{Chapter Three: The Dynamics of Policy Advice}

"At the heart of public management then, is the question of how those charged with the task of governing can secure the best possible advice in the most cost-effective manner and ensure that their decisions based on this advice are implemented efficiently and effectively" (Boston et al, 1996: 121). The manner in which policy advice is organised plays a central role in this study.

This chapter considers policy advice as a concept and as a function within the governmental system. Five areas are examined. First, discussion is focused on explaining the concepts of "public policy" and "policy advice" and the relationship between advice and public policymaking. The second part discusses the nature of advice, the distinction between policy advice and political advice and the different types of advice sought by policy clients from the public service. Thirdly, analysis is centred on the crucial role of the advice function in policymaking. Approaching this topic from different perspectives, the chapter analyses the particular challenges that underline the need for quality and timely advice. The fourth part discusses the way in which governments get advice from different sources, focusing mainly on the distinction between internal (in-house) advice, and external advice. The chapter concludes with a synopsis of recent developments aimed at improving policy advisory capability in Westminster countries.

\section{Public Policy and Policy Advice}

The concept of "public policy" is conceived in different ways. Its precise meaning remains elusive (see, for example, Parsons, 1995; Edwards, 2000). Bridgman and Davis (1998: 3), for example, show how "public policy" can be expressed in various ways - for example, "legislation", "a government White Paper" or a "ministerial statement" can all be seen as expressions of public policy. These examples also serve to highlight the "public" element of public policy. While private and voluntary entities have 'policies' - and indeed are affected by (and can influence) public policy - the concern of this study is with the actions (and inaction) of governments, as suggested by Dye's simple definition of public policy as "anything a government chooses to do or not to do" (Dye, 1972:2 cited by Howlett and Ramesh, 1995: 4). This definition is very broad, too broad, but directs attention to the centrality of government in the practice and study of public policy. (In practice, most discussion of 
public policy tends to be about specific areas of policy (e.g., health policy, energy policy, welfare policy or particular programmes within those policies. $)^{24}$

Looking beyond the form that the output of the policy-making process might take, William Jenkins (1978, cited in Howlett and Ramesh, 1995: 5) gives an overarching definition of public policy as a

.... set of interrelated decisions taken by a political actor or group of actors concerning the selection of goals and the means of achieving them within a specified situation where those decisions should, in principle, be within the power of those actors to achieve....

This definition highlights significant constituents of public policy with which this study is concerned particularly the "interrelated" nature of policy issues and the significance of process over time. (It also highlights, importantly, the consideration of how decisions are to be implemented, a matter beyond the scope of this study).

A common approach in the literature has been to view public policy as constituting a process comprising interlocking stages. Most "cycles" are variations on: agenda setting, policy formulation, decision-making, implementation and evaluation (see Hogwood and Gunn, 1984; Howlett and Ramesh, 1995; Parsons, 1995; Bridgman and Davis, 1998; Colebatch, 1998). The conceptualisation of policy as process and in stages suggests that public policies are not the outcome of a single spontaneous decision derived from a "moment of choice"; rather public policies evolve in stages arriving at a point where decisions are made and then implemented and evaluated. In reality, however, public policymaking is far more complex, "a more messy reality" (John, 1998:7), and is shaped by political values and preferences. As observed by the State Services Commission of New Zealand (SSC) (1991: 131) "[p]olicymaking is rarely...tidy. Policy arises from a combination of problems presenting themselves for solutions and solutions available for problems". The conceptualisation of policy as a staged process is therefore a heuristic schema aimed at simplifying the complexity of policymaking so its dynamics can be more easily understood.

Policy advice plays a significant role in informing and shaping public policymaking.

24 The boundary between "public' and "private" is fluid and has become increasingly permeable in recent years. This is an important and complex topic but outside the scope of this study except in the context of outsourcing policy advice discussed in this chapter. 
As with "public policy", the concept of "policy advice" has various definitions and has been given a wide coverage in the literature (for example, Campbell, 1987; Plumptre, Weller, 1987; Blackstone and Plowden, 1988; SSC, 1992; 1999; Waller, 1992; Weimer and Vining, 1999; Edwards, 2000). Weimer and Vining (1999: 1) see advice as a product of rational analysis. This view posits that advice is a function of a structured process in which analysts seek to understand the nature of policy issues, assess their actual and potential impact on society, strategise about how best to tackle the negative impact of such issues and then recommend a plan of action on how to respond. Waller (1992) has a similar view. He conceives of advice as the "communication of results" [arising from rational analysis] which convey different policy positions on an issue or given problem. This entails a long process involving information gathering, structuring of the problem and diagnosing it, assessing possible solutions and then identifying and proposing the most feasible solution(s) to the problem.

Another perspective advanced by Shaw defines "policy advice" as "the information and knowledge that the political executive requires to inform the decisions it takes at each stage of the policy [cycle] "(Shaw, 2003: 149). Mayntz (1987: 3) sees advice as a "recommendation for action" and contends that advice is not simply the provision of information; rather, he argues, it constitutes evaluative judgements on what decisions should be taken, why, and their associated costs and benefits. Others share the view that advice is essentially information derived from the accumulation, analysis and presentation of data for decision-making. Boston (1993: 4), for example, sees advice as "involving the production of well-researched, in-depth reports for political executives on various matters of public policy...setting out the issues and exploring the options". This view is closely aligned to the perception of public policy based on the rational process - that is the development of public policy using several logically connected stages (Jones, 1979; Hogwood and Gunn, 1983; Parsons, 1995).

As observed by Shaw (2003), in practice the task of giving advice is an activity that pervades all the stages in the policy cycle (as discussed earlier): analysis and advice may occur at each stage of the process (SSC, 2000). This is shown in Figure 3.1 below, which shows how an issue can be segmented into its constituent problems solving parts (or stages) and then analysed. Each stage would then be the focus of specific advice. 
Figure 3.1: Policy as Problem Solving and Policy Advice

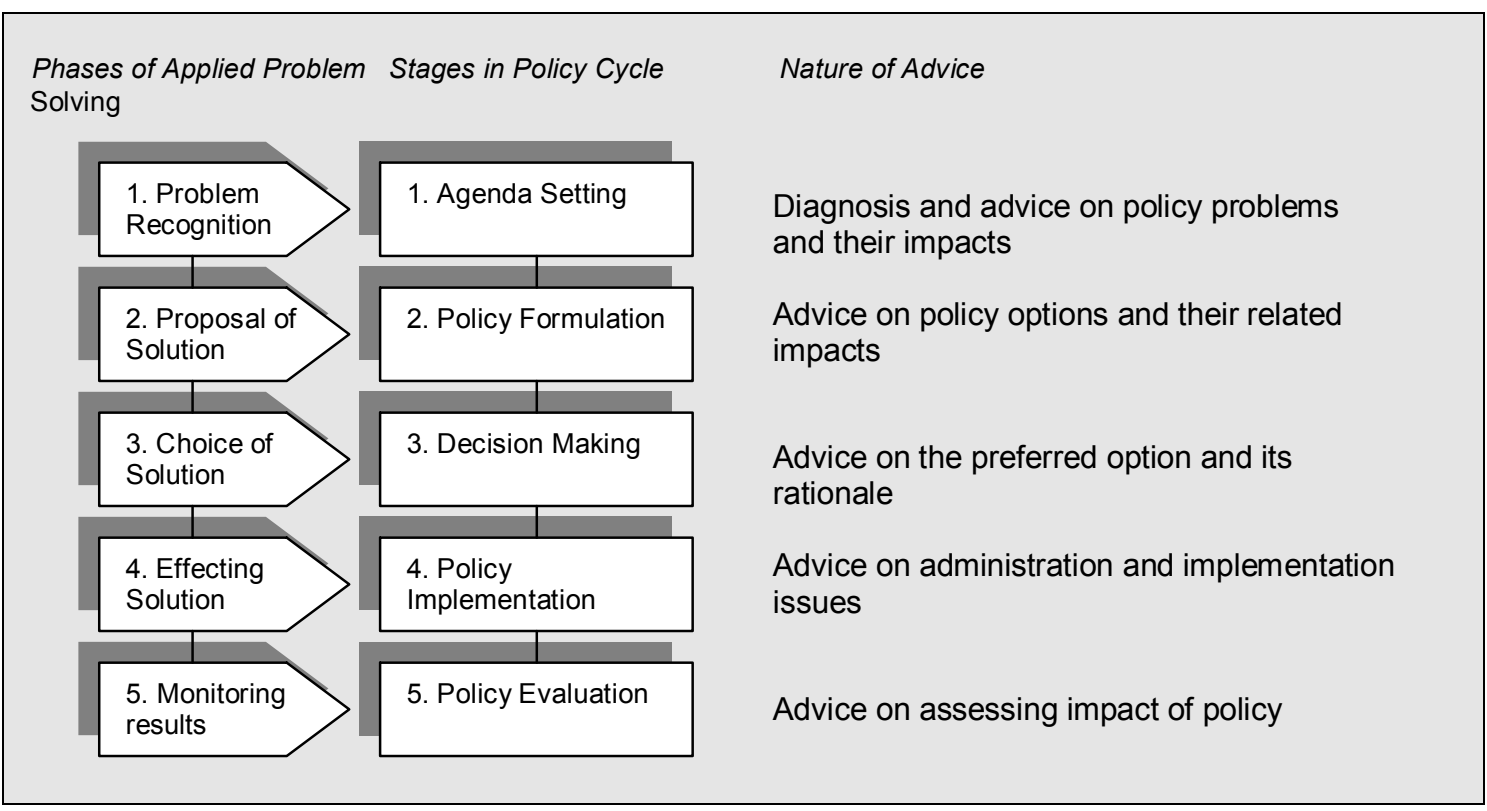

Source: Adapted and modified from Howlett and Ramesh (1995: 11).

Providing policy advice is not an easy task. Its organisation and delivery is shaped by the interaction of interlocking factors in a complex bureaucratic and political environment. Boston et al. (1996: 123) capture this environment as follows:

\begin{abstract}
When ministers seek advice on issues like unemployment, education, immigration, or defence, they also expect and require an integrated, fully coordinated, ongoing servicing capacity. This will include the day-to-day provision of oral advice, assistance with the task of negotiating policy trade-offs and explain (sic) policy proposals to the various interested parties both inside and outside the government....advice on implementation issues (including subsequent monitoring, review, and policy adaptation), advice on to deal with anticipated and unanticipated problems, and capacity to undertake foreign negotiations with foreign government and sub-national governments and so on.
\end{abstract}

As observed by Boston et al, providing policy advice is intensely a political matter and ministers (and cabinet) will often impose their wishes - as they are entitled to do - about the types of advice they want. Thus, a view that policy advice should be based purely on technocratic, even rational, considerations is impractical as political considerations frequently play a large role in determining what type of advice should be provided. Furthermore, politicians may wish to get advice from sources other than the public service - for example, from ministerial or political advisers or from "think 
tanks", academic or international sources. Secondly, providing advice can be a complex organisational task. For example, different types of policy advice may be required from time to time on the same issues or ministers may require advice on a range of issues that cut across departmental boundaries. This is likely to require interdepartmental consultation in the provision of advice. Finally, within the government machine there is a need for adequate in-house capability to service the advisory needs of ministers and important clients. What is crucial for this service is its readiness to respond with reliable and timely advice. Such a readiness does not only depend on the quality of analysis employed on policy issues, but is also dependent on the key elements of capability discussed in Chapter One.

\section{Policy and Political Advice}

In many Westminster systems there is an important distinction, at least in theory, between policy advice and political advice. This distinction has been important in separating the roles of ministerial or political advisers who provide political advice, and professional public servants who provide policy advice (Plumptre, 1987; Hensley, 1995; Voyce, 1996). Advice on matters clearly directed at the improvement of the public's welfare would be seen as policy advice, while that concerned with achieving or retaining control over the apparatus of the state would be considered political advice. The latter category would cover issues about political party operation, running of the government caucus, those about trade-offs among parties (whether on policy or procedural matters) and the mobilisation of political support during elections.

Underpinning the process of governance in Westminster systems are the conventions that regulate the relationship between professional public servants and the political executive (most notably ministers) and the way in which public servants should discharge their duties (see Mulgan, 1997; Roberts, 1987; SSC, 1995). In the provision of policy advice several conventions remain important, although evolving state tradition has meant that some of them may have been modified to suit particular jurisdictions. First, public servants are expected to provide advice in a free and frank manner unconditioned by fear of retribution (for example, by dismissal) - i.e., it is the duty of public servants to tell the minister what he or she needs to know rather what the minister wants to know - and in turn officials have traditionally been assured of their tenure in office (Hensley, 1995). Then there is the pre-eminent role of ministers in the political management of their departments and in determining the extent and manner in which advice should be provided to them: ministers have the 
final say in advice and they may accept, vary or reject the advice received from public servants. Once a ministerial decision is taken, public servants have a duty to carry out or follow that decision. In the words of the 1962 Royal Commission on the State Services in New Zealand (paragraph 62 cited in Joseph, 1993: 260), "to make [their] experience judgement and departmental knowledge available to [their] political masters no matter what party is in office, and to accept and put into effect the Minister's decisions". Finally, a public servant's loyalty (and constitutional duty) is to the Crown rather than to the party or parties controlling the executive branch. Advice to New Zealand public servants on the introduction of proportional representation puts this convention succinctly:

Public servants serve the Government in the formulation and implementation of its policies; but they do not serve the interests of the political parties that comprise that Government (SSC, 1995a: 6).

Therefore the advice they provide should be politically neutral, promoting the interest of the Crown and should not advance the partisan interest of the party or parties in government (or any political party) (Martin, 1996; Voyce, 1996). This principle (of political neutrality) makes it clear that although public servants provide policy advice, they are restricted from giving political advice - i.e., advice that can be construed as partisan advice.

In practice, however, separating political and policy advice is difficult. Timothy Plumptre (1987: 378), an experienced Canadian public servant, explains such a difficulty often confronting public servants in all Westminster jurisdictions:

Being a deputy minister requires a capacity to understand, and work to the subtle shades of meaning surrounding the concepts of "policy advice" (a legitimate critical part of the job), "political advice" (goes with the territory, but a minefield) and "partisan advice" (off limits). These are shades ministers, particularly new ones, may have trouble grasping....

In Plumptre's sense, the line between administration and politics is very fluid in Westminster systems. Public officials may venture into giving political advice - for instance in matters of negotiation among ministers over policy trade-offs, soliciting support from different stakeholders, and advising the minister on how best to communicate the policy stance of the government to citizens at large, and perhaps to 
parliament (Nairne, 1996; Plowden, 1996). ${ }^{25}$ According to the New Zealand State Service Commission (SSC) (2000: 9), "the art of policymaking is the creation of means/ends packages, and is largely developed in an evolutionary interaction sequence between the minister and analyst". Thus, the view that public servants do not get involved in giving political advice - and therefore influence the scope and manner in which political advice is tendered - is often unrealistic in practice (Campbell, 1988). This notwithstanding, the constitutional obligation of public servants to serve the interest of the Crown (rather than the interest of the political party that is in office and in control of the executive branch) and therefore to provide policy advice on that basis, is formally recognised in virtually all Westminster jurisdictions (see Shaw, 2003).

Of particular interest is the status of ministerial, political and special advisers (hereafter political advisers) located within the offices of ministers and whose role in the provision of advice has seldom been clear (see Plumptre, 1987; Eichbaum and Shaw, 2003). King (2003) notes that there has been an increase in the number of political advisers in some Westminster jurisdictions, especially in Ireland and New Zealand, and that their influence on public policy has been growing. A concern raised by King and others relates to the responsibility and accountability of these advisers. Whereas the accountability of public servants is regulated by established conventions and ethical guidelines - such as those discussed earlier and various codes of professional conduct - the same may not necessarily apply to political advisers who owe their job to the minister in office. As noted above, there is less clarity in the way political advisers should discharge their duties and account for their actions. $^{26}$

\footnotetext{
${ }^{25}$ A recent study by King (2003) comparing four Westminster jurisdictions - Australia, Canada, New Zealand, and Ireland - to Britain has found that the boundary between political advice and policy advice is becoming increasingly blurred as a result of the larger role of political or ministerial advisers in providing a variety of advice to ministers and cabinet. The study observes that such advisers are increasingly venturing into providing policy advice, traditionally the province of civil servants, and that "the varying category of adviser seem to have placed a strain on the ability of regulatory rules to provide clear ethical guidelines" [on the performance of political advisors] (ibid: 11).

${ }^{26}$ For example, according to King (2003: 14), "There is little regulation of special advisers in all our comparator countries [Australia, Canada, New Zealand and Ireland] despite the fact that their numbers are on the increase". Notwithstanding the observation by King, individual ministerial responsibility applies in some jurisdictions (for instance New Zealand) as regards the activities of ministerial staff. This may be the basis of regulating ministerial advisers as ministers may require their advisers to observe certain codes of conduct when dispensing advice.
} 
Such an ambiguity may lead to tensions between public servants and political advisers about the type of advice they should provide and the manner in which advice should be provided. ${ }^{27}$

Moreover, political advisers are held accountable for the advice they provide (for instance, with regard to the comprehensiveness and quality of advice) only to their political master(s). Such a lack of public accountability may lead to a situation where political advisers may not be vigilant in providing high quality advice to ministers. There is also a possibility of "policy capture" by political advisers (to follow the argument of proponents of rational choice theory), especially in situations where political advisers are highly influential (with little counter-balance from the public service) in both policy formulation and delivery. A likely risk is that policies may be politically driven and hence fail to take into account important analytical, administrative and technical considerations which public servants would be expected to consider when giving policy advice. Also there seems to be a risk, at least from the officials' point of view, that increased influence may lead to political advisers usurping the prerogatives of ministers on matters of advice (as has apparently occurred in the UK) (see Maley, 2000).

The increasing influence of political advisers has also led to concerns about the possibility of 'politicising' the public service. Michael Wintringham, the New Zealand State Services Commissioner, echoing similar observations to those made by King, notes that the recent increases in the number of political advisers in ministers' offices had "raised fears in some quarters about the potential for the politicisation of the public service" (Wintringham, 2002).

Although Wintringham's observation remains speculative at best, it raises important implications for some fundamental principles governing the provision of advice in Westminster systems. For example, to the extent that the public service is politicised by the role of political advisers or by ministerial intervention in public service appointments, the important principle of providing free and frank advice unconditioned by fear of retribution may be undermined. In particular, advice provided by political advisers is likely to be coloured with a degree of political bias -

\footnotetext{
${ }^{27}$ Eichbaum and Shaw (2003: 6), for this reason, have recommended a Code of Conduct for Ministerial Advisors (CCMA) in New Zealand. They note, "An obvious initiative in this direction would be the development and publication of a [CCMA]...[s]uch a code could usefully clarify the distinction between advisers and permanent officials by explicitly recognising the partisan nature of the adviser's role".
} 
that is why they are appointed - and there is a possibility that advice may be provided on the basis of what ministers want to know rather than on what ministers need to know. Also, the growing influence of political advisers could well undermine the critical relationship that departmental heads have with their ministers (based on mutual trust and dependency, confidence, and open and frank dialogue). For example, departmental heads may find themselves becoming increasingly isolated, their role as key advisers to ministers replaced by political advisers. This in turn raises again questions of whether political advisers are in a position to provide quality and timely technocratic advice.

As observed by King and others, if the responsibilities of political advisers are not carefully regulated their growing influence may undermine the capability of the public service to provide quality and timely policy advice. At stake also is the interest of the Crown - that is, the public good. The principle of political neutrality which public servants are required to observe is an important shield in protecting the interest of the Crown against the partisan interest of the party or parties controlling the executive branch. Underpinning this principle is the assumption that public servants would remain influential in the provision of policy advice. In practice, however, this view is increasingly being challenged by the growing influence of political advisers on policy advice. There is the likelihood that partisan politics might compromise the Crown's interests.

\section{Types of Policy Advice}

The diverse range of functions performed by governments has meant that different types of advice will be required from time to time. Categorising or differentiating policy advice is not new and has been attempted in numerous scholarly works (see, for example, Machin, 1987; Seymore-Ure, 1987; Weller, 1997; 2001; Jones 1987; Castles, 1996; Shaw, 2003). But such differentiations have been problematic, and in some cases, superficial. To quote Boston (1994: 4), the boundaries between different types of advice "are extremely fluid". The case of central agencies providing advice is illustrative. Central agencies deal with diverse matters pertaining to the management, control, coordination and oversight of specific programmes as well as broad policies; they are confronted with crosscutting issues (for example issues which have economic, social and financial implications); they are concerned with policies that have both longer-term and short-term focus. Accordingly, there is bound to be overlap in the different types of policy advice they offer. 
One way of classifying advice, which is in common usage, is to group advice under fields of government activity (Weller, 1987; Machin, 1987). For instance, advice on health, education, economic and foreign affairs would be seen as advice on "health policy", "education policy", "economic policy" and "foreign policy" respectively.

Policy advice may also be classified on the basis of specific administrative tasks performed. For example advice may be classified in relation to tasks such as "policy coordination", "control", "oversight" and "monitoring", rather than the field of activity such as education, health or defence. Some scholarly analyses of policy advice (Aberbach et al., 1981; Boston, 1994) have viewed advice in this fashion. Boston, for instance, uses the generic term operational advice to describe advice that is task specific, while Aberbach et al. view it as technical advice.

\section{Operational, Substantive and Strategic Advice}

There have also been numerous schemes to classify policy advice in a hierarchical manner showing different levels of advice. Sharpe's (1991) classification of four distinct types of policies and their associated tasks is one such attempt (Figure 3.2). The type and nature of advice is defined by the policy type, which according to Sharpe, begins with implementational issues and ascends to high-level 'big' issues. Accordingly, advice can range from matters of detail about putting policies in place through to questions relating to particular programmes and then through strategic sectoral concerns, to society-wide issues.

Figure 3.2: Sharpe's Four-Level Policy Framework

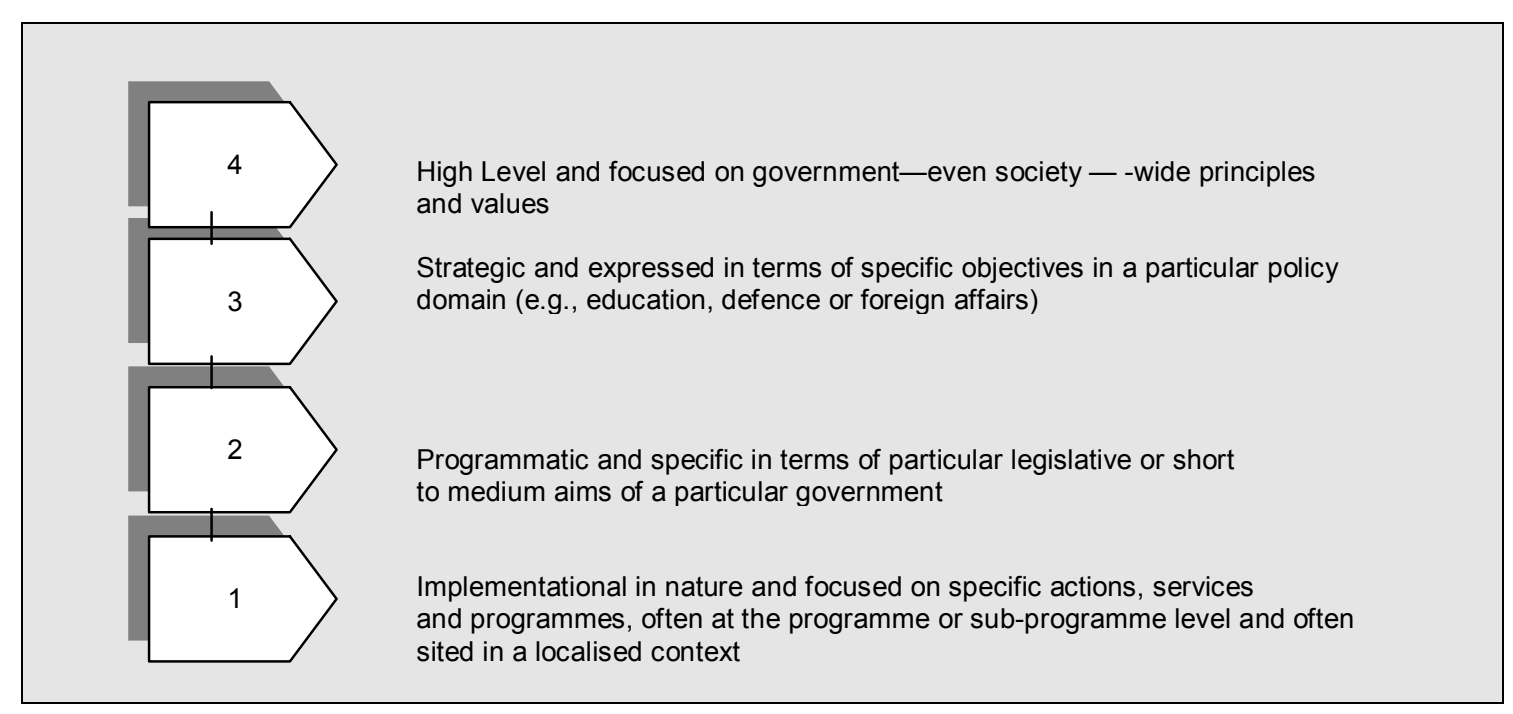

Source: Adapted and modified from Sharpe (1991: 79) 
Boston et al. (1996a) - adopting a broadly similar (but simpler) approach to Sharpe's - suggests another useful approach in classifying the type and nature of policy advice (see Table 3.1). This study generally subscribes to this approach. The defining character of this classification of advice is based on the "scale of task" and the 'time horizon' of the policy issue considered. Under this classification policy advice can be categorised under the headings of: operational, substantive, and strategic advice. Boston et al's schema has a universal appeal since it can be used at different levels.

Table 3.1: Types and Nature of Advice

\begin{tabular}{|c|c|c|}
\hline Type of Advice & Nature of Advice & Focus or Outlook \\
\hline Strategic & $\begin{array}{l}\text { Advice is broad and multi-sectoral, focusing on } \\
\text { anticipated and future strategies of government. } \\
\text { Such a focus may be on the anticipated } \\
\text { or projected outcomes sought by government in } \\
\text { respect of policy issues and problems. Some form of } \\
\text { planning is involved in ironing out the elements of } \\
\text { policy objectives, content, implementational } \\
\text { issues and the link to the interests of government. }\end{array}$ & $\begin{array}{l}\text { Futuristic; longer term } \\
\text { in focus. }\end{array}$ \\
\hline Substantive & $\begin{array}{l}\text { Advice on discrete policy issues; focused on } \\
\text { specific issues or problems confronting government } \\
\text { in individual policy domains or in } \\
\text { specific sectors; and may entail the production of } \\
\text { systematic, in-depth and well-researched reports. }\end{array}$ & $\begin{array}{l}\text { Combining both, i.e., } \\
\text { short and longer term } \\
\text { in focus }\end{array}$ \\
\hline Operational & $\begin{array}{l}\text { Advice on more technical or practical issues } \\
\text { relating to implementation of policy. } \\
\text { administration of government programmes. } \\
\text { Such advice may be focused on } \\
\text { operating practices; it may be aimed at } \\
\text { addressing recurrent issues of administration. }\end{array}$ & $\begin{array}{l}\text { Short-term in focus. } \\
\text { Some is routine. }\end{array}$ \\
\hline
\end{tabular}

Source: Adapted from Boston et al. (1996a: 122).

This categorisation suggests different levels of complexity, from relatively simple issues requiring straightforward advice to more complex issues requiring comprehensive and in-depth analysis. Operational policy advice arguably is fairly straightforward, as it covers routine administrative matters or procedures and programmes that are likely to be familiar to those involved. Substantive and strategic advice are prima facie more complex as they cover emerging issues and manyfaceted policy problems spanning a longer time frame. An effective response to such issues or problems is likely to require agencies to work horizontally across departmental boundaries. 
In so far as capability is concerned, the demand for robust capability in the provision of advice, especially in the ability to undertake comprehensive and reliable analysis, will be especially high if the providers of advice are required to provide all three types of advice. Operational advice alone, on the other hand, can be expected, all things being equal, to place less pressure on advisory capability. Having said this, it is important to recognise that many operational issues are complex and do require comprehensive analysis. In PNG, for example, starting complex projects such as mining and gas operations often requires sophisticated analysis of the likely impact of their implementation even though there may be no disputing the positive gains to the nation at the micro level of analysis. A key requirement of such projects is the ex ante evaluations of the various effects on the environment (environmental impacts assessment) and the local population (social impact assessment). Information derived from such ex ante evaluations is then used to determine the viability of the implementation strategy and of the project as a whole.

In practice, policy advisers will often offer a "cocktail" of operational, substantive and strategic advice at the same time (see Craswell and Davies, 1994). Indeed, in many practical settings there is no limiting the position of advisers to one type of advice. Broad and crosscutting policies contributing to the desired outcomes by the government, for example, are very likely to require a "cocktail" of advice. Here policy advisers are required to consider policy in a comprehensive manner by exploring the linkages and impact of sector-specific policies and programmes in relation to the broad outcomes sought by government, and how such policies and programmes are to be coordinated, implemented, monitored and evaluated.

A frequently confronted situation illuminates the point. Suppose that a government has the overall goal of maintaining a surplus fiscal position. It would need to determine and implement specific policies and programmes to deliver that outcome. It may, for example, develop a public sector-wide strategy for controlling expenditure. It may also initiate a specific programme of public expenditure survey and/or monitoring within individual departments. This is necessary to ensure that budget limits are adhered to (see, for example, Brinkerhoff, 1991 and Crosby, 1996 for policy-programme linkages). Figure 3.3 demonstrates the interconnectedness of the different types of advice in the above example. 
Figure 3.3: Providing a Mixture of Policy Advice

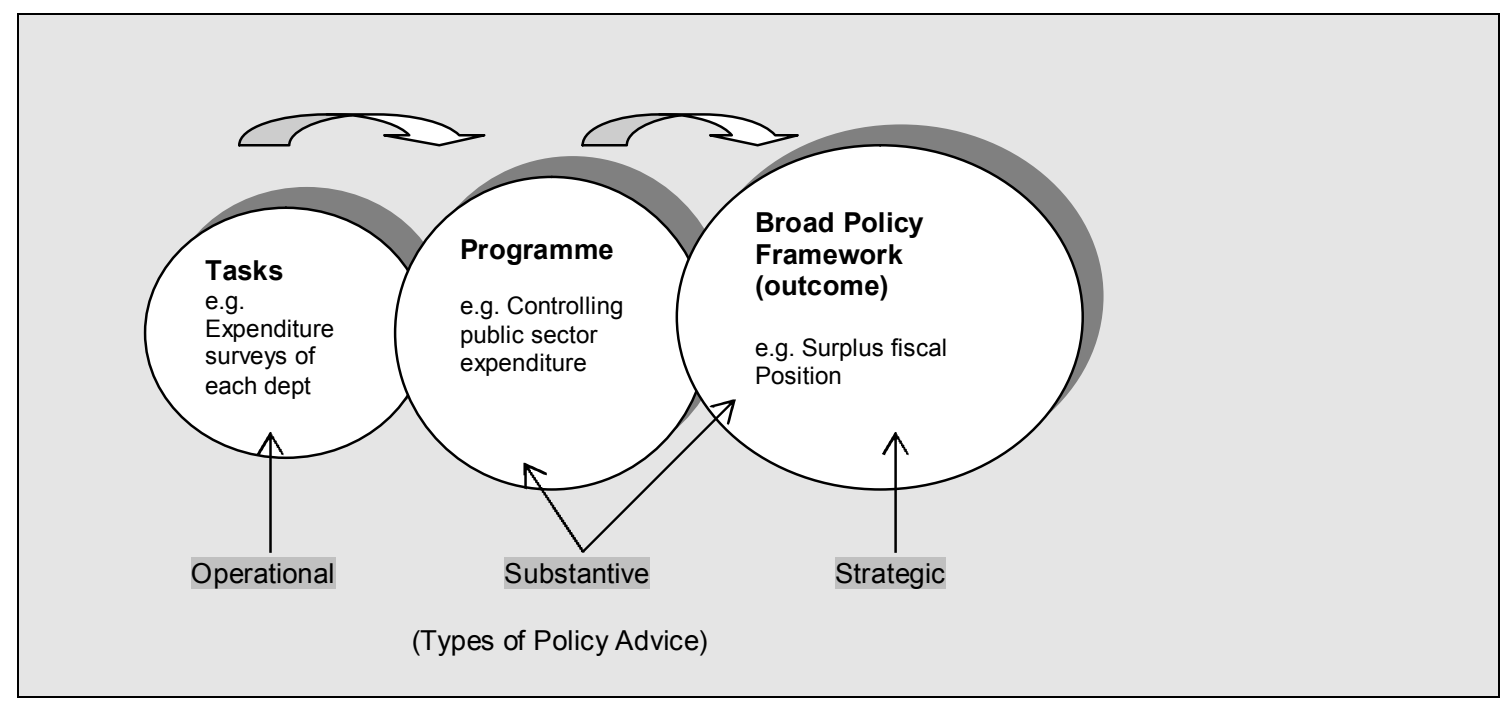

Figure 3.3 shows that when giving policy advice not only may policy advisers need to tender operational, substantive and strategic advice simultaneously on a given issue, but there is also a need to consider the interlocking relationships that exist between outcomes and programmes and the implications arising from such linkages. Notwithstanding these cautionary comments, the classification of operational, substantive and strategic advice provides valuable insights into the process of policy advice and plays an important part in this study.

\section{The Importance of Policy Advice}

The importance of policy advice as an activity within the government machine cannot be overemphasised. Governments are required to respond decisively and effectively to a myriad of policy challenges confronting society. They purchase (fund) the production of advice and not surprisingly seek an efficient, reliable, and comprehensive service, in return (SSC, 1992; Stewart, 1999; Boston et al, 1996). Inability to rely on a robust system of policy advice could have enormous costs for society and the government. As observed by the Provincial Auditor of Manitoba, Canada (2001:3):

The impact of poor quality advice on government decision-making is potentially profound and costly. The stronger the policy capacity, the greater the potential for good decision-making and ultimately, good government. 
The quest for more accurate and reliable policymaking (Boston et al., 1996; Di Franceso, 2000; Bhatta, 2002), and the corresponding reforms that have sought to improve existing advisory arrangements in recent years (Waller, 1996; SSC, 1999; Sanderson, 2002; UK Cabinet Office, 1999; 2000) have demonstrated, without question, the crucial role that advice plays in policymaking. As noted in Adding it up: Improving Analysis \& Modelling in Central Government (2000: 5), an initiative of the UK Government in improving the quality of policy advice:

Better analysis requires commitment throughout Government. Ministers and senior civil servants have a crucial leadership role in expecting soundly based analysis in support for policy. They need better understanding of the importance of analysis and how it can contribute to good decisions and policy outcomes.

Providing advice is not a simple task, though at times this may seem to be the case, for example in the provision of some operational advice. As mentioned earlier, the complex nature of many of the issues confronting public decision-makers and the potential for such issues to harm (or benefit) society require that they be given serious thought and consideration. Public officials on whom decision-makers depend for advice need to carefully blend their skills and knowledge with experience in order to generate relevant advice. This requires them to undertake rigorous assessment, to use the relevant evidence, to consult widely with key stakeholders, to consider policy trade-offs and political goals, and to respond within the required timeframe (see Sanderson, 2002; Bhatta, 2002; UK Cabinet Office, 2000).

In the final analysis, the supply of quality advice depends on a well-developed system having the capacity to respond to the demands of relevant policy clients on an effective and timely basis. The calibre of this system, especially in developing countries, is related to four basic considerations: (a) time, (b) availability of relevant skills in policy analysis, (c) changing policy environment, and (d) the inherent uncertainties and complexities associated with decision-making. These are discussed below.

\section{The Time Factor}

The time frame is an important factor in the policy advice process. Often policy clients such as politicians and top bureaucratic decision-makers are required to respond to policy issues at short notice - for example in times of crisis or 
emergency situations. They must therefore depend on advice that is not only comprehensive and reliable, but that is supplied in a timely manner.

In almost all political jurisdictions, policy complexities (Arberbach et al., 1991; Boston, 1994) require the input of professional public servants who form part of an organised network of advice within the bureaucracy. Such officials do not only know how to analyse complex policy issues; their professional position within the bureaucracy and their understanding of administrative and constitutional issues place them in a position where they can respond within a time frame calibrated to the needs of their political masters. Allison's (1971) and Anderson's (1983) analyses of the process of decision making of the United States Executive Committee of the National Security Council (ExCom) during the Cuban missile crisis are illustrative of a network of advice upon which President Kennedy relied in a time of crisis. Although the analyses show that often ExCom's decisions were inconsistent, the very fact that ExCom was able to provide the President with advice at the moment of need ultimately led to the defusing of the conflict.

In developing countries, the continuous cycle of crisis situations often requires spontaneous advice, which policymakers must draw from the public service. Famine, the increasing incidence of HIVIAIDS, and a collapsing economy, are some of the key situations that require immediate policy responses. Delays in furnishing advice can cause delays in mounting responses. In other instances, delays may force policymakers to make erratic decisions, lacking reliable and comprehensive policy responses. Or, when policy decisions are finally taken, these can be too late to stop the impending calamities. As an illustration, the highly published case of PNG facing imminent economic collapse in mid-1994 amply demonstrate the significance of Treasury's timely advice in formulating policy intervention measures (see Duncan and Temu, 1995; Garnaut, 1995; Chand and Stewart, 1997). The department led the negotiation with the World Bank; devised an economic rescue package in consultation with the Bank; and implemented the rescue package thus stopping a further deterioration of the economy. Delays at any stage would have prejudiced this recovery. (Equally, of course, ministers were required to take difficult decisions within a tight time frame). The obvious qualification to this emphasis on timeliness is that rapid response carries with it the danger that advice proffered may be inadequate or just wrong. In crisis situations this observation simply strengthens the case for quality advisory arrangements. 
Availability of Skills in Policy Analysis

Over the years the art of policy analysis has become increasingly sophisticated. This sophistication has accompanied the creation of a profession in policy analysis whereby requisite skills are developed, experience is gained, and a suitable knowledge base is created. It has also has created a gulf between those who require advice but do not have the policy skills or the experience and those who supply it. In most developing countries at least policy clients at the political level, ministers especially, are unlikely to have the skills and knowledge of policy analysis. Ministers are also constrained by having little time for in-depth research or to go through the myriad data required to carry out comprehensive analyses.

As shown in Chapter One, a characteristic feature of many developing countries has been the slow progress in strengthening the capability of personnel working in all strata of the government machinery. In some countries, the lack of skills and expertise has been particularly acute thus affecting the whole of the government machine (Grindle, 1997). Legislators, in particular, often have little education, many having been voted into office on the basis of ethnic or tribal affiliation rather than on a concrete party platform and a sound knowledge of policy dynamics (see Reilly, 2000). This situation places policymaking at risk if decisions are made without the benefit of quality advice.

Policy makers are therefore likely to depend on the advice from experts (policy analysts) who can diagnose problems, evaluate and predict policy impact with some measure of reliability, and propose policy intervention measures. As one New Zealand cabinet member has commented, ministers are "only as good as the advice [they] get" (cited in Hawke, 1993: 1). Certainly, the complexity of some of the issues confronted inevitably makes the task of advising on policy difficult. And, there will be times when advice will be wrong (see Wildavsky, 1979; Weimer and Vining, 1999; Radin, 1997). However, relying on people who have developed specific skills, acquire specific knowledge and experience over time, and are familiar with the multidimensional aspects of policy can help to avoid the pitfalls of faulty political judgement.

\section{A Changing Policy Environment}

The demand for good policy advice is also driven by changing circumstances in the policy environment. Policy environments are not static; rather they are subjected to the shifting nature of the expectation of government responsibility, changing global 
trends, and new issues. New policy challenges require appropriate responses. They in turn impose demands for advice on how to respond in an appropriate fashion. Changing circumstances have also seen the emergence of new policy problems that transcend national boundaries. According to the OECD, the interpenetration of domestic and international issues such as the reinforcement of multilateral agreements and regional groupings of countries, decentralisation of government functions and the availability of information by way of the advancement in information technology have drastically changed the scope and magnitude of public policy (OECD, 2000; 2000a). Cross-border air pollution, international terrorism, and violations of human rights, for example, are policy issues that were once rarely heard of, and attracted little global attention. The evolving nature of these problems and their impact across national borders has now made them key policy problems warranting the full attention of governments.

In developing countries such as PNG the policy challenges are, if anything, even more daunting. Crisis situations of the kind mentioned in Chapter One - policy instability, economic mismanagement, and the need to lift the performance of many public services - are some of the issues the governments of developing countries' need to tackle. As an illustration, consider the issue of public sector reform, which has been among the most important issues on the policy agenda in the 1990s and beyond. A key challenge for many developing countries is how to mount sustainable reform strategies that can bear results in the longer-term (Grindle and Thomas, 1990; Brinkerhoff, 1996). Experience with numerous development efforts has demonstrated the complex nature and uncertainties of many public sector reform policies in developing countries (Kibria, 2001; Rondinelli, 1993). A key criticism has been directed at the introduction of prototypes from the West, which have little relevance to the particular political, administrative, and socio-economic contexts of developing countries, and whose sustainability therefore has been problematic (Caiden and Wildavsky, 1974; Rondinelli, 1993). In particular, criticism has been levelled against the lack of careful formulation, sequencing and execution of implementation strategies, which has led to the failure of many reform programmes. For example, in respect of reform initiatives supported by the US International Agency for International Development (USAID) in Africa, it has been found that "many policy failures can be attributed to the lack of careful consideration by developing countries' governments and aid donors of how the reform policy implementation effort is or should be organised" (Crosby, 1996: 1403). This discussion underlines the need for careful analysis and prescription of viable policy 
solutions for developmental projects taking into account the particular circumstances of individual countries.

A key challenge in recent years has been the emergence of so-called "crosscutting" issues, which has placed pressure on intra and interdepartmental coordination and management of policy across the public sector (OECD, 2000a). Such issues are multifaceted, spread across a number of departments "with each department responsible for one aspect of it but none is responsible for the issue in its entirety" (OECD, 2000a: 1). The challenge, of course, is how to bring together a comprehensive and holistic response, ensuring that advice and subsequent policy responses are coordinated and integrated horizontally across a range of departments and agencies.

\section{Problems of Decision-Making}

Public policymaking entails making judgements about how, where and when to act on issues confronting government. However, the multifaceted nature of policy problems and the interlocking nature of many policy issues are key constraints on the decision-making function. There is already a large body of literature documenting the difficulties of decision-making in both organisational and political contexts (for a review see, for example, Eisenhardt and Zbaracki, 1992).

Earlier rationalist models of decision-making — often referred to as the synoptic or rational-comprehensive model (Anderson, 1983; Gregory, 1989) - depicting decision-making as an activity that is fairly orderly and straightforward, have now been discounted in empirical studies (Carter, 1971; Allison 1971; Hickson et al., 1986). Cognitive limitations (Simon, 1957, Lindblom, 1959; Irwin, 1996); adherence to standard operating procedures (Allison, 1971); uncertainty of options (Anderson, 1983) politics and power (Wildavsky, 1978; Lindblom, 1979); and extreme ambiguity (Cohen et al., 1972) variously impact on decision-making, rendering it an uncertain exercise. Gregory's (1989) analysis of Lindblom's work, for instance, illuminates the constraints on rationality and therefore the problematic nature of public policymaking. A low level of understanding of the relationship between variables, self-interest of policymakers, political tradeoffs in negotiation and bargaining, and conflicting objectives all create uncertainties and can obscure an objective analysis of public policy (Gregory, 1989: 176). Ultimately, policy analysts and advisers have to negotiate their way around those hurdles in proposing relevant policy options to policy clients. 
Policy uncertainties and complexities surrounding policymaking will never go away. Rather they call for more coordinated, robust, and comprehensive decision-making processes. Within the government machine such processes depend on a quality advisory system that would inform decision-making. The key challenge for such a system is how to respond in a manner that recognises the uncertainties and problems identified above. Critical to the response is the provision of good policy advice - in the form of being comprehensive, reliable, and timely. This is the "antidote" that works to cut down the uncertainties and pitfalls arising out of policy complexities, multiple causes of policy failure and the interlocking nature of policy (Goodin, 1982). By relying on relevant expertise in policy analysis and incorporating the type of analysis that can effectively diagnose the nature and causes of problems, risks can be minimised and policy objectives are given some assurance of success.

The strength of policy analysis depends to a significant extent on the acquisition and use of information in a manner that can generate relevant policy options. There is already a large literature on the "bounded rational" approach, which supports the view that better ways of acquiring and processing information can improve decisional outcomes (Schweiger et al., 1989; Cosier and Schwenk, 1990; Simon, 1991). The role of the analyst or adviser in this instance is to use his or her existing skills in negotiating through the available information; to collate evidence from it; decide on policy trade-offs; and to make informed judgements on policy viability. This task is summarised by the OECD:

What matters most is not simply whether contrasted policies are being pursued, but whether they are being pursued knowingly, or unwittingly. If contradictory decisions must be made, the key concern is that they be made lucidly, deliberately, and on the basis of information and analysis that enable the decision takers to mitigate the costs of incoherence, as well as to explain their course of action in the context of difficult choices they are confronted with (OECD, 2000: 8)

\section{Organisation of Advice}

As observed in the prefatory part of this chapter, the way policy advice is organised and delivered remains an important concern to those who receive advice. Policy clients rely on different arrangements to get the kind of advice they seek (e.g., see Figure 3.4). To quote Seymour-Ure (1987: 175) policy advice can be "coordinated as well as uncoordinated"; it can also be "institutionalised" or non-institutionalised". 
Uncoordinated advice may be spontaneous and in some cases may not be provided by institutionalised sources such as public service departments. In some political jurisdictions different in-house arrangements - for example, taskforces and commissions of inquiry - may be utilised to service the advisory needs of ministers. Others rely on external sources, for example, think tanks and research institutes, to provide the necessary advice.

Arrangements relying on political advisers, trusted friends and "kitchen cabinets" (Bakvis, 1997) often provide uncoordinated, external advice to accompany the bureaucracy's in-house advice. Countries such as the USA show a strong tendency to rely on external advice from policy networks, policy communities, think tanks, and independent research institutes (see Halligan, 1995; Stone, 2000). In Westminster countries, the public service is the main provider of policy advice. Nonetheless, there has been a pronounced tendency over the past decade to have a stronger mix of advisory arrangements combining internal and external providers, especially in the use of consultants and political advisers (see Shaw, 2003; Eichbaum and Shaw, 2003; King 2003).

In developing countries, including PNG, advice continues to be largely obtained from the public service. With the advent of various structural and economic reforms, however, there has been a tendency to acquire external advice from bilateral and multilateral aid organisations responsible for managing and distributing development aid - for example the World Bank (IBRD) and the International Monetary Fund (IMF). Using the coercive transfer of policies (Dolowitz, 2003), these organisations have often successfully institutionalised their policy advisory services within developing countries' policymaking process, thus making them some of the powerful sources of advice within the government machine (see Chapter Four for an in-depth discussion).

\section{In-House Advice}

Traditionally, in-house advice has been the most common type of advice provided to policymakers (Boston, 1994). In-house advice, by definition, is advice that is produced by various instrumentalities of government of which the departments in the public service are the key providers. The power and operations of such instrumentalities vary in scope (Boston, 1994; Seymour-Ure, 1987; Bakvis, 1997) — certainly, the powers of central agencies are usually pervasive. 
Figure 3.4 gives a brief synopsis of the different sources of in-house advice within the government machine. Some scholars, for example Halligan (1995: 158), have differentiated them into two groups: "internal public service", and "internal non-public service". For example, departments and agencies and inter-departmental committees may be classified under the former heading, while royal commissions, commissions of inquiry, and taskforces may be grouped under the latter.

Figure 3.4: Sources of In-house Advice

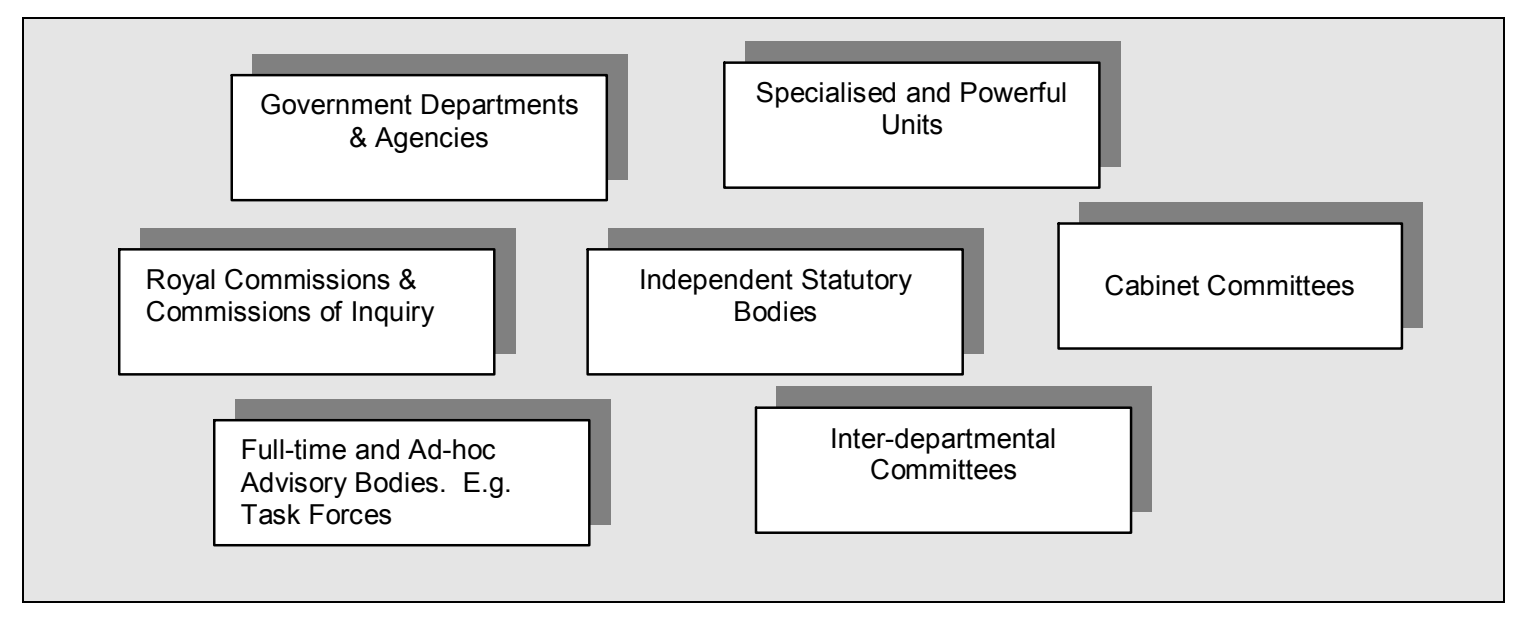

Generally the funding of such instrumentalities comes from the government, which, to some extent, determines their modus operandi (Halligan, 1995). Despite this general observation, some may be independently established and operate under specific statutes while others, as is the case with public service departments, may come under direct ministerial control. Some may be established on an ad hoc basis comprising experts and charged with examining specific issues and reporting their recommendations. Royal Commissions and Commissions of Inquiry are perhaps the best examples of this kind of advisory arrangement. Such bodies can probe issues by soliciting data from experts, obtaining public input and then making their recommendations to authorities. These often carry weight because the commissioners are credible figures, and because wide public consultation is an important source of validating recommendations (see Bakvis, 2000: 81).

The manner of transmission of advice from internal sources often varies, depending on who has been assigned the task or requires advice, and the need to filter and horizontally coordinate and integrate advice. Advice can be directly provided, for example, by a taskforce to the minister, or advice may be indirect, for example, from an inter-department committee to a lead department (for example, a core central 
agency) and then to the minister (Figure 3.5). In the former case, a taskforce may be set up by ministerial direction, perhaps to provide an alternative view to his or her own department; in such a case the taskforce might be expected to provide its recommendations directly to the minister. In the latter case, the work of an interdepartmental committee (for example a draft report) may be forwarded to a coordinating department (for instance the Department of Prime Minister and Cabinet) to ensure that the views of all the departments with a legitimate interest are included prior to ministerial deliberation. In addition, advice on a particular policy issue may be derived from a variety of internal sources, the aim of which is to provide a second or third opinion on issues that are deemed particularly important.

\section{Figure 3.5: Transmission of Internal Advice}

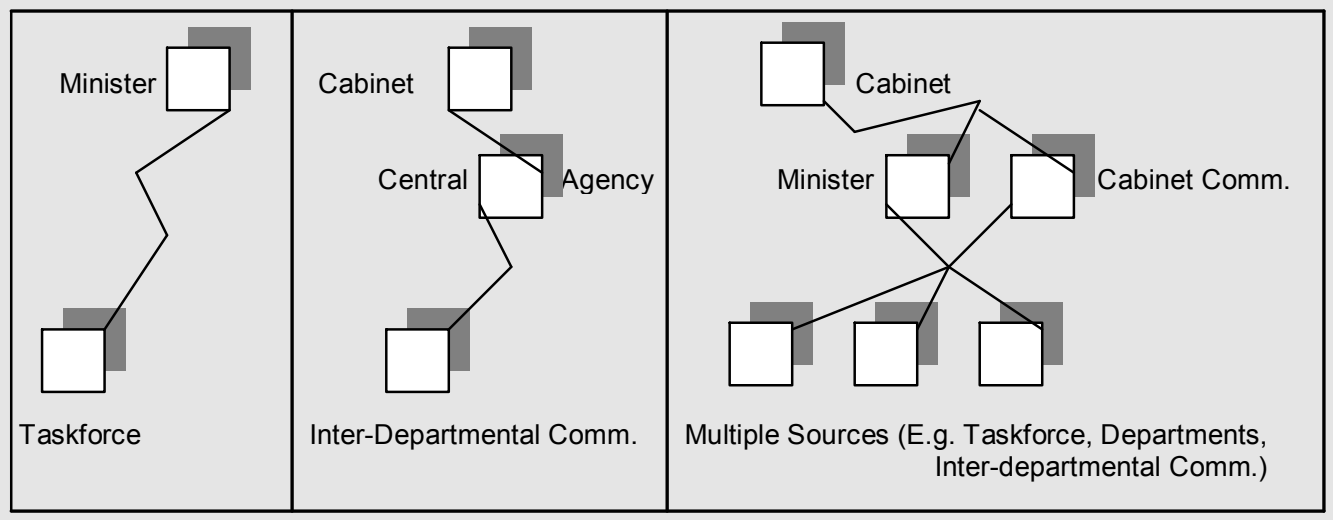

\section{Use of departments}

Public service departments remain the principal source of policy advice in Westminster countries despite an increasing tendency of policymakers to draw on both internal and external advice for the development of public policy (Halligan, 1995; Ayres, 2000; Shaw, 2003). Boston (1994), for example, notes the growing preference of governments for "multiple-provider arrangements" in which external (usually market) providers of advice are contracted to provide policy advice on a range of issues.

Although the contracting out of policy advice and certainly the increased use of political advisers in developed Westminster countries has become common (Ayres, 2001; Eichbaum and Shaw, 2003; King 2003), departments continue to provide the bulk of policy advice in Westminster countries (this includes many developing countries such as PNG) (see Boston et al, 1996). This is largely attributable to two 
main reasons. One is the long-standing reliance by ministers and cabinet on the public service to provide advice. Moreover, the working relationship between the core executive (cabinet) and departments in Westminster systems has traditionally been very close, perhaps organic - evident, for example, in ministerial control of departments and the responsibility and accountability of departmental heads to ministers. It would be - and sometimes is - surprising if ministers were not inclined to rely on their department prior to considering other sources. Secondly, in most countries professional public servants constitute the repository of the knowledge important to managing the government machine. Such knowledge is difficult to find elsewhere thus making the public service an invaluable source of advice to ministers.

Advice provided by departments and agencies is highly institutionalised, aimed at serving particular clients within and outside the department - for example, departmental secretary (CEO, or permanent head), the portfolio minister, other ministers, cabinet committees and cabinet. Policy clients would receive a mixture of operational, substantive and strategic advice, although it might be speculated that departmental managers would be more concerned about operational and substantive advice, while ministers and cabinet might, in principle, be more focused on strategic matters.

Within departments policy advice is organised along established lines governed by rules prescribing the conduct and performance of policy officials, and subject to various reporting and accountability arrangements. Variations notwithstanding, the typical arrangement within a department would be several units specifically concerned with individual policy areas and responsible for undertaking a range of policy work in these areas. The strength of a department in organising and supplying advice is, by and large, a function of the capability of its policy units to maintain a well-organised system of supplying policy advice to policy clients. Critical factors that are important to a unit's performance are the way the unit is organised and managed, the level of skills and knowledge possessed by the staff, the facilities at the disposal of the policy unit (what the SSC (1999a) calls the required "infrastructure" for policy work) and the development and use of best practice in maintaining the quality of such work - for example, in establishing relevant benchmarks for guiding policy advisory work; setting the protocols for interdepartmental cooperation or "joined-up" activity for tackling crosscutting issues; and in establishing the criteria upon which policy advisory work is to be assessed and evaluated (see SSC, 1991, 1999a; Bhatta, 2002; UK Cabinet Office 2000). 


\section{External Advice}

Reliance on the public service for policy advice is not without risk. A significant risk is that departments and agencies may not be capable of providing highly technical and sophisticated advice on specialised areas, for instance on complex matters of science and technology, in matters of risk assessment in fields such as the global environment and finance and investment; and in developing countries, in major ventures that are capital and technology intensive, for instance, in gas, mineral and petroleum projects. As noted elsewhere in this chapter, the growing complexity of policy issues has placed a demand for more specialised and expert advice. The "Joined-Up-Government" initiative in the UK (Richards and Smith, 2002) using task forces that draw expertise from external sources to enhance the advisory capability of the central government is a recent response to this (Taylor, 2000).

The perceived risks associated with the public service as the sole provider of advice have influenced many governments to seek advice from a range of organisations and individuals outside the established public service machinery (Figure 3.6). Such sources of advice differ from government funded and established sources in that they operate independently; they are not dedicated to one particular policy client, and their services are usually bought at market prices.

Figure 3.6: Main Sources of External Advice

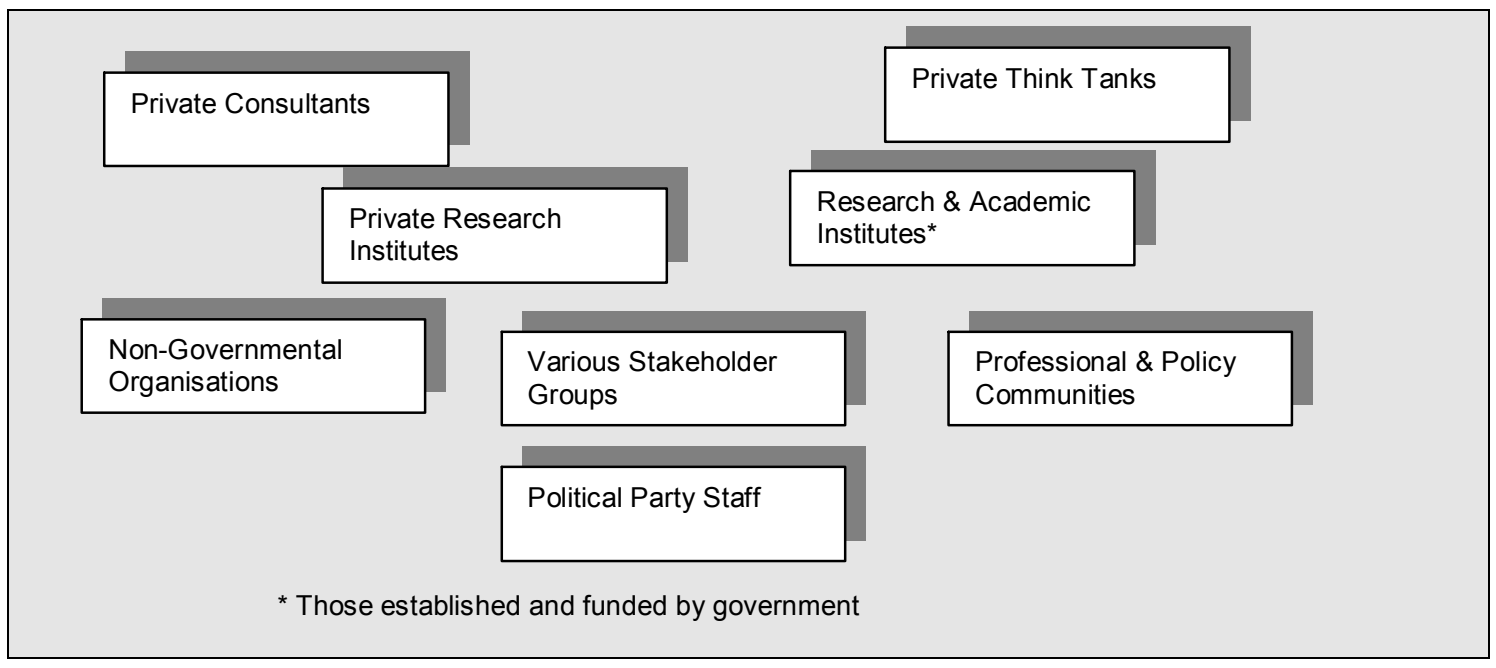


Some government instrumentalities can be external providers, often acting as consultants providing particular advice. Academic institutions and research institutes established and funded in whole or in part by governments are examples. Unlike departments, they operate independently, make their services available to a range of clients without being "dedicated" to a single client (for example, a minister or CEO), and they charge for their services at a market rate.

Of particular interest is the role of non-governmental organisations (NGOs), stakeholder interest groups (for example, groups from the voluntary sector, business community and trade unions) and policy communities. Many of these have been drawn into the policymaking process because of the highly pluralistic nature of public policy (Heclo, 1978; Smith, 1993). Driven by their wish to influence public policy, and, on many occasions providing their services free of charge, these groups can play an influential role in public policymaking as they may be seen by officials and politicians to be effective and less costly sources of advice. In developing countries, the need for more open and transparent government (inclusiveness) coupled with the importance placed on these groups by donors such as the World Bank have gradually increased their influence on the policy process. This has especially been the case with NGOs. In PNG for example, various NGOs - for example, the Forestry Watch Group, Melanesian Solidarity and Individual and Community Rights Advocacy Forum (ICRAF) - have been successful in influencing both social and economic policy, and recently environmental policy. Given their roles in delivering various public services, some of the NGOs have been incorporated into the formal policymaking process of government - for example in having representatives on boards of organisations and advisory task forces.

\section{Improving Policy Advisory Capability: International Trends and Issues}

Many of the changes aimed at improving policy advisory capability over the past twenty years were elements of the New Public Management (NPM) led reforms from the 1980s. The NPM agenda was to introduce "flexibility", "responsiveness", "quality of service", "effectiveness", and "efficiency" into what were perceived as less than adequate public services (Hood, 1991; Aucoin, 1990; 1995; Pollitt, 1993; 1998; Considine and Painter, 1997). Policy advice, as with other functions performed by the public service, has come under scrutiny and criticism. Politicians in particular, 
formed a view that there was a discrepancy between the quality of advice expected and that rendered by public servants (Bhatta, 2002: 98): advice often did not match expectations resulting in policy clients expressing doubts on whether they were receiving the correct advice.

In Australia, for instance, there was growing concern in the 1990 s by parliament about the value of advice produced by government departments. In addition, the Department of Finance questioned its own internal processes for producing and evaluating policy advice as early as the mid-1980s (Uhr, 1996; Weller and Stevens, 1998). Weller and Stevens (op. cit) note some of the underlying concerns:

... central agencies were faced with a different problem. When parliamentary committees asked what 'added value' they provided, the response was policy advice. If the question was then asked: "how well was it provided, there was little evidence. The central agencies therefore had to develop a means of assessing policy advice in order to conform to the same standards of evaluation imposed on line departments (Weller and Stevens, 1998: 581-582).

Similar concerns have been raised in New Zealand over the past decade. For example, a recent State Services Commission (SSC) evaluation sought "to establish why a large and costly policy advice system apparently does not provide ministers with the information they need to make sound decisions" (SSC, 1999: 5). This is despite some changes in advice provision - for example, initiatives designed to improve the quality of policy advice and the policy/delivery split of departments that took place close to a decade and half ago (see SSC 1991; Boston et al., 1996). At the time of writing the SSC has mounted a full-scale investigation aimed at determining the advisory capability of the public service (under what it calls Improving the Quality of Policy Advice Project and to propose relevant policy intervention measures (see SSC 1999; 1999a). Canada, another Westminster-style country, has attempted similar reforms focused more on organisational rearrangements for the delivery of policy advice (Bakvis, 2000; Office of the Provincial Auditor, 2000). In the United Kingdom one element of the responses to similar concerns was the Investors in People (1999) training standard, aimed at improving the quality and capability of personnel (including policy analysts) within the public service. More recent efforts by the UK Cabinet Office on Professional Policy Making (1999) draw attention to the perceived weakness of existing advisory arrangements and the need for their improvement. 
The experiences of many developed countries so far show different approaches to improving policy advisory capability - though it can be said that there has been a general tendency to combine policy intervention measures aimed at improving inhouse advice with the increased supply of external advice. Broadly, favoured measures include an increasing use of market-type arrangements, especially in outsourcing advice (Halligan, 1995; OECD, 1995; 1996; 1997; Ayres, 2001); introducing systemic changes to the budgeting framework (aimed at funding policy advice as a specific output); the increasing use of a range of performance and evaluation measures directed towards improving and sustaining the quality of advice (SSC, 1992; 2000; Boston et al, 1996; Weller and Stevens, 1998; Uhr, 1996; Weller and Stevens, 1998); reorganising existing departments to sharpen their policy focus (Hunn and Lang 1989; Boston, 1992) - for example through the creation of smaller policy ministries and executive agencies and creating high-powered policy units such as the Performance and Innovation Unit (PIU) of the Cabinet Office in the UK (Richards and Smith, 2002); increasing reliance on policy networks (Rhodes, 1997); and improving organisational capability - for example by introducing relevant training for policy analysts and improving processes and systems for policy work (Lindquist, 2000; SSC, 1999a).

A particular focus has been on improving the quality of policy analysis carried out by departments using of a variety of benchmarks defining best practice in policy analysis work (see SSC, 1999a; UK Cabinet Office, 2000). Such benchmarks are used as guides for carrying out policy advisory work and also specify the scope and quality of policy advice provided to policy clients. Moreover, they can be used for monitoring and evaluating the quality of policy advice and for accountability purposes - for instance in holding policy managers and their units accountable for the quality of advice they provide. The UK Government's initiative, Professional Policy Making for the Twenty First Century (1999), for example, uses the following benchmarks for organising policy advice: "forward looking; outward looking; innovative and creative; using evidence [evidence-based analysis]; inclusive; joined up; evaluation; reviews; and learning lessons [from past experience]". Moreover, new and arguably more robust benchmarks can be seen in the recent emphasis on more evidence-based analysis found in the Adding it Up: Improving Analysis and Modelling in Central Government (2000) document (see UK Cabinet Office, 2000; Sanderson, 2002). 
In New Zealand, benchmarks attempting to serve similar objectives were first introduced by the State Services Commission (SSC) in 1992 in its work, Improving the Quality of Policy Advice and were later adopted by various departments (see SSC, 1992; 1999; Boston et al, 1996: 132). Three key benchmarks were proposed and subsequently used, although with departmental variations: performance measures, quality characteristics and the quality management of policy advice (see SSC, 1992 and Boston et al., 1996: 132). Each measure is designed to address an aspect of policy advice perceived to be important. Performance measures are to be used for guiding the work of departments in providing policy advice; quality characteristics define how well policy advice is to be provided, highlighting what advice should contain and how advice should be framed when furnished to ministers; and quality management specifies different review processes that managers should maintain in order to sustain a high level of advisory service within their departments. Similar benchmarks to those of New Zealand, especially on the quality of policy advice, were proposed for possible adoption in Manitoba, Canada in 2001 (see Office of the Provincial Auditor, 2001). The verdict on the efficacy of the changes discussed above can only be tentative, although progress in some countries has been made in certain areas - for instance in the coordination of advice, the focused manner in which political executives have been receiving advice, and the effort in sustaining the quality and comprehensiveness of advice.

\section{Conclusion}

Throughout the discussion, the rational-comprehensive model (or the stagist approach) has been depicted as the dominant paradigm influencing the generation of policy advice. There is no denying that the 'rational' step by step organisation of policy advice - in the form of problem and/or issue diagnosis, assessing the consequences of not responding, and devising options to respond and their associated consequences - underpins a common approach to providing advice, at least in a technocratic sense. There is clearly a place for rational analysis in the provision of policy advice. And for this discussion, the rational model has been used as a "mirror" to reflect the provision of advice in practice. However, providing policy advice in the real world is intensely political and is a far more complex exercise. In reality, providing policy advice often involves a clash of values and is shaped by intuitive judgement and perception, political goals, interests and trade-offs and is constrained by the availability of information at hand. Above all, the provision of advice is shaped by the values and perceptions of different actors in the process the 
historical and institutional context in which it takes place, and the political processes and requirements which underpin the roles of politicians and advisors..

Discussions in this chapter have also shown that the scope of public policy and the complex nature of policy issues that require the attention of governments have created a widespread need for quality and timely policy advice. There is an increasing requirement for governments to respond decisively and effectively to policy issues confronting society; and the need for more rigorous and effective advisory systems is apparent (Waller, 1992; SSC, 1992; 1999; OECD, 2000). Inhouse advice provided by the public service continues to occupy a special and dominant place in public policymaking despite the tendency in some countries to resort to multiple provider arrangements. The role of the public service, however, has received increased scrutiny and criticism. As noted earlier, there is now a widely held perception in many countries that the organisation and delivery of policy advice by the public service has been less than adequate. As a result there have been various efforts to improve the quality and timeliness of advice in many developed countries.

Similar reforms in developing countries have been slow. Certainly, for countries like PNG such reforms have yet to eventuate to any significant degree. Despite the socio-economic and political differences, developed and developing countries confront similar challenges in respect of the provision of advice. How can present advisory capability be strengthened so that there is an improvement in quality and timeliness of policy? Despite the widespread application of the NPM model (and hence similarities in many policy responses), the question will most definitely elicit different responses in different countries, and indeed responses so far in the developed world have been varied. Differences in political tradition, the state of public administration, and the priorities of individual governments will ultimately shape policy responses. Although responses are likely to be different, the experiences of developed countries show that successful strategies are to be multidimensional, encompassing a mix of policy intervention measures. While improving the quality of analysis would remain central to any capability building effort, there is, above all, a need to focus on the holistic nature of capability described in Chapter One. There is a need to investigate the existing level of capability focusing on the skills and expertise of policy staff, experience of policy officials, resources and facilities, managerial skills, the planning and organisation of advice within departments and the political context within which public servants organise advice 
and then propose appropriate policy intervention measures. Chapters Six, Seven and Eight report on such an investigation of three central agencies in PNG. However, before embarking on an investigation of the situation in PNG, it is necessary to consider the body of policy literature built around the notions of "policy transfer" and "lesson drawing". The next chapter (Chapter Four) considers the relevant literature. 


\section{Chapter Four: Policy Transfer and Lesson Drawing}

\section{Introduction}

As mentioned in Chapter One, this study will use the analytical insights of the policy transfer literature in considering the relevance to Papua New Guinea (PNG) of lessons from other jurisdictions, particularly in developed Westminster systems. It will also use the insights of new institutionalism theory to consider the institutional contexts in which policy lessons will be transferred. For the purpose of informing discussion, analysis and developing arguments in transferring lessons in the final part of the thesis, this chapter discusses the "new institutionalism" theory and the essential elements of policy transfer from the wider policy convergence and policy transfer literature. The Chapter begins with the brief review of the rich literature on new institutionalism and its various strands and then discusses the wider policy convergence literature.

\section{New Institutionalism}

"New institutionalism" is a body of thinking which examines the ways in which institutions structure social and political behaviour, and in the context of this thesis, the role of institutions in respect of both the context and types of policy transfer and adoption. Institutions, briefly defined, include "established rules, customs or practice and conventions" (Lowndes, 1996) that govern or determine individual or organisational action in the pursuit of some goal (however defined). ${ }^{28}$ Such rules, customs and practices can be formal or informal. The strength of new institutionalism theory lies in its ability to provide explanations to change (or alternatively lack of it) in policy behaviour and outcomes, the context of policy change and the rationales or motives for policy change ((March and Olsen, 1996; Peters and Pierre, 1998; Nielson, 2001).

New institutionalism is not a single or coherent theory (see Lowndes, 1996); rather it constitutes a variety of strands including "historical institutionalism" (commonly found in political science and comparative politics analyses), "rational choice institutionalism", and "sociological institutionalism". These strands in turn are influenced by, and draw their impetus from, the fields of political science, economics,

\footnotetext{
${ }^{28}$ Using the historical institutionalist definition, Hall and Taylor (1996:938) define institutions as, "the formal or informal procedures, routines, norms and conventions embedded in the organizational structure of the polity or political economy".
} 
organisational theory and sociology. It is therefore not surprising that various strands of the new institutionalism emphasise different theoretical assumptions and predispositions (Stacey, 1995; Lowndes, 1996; Thenlen, 1999; Nielsen, 2001). In general, however, numerous analyses in new institutionalism have attempted to reassert the role of institutions in policy change or the lack of it; to explore the motives for change and what triggers it; to track the paths or processes of change; and to identify the different outcomes of the change process with their various implications (see for example, Steinmo, 2001; and Hall and Taylor, 1996). Such change can be endogenous or exogenous with institutions being the explanatory (independent) variable causing change (see for example, March and Olsen, 1996), or the resultant (dependent) variable responding to and impacted by change (see for example, Powell and DiMaggio, 1991). A key emphasis has been to explain how the different trajectories of the change process have led to similarities in organisational features and functions.

\section{Historical Institutionalism}

Historical institutionalism arose out of what might be considered a more traditional political science. Gaining momentum in the 1970s, historical institutionalism was a response to what was perceived as a weak and/or shallow explanation of the distinctiveness in political outcomes from a variety of individual and collective action in different countries by structural functionalists and neo-marxists (Hall and Taylor, 1996). In accounting for the role of institutions, historical institutionalists, unlike say, the rational choice institutionalists, use inductive analyses by first explaining a particular state of event, for example a political outcome, or a change in policy, and then seek to explore possible explanations or causes for such outcomes or changes. While emphasis is placed on the role of institutions in shaping such changes, historical institutionalists also emphasise the impact of the external environment on institutional changes. Overall, historical institutionalists are primarily interested in understanding and explaining real world events and see institutions playing a key role in providing clues to understanding such events (Steinmo, 2001).

According to Hall and Taylor (1996), historical institutionalism has four distinctive features. First, it views the relationship between institutions and individuals in relatively broad terms: that not only can institutions facilitate, constrain or alter human behaviour in optimising policy change or political outcomes, but also the alteration or 
development of institutional forms and practice can be precipitated by the external environments within which institutional structures are found. Second, it emphasises the distribution of power associated with the operation and development of institutions, especially in situations where uneven distribution of power tends to enable individuals or groups to have access to decision-making or attain desirable political outcomes thereby leaving other individuals or groups worse-off. Third, historical institutionalists place a great deal on understanding and accounting for change by a historical study of change dynamics whereby the trajectories of change and their various outcomes are traced. They reject the notion that the same operative forces will generate the same results everywhere, instead they believe that changes are mediated by contextual features of a given situation, which may bring different outcomes (ibid: 941). Fourth, historical institutionalism views the changing dynamics of policy and political life as a consequence of interplay of a range of factors. While institutions matter, changes are precipitated by a host of factors, notably "socio-economic development and the diffusion of ideas" (ibid: 942). Indeed, by taking such a view, it is not too difficult to understand why historical institutionalists are keen to employ an inductive approach to understanding and explaining change in policy and politics.

\section{Rational Choice Institutionalism}

Like other schools, rational choice institutionalism contains some variations in its postulations about institutions. Underpinning the rational choice institutionalism is a set of assumptions about human behaviour, which posit that individual actors in any institutional setting will seek to maximise their interest at any given opportunity. While historical and sociological institutionalists tend to look to institutions and other variables in the external environment for explaining change dynamics, rational choice institutionalism place primacy on the purposive conduct of individuals in determining policy change and political outcomes. According to Hall and Taylor (ibid: 945), "the relevant actors have a fixed set of preferences or tastes, behave entirely instrumentally so as to maximise the attainment of these preferences, and do so in a highly strategic manner that presumes extensive calculation" (ibid: 945).

Various implications can be drawn from the postulations of rational choice institutionalists. First, self interest is the primary motivator for change, rather than institutions. Second, political actors create institutions on the basis of what they can 
secure from such institutions. Third, by extension it also implies that institutions arise out of the need to solve collective action problems (i.e., maximising gains from cooperation) where everyone benefits and no-one is worse-off in terms of securing preferences (see Lowndes, 1996). That is, by establishing the "rules of the game" and actors subscribing to such rules, cooperation can be secured and political and policy outcomes that make no-one worse off can be realised. Fourth, institutional survivability and stability is possible only if such institutional arrangements continue to secure the policy or political outcomes sought by relevant actors, or where such arrangements can solve collective action problems leaving no-one worse off.

\section{Sociological Institutionalism}

Like historical institutionalism, sociological institutionalism views institutions as a key element in explaining the change patterns in and between different institutional structures. A key concern for sociological institutionalists is to account for the adoption of similar practices and norms across different institutional structures: What triggers the adoption of similar norms and practices between different institutional structures, and in doing so, causes change in the environment adopting or replicating such norms and practices? What is the process used? And what are the possible outcomes of change?

In recent years, insights from sociological institutionalism have provided the impetus for analysing and explaining change dynamics in policy and politics. In particular, the notion of mimicking or emulating institutional forms and practices has become prominent in explaining policy transfer or lesson drawing between different organisational structures and countries (see for example, Ingraham, 1993; Pollitt, 1993; and Peters and Pierre,1998). ${ }^{29}$ While not discounting the contributions of the other new institutionalist schools, sociological institutionalism's explanation of change dynamics, especially in relation to the adoption of policy ideas and practices across different institutional structures, is directly relevant to this thesis. For this reason sociological institutionalism is discussed in some detail in the ensuing section.

\footnotetext{
29 Radaelli (2000), for instance, uses the framework of sociological institutionalism to demonstrate how certain policies within the European Union (EU) can be easily transferred among member states using the isomorphic process. In business, Havemen (1995) demonstrates how smaller firms using mimetic isomorphism copy strategies of larger firms. Copying is triggered by the perceived significance in status of bigger firms but, as Havemen demonstrates, is often done with little success.
} 


\section{Sociological Isomorphism}

DiMaggio and Powell (1991), arguably the two leading exponents of sociological institutionalism, describe this homogenisation process as institutional isomorphism (see also Peters and Pierre, 1998; Nielson; 1998). Their analysis is not so much concerned with proposing a strategy enabling organisations to adapt; rather their concern is to explain what they see as a startling trend in organisational homogenisation. In other words, given the increasing prevalence of organisational homogeneity, the challenge was to explain how this process has come about in the first place.

In their words:

Much of organisational theory posits a diverse and differentiated world of organisations and seeks to explain variation among organisations in structure and behaviour...We ask, instead, why there is startling homogeneity in organisational forms and practices, and seek to explain homogeneity, not variation (DiMaggio and Powell, 1991: 64).

At the heart of explaining the process of homogeneity in forms, and practices (and in our case policies), is the concept of sociological isomorphism. Briefly defined, isomorphism is an adaptation strategy and pertains to the "adoption of a common structure and approach resulting in the homogeneity in institutional (organisational) forms and practices" (Pugh and Hickson, 1996: 188). In other words, a unit in a population will adapt the features of successful units in the same environment because of environmental pressures exerted on it (Hay, 1996). The reason is that increasing compatibility with environmental conditions will lead to the survival of the unit and that this process will lead to homogeneity (convergence) in institutional form. As will be seen, although the initial use of the concept was limited to organisations and institutions, the insights of isomorphism can be applied to the drawing of policy lessons across state and organisational boundaries.

\section{Competitive isomorphism}

According to Powell and DiMaggio (1991), two types of isomorphic processes lead to homogeneity in institutions: competitive and institutional. The environment in which institutions are said to exist essentially determines these processes. Competitive isomorphism has its origins in the work of Hannan and Freeman (1977) and pertains 
to the adoption of similar institutional forms and practices because of the pressure to compete efficiently. Drawing again from the backdrop of the environment, this view posits that institutional structures that exist in a market environment are subject to a range of competitive pressures and that, their survival is a function of remaining efficient. Firms which are not performing well will be more inclined to adopt the organisational structures, practices and strategies of the more successful and larger firms. This inevitably results in homogeneity of organisational forms, practices, policies and strategies. Viewed in this light, isomorphism is a not only a common strategy but a necessary one.

Unlike, for example, the modern theory of bureaucracy which posits a view that "organisational convergence" (to the more efficient form of bureaucratic organisation) follows a predetermined path $^{30}$, convergence through competitive isomorphism has no set path: while being competitive is the trigger of convergence, there are different strategies across firms and managers would be required to scan what lessons are available, and how best such lessons can be copied into their firm's operation. Moreover, emulating strategies for efficiency does not only involve those firms that are finding it difficult to survive in the market place (i.e. existing firms); new entrants are likely to mimic larger profitable firms as well. To put it in the words of a researcher on new market entry using isomorphic analysis:

The presence of large incumbents in any market therefore will have its strongest impact on large potential entrants to the market as large potential entrants respond to mimetic pressures acting in concert: imitation of similarly sized organisations and imitation of successful organisations (Haveman, 1993: 600).

\section{Institutional isomorphism}

Sociological institutionalists argue that competitive isomorphism is only part of the picture and that organisational isomorphism should extend to non-competitive organisations as well. According to Powell and DiMaggio (1991: 66), this is because "organisations compete not just for resources and customers, but for political power

\footnotetext{
${ }^{30}$ Max Weber's work on the theory of modern bureaucracy posits a convergence process in which traditional organisations will inevitably adopt a more efficient form, the modern bureaucratic form, by adopting key features or characteristics of the modern bureaucracy (see Albrow, 1970 and Gregory, 1982). Convergence to the modern bureaucratic form is deterministic, triggered by the process of industrialisation. Implicit in the theory of bureaucracy is the view that convergence (to the modern bureaucratic form) is universal, experienced by virtually every traditional organisation that is subject to the process of industrialisation.
} 
and institutional legitimacy, for social as well as economic fitness". This view is affirmed by Radaelli (2000: 27), "Copying organisational structures is not a process driven by efficiency considerations, but a way of securing legitimacy in political life'. DiMaggio and Powell (1983) describe the isomorphic changes in non-competitive organisations to be institutional isomorphism (see Powell and DiMaggio, 1991; Radaelli, 2000; Pugh and Hicks, 1996).

Three sources of isomorphic changes are apparent under institutional isomorphism: coercive, mimetic and normative (Powell and DiMaggio, 1991; Pugh and Hicks, 1996). Coercive isomorphism is brought about by numerous pressures that require institutions to adopt forms and practices thereby resulting in homogeneity (convergence) in organisational forms or strategies. Such pressures may commonly be exercised through political and law-making power. For instance, a member state of the European Union (EU) may be required to adopt a common policy of the EU to which it is opposed. In other cases, smaller organisations may have no choice but to copy the features of key and dominant organisations on which they are dependent. For instance, in a unitary system of government, the national government can force sub-national units of governments to adopt similar features in governance structures through legislative changes.

Not only political and organisational pressures are a common source of coercive isomorphism; DiMaggio and Powell (1983) cite cultural pressures as another source, pointing out that cultural expectations in a society can profoundly alter institutional forms and practices thereby bringing about organisational convergence. Furthermore, coercive isomorphism can be analysed in the context of the market environment. For example, coercive pressures from a market environment - for example, in the need to stay profitable or to expand - can be brought to bear upon an organisation resulting in the adoption of common features. Indeed, on this point DiMaggio and Powell are clear in stating that "the typology [on institutional isomorphism] is an analytic one: the types are not empirically distinct" (DiMaggio and Powell, 1991: 67). This suggests that firms in a market environment are as equally susceptible to coercive pressures as other organisations that are non-profit oriented.

By contrast, uncertainty rather than coercive pressures triggers mimetic isomorphism. According to Powell and DiMaggio, "When organisational technologies are poorly understood, when goals are ambiguous, or when the environment creates symbolic uncertainty, organisations may model themselves on other organisations" 
(Powell and DiMaggio, 1991: 69). By adopting similar institutional forms, practices and strategies that are perceived to be correct or seen as being at the "cutting edge", organisations are likely to be perceived as doing the right thing. Numerous examples serve to demonstrate this. For instance, smaller firms will tend to copy the strategies of larger firms in a particular market domain because size is equated with reputation and success (Haveman, 1993). Thus, for smaller firms to copy strategies that increase size is seen as the right thing to do. In other cases, what is perceived to be "best practice" tends to be the benchmark and other organisations will be inclined to copy the best practices of those organisations that are perceived to be at the forefront. As an example, consider the adoption of market driven ideas in the administration of the public sector over the past twenty years influenced by the New Public Management (NPM) model. Could it be that the adoption of such practices is largely owed to the perceived "superiority" of the private sector mode of management over those that are found within the "traditional" public service?

While there are differing views, the widespread adoption of "market solutions" in a range of public sector reforms suggests that mimetic pressures may explain to some extent the transfer of private sector techniques of management into the public sector (see for instance Pollitt, 1993). To the extent that this is the case, a particular danger is that adopted lessons may be employed without consideration being given to their likely impact in the short and longer term. Ingraham's (1993) analysis of the introduction of the private sector's "pay for performance" schemes into the Senior Executive Services (SES) of a number of countries in the developed world would appear to demonstrate the above danger. Ingraham contended that the failure of the scheme in the Unites States and other countries was largely attributable to reformers acting on their impressions of the efficacy of schemes - here seen as a key incentive for improving performance - in the private sector without due consideration of the financial capacity of the public sector to sustain high salary costs.

The third type of isomorphic change pertains to normative pressures as a result of professionalism (Radaelli, 2000). Members of a particular profession hold in common certain skills and knowledge. Expressed in the guise of "common ideas" or "common principles" these are often the basis for isomorphic change influencing both organisational forms and practices across organisations. The power of professionals to promote change can be significant given that their members can be found across many different organisations. Powell and DiMaggio identify two aspects of 
professionalism as important sources of isomorphism: one is the role of formal education especially in colleges and universities; and the other is the growth and elaboration of professional networks that span organisations. In the former, universities and formal training institutions are key places for instilling ideas and training professionals, who in turn find their way into organisations, build networks and disseminate ideas and professional knowledge across organisations. In the latter case, existing professional networks have been used as conduits for disseminating and transferring ideas influencing similar changes in organisation forms and practices across organisational boundaries. Policy transfer researchers such as Stone (2000) and Dolowitz and Marsh (2000) have demonstrated the power of learning through a variety of professional networks, suggesting that the view held by Powell and DiMaggio on professionalism is relevant and consistent with policy transfer observations.

\section{New Institutionalism and Policy Transfer}

The insights provided by the different strands of new institutionalism, in particular sociological institutionalism, are useful in analysing capability and the application of policy lessons to PNG. For example using the theoretical lens of historical institutionalism, one might engage in an inductive analysis examining why capability has eroded over time. Thus using a historical assessment one might consider how institutional structures have contributed to the current state of capability over time and whether such structures should change? Or using the rational choice institutionalists' postulations on human behaviour, determine why institutional structures which shape policy initiatives on capability persist over time.

Perhaps a key contribution comes from sociological institutionalists, especially in building a framework for effecting change by way of transferring lessons from one jurisdiction to another. For example, Haveman's (1993) study on mimetic isomorphism, for instance, can be extrapolated to policy transfer. Countries that are seen to be at the "cutting edge'", or "leading" in policy developments, are often seen as exemplars legitimising the successive adoption of policy. Emulating a similar policy elsewhere therefore may be a function of this perceived legitimacy. As demonstrated earlier, we could use that to analyse why market driven ideas have becoming fashionable in the public sector.

Finally, specific sources of institutional isomorphism can be used as units of analysis in policy transfer, suggesting that there is room to expand on the isomorphic trends 
proposed by Powell and DiMaggio. By using one isomorphic change as a unit of analysis, a whole process of policy transfer can be analysed. For instance, normative pressure can be used as a unit of analysis where the role of professionals in policy transfer could be examined. Who are the professionals involved in policy transfer? How do they influence and therefore get involved in the policy transfer process? Why do they get involved in the first place?

\section{Policy Transfer or the Comparativists' Model}

In recent years, particularly from the early 1990s, policy transfer as a field of comparative public policy has experienced rapid growth. This is evidenced by the increase in the scholarly literature devoted specifically to it (see Rose 1993; Horberg, 1991; Radaelli, 2000; Bennett, 1988, 1991 1991a \& 1997; Dolowitz and Marsh 1996 \& 2000; Majone, 1991). Policy transfer, which is often referred to as lesson drawing $^{31}$, is the process whereby policies and ideas from one political jurisdiction and/or policy domain are used in the development of policy and ideas in another (Dolowitz and Marsh, 2000). Bennett (1988; 1991; 1991a) refers to this process as the successive development of a policy in a number of political jurisdictions. Rose (1991; 1993) refers to it as lesson drawing - a process where policy lessons are drawn from elsewhere by policymakers of one jurisdiction to shape policy in their own. Such a development usually follows a number of processes. These have been referred to as "copying" (where the same policy is replicated or adopted); "emulation" (where the policy is modified to suit different contexts and conditions); and "inspiration" (where the policy stimulates the creation of novel policies elsewhere (Bennett, 1992; Rose, 1991; Dolowitz and Marsh, 2000).

Policy transfer as a distinct field in the study of comparative public policy owes its advancement and prominence to the work of policy transfer researchers or those whom Radaelli (2000: 25) calls "the comparativists". By combining both theoretical and practical studies of specific policies, policy transfer researchers are able to

\footnotetext{
${ }^{31}$ Although "policy transfer" and "lesson drawing" are frequently used interchangeably they carry slightly varying meanings. "Policy transfer" is the term found in the work of scholars such as Dolowitz and Marsh (1996; 2000) and embodies the "generic" definition of using policies found elsewhere to develop policies in a "new" jurisdiction. It may, however, mean exerting external influence over policy adoption in a political jurisdiction, suggesting that this is largely due to undue pressure from the "outside". "Lesson drawing" is the term used by Rose $(1991 ; 1993)$ and entails the deliberate effort of policymakers of one jurisdiction to draw lessons from elsewhere to solve policy problems in their own, suggesting that this process is voluntary. This thesis uses the terms (policy transfer and lesson drawing) interchangeably and refers to the generic process of the development of policy in one political jurisdiction using policy lessons from one or several other jurisdictions.
} 
identify specific issues of transfer that have not previously been examined in detail in the earlier frameworks. For instance, this is evident in numerous studies examining the role of learning in policy transfer (Rose, 1993); the rationale of policy transfer (Rose 1991 \&1993; Dolowitz and Marsh 1996); the causes/reasons of policy transfer (Dolowitz and Marsh, 2000; Horberg, 1991; Rose, 1993); types of policy transfer (Dolowitz and Marsh, 2000); the rate and pattern of convergence or diffusion in policy transfer (Bennett, 1997; Radaelli, 2000), and the likelihood of policy success as a result of policy transfer (Dolowitz and Marsh, 2000).

With the exception of some research focusing generally on the nature and essence of the subject — for instance, studies by Rose (1991 \& 1993), Dolowitz and Marsh (1996; 2000) and Bennett (1991a) and Wolman (1992) - the literature is diverse. Among the many studies of policy transfer, Dolowitz and Marsh (2000) propose a useful framework, which illuminates the nature, process and outcome of policy transfer. This framework is an attempt to incorporate the efforts of many scholars who have examined policy transfer in recent years. More particularly, it is an effort to build on the work of Rose (1991 \& 1993) and Bennett (1988; 1987; 1991a). The framework is built around a set of questions pertinent to policy transfer, which according to Dolowitz and Marsh can be used either to explain the transfer process or transfer outcomes (Tables 4.1A \& 4.1B). 
Table 4.1A: Explaining Policy Transfer - The Dolowitz and Marsh Framework

\begin{tabular}{|c|c|c|c|c|}
\hline \multicolumn{3}{|c|}{ Why transfer? Continuum } & \multirow{2}{*}{$\begin{array}{l}\text { Who is involved in } \\
\text { Transfer? }\end{array}$} & \multirow[t]{2}{*}{ What is transferred? } \\
\hline $\begin{array}{l}\text { Want to } \\
\text { Voluntary }\end{array}$ & Mixtures & $\begin{array}{l}\text { Have To } \\
\text { Coercive }\end{array}$ & & \\
\hline \multirow[t]{6}{*}{$\begin{array}{l}\text { Lesson drawing } \\
\text { (Perfect } \\
\text {..rationality) }\end{array}$} & $\begin{array}{l}\text { Lesson drawing } \\
\text { (Bounded } \\
\text { rationality) }\end{array}$ & Direct imposition & $\begin{array}{l}\text { Elected Officials } \\
\text { Bureaucrats/civil } \\
\text { servants }\end{array}$ & $\begin{array}{l}\text { Policies (goals, contents, } \\
\text {..instruments) }\end{array}$ \\
\hline & $\begin{array}{l}\text { International } \\
\text { Pressures }\end{array}$ & & & Programmes \\
\hline & $\begin{array}{l}\text { (Image) } \\
\text { (Consensus) } \\
\text { (Perceptions) } \\
\text { Externalities }\end{array}$ & Pressure groups & Institutions & Negative lessons \\
\hline & $\begin{array}{l}\text { Conditionality } \\
\text { (Loans; Conditions } \\
\text { attached to } \\
\text { business activity) }\end{array}$ & Political parties & Ideologies & \\
\hline & Obligations & $\begin{array}{l}\text { Policy } \\
\text { entrepreneurs } \\
\text { experts }\end{array}$ & Attitudes/Cultural values & \\
\hline & & & $\begin{array}{l}\text { Consultants; Think tanks; } \\
\text { Transnational corporations; } \\
\text { Supranational institutions }\end{array}$ & \\
\hline
\end{tabular}

Table 4.1B:Explaining Policy Transfer — The Dolowitz and Marsh Framework

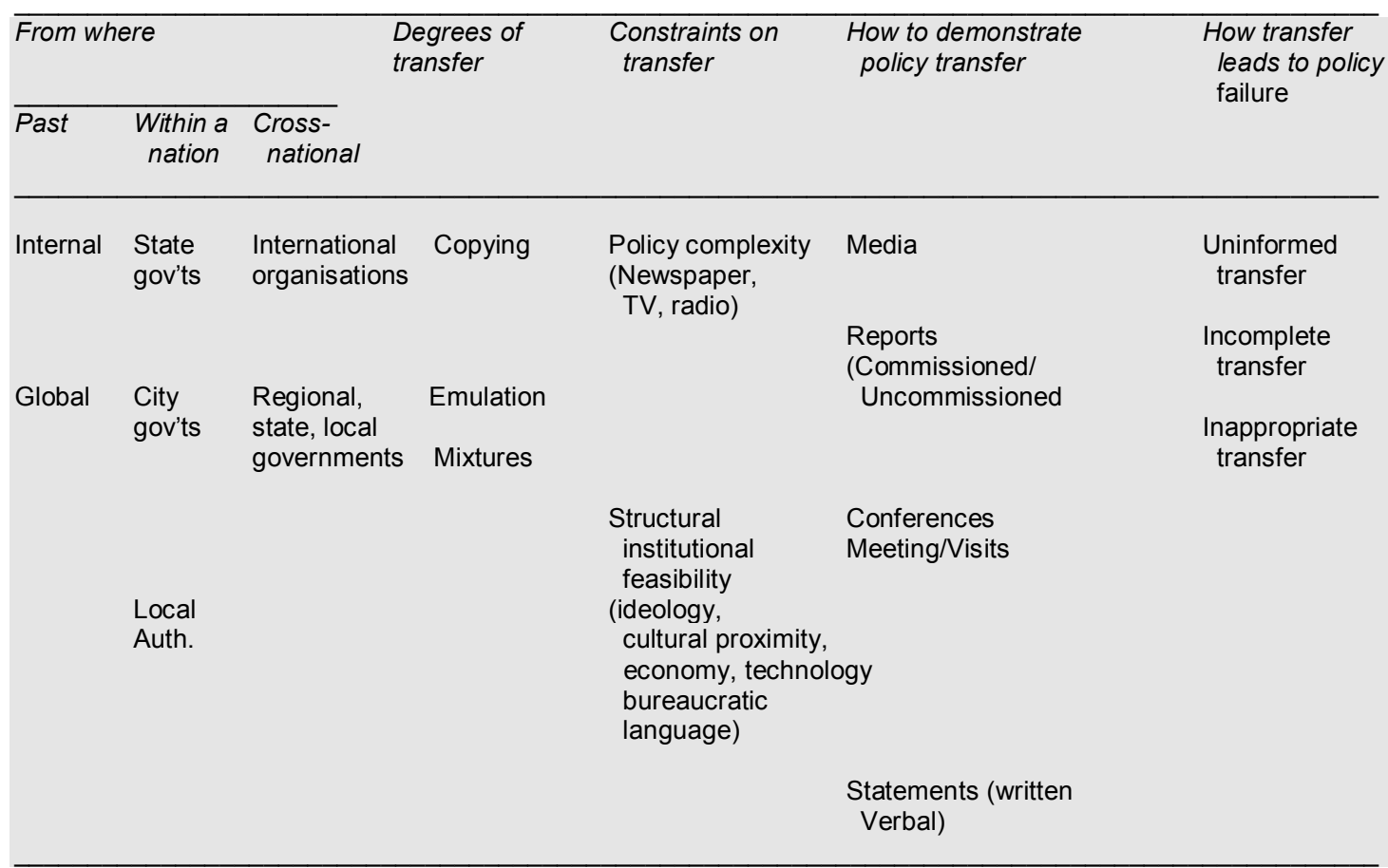

Source: Dolowitz and Marsh (2000: 9). 
Because of the wide range of issues raised in the tables, the following discussion will be limited to the key factors.

\section{Triggers of Policy Transfer}

Most recent work in policy transfer (see Knill, 1999; Bennett, 1997; Rose, 1993; Dolowitz and Marsh, 2000) posits that the act of transferring policy is purposeful; policy actors transfer policy lessons because there is a reason to do so. Triggers of policy transfer can be diverse, ranging from pressures for economic reforms (for example, in improving flagging macro-economic conditions) and forceful transfer (for example, imposition of policies by international financial institutions such as the World Bank) to electoral pressure to solve an emerging problem faced by governments in a particular jurisdictions (see Hoberg, 1991; Majone, 1991; Bennett 1988; 1997; Dolowitz, 1998). According to Rose (1991; 1993), perceived policy problems are generally the triggers of policy transfer. To quote Rose (1991: 11):

A necessary condition for lesson drawing is that policymakers want to learn something that they do not already know. This occurs when routine is disrupted and policymakers can no longer operate on the assumption that what was satisfactory before is satisfactory.

Dissatisfaction about policies arises from a variety of sources. These may include: the apparent failure of a policy; changes in policy environment, changes in political values, influence of expert opinions and values, and lessons seen from abroad (Rose, 1993: 60-61). First, the failure of policy is, perhaps, an obvious source of dissatisfaction. For example, once programmes have failed or when there is incontrovertible evidence that policy is bound to fail, policy actors may be expected to be dissatisfied with existing policy. As a result, the pursuit of alternative policies or remedies from elsewhere becomes a necessary task. In a study dealing with the transfer of the American "welfare-to-work" experience to Britain in the 1980s, Dolowitz (1997) notes that the Thatcher Government was driven to borrow from the American system because of increasing dissatisfaction with British employment policy. According to Dolowitz, the unprecedented levels of unemployment reflected in the official statistics in the early 1980s were seen as an "unemployment crisis"; the Thatcher Government's decision to draw from the American experience was largely owed to the need to change (and be seen to change) policy and therefore reduce unemployment. 
In developing countries, the discontent over policy outcomes and particularly the performance of the public sector and the economy has been the rationale for public management reforms drawn from other jurisdictions. Although the convergence of similar ideas in numerous public sector reforms has been contested (Pollitt, 2001), there is considerable literature demonstrating that discontent with poor public sector performance in many developing countries has been followed by the transfer of reforms from developed countries' experience (see Kibria, 2001; Hughes and Samaratunge, 2001; Curtain, 1999; Whimp, 2000).

\section{Policy Learning}

Policy learning is often viewed from different angles during the process of policy transfer. For instance, Bennett (1991a) and Dolowitz (1997) argue that to determine whether one country's policy is being influenced by lessons from elsewhere, it would be necessary to determine whether there has been a learning process. This should be demonstrated by the identifiable use of knowledge or policy lessons derived from the model country in the recipient country. Implicit in this view is the notion that if there is no demonstrable evidence of policy learning culminating in the application of lessons, then it cannot be claimed that policy transfer has occurred (see Bennett, op. cit). Hence learning becomes the independent variable used in explaining and justifying policy transfer. While using policy learning as an explanatory variable is noteworthy, we are, however, concerned with discussing its general use during the transfer of policy lessons.

Policy transfer or lesson drawing is viewed as being contingent upon policy learning, a process which according to May (1999: 22) provides a new understanding of policies that exist elsewhere. Such an understanding becomes the basis for assessing how particular policies have fared in their original place of adoption (or other jurisdictions), the strengths and weaknesses of such policies, and how they will apply to a new setting (Rose, 1991; Dolowitz and Marsh, 1996; 2000). Decisions about transfer and subsequently implementation are therefore a consequence of policy learning (Bennett, 1991; Rose, 1993). 
Rose $(1991 ; 1993)$ devotes considerable attention to the learning process and pays a particular importance to its role:

Learning constitutes what is learned. A lesson is more than learning for its own sake; it relates actions elsewhere to substantive problems in a government agency. Lessons do not require a change in behaviour as a condition of learning; a program elsewhere may be evaluated negatively or the conclusion may be that there is no way in which it could be transferred (Rose, 1991: 7).

Rose $(1991 ; 1993)$ describes the learning process as "prospective evaluation" where positive and negative lessons from an existing programme are determined; and where analyses of how they are going to be applied and their expected impact are projected and or simulated in a new setting. According to Rose (1991: 4) the key question is: "Under what circumstances and to what extent would a programme now in effect elsewhere work here?" Making judgements on the operational viability of a certain policy in a new setting that has not implemented the policy entails prospective evaluation (Rose, 1991; 1993). Prospective evaluation involves making judgements about the viability of transferring policy lessons; it is about projecting what is likely to happen in the country or jurisdiction that is going to borrow.

A lesson is positive if its adoption would improve existing policy, or create new conditions for solving a particular problem. By contrast, a lesson is negative if its adoption would undermine the operational efficacy, or overall success of policy. The usefulness of negative lessons lies in their future use by policy actors. By comprehending them, policy actors could improve policy either by avoiding future problems; or by introducing positive changes to existing policies. Both negative and positive lessons can be sources of inspiration. Through policy learning they can inspire the creation of new policies that supersede what is originally thought to be novel.

Decisions about what lessons to transfer, how they are going to be transferred, and their implementation are therefore contingent upon the comprehension of both positive and negative lessons and the viability of their application (Figure 4.1). 
Figure 4.1: Policy Learning and Prospective Evaluation in Policy Transfer

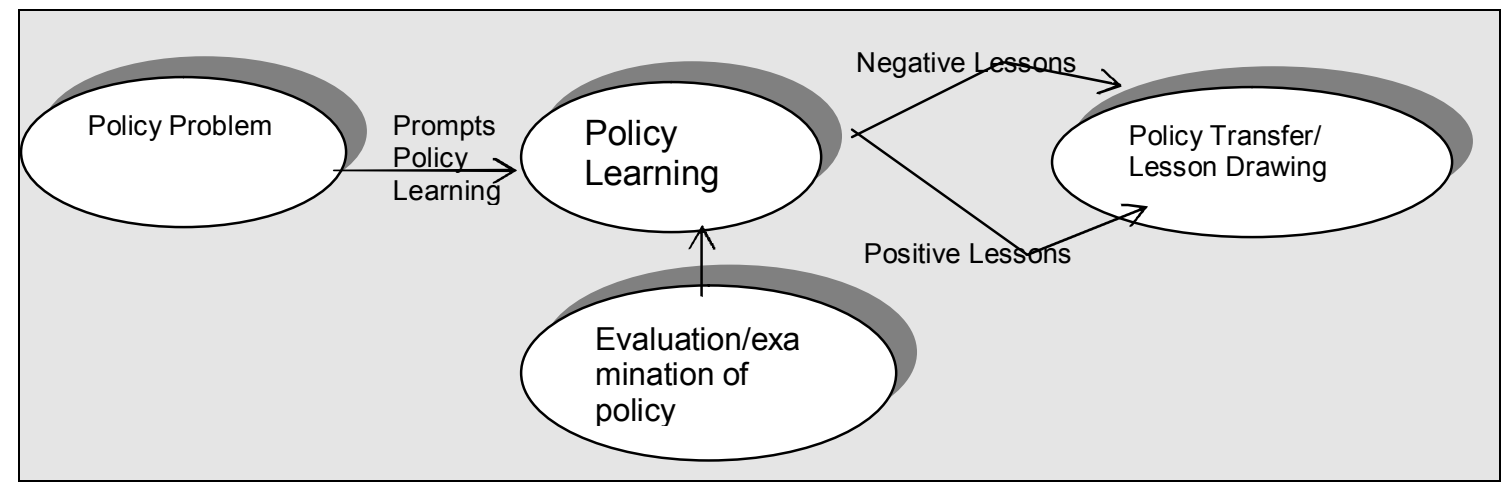

\section{Types of Policy Transfer}

Table 4.1A (p.82) shows that transfer of policy can be of two major types: voluntary and coercive transfers. Dolowitz and Marsh (2000) posit that the best way to understand the two types is to conceptualise them as lying along a continuum that runs from lesson drawing to the direct imposition of programme, policy or institution on one political system by another. In practice, policy transfer often involves a mixture of different types/degrees of transfer and the boundaries between them are often unclear. Voluntary transfer involves the drawing of policy lessons from one jurisdiction by policy-makers of another jurisdiction and is initiated out of a desire to learn and borrow lessons from elsewhere in order to address policy problems. Rose (1991 \& 1993) conceives this as lesson drawing, implying that policy actors draw lessons from other political jurisdictions because they choose to. The Dolowitz and Marsh conceptualisation supports the view held by Rose except that they advance two different environments where lesson drawing is done: one is where lessons are adopted under perfect rationality; and the other, under bounded rationality. This implies that when perfect rationality is evident, policy transfer is complete and will therefore be successful, whereas in a situation of bounded rationality, lesson drawing is likely to have shortcomings (Dolowitz and Marsh, 2000). Consequently lesson drawing has to follow a different track: it has to be subjected to a process of learning and refinement so that policymakers are certain that what is transferred holds some promise of being successfully implemented (see Figure 4.2).

The reality of lesson drawing is that it is complex and there are risks and uncertainties involved - for example incomplete transfer as a result of lack of understanding of policy dynamics or poor transfer arising from mimetic isomorphism. As a result, one cannot simply transfer on the assumption that common problems 
have common solutions; and it is necessary to learn before transfer takes place. Indeed much of Rose's work and numerous studies of policy transfer by others (Dolowitz, 1998; Bennett, 1991; Majone, 1991) have demonstrated that states that borrow lessons have done so on the basis of prior learning and comprehension of the policy intended to be transferred.

Yet while voluntary transfer may project a view that transfer is triggered out of a desire by policymakers to adopt lessons without any undue pressure, this view is challenged by the fact that voluntary transfer is often a function of passive pressures faced by policymakers (Rose 1991 \& 1993; Dolowitz and Marsh 1996; Wolman, 1992). Obligations created by bilateral treaties or the desire to gain international acceptance become the passive force behind importing lessons are illustrative. For example, membership of international organisations as well as the desire not to be left behind, especially when one is in a prestigious community such as the OECD, can induce policymakers to become involved in policy transfer. The case of the members of the European Union (EU) in aligning domestic policy to the common policies of the EU (Radaelli, 2000; Toonen, 1992) and the drive to take the top position in comparative indicators such as the OECD Economic Performance ranking serve to demonstrate this aspect of voluntary transfer. ${ }^{32}$ Perhaps the differentiating factor about this form of transfer as opposed to coercive transfer is that there is no direct authority compelling policymakers to adopt policy lessons; nor are there immediate consequences of not adopting lessons.

In contrast, coercive transfer involves compelling policymakers to transfer policies against their will (Dolowitz and Marsh, 2000; Rose, 1991; Stone, 2000). In such a circumstance, policy transfer is forced and is not a function of the initiative of domestic policymakers pursuing policy lessons from elsewhere; rather transfer is dictated by external forces which decide on the types of lessons, timing and extent of policy transfer. Generally, when transfer is a consequence of coercion, the process of transfer can be expected to follow a different path from voluntary transfer. First, policymakers of the country in receipt of policy lessons can expect no learning at all about the policy being transferred. Consequently, there is likely to be less attention to the manner and extent whereby transfer is to take place. Secondly, it can be expected that external influence on the adoption and implementation of policy will be

\footnotetext{
${ }^{32}$ For example, the New Zealand Labour Government (1999) has announced as an objective a return to the "top half" of OECD.
} 
high, and where policymakers of the recipient country are allowed to make decisions, their decision-making will be subsidiary to those who exert influence. Finally, it can be expected that there will be a high degree of external control over the process of policy adoption and that such control will be reinforced by a range of sanctions at the disposal of those who are influencing transfer. Such sanctions have the capacity to do inexorable harm or place excessive costs on the country experiencing transfer. This leaves it with little choice but to engage in policy transfer. ${ }^{33}$

\section{Transfer Processes}

The dynamics of transferring policy lessons can be complex. Different transfer processes can have different trajectories with different outcomes (Figure 4.2).

Figure 4.2: The Dynamics of the Transfer Process

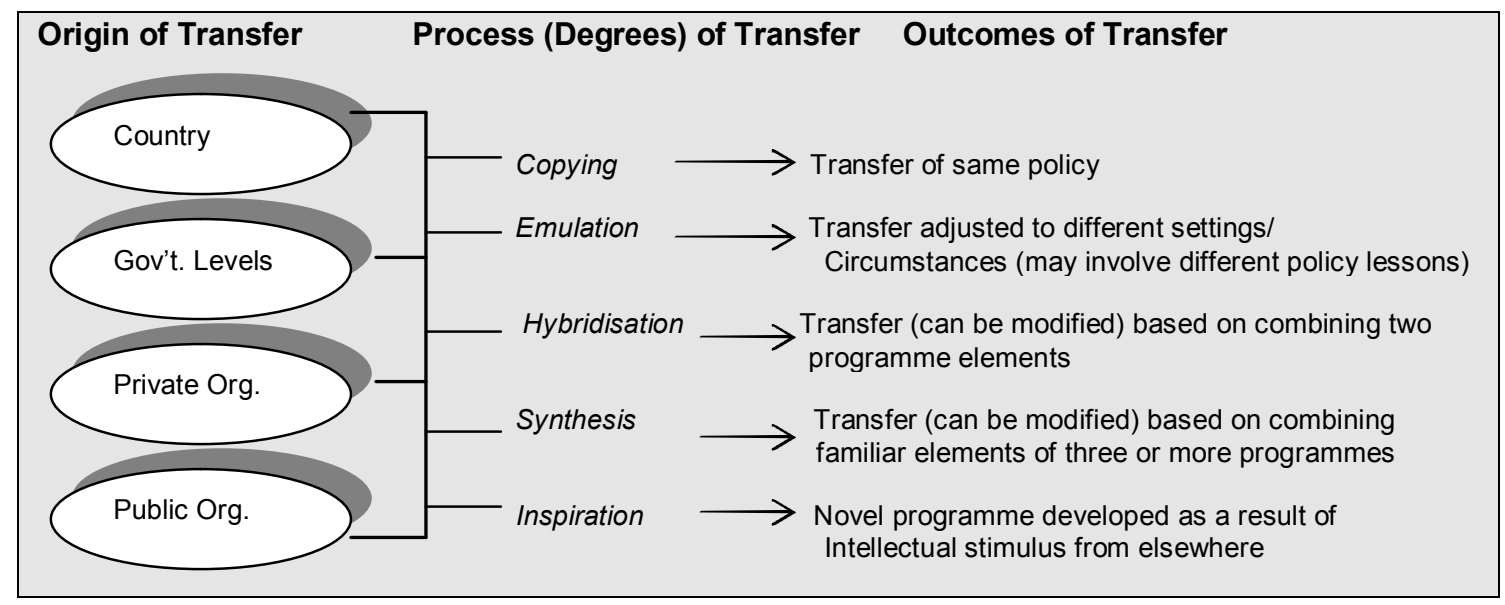

Source: Developed from Rose (1991) and Dolowitz and Marsh (2000).

Copying involves the transfer of the exact programme or policy. For example, assuming that a programme is made of related components including programme goals, contents and instruments, we would expect all of these components to be transferred in their entirety if copying is used. For emulation, it is expected that there will be some modifications in the lessons drawn to contextual features. A mixture of transfers entails a combination of these approaches where it is expected that some aspects of copying, emulation, and inspiration will be involved. It is worth pointing out that in practice the above techniques of transfer would almost always involve a mixture of process in which the boundaries overlap.

\footnotetext{
${ }^{33}$ The assessment of the role of the World Bank in imposing macro-economic reforms through coercive transfer by Dolowitz and Marsh (2000) and Larmour (2002a) is an illustration.
} 


\section{Focus of Transfer}

On a general level, broad policies can be the objects of transfer as is the case, for example, in such areas as freedom of information, data protection, the role of the ombudsmen (Bennett, 1997), environmental protection and pollutants (Horberg, 1991), and health policy (Jacobs and Barnett, 2000). However, when policy transfer is considered on a generic level, the danger is that specific aspects of the policy that are of interest to lesson drawing get less attention because the discussion is focused on the policy as a whole. There have also been cases where attempts have been made to identify specific aspects of transfer. For instance, Stone's (2000) analysis of the role of non-governmental organisations discusses ideas and ideologies, policy proposals and justifications, and personnel and expertise as well as documents for policy discussion and exchange as subjects of policy transfer. In the same vein, Dolowitz's (1997) study of Britain's Welfare-to-work programme shows that specific components of a large policy can be transferred. His analysis of a range of smaller programmes as constituting a larger policy -- the welfare-to-work policy - suggests that these smaller programmes may be considered selectively and therefore become subjects of transfer. Thus, generally a range of things can be transferred including whole policies, policy goals, policy content, policy instruments, policy programmes, institutions, ideologies, ideas, attitudes and negative lessons (Dolowitz and Marsh, 2000, Rose, 1991; Bennett, 1991a).

\section{Policy Transfer and Policy Failure}

What accounts for policy success in the adoption of lessons cross-nationally is a significant question that has been the subject of some scrutiny (see Schick, 1998; Rondinelli, 1993; Mossberger and Wolman, 2003). For example, Mossberger and Wolman (2003) discuss how those who want to borrow lessons could carry out prospective evaluation to determine the effectiveness of transferred policies. Drawing from the work of Rose (1991) they propose three key areas policymakers should take into account if they want to engage in effective transfer: (a) awareness, that is the need to be become aware of policy developments in other jurisdictions; (b) assessment, which involves evaluating the strength of policy lessons, differences in settings and whether the transferred lessons are going to be applied to similar problems or policy goals; and (c) application, which requires the consideration of relevant techniques or degrees of transfer. 
Rose (1991: 33) best summarises the nature and use of prospective evaluation:

Prospective evaluation differs from conventional evaluation research, because the latter is retrospective, examining a programme after it has been effect for several years...Prospective evaluation starts by observing how a programme operates in another country and developing a model of what is required to produce its effects there...Prospective evaluation is concerned not only with whether a programme can be implemented but also with what substantive effects it may have.

Dolowitz and Marsh (2000) take a slightly different approach and caution policymakers to avoid the tragedies of policy transfer. They attribute failure in policy transfer to three general causes viz., uninformed transfer, incomplete transfer, and inappropriate transfer. In uninformed transfer, failure comes about when 'the borrowing country may have insufficient information about the policy/institution and how it operates in the country from which it is transferred. Policy transfer could also fail if, despite transfer, "crucial elements of what made the policy or institutional structure a success in the originating country may not be transferred" (i.e., an incomplete transfer) (ibid: 17). Finally, failure in transfer can be a consequence of inappropriate transfer. This may come about as a result of insufficient attention being paid to the differences between the economic, social, political and ideological contexts in the borrowing and transferring country (ibid: 17). Differences do exist between countries. Failure to recognise these differences can result in uniformity in the application of lessons with transfer becoming a failure as a consequence. Furthermore, transfers differ in degree; at some stage there are instances of modification based on different contexts (Bennett, 1991 Schick, 1998).

Generally, the work of Dolowitz and Marsh has summed up the sources of transfer failure - bounded rationality resulting in misjudging whether or not transfer should take place and how transfer should proceed; imperfect implementation of transfer; and, failure to recognise different country contexts. It would be wrong, however, to suggest that these are the only causes of failure of policy transfer. Other factors also contribute to policy failure during transfer, and some cannot be placed in the Dolowitz and Marsh typology (above). For instance, lack of resources, funding and qualified technocrats to implement transfer can contribute to the failure of transferred lessons in developing countries. In other instances coercive transfer can bring suspicion about the motive of transfer and the eventual failure of policy lessons. For example, this has been the case in the transfer of some reform policies by the World Bank in 
developing countries in which the motives of the Bank have often been questioned resulting in some developing countries' governments withdrawing the domestic support necessary to make the transferred lessons work (see Sender, 1999; Larmour, 2002a).

\section{Conclusion}

This chapter has reviewed two different theoretical frameworks seeking to explain the dynamics change illuminated in policy transfer and lesson drawing. The insights from these frameworks will be taken up again in the analysis of the possible drawing of lessons by PNG from Westminster models in Chapter Ten. Although the essence of the two frameworks is the same - that is, conformity of 'policy' between political jurisdictions - the process of how to get there takes different routes in the two models. New Institutionalists place primacy on the role of institutions as the drivers for change in policy and political outcomes, although how this plays out in effecting change differ among the different strands. Theorists such as Powell and DiMaggio (1991) see transfer as a purposeful action taken by policy actors using various processes. In this approach institutional homogeneity is characterised by isomorphic processes brought about by three distinct sources: coercive isomorphism, mimetic process and normative pressures. The insights of Powell and DiMaggio have been used in a variety of work analysing policy transfers. For instance, Bennett's (1991a) demonstration of transfer being adopted for a variety of reasons including that of legitimising political agendas affirms the fact that coercive isomorphism can be a powerful force in policy transfer. Similarly Radaelli's (2000) work demonstrates that the process of isomorphism in the EU can be a strategy to gain legitimacy for policies when direct transfer among member states is difficult.

Policy transfer researchers or comparativists such as Rose (1991 \& 1991), Dolowitz and Marsh (1996, 2000) and Bennett (1988, 1991a, 1997) and others examined in this chapter provide a more robust framework addressing issues of transfer not considered in the new institutionalists' framework. Policy transfer is a purposeful act engaged by policymakers who rely on policy learning to transfer lessons perceived as capable of improving policy conditions in another jurisdiction. Transferring policy is a complex issue and often runs in different directions depending on the types and degrees of transfer and who influences it. Like all rational exercises, policy transfer has its own risks - faulty judgement, failure to understand policy dynamics in the place from which lessons originates, incomplete information and poor transfer techniques are some examples. Any prospective evaluation carried out for purposes 
of lesson drawing should consider such risks. Chapter Ten relies on the insights of the new institutionalism and the policy transfer/lesson drawing literature in considering whether practice and innovation in developed Westminster jurisdictions could assist in strengthening policy advisory capability in the three central agencies in PNG. 


\section{Chapter Five: Methodology}

\section{Introduction}

Any outsider who seeks to gain an in-depth insight into what actually goes on in the Papua New Guinea (PNG) public service or more specifically in individual departments is likely to face problems. This study is no exception. Access to information within departments and agencies can be problematic. Important documents are usually confidential and guarded jealously so that it is often difficult to penetrate the bureaucratic barrier and get what is required. There is no "Freedom of Information Act" ${ }^{34}$, so information kept within departmental domains is particularly difficult to access, unless of course the researcher is an "insider", or has very good links with the sources of information. Often the process of getting approval and access to the documents can be frustratingly slow. Even in cases where prior approval has been given, the release of information may be selective and, therefore, may not entirely satisfy the research requirement of the researcher. Essentially, the exchange of information is dependent on the goodwill of those who give it.

Leaving aside the statutory position, the attitude of the PNG public service to approaches for information reflects the legacy of the classical Westminster model of bureaucracy. Information that is deemed to be damaging to the image of the bureaucracy is seen as unworthy of release and may not be released at all. It is, therefore, not surprising that public servants will often treat the researcher with apprehension and caution, despite their expressed willingness to assist. Public servants will take great care in divulging information and in nearly all cases will do so only if a recognised superior gives prior approval and if they are reassured that they will not get into trouble. When such information is given, the condition is usually that the identity of the supplier is not revealed. Under these circumstances, it is imperative that the researcher assures his or her informant of their anonymity in any oral or written record.

Recorded data is often patchy and inaccurate, something which perhaps resembles the state of data management in similar developing countries. It was on this basis that AusAID (1999:107) made the following comment: "....in any assessment of the

34 The Public Service General Orders (PSGO) issued by the Secretary of the Department of Personnel Management regulate the issuing of information within the public service. Under the PSGO public servants are restricted from giving official information, unless permitted by an authorised superior. 
PNG economy, care must be taken in interpreting official statistics. In common with small developing economies, few resources are devoted to collecting statistics and the quality of data is uneven". Furthermore, the status of the archives in PNG and record keeping generally is in bad shape because of inadequate storage and compilation of data. Departmental records seldom go to the archives, and the exchange and communication of information within the public service leaves much to be desired. More significantly the value of such information held in archives depends on the type of inquiry, that is, the nature of the research conducted. In the case of the present study, the poor state of contemporary information on the operations of departments and on government policy has presented particular difficulties in relying on the archives as a key source of data. These problems of access to data are confirmed by the researcher's experience with two departments of the PNG public service as an employee and in association with earlier research projects.

Finally, the study could draw on other available studies conducted on the PNG public service. However, as indicated in Chapter One, most of that material is indicative only, pointing to general matters of public administration: it does not reveal how departments are organised to produce policy advice; nor does it identify the constraints on policy advisory capability experienced by the three central agencies. This suggests that reliance on the available studies would not provide the insights necessary to reach conclusions about the phenomena under investigation.

The present study was therefore mounted to acquire first-hand information about the role of policy advisory units within three central agencies, how they are organised to provide advice to policy clients, and the internal and the external factors that impede the production of high quality advice. Such information must necessarily, to a large extent, be derived from the perceptions of policy staff themselves. Three methods of data collection are used in the study. All have been shaped in one way or another by the practical considerations outlined above. Each method is aimed at filling in the gaps, if any, which might occur during analysis. The first is straightforward and relies on the publicly available records of each agency. The two other methods considered appropriate under the circumstance of PNG are the survey questionnaire and openended interviews. As discussed below, these formed the primary sources of data in the study. 


\section{Data Acquisition and Limitations}

\section{Survey and Interview Participants}

One of the main preliminary concerns was to determine who should be involved in the survey and the interviews. It was decided that policy staff - variously described as "policy managers", "policy analysts", "researchers" and "policy advisers" - in the lead policy unit within each central agency should be the target of the survey and indepth interviews. In accordance with this criterion, staff of the lead policy units in each agency were selected for the survey and interviews. These units were (a) the Economic Planning Unit (EPU), Department of Finance \& Treasury (DF\&T); (b) National Development Services \& Government Services (NDS\&GS), Department of Prime Minister and National Executive Council (DPM\&NEC); and (c) Strategic Planning \& Development (SP\&D) Branch, Department of Personnel Management (DPM).

There were several reasons for the decision to focus on policy staff of the lead policy units. One of the obvious reasons is that policy units are relatively small in size and therefore have smaller staff numbers. Hence they are manageable in a survey or interview situation by a visiting researcher. Secondly, such units do much of the work in both the formulation and implementation of policy; they are the linchpins of the policy advice process, providing nearly all the in-house advice to their parent department and the government. Officials from these units comment on most policy briefs and submissions; they carry out most research work within central agencies; and are responsible for devising most policy proposals originating from central agencies. Thirdly, in circumstances where policy work is required at short notice, or involves collaboration with other departments, lead policy units usually attend to such demands. Unsurprisingly, some of the best-trained staff in the public service are concentrated in such units. In short, lead policy units can be portrayed as internal "think tanks" of central agencies: policy advice originates from such units and finally reaches clients such as the secretary, minister and National Executive Council (NEC). Finally, given their pivotal role in policy advice, officials in these units are more likely than line staff to understand the constraints on policy advisory capability. It is for those reasons that policy staff in lead policy units are best positioned to provide in-depth information on how policy advice is organised and tendered. 


\section{Process of Data Acquisition}

Initial contacts were made with each department secretary by letter, telling them about the overall purpose of the study, the survey and follow-up interviews; the ethical protection; and also requesting their permission to engage in data collection. Permission for both the survey and the interviews was given around January 2002 after initial correspondence with the respective heads of each central agency. In early February 2002, the researcher travelled to Port Moresby to administer the survey and to conduct the interviews. Initial contacts on the ground in Port Moresby were made with respective First Assistant Secretaries (FAS) and Assistant Secretaries (AS) of the policy branches and units to organise the survey and carry out the interviews. The survey was administered and then followed by the interviews.

The process was frustratingly slow at times. The visit to PNG coincided with the lead-up to the 2002 National Election in June. Anybody who is familiar with PNG politics would acknowledge that every election is a period of great anxiety and in many instances hyper activity - each election in PNG is treated with the same degree of national exuberance as political independence itself and this can be destabilising for the public service. For example, in this period the movements of departmental heads and branch heads are often unpredictable because of pressing demands from cabinet and ministers to attend to urgent matters. So when appointments are made to sort out the logistics of administering the survey and to become familiar with the lead policy units, delays are to be expected. The survey and half of the interviews were conducted amidst this flurry of activity by late March 2002. But some of the in-depth interviews were still outstanding and could not be completed before the researcher had to travel back to Wellington. In early November 2002, another trip was taken. As was the case with the previous visit, letters were sent to the respective agencies to remind them again of the ongoing research work and the need to "reconnect" with the lead policy units to complete the interviews. The outstanding interviews were completed by the end of November.

\section{Difficulties and Limitations}

All study methods have their own difficulties and limitations. ${ }^{35}$ In the case of this study, some of the administrative and logistical obstacles have already been cited. One apparent difficulty of the survey method using a semi-structured questionnaire is

\footnotetext{
${ }^{35}$ Some of the limitations especially in social sciences are described in various texts. For example see Leddy (1989), Robson (1993), Marsh and Stoker (1995; 2000), and Moore (2000).
} 
that it may not capture all the information that the researcher wants. Further, there are potential difficulties in seeking further explanations in respect of responses that are ambiguous: the researcher does not have the opportunity to go back and ask the respondents. In the case of the interview method, views may be distorted, biased or inaccurate. In the words of Boston (1980: 36), "the interviewer is confronted time and again with respondents whose memories are faulty, whose perceptions are flawed and who are inclined to shape evidence, or tell the story to suit their own interests". Furthermore, the line of questioning of the interviewer may also be biased, or the interviewer may be pushing a line of questions that elicit responses in a biased way. It is therefore important to let the interviewees speak on themes, to lead the discussion and relate what they feel or see. This is the reason why corroborating perceptions or "stories" and balancing the views and responses that emerge from different data sources - in the case of this study, from the survey and interviews are imperative.

Despite the obvious limitations, the semi-structured questionnaire survey and the open-ended interviews were seen, under the circumstances, as the only methods capable of acquiring the perceptions and insights of the officials. They are appropriate methods to delve into the confidential and often secretive bureaucratic world. Furthermore, they are complementary as the data gap in the survey questionnaires can be remedied by the data from the interviews. The researcher has made every effort to pre-test the questions and to go through the themes and issues of the interview with people familiar with the PNG public service. Corroborating information from the three sources is the key one way of ensuring that data is not distorted and that analysis reflects the status of policy advisory capability within the central agencies.

\section{Questionnaire Survey}

The survey consists of a semi-structured questionnaire and has two aims. One is to build-up the personal profile of policy staff in the lead policy units - their age group, qualifications, skills, designation and/or position and level of experience in the agency and the lead policy unit. The other is to solicit the perceptions of policy staff especially about what they have experienced, see or feel about policy advice in their respective unit and department. Such perceptions were gauged from 14 perception statements (Section B) to which respondents were asked to respond. In addition, there were several open-ended questions which required the respondents to fill in their answers. A full description of the nature of the perception statements and the 
open-ended questions is contained in Appendix 3. The different perceptions form part of the analysis of policy advisory capability in the ensuing chapters.

Staff who were involved in the survey questionnaire and the interviews can be classified under three broad headings occupying various grades. Table 5.1 places the positions and grades of the interviewees in these basic categories in descending order of seniority: heads of policy units, strategic advisers and senior policy analysts, and policy analyst and research officers. The table is a broad summary and similar positions often carry different titles and grades. For example, heads of policy units are referred to as 'Director General' (grade 19) in DPM\&NEC, whereas they are referred to as 'First Assistant Secretary' (grade 18) in DF\&T and DPM.

Table 5.1 Selected Categories of Staff by Position and Grade

\begin{tabular}{|c|c|c|}
\hline \multicolumn{3}{|c|}{ Category 1: Head of Policy Divisions \& Units } \\
\hline Position & Grade & $\begin{array}{l}\text { Remuneration Level } \\
\text { (minimum (base) }(K)^{*}\end{array}$ \\
\hline Director General & 19 & 42,000 \\
\hline First Assistant Secretary & 18 & 37,000 \\
\hline \multicolumn{3}{|c|}{ Category 2: Strategic Advisers and Senior Policy Analysts } \\
\hline Position & Grade & Remuneration Level \\
\hline Director & 17 & 35,000 \\
\hline Assistant Secretary & 16 & $\uparrow$ \\
\hline Senior Programme Officer & $14-15$ & \\
\hline Senior Policy Officer & $14-15$ & ] \\
\hline Principal Economist & $14-15$ & 24,000 \\
\hline \multicolumn{3}{|c|}{ Category 3: Policy Analysts and Research Officers } \\
\hline Position & Grade & Remuneration Level \\
\hline Human Resource officer & $12-13$ & 22,000 \\
\hline Senior Economist & $12-13$ & 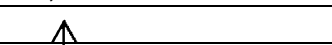 \\
\hline Programme Officer & 12 & \\
\hline Economist & 11 & \\
\hline Policy Analyst & 11 & \\
\hline Research Officer & 10 & 1 \\
\hline Assistant Research Officer & 8 & 12,000 \\
\hline
\end{tabular}

*Estimated minimum salary.

Source: Generated from Department of Personnel Management Item 111 Salaries and Allowances, 2002.

The Victoria University of Wellington Human Ethics Committee (VUWHEC) sanctioned the survey. Respondents were given an Information Sheet (see Appendix 2) which explains the object of the study, the nature of the survey and the maintenance of anonymity of the participants. Participants were instructed to read the Information Sheet prior to filling in the questionnaire. The exercise was voluntary and participants were told to pull out, or cease from participating, if they chose to do so. 


\section{Summary Data of the Survey}

Three lead policy units were involved in the survey. Table 5.2 gives the data of each agency highlighting the lead policy unit involved in the study and the staff ceiling strength of the staff of respective agencies relative to each lead policy unit. The data does not take into account the support staff - secretarial, library, administrative assistant etc — of each lead policy unit. ${ }^{36}$

Table 5.2: Staff Strength of Lead Policy Units

\begin{tabular}{llllll}
\hline \multirow{2}{*}{$\begin{array}{l}\text { *Department \& } \\
\text { Lead Policy Unit }\end{array}$} & Dept Total & \multicolumn{4}{c}{ Policy Staff of Lead Policy Unit } \\
\cline { 3 - 6 } & & Ceiling & (Percentage) & Actual & (Percentage) \\
\hline $\begin{array}{l}\text { Finance \& Treasury (DF\&T) } \\
\text { Economic Policy Unit }\end{array}$ & 739 & 21 & $(2.8)$ & 12 & $(1.6)$ \\
$\begin{array}{l}\text { Prime Minister \& NEC (DPM\&NEC) } \\
\text { National Development } \\
\text { Services \& Government Services }\end{array}$ & $212^{* *}$ & 12 & $(5.6)$ & 9 & $(4.2)$ \\
$\begin{array}{l}\text { Personnel Management (DPM) } \\
\text { Strategic Planning \& } \\
\text { Development Branch }\end{array}$ & 127 & 26 & $(20.5)$ & 18 & \\
\hline
\end{tabular}

* Care should be taken when relying on the data of each department. Often records are inaccurate, especially for total ceilings and vacancies. In fact, while this research was being carried out the Department of Personnel Management commissioned the installation of a new database system to record and keep track of all personnel employed in government after finding out that many "ghost" names have appeared, listed as employed in the public service and who continue to draw salaries from the public purse.

** This figure does not take into account ministerial or political staff.

Source: Departmental Corporate Plans (various); Records from Items 111, Salaries \& Allowances; 2000-2001 Budget of departments (various).

Thirty six survey questionnaires were sent out: 13 to the Economic Policy Unit (DF\&T); 10 to the National Development Services and Government Services (DPM\&NEC); and 13 to the Strategic Planning and Development Branch (DPM) (see Appendix 3). A total of 25 responses was received from the 36 questionnaires sent out: 8 were from the Economic Policy Unit (DF\&T); 7 from the National Development Services and Government Services (DPM\& NEC); and 10 from the Strategic Planning and Development unit. There was an overall response rate of 71.4 percent. Records of the of participation rate (as a percentage of current staff) of each policy

${ }^{36}$ Care must be taken when discussing staff numbers. There is a distinction between projected and actual staff numbers. Projected staff numbers represent the total ceiling of staff, which is based on the positions created. However, such ceilings may not be reached. Actual staff numbers refer to the positions that are filled or occupied at a particular date within a given ceiling. 
unit shows that 55.5 percent of policy officials responded in DPM; 77.8 percent in DPM\&NEC and 66.6 percent in DF\&T.

\section{Interviews}

Open-ended interviews were a necessity. Because of the obvious limitations with the survey method, the data from the survey needed to be complemented by interview data. Furthermore, interviews enabled the researcher to gauge the perceptions, insights, and feelings of policy staff in a way that could not be satisfied by the questionnaire. Generally interviews were of the type discussed by Powney and Watts (1987) in which the interviewer has a "shopping list" of topics and seeks responses to them, but as a matter of tactics has freedom in the sequencing of questions, in their precise wording, and in the amount of time and attention given to different topics.

Twenty-three officials were interviewed for this project (see Appendix 7). It was not practical to interview all staff members of each policy unit for reasons discussed earlier. Because of work commitments some officials could not make themselves available for the interview at the time available. Despite scheduled appointments, others could not participate at the last minute because they had to attend pressing matters. As explained earlier, the above problems necessitated carrying out the interviews on two different occasions, one in February/March, 2002 and another in November 2002.

Of the 23 officials interviewed, thirteen were from the Economic Planning Unit (EPU), Department of Finance and Treasury (DF\&T). They comprise one First Assistant Secretary (FAS) who was the head of the unit, four senior analysts and officers of which three were section heads at the Assistant Secretaries (AS) level, and seven analysts and researchers. Four other policy officials from National Development and Government Services (NDS \& GS) units of the Department of Prime Minister and National Executive Council (DPM\&NEC) were interviewed. They include three Directors (equivalent to the rank of AS), and one policy analyst. In the Department of Personnel Management, interviews were held with seven officials of the Strategic Planning and Development (SP\&D) Branch. One was the Assistant Secretary who was the head of the branch, one was a senior analyst and five were described as analysts and researchers. 
Each interview took about 30 minutes, although some were extended beyond 45 minutes. Questions were posed using an interview guide (Appendix 6) covering key issues relating to the organisation of policy advice and factors that affect the provision of policy advice. Generally, the interview atmosphere was relaxed and themes were discussed back and forth freely with the interviewee. A modus operandi of asking the interviewees to explain or relate what they feel or see about the theme or issue under discussion was employed, rather than the interviewer insisting on a certain line. As a result often the interviewee's account of his or her perceptions was left uninterrupted for several minutes. The interruptions only came when clarifications were sought, or where a particular point raised by the interviewee was challenged, or to move on the next point of discussion. This conforms to Dexter's (1970) portrayal of effective interviewing, which points out that the best interview situation is one in which the interviewee "teaches" the interviewer about the situation. As a result, responses are likely to reflect the true experience of the interviewee. The downside of this kind of style is that discussions may get out of hand if not carefully steered by the interviewer. On the other hand, the advantage of open-ended interviews according to Cohen and Mannion (1989: 313 cited in Robson, 1998), is that "they are flexible; they allow the interviewer to probe so that he may go into more depth if he chooses, or clear up any misunderstandings; they allow the interviewer to test the limits of a respondent's knowledge".

\section{Summary Data of Interviewees}

The percentage breakdown of those interviewed $(\mathrm{N}=23)$ reveals differences between DF\&T and DPM on the one hand and DPM\&NEC on the other (Figure 5.1). In the former two agencies there is a higher percentage of "policy analysts" and "researchers"; in DPM\&NEC the highest percentage of those interviewed were "senior policy analysts". The reason for DPM\&NEC having a high number of senior analysts in the interviews is that more than 60 percent of the positions are on Grade 15 and above (Director and Senior Analyst) by design (see DPM\&NEC Budget Submission 2001). Overall, the spread of the interviews is consistent with the staffing arrangements within each lead policy unit in which there is usually one policy manager, a few senior analysts and many analysts. 
Figure 5.1: Interviewees by Department and Category

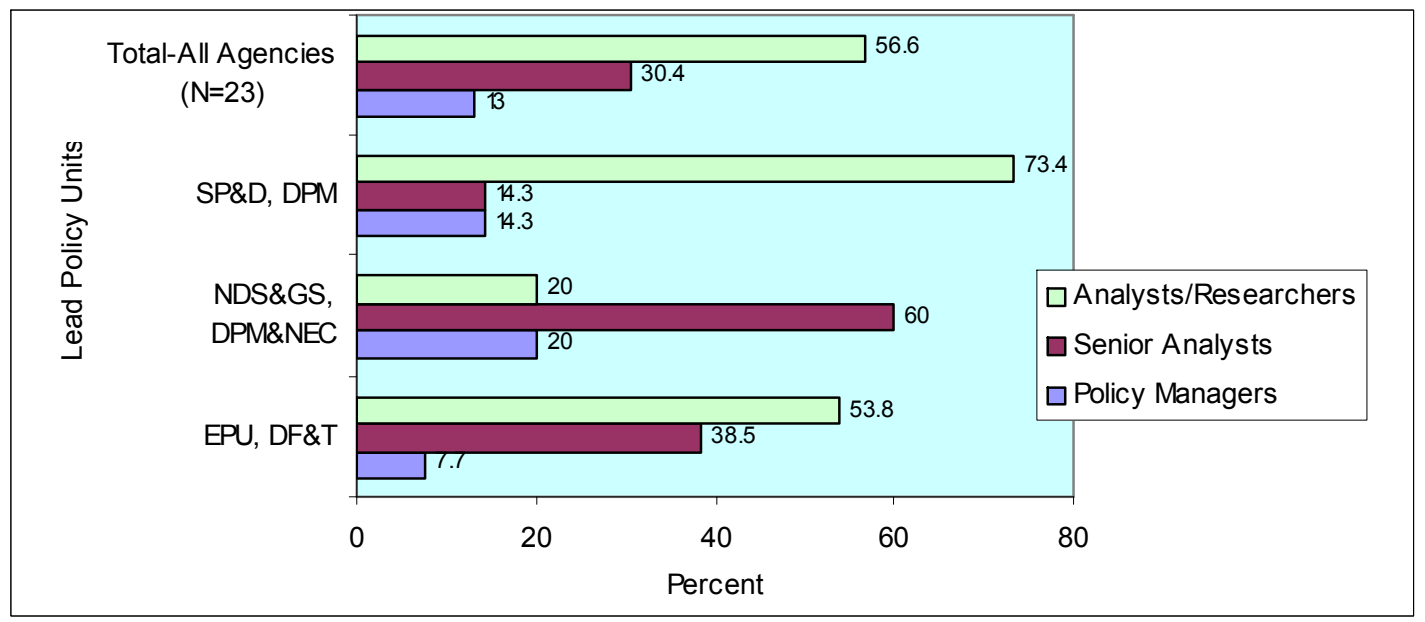

\section{Site Visitation}

The interviews were held in the offices of the respective policy units. This gave an opportunity for the researcher to observe first hand the way policy units were organised. Also additional visits were made and further discussions were held with policy staff known to the researcher after the formal interviews. Such visitations were of particular benefit and allowed the researcher to acquire specific baseline data that was needed for the study - for example, on the number of employees, work environment and equipment used - and to follow up on issues which were ambiguous or unclear during the interviews.

\section{Anonymity and Confidentiality}

In research such as this, where participants' views and feeling constitute the bulk of data, it is important to consider how such views can be expressed in a frank and candid manner. Ensuring that participants participate fully and honestly is a paramount consideration. Equally, care is necessary in circumstances where official information is guarded jealously and its release can have significant costs for those who express their views. In the interest of getting a frank response from those who participated and in order to protect the sources, the survey was executed on condition of anonymity. The name and departmental location of interviewees were set aside. Identification was confined to the position of the participant using a generic title rather than a specific name and title (see Survey Form Appendix 3). 
In the interviews a Consent Agreement (refer to Appendix 5) entered into between the interviewee and the researcher has ensured anonymity. ${ }^{37}$ The Agreement stipulates that the transcripts of the interview will be kept confidential and interviewees will be referred to by their generic title ("policy manager", "senior analyst", "senior official", and "official" in the study. Under this Agreement, interviewees are required to give their prior permission if they were to be referred to by their personal name and specific title in the discussion. This study has conformed to this agreement by referring to generic titles only.

\section{Reporting of Data}

Reporting on perceptions and feelings, as is the case here, cannot be reduced to mere statistical analysis, although it is useful in other cases, especially in studying specific variables that have an influence on a certain phenomenon. It is the strong feeling of the researcher that a highly quantitative exercise would distort the attitudes of policy staff toward the organisation and delivery of policy advice in their respective policy units. Data analyses in the study therefore are qualitative (i.e., reporting perceptions) except for basic baseline data of staff and agencies in which a quantitative analysis is used.

Each central agency is analysed separately in the ensuing chapters - Chapter Six, Department of Finance \& Treasury; Chapter Seven, Department of Prime Minister and NEC; and Chapter Eight, Department of Personnel Management — although the analysis focuses on the same elements of capability. The survey results, which report on the perception statements, use an initial "P", referring to "Perception", and a corresponding number, for example "No.1", which refers to the number of the perception statement. Thus, "Perception Statement 1" in the survey is referred to as "P1" and so on. In conformance with the Anonymity Agreement as described previously, sources that are quoted are referred to by their generic title, for example "senior analyst", "policy analyst", "senior staff", and "junior staff".

Before presenting the results of the survey and perception of staff, it is necessary to comment on the use of data from various budget sources. For each agency, budgetary data is drawn from a variety of sources including various budget submissions from each agency, specific data on certain items - for instance on Item

\footnotetext{
${ }^{37}$ This was in accordance with the requirements of Victoria University of Wellington Human Ethics Committee.
} 
111 Estimates on Salaries and Allowances - and especially from the annual Estimates passed by parliament for each agency. Care has been taken to establish the validity of the data; and where necessary to corroborate them with other sources prior to their use. It has been observed, however, that some documents are incomplete, or available figures do not correspond to previous data (as observed in the prefatory part of this chapter this is a recurring problem in PNG). Where such situations exist, complete data from the next available source are relied upon. 


\section{Chapter Six: Department of Finance \& Treasury (DF\&T)}

\section{Introduction}

In the preceding chapter, the methodology used for data collection in this study was outlined. It was noted that such data would be primarily based on the views and perceptions of officials from lead policy units. This particular method of acquiring information (for this thesis) was justified by a number of reasons already discussed - the key one being the lack of availability of in-depth information regarding the provision of advice within the PNG public service, and more specifically within the three central agencies. Using the method discussed in Chapter Five, this chapter is the first of a series of chapters which examine in detail the problems of capability encountered by each central agency. Informed by the objective of the study (i.e., the need to determine how policy advisory capability has weakened) and recalling the key elements of capability spelt out in Chapter One, this chapter will show, from the perceptions of policy officials, the impediments encountered by the Department of Finance and Treasury (DF\&T) in the provision of policy advice, and their impact on the quality and timeliness of advice.

\section{Roles and Responsibilities}

The Department of Finance and Treasury (DF\&T) is a multi-functional central agency combining both policy formulation and delivery roles. Its responsible minister is the Minister of Finance. The department has in the past decade undergone two separate machinery of government changes, in 1995, and then, in 1999. In 1995, the Office of International Development Assistance (OIDA) was incorporated into the department to coordinate and facilitate international aid and project funding from bilateral and multilateral donors. Structurally, this office has a different director, who reports directly to the minister. The department was reorganised again in 1999 when the National Executive Council (NEC) decided to detach the planning and aid management functions from the department and place them in the Department of National Planning and Monitoring (DNP\&M). That department is now responsible for national development planning and for managing and coordinating all projects and funding that comes from donor agencies and bilateral and multilateral organisations (Department of National Planning and Monitoring, 2000). Although structurally it is divorced from DF\&T, the two departments are located in the same building and work in close consultation with each other. In particular, the DNP\&M is required to liaise 
with DF\&T on the injection of donor funds into the national budget and how the funds are to be used within the country.

A large part of DF\&T's responsibility is devoted to policy formulation and regulation. This consists of all matters pertaining to economic management and the formulation and management (including implementation) of the budget (see Table 6.1). Implementation activity largely revolves around the disbursement of public expenditure and subsequent inspection and audit.

Table 6.1: Functions of DF\&T

\begin{tabular}{lc}
\hline Function & Responsibilities \\
\hline Macroeconomic management & $\begin{array}{c}\text { Monitoring domestic and international developments; formulation of macro } \\
\text { economic policy framework of government; preparing relevant NEC } \\
\text { submissions on economic policy; upgrading economic data }\end{array}$ \\
$\begin{array}{l}\text { Budget analysis, preparation } \\
\text { \& control }\end{array}$ & $\begin{array}{l}\text { Evaluan of expenditure proposals, preparation of annual budget and } \\
\text { monitoring of expenditures }\end{array}$ \\
$\begin{array}{l}\text { Receipts, payments \& } \\
\text { preparation of public accounts }\end{array}$ & $\begin{array}{l}\text { Preparation of monthly consolidated statement of government's revenue, } \\
\text { and circulation of financial instructions }\end{array}$ \\
$\begin{array}{l}\text { Coordination and regulation of } \\
\text { insurance services }\end{array}$ & $\begin{array}{l}\text { Collection of data on insurance company performance; monitoring solvency } \\
\text { requirements; formulation of insurance policies; promotion } \\
\text { and strengthening of the national insurance market and implementation of } \\
\text { relevant laws }\end{array}$ \\
$\begin{array}{l}\text { Provincial liaison } \\
\text { Facilitate the implementation of the OLPLG especially on financial } \\
\text { management, grants and administration and management of Provincial and } \\
\text { District Treasuries. }\end{array}$ \\
\hline
\end{tabular}

Source: Department of Finance \& Treasury, Corporate Plan, 1998-2000

The department's powerful role is evident in both in policy formulation and coordination. In policy formulation, the department is responsible for developing medium term sectoral and regional development plans and helps formulate, in consultation with other key departments such as the Department of Prime Minister and National Executive Council, the government's economic and fiscal policy. The department is also the chief coordinator of crosscutting policy work especially on matters of finance, and provides the necessary leadership in organising policy proposals, synthesising departmental views and inputs, and formulating policy for consideration by high-level authorities such as the Finance Minister, the Central Agencies Coordination Committee (CACC), and the National Executive Council (NEC). 
The department's administration of the Public Finance Management Act 1995 — the key statute that regulates the appropriation, use, accounting, and reporting of public finance - has been a key factor in ensuring DF\&T's dominance and control over economic and financial management matters and other areas of public policy. Its influence on the allocation and disbursement of public expenditure and on macroeconomic and fiscal policy formulation is felt both at the national and provincial levels. For example, its locus of authority at the centre of the administration of the nation's finances has meant that its financial decisions and recommendations pervade every aspect of government activity. Furthermore, key stakeholders such as the Central Bank, the business community, the PNG Chamber of Commerce and a range of bilateral and multilateral donor agencies consult the department and seek its advice on matters of macroeconomic and fiscal management.

The department has the first word on many cabinet-level debates. For example, almost all policies having financial or economic implications have to be referred to the department, prior to cabinet's deliberation. This role, undoubtedly, provides the department with the opportunity to have an overarching influence on public policymaking since virtually every policy proposal presented to the NEC has some economic and financial implications. It is therefore evident that the department is not only the principal adviser to the Minister of Finance, but is the chief adviser to the government on economic and fiscal matters.

In the management of the budget, the department plays a powerful role in vetting and approving budget estimates for all the public sector entities that are funded by the government. In this role, the department is responsible for setting budget parameters in consultation with the government, ensuring that the submissions of those entities funded by government conform with the policy objectives of the government, and revising any estimates that in its judgement are not sound, or do not conform to the fiscal parameters set by the government.

\section{Organisation}

The department has a pyramidal-hierarchical structure with a chain of command and reporting linked to the portfolio minister. Figure 6.1 outlines the structure of DF\&T. 
Figure 6.1: Organisation Chart-DF\&T

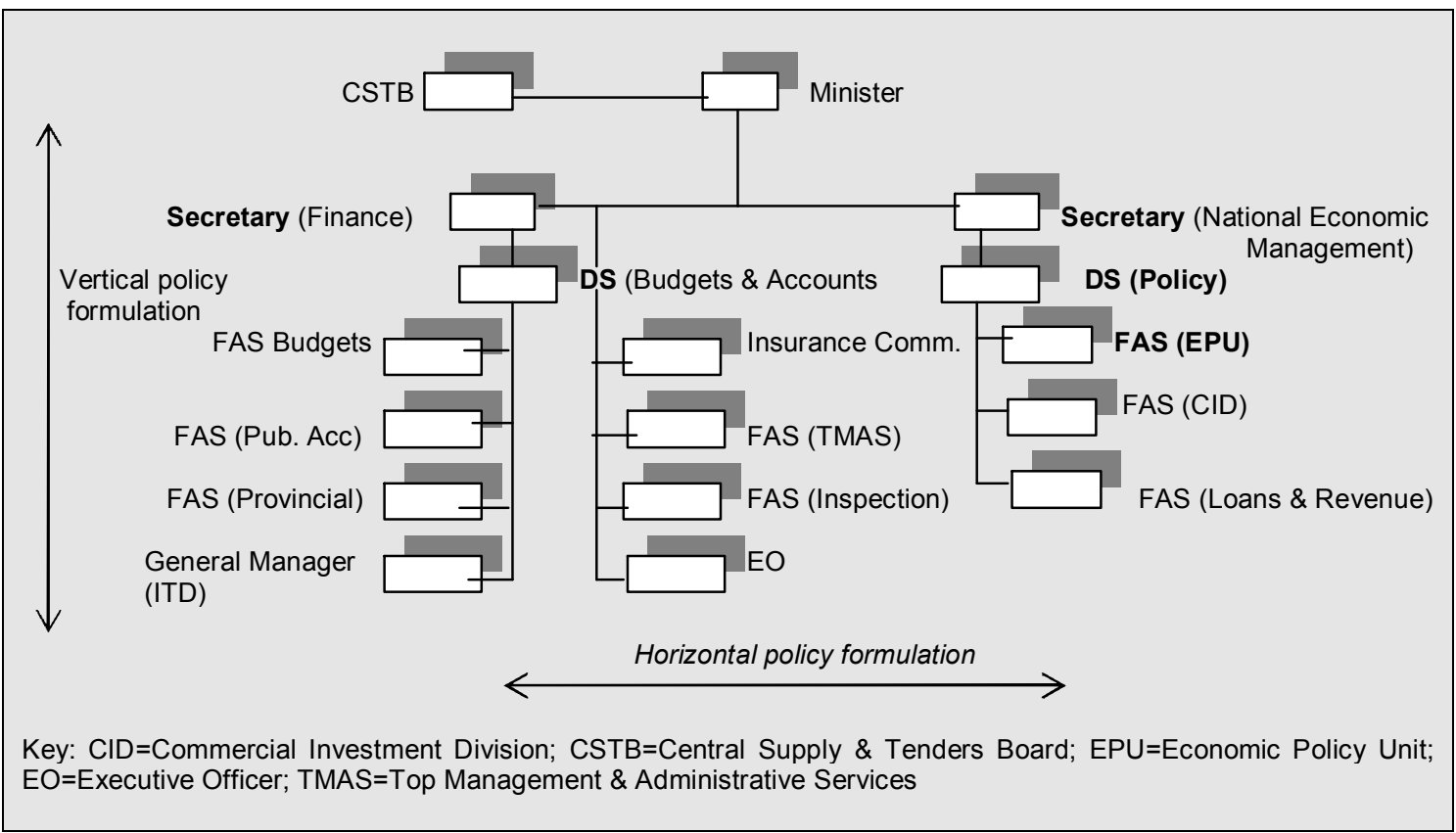

Source: Department of Finance \& Treasury, Corporate Plan, 1998-2000

Unlike some countries where there is a preference for separating economic and financial portfolios into separate departments - Australia, for example - both portfolios are retained in the same agency. DF\&T's organisation is therefore similar to that of the United Kingdom or New Zealand Treasuries where policy advice on economic and financial matters - essentially control of government expenditure - is combined in one department. However, unlike the New Zealand Treasury, which has one chief executive, DF\&T has two separate heads - Secretary of the Treasury and Secretary of Finance. The Secretary of the Treasury is responsible for national economic management (macroeconomic policy analysis and coordination, promotion and regulation of the financial sector, and sectoral policy analysis and government budgeting). The Secretary of Finance has the responsibility for government financial operations, (control of public expenditure, inspection and audit and management of grants to provinces and districts). Each secretary reports to the same minister (see above figure).

The department is one of the large departments in the PNG public service. Among the three central agencies considered in this study, it is certainly the largest department with more than 700 established positions (this includes the staff of provincial treasuries) in ten different branches, each headed by a First Assistant 
Secretary (FAS) reporting to a Deputy Secretary (DS) (DF\&T Corporate Plan 19982000: 108). Furthermore, the department is represented in each province through nineteen Provincial Treasuries whose head, the Provincial Treasurer, is a member of the DF\&T staff and therefore reports directly to the Secretary of Finance at headquarters in Port Moresby. The provincial treasuries are responsible for managing the disbursement of financial allocations to provincial governments as well as accounting for the use of such funds on behalf of the Secretary of Finance.

The organisation of policy work within departments in the PNG public service was briefly discussed in Chapter Two. Within DF\&T the "policy process" - a term used here to denote the way policy formulation and implementation is handled within the department - follows the pattern identified by Matheson (2000) in that it is done on both the vertical and horizontal axis. That is, policy work is performed, coordinated and monitored both up and down (vertically) the department's structure, as well as across different units and branches (horizontally) to fulfil its various functions. As in many Westminster systems, the vertical relationship between the department and its political masters is particularly important because of the political management of the department by the minister and the cabinet's relationship with the department in the development and implementation of policy. Thus cabinet and, especially the minister, remain the two most important policy clients of the department in the provision of policy advice.

\section{The Economic Policy Unit (EPU)}

As shown in Figure 6.1, the structure of the department is organised around two key divisions, the Policy Division and the Operations Division. As would be expected the Policy Division does much of the work on policy formulation and advice. Within the department, the lead policy unit responsible for most policy analysis and advisory work within the department is the Economic Policy Unit (EPU) of the Policy Division. The EPU is something of an elite unit located at the centre of the department's operations and commanding both influence over and respect from managers within DF\&T and the two secretaries. It provides a range of operational, substantive and strategic advice to the two secretaries (especially the Treasury Secretary), Central Agencies Coordination Committee (CACC), the Finance Minister and NEC.

The unit is headed by a First Assistant secretary (FAS) and has four sections headed by respective Assistant Secretaries (AS). These are the Fiscal Policy Branch, the Forecasting Branch, the General Economic Policy Branch, and the Monetary Branch. 
Each of these branches is responsible for a diverse range of responsibilities in fiscal, monetary and economic management. Figure 6.2 outlines the organisation of the unit and describes the role of the various branches.

Figure 6.2: Organisation and Role of EPU

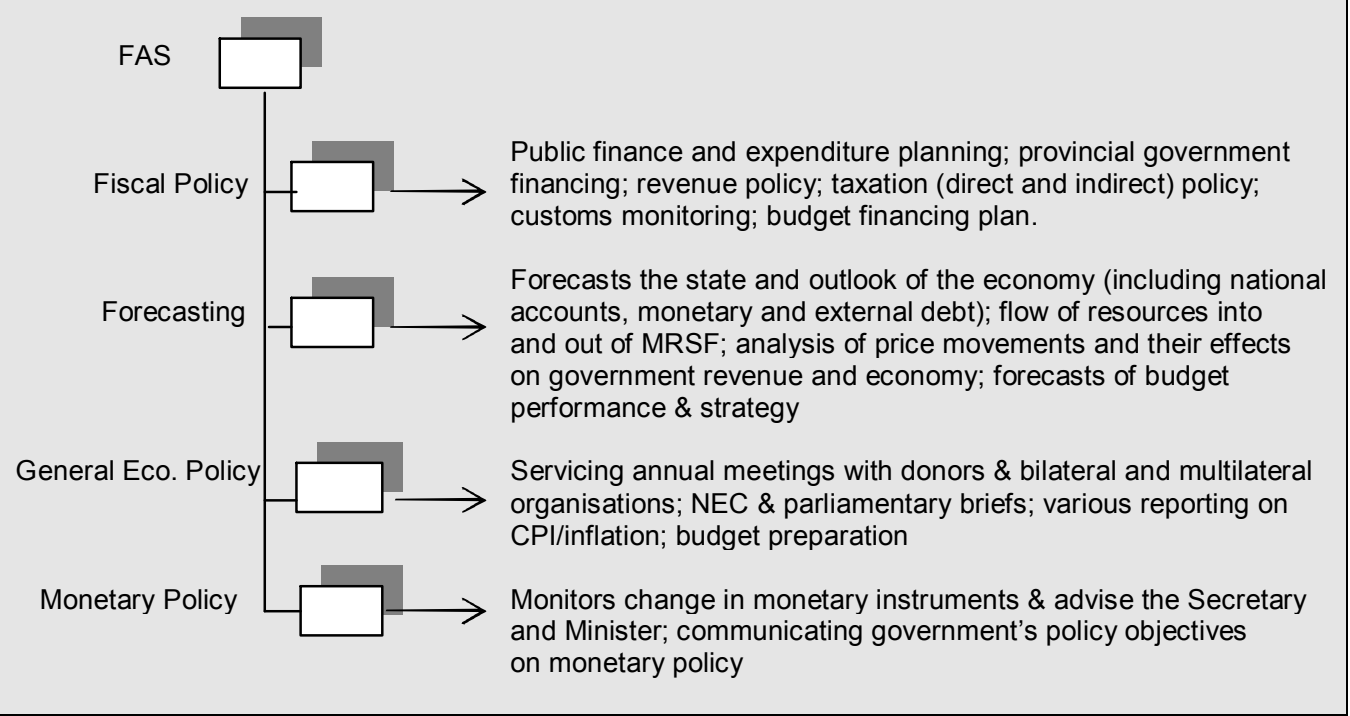

Source: Department of Finance \& Treasury, 2000.

The unit has five key roles with respect to policy work. One is that it provides contestability in policy advice, scrutinising and filtering (and therefore refining) policy proposals from line departments and other central agencies that come before it. Nearly every policy proposal that has economic or financial implications and which requires the DF\&T's comments would need to go to the EPU, as the first point of contact. Depending on the nature of the proposal or submission, work is then channelled to the other units and branches.

The unit is also responsible for policy formulation. This is done alone or in horizontal collaboration with other units of the line departments and external stakeholders, for instance with the Central Bank. For example, the unit is the department's leader in public finance and expenditure planning. Under this role, the unit helps formulates the country's annual budget and works closely with the Budget Branch reporting to the Secretary of Finance on the development of the Appropriation Bill. A key aspect of its policy formulation role has been the regular research on economic and fiscal issues and the generation of various economic models and forecasts of the economy 
and the fiscal position of the government. This underpins much of EPU's advice on substantive and strategic policy.

Thirdly, the unit is the linchpin of coordination, harmonising and actively liaising with other branches and units within DF\&T. All major internal work on economic and fiscal policy must pass through the unit for scrutiny. For example, key policy work that goes to the AS, FAS and Deputy Secretary levels requires the comment of the unit. Thus, EPU is an important point of policy authorisation within the department. This coordination role is also evident in organising and developing policy work involving crosscutting policy issues across departments. Often EPU officials are seconded to interdepartmental committees to provide the necessary leadership in the development of policy, or to inject expert policy advice on policy work from other departments.

As the lead policy unit of DF\&T, EPU plays key advocacy and negotiation roles with bilateral and multilateral donors on a diverse range of matters particularly dealing with loans on structural adjustment issues, and on fiscal and economic reforms. Key donors such as the World Bank consult the unit for important data on PNG's economic and fiscal position and in developing reform proposals and evaluation of previous programmes - for example, EPU assists departments in carrying out regular evaluation exercises on the dispensation of loans and the impact created by donor-funded programmes and then report to donor agencies. EPU also plays an important mediating role, often representing the government in reconciling conflicts over policy intervention measures with donor agencies.

\section{Perceptions of Roles}

One of the aims of the study was to acquire the views of staff about their perception of the role of their department in policy advice. Officials felt strongly about their department. There was an overwhelming feeling among staff that DF\&T plays an important role in what it does. This was evident from the response to the question: "My department plays a vital role in providing policy advice to the minister and cabinet" (P1). The majority (62.5 percent) "strongly agreed" with the statement, while 37.5 percent had agreed.

The perceptions of the staff about the capability of the department in providing policy advice based on specific benchmarks of quality (how well policy advice is provided) (P13) and in its overall ability to respond (P14) received a mixed response. Half of 
those surveyed felt that the department has the capability to produce quality advice, while a corresponding 50 percent "disagreed" or "strongly disagreed". A similar response was gauged on the general capability (i.e., everything that the department does including the organisation of policy advice) of the department to respond, i.e., half of those surveyed thought the department could respond decisively in time, while another half thought that the department did not have the capacity to respond.

The survey responses notwithstanding, virtually every staff member interviewed expressed some apprehension about the department's capability - for example, about an overall lack of high quality staff; poor facilities; the need for more intradepartmental cooperation at the managerial level; and poor ministerial guidance on the quality of advice expected.

There was a perception that DF\&T has been increasingly drawn into performing multiple and often confusing functions, and that some of the functions "do not fall within the formal jurisdiction of the department" (excerpt from interview). One main reason for DF\&T involvement in non-core areas has been the lack of policy capacity of other key central agencies responsible for providing strategic direction and maintaining a whole of government perspective on policy. For example, it was observed that the lack of capacity of the Department of Prime Minister and National Executive Council (DPM\&NEC) has been a primary reason for DF\&T's involvement in managing crosscutting policies. But this expanded role has not been without risks. According to one senior policy official, "this has spread the resources of the department too thin and is just creating an unnecessary administrative workload on the department". Moreover, there was a real risk of mismanaging government policy. The same official observed that strategic coherence and direction "was not the province of the department" implying that, while DF\&T could provide advice on fiscal and economic matters, it cannot do the same on overarching policies that concern the whole of government; this was the responsibility of DPM\&NEC. There was a perceived risk that the DF\&T could misrepresent the policy directives of the NEC on strategic policy.

Responsibilities evolve over time and resources may not necessarily enable an agency to cope with expanded responsibilities. In the case of DF\&T, there was a concern among staff about the increasing workload arising from the department's recently-acquired role of maintaining coherence in strategic policy and especially from the shortage of staff (a situation largely caused by not filling positions that were 
vacant). Inadequate staff having to deal with a large workload (especially during budget rounds) was seen as an ongoing problem. Within EPU, for example, only 14 of the 21 established positions had been filled when this research was carried out (April 2002).

Although traditionally the provision of policy advice has been limited mostly to ministers, cabinet, and line departments within central and provincial governments, the macro-economic reforms of the 1990s have expanded the client base of the department. The proliferation of donor agencies, international financial institutions and foreign governments with strong financial ties with PNG in recent years, especially after the mid-1994 financial crisis, is an example. Such a growing client base has brought about particular difficulties for staff as shown by the following statement by a policy analyst:

Negotiating with agencies like the World Bank is not easy. Often Bank officers would need economic and other financial data and those who are there to negotiate must ensure that they know these and that such information is actually made available. One also needs good negotiating skills to convince stubborn Bank officials of your position.

Clearly, the expanding list of policy clients has ushered in new demands for DF\&T to have the necessary capability to manage a range of policy issues important to donor agencies and foreign governments involved in foreign aid. This was evident in the need for more competent policy officials possessing the ability to create the necessary networks with external agencies, negotiate with donors, formulate and execute macro-economic and public sector reform initiatives, manage donor funds, and monitor and evaluate donor-funded programmes.

The vertical and horizontal coordination of policy between DF\&T and other central agencies and between DF\&T and line departments and agencies was considered by staff to be essential in ensuring that key policy clients get the right kind of policy advice when it is needed. However, some officials did not feel that this has been effective as it should have been. For example, there has been a tendency for some central agencies to be "inward looking, concentrating on their own 'turf' and forgetting important and crosscutting issues, which require the cooperation and support of other agencies" (excerpt from interview). In the process, the flow and exchange of important information gets stifled. There was a perception that too little information is 
released or opportunities for accessing such information, for instance through interdepartmental committees, are not taken.

The above situation has frustrated some officials, as it has limited their ability to analyse issues in a coherent and comprehensive fashion. Some senior officials believed that the inward looking phenomenon has contributed to sporadic liaison, and poor interdepartmental collaboration on policy work on very important crosscutting issues. This has often worked against the collective interest of the government.

The lack of effective liaison between DF\&T and other agencies on crosscutting policy issues carries the risk of ministers receiving one-sided and conflicting advice. Insofar as one-sided advice is concerned, some senior officials observed that the most powerful central agency is likely to have its way in influencing the advisory process if there is no coordinated input from other central agencies. In the latter case (i.e., conflicting advice) key policy clients are likely to be confused by uncoordinated advice emanating from different agencies. As one official commented, "there is a risk that effective policymaking may be compromised due to conflicting information reaching ministers".

Turf protection and the advancement of narrow departmental interest are likely to result in conflict at some point, as departments try to advance their own policy position. There has to be some way of resolving conflicts should they arise. Asked what avenue exists for resolving conflicts in policy advice, most DF\&T officials considered that there isn't any formal way of solving conflicts; central agencies tend to discuss things among themselves in situations of conflicting position. A few officials saw CACC as now being responsible for managing conflicts between central agencies.

In performing its scrutiny and advisory role, DF\&T reviews virtually every policy submission that has economic and financial implications for the government to ensure that cabinet is getting sound advice from departments. DF\&T's review and subsequent action depends on the importance of the submission received: those of lesser importance that do not contain sufficient information are referred back to the originating department, while those that are deemed to be important, requiring the immediate attention of the minister or cabinet are refined by the DF\&T, in which case staff have to consult the sponsoring department and a variety of other sources to get 
additional information and then restructure submissions to comply with the required format and standard.

One area of anxiety was the poor quality of information and data provided to DF\&T from time to time in the policy submissions (proposals) it receives from departments and other agencies. Figure 6.3 summarises the responses of 13 interviewees from the department on their views on the reliability and comprehensiveness of departmental policy submissions based on a "very good, good, fair, poor and very poor", scale.

Figure 6.3: Perceptions on the Quality of Policy Submissions ( $\mathrm{N}=13)$

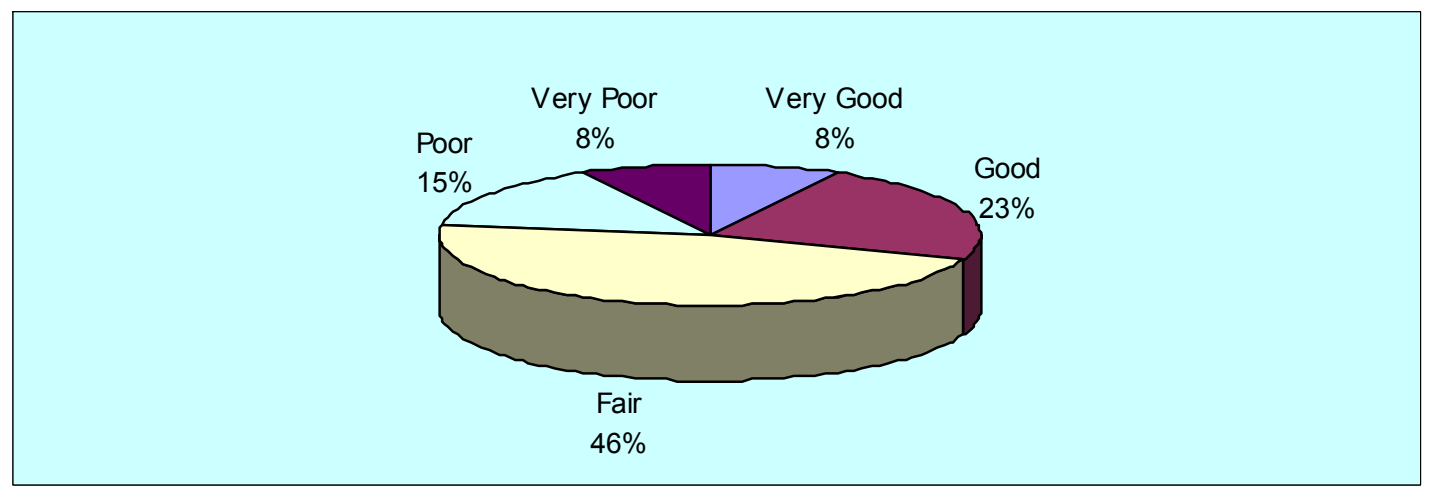

As indicated in the above figure, the quality of policy submissions requires significant improvement as the majority of submissions were rated as "fair" or below that. According to DF\&T officials, a number of key areas require improvement. These include improving financial data so that government knows the full costs of policy; clarifying the objectives of submissions and showing the likely benefits expected to be derived from the policy (this also includes the inclusion of supporting documentation and/or information that is deemed necessary); and aligning policy submissions with policy intents of the governments.

Dealing with the "poor" quality of policy submissions has not been without costs to DF\&T. The review and reformulation of policy submissions has placed unnecessary strain on DF\&T staff and the resources of the department (for instance in reviewing and reformulating submissions). As observed by one official, "this has imposed unnecessary hidden costs [especially in terms of man-hours] on the department [DF\&T]". The review and remedial role of DF\&T may also remove the incentive for departments to bring forward well-developed submissions. In the view of DF\&T 
officials this situation has created a tendency for other departments (including the two other central agencies analysed in this study) not to take policy advice seriously.

There were other fears as well. For example, some DF\&T officials were concerned that "with the increased dependency on DF\&T, the department (DF\&T) runs the risk of becoming a 'know it all' department, and may tread on policy areas which it may have no substantive knowledge of" (excerpt from interview). The lack of seriousness in the formulation of submissions shown by departments may also lead to ministers and cabinet being ill advised on policy matters. The likelihood of this happening is greater especially in situations where there are serious lapses in the judgement of DF\&T officials who are responsible for providing the required scrutiny.

Providing rigorous assessment on finance and economic issues is one important aspect of DF\&T's function. As an illustration, the department produces the quarterly Treasury Economic Monitor to provide up-dates on international economic trends, their impact on PNG's economy and the status of the PNG economy. The information generated from this source is disseminated widely and utilised for a variety of purposes including formulating policy proposals, and advising ministers and the NEC. To maintain this function the department relies heavily on the National Statistics Office (NSO) and the Central Bank for some of its data; in some cases it relies on data from other public and private organisations. Externally, it relies on published reports, economic and financial journals and specific studies from such sources as well-known publishers, independent think tanks and government institutes, especially within the Asia-Pacific region.

However, the quality and reliability of data remains a key problem within DF\&T. This has been particularly evident in the EPU. A frequent problem is that data is not synthesised in an accurate and up-to-date manner. This problem is compounded by the limited skills available to collect and synthesise data. As one policy official commented:

I do not think key stakeholders responsible for economic and fiscal management in the country value research very seriously. If they do, we would have a good database by now.

Furthermore, key data sources often prove to be unreliable, given the lack of robustness and poor quality of information they generate. For example, it was 
suggested in the interviews that the National Statistics Office database is outdated and at times cannot be relied on to provide the kind of information necessary to mount specific analysis on economic issues. There is a common view among policy officials that the NSO database requires constant upgrading. That was not always done.

Access to important external data sources electronically is an important means of acquiring critical data for policy analysis work. However, within EPU, for example, electronic access to important data has been minimal, if not restricted. For example, 85 percent of staff are not connected to the Internet, although virtually all the officials have access to e-mail facilities. Also, subscription to important data sources has been minimal despite a huge demand for it. One senior official was of the opinion that heavy reliance on external sources of data will not go away until improvements are made to internal database management and the research portfolio of the department. In other words, DF\&T needs to enhance its internal capacity to acquire and utilise data. This would mean focusing more on original research and imposing better processes and techniques for data acquisition, storage, and transmission.

This problem of data access (and management) is further complicated by the way data is treated poorly across the PNG public service - a problem briefly discussed in Chapter Five. Because the storage of reliable data is a common problem across departments, policy analysts frequently find that other departments do not have the necessary data. Analysts are then left to carry out policy analysis without adequate information.

The inadequacy of existing data has created many complications for policy officials. For example, looking for valuable data can be time consuming. Valuable time is lost trying to find the necessary information to assess policy. As one official commented:

Identifying the source of data can be tricky. Of the sources you have, you have to figure out which source is more reliable and credible and which should not be relied upon...sometimes you get conflicting information and you have got to really sit down and work through the information you got.

In the long run, weaknesses relating to the access (and management) of data are likely to impair the development of policy options for key policy clients, as illuminated in the following comment by one official: 
My fear is that without reliable information we cannot respond in a decisive and effective way. Sure we will respond quickly, but the question remains whether our response will be reliable in order to create the desired impact on government policy (senior policy official in interview).

At risk especially is spontaneous advice. With limited information and unreliable data, and a short deadline to meet, there is a high risk of ministers and cabinet getting bad advice on issues requiring immediate advice. As noted by the official above, although the capacity to respond is there, doubts remain about the department's ability to give reliable and comprehensive advice.

The political nature of advice has been noted in Chapter Three, and as noted in that chapter, providing advice is intensely a political matter. Politicians may wish to get advice from sources other than public servants; they may decide on their own on what is the "best" policy. When this happens normal routes for providing advice based on reliable and comprehensive analysis, for instance using departmental channels, may be bypassed.

A troubling aspect of policy advice encountered in DF\&T is that submissions were frequently brought directly to cabinet and approved, in which case DF\&T is required to work out their financial implications after decisions are taken. Some officials blamed ministerial and political advisers for this. According to some officials, there is a risk of bad policymaking especially when politically desired gaols have not been fully assessed against their estimated costs and benefits.

There was a perception among staff that the practice of circumventing DF\&T undermines the important role of the department as the guardian of economic and fiscal policy. Most officials strongly believed that policy advice provided by the DF\&T should form the basis of policy formulation, and that there are a lot of risks involved when policy is not properly assessed. This observation is reflected in the comments from one senior analyst:

There are times when we are told to find money to fund policies that we would have said no to if we had an earlier opportunity to provide our advice. Our problem has been to find money somewhere to fund them, even though there aren't any budgetary allocations for them. 
Intra-departmental cooperation, though valued, was seen as problematic. There was a perception that cooperation among different branches and units of DF\&T could have been better than it currently was. Strong leadership that values consultation and cooperation at the branch and units levels was felt to be lacking. One senior official mentioned that it was often impossible to get into the "turf" of another branch or unit, especially when "you know that its boss isn't as cooperative as he should be in working with you".

It was also felt that departmental resources and especially information could have been shared more effectively among different branches and units. For example, the transmission of information between EPU and the units responsible for expenditure control in Finance has often been slow, resulting in situations in which EPU has had difficulty in providing advice on appropriations in the annual budget. Data accessibility from provincial treasuries is also problematic resulting, for example, in instances where it has been difficult for DF\&T at Waigani to monitor and evaluate the performance of provincial treasuries.

\section{Managing Staff}

Based on 2000 figures, DF\&T had 739 established positions, 721 of which are allocated to PNG nationals, and another 18 for expatriate staff (DF\&T Corporate Plan, 1998-2000). Expatriates are expected to take up positions in areas in which local skills are scarce or absent. At the time the fieldwork was mounted (2002), six consultants were working with the department. These consultants were playing various support roles mainly in the area of technical advice to the department. Their engagement was paid for by donor agencies and the PNG government through counterpart funding - an arrangement in which the PNG government and the donor share the cost of remuneration.

The EPU has 14 staff. All staff were positioned between grades 11 and 18 on the Public Service Staff structure (refer to Table 5.1 in Chapter 5). Table 6.2 gives the percentage breakdown of staff by position based on three broad categories: Head of Policy Unit; Head of Sections, Strategic Advisers and Senior Analysts (Grades 1417); and Policy Analysts and Programme Officers (Grades 8-13). 
Table 6.2: Breakdown of EPU Staff by Category (\%)

\begin{tabular}{ll}
\hline Staff Category & Percent $(\%)(N=14)^{*}$ \\
\hline Head of Policy Unit (Grades 18-19) & 76 \\
Head of Section, Strategic \& Senior Analysts (Grades 14-17) & 57 \\
Policy Analysts, Researchers (Grades 8-13) & \\
\hline *Based on the actual staff strength rather than the total staff ceiling of the unit. \\
Source: DF\&T, 1998-2000
\end{tabular}

Most staff were fairly young, in the age group of 30-35 years. Table 6.3 shows the number of years officials have worked with the department and the experience in the current post based on the survey data.

Table 6.3: Work Experience of EPU Staff

\begin{tabular}{lll}
\hline No of Years & \multicolumn{2}{c}{ Work Experience $(\%)(N=8)$} \\
\cline { 2 - 3 } & DF\&T & Current Post, EPU \\
\hline $0-2$ & 25 & 62.5 \\
$3-5$ & 12.5 & 0 \\
$6-8$ & 25 & 25 \\
$9-11$ & 25 & 0 \\
$>11$ & 12.5 & 12.5 \\
\hline
\end{tabular}

Officials who have five years work experience or less comprise only 37.5 percent, while the majority, 62.5 percent, have been working in the department for more than five years. However, a majority of staff has had no more that two years of working in their current position within EPU. There was some concern about the lack of experience in the current job. Some specifically acknowledged that they have joined the unit fairly recently and need more time to get to know the job.

Lack of staff was a major problem facing the department. Of the department's full strength of 739 positions in 2000, 318 positions were not filled when this research was carried out at the end of 2002 (DF\&T, 2000a), leaving the department with the strength of 421 staff. In percentage terms, the department has to rely on 56 percent of its projected total strength to carry out its responsibilities. In the EPU, out of the staff ceiling of 21 , only 14 positions were filled (see Figure 6.4 ). 
Figure 6.4: Staff Strength in EPU and DF\&T

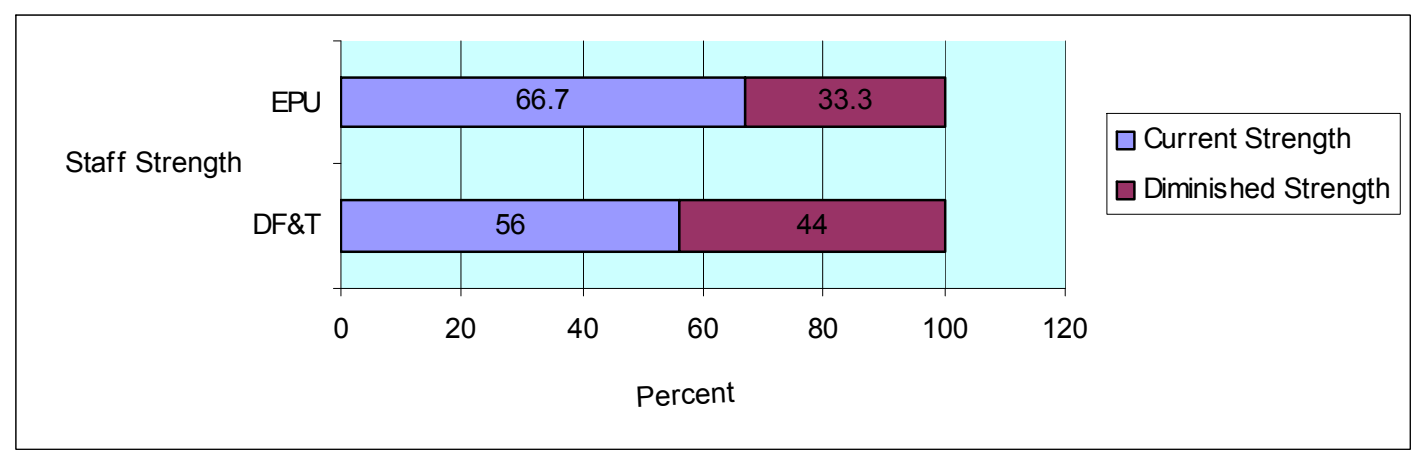

The issue of vacancies was seen as needing urgent attention. This has been especially the case with principal and senior economist positions, which according to one official "require some urgent action by management to fill the positions". Among the factors cited as contributing to these problems was the frustratingly slow process of recruitment:

The progress in filling the vacant positions (professional policy positions) is very slow. It is taking 3 years to advertise the positions, as such very little is done in research; most work is basically routine policy advice.

Some officials cited budgetary constraint as the key impediment to recruiting staff to fill the vacancies. For example, one senior policy official saw cuts in budgetary allocations, especially to Personnel Emoluments as one major hurdle preventing the recruitment of staff. Others saw this situation as a reflection of poor management i.e., those who are responsible for recruiting staff are not doing enough to remedy the situation. A major cause has been the shortage of qualified economists. For example, of all the applications received in 2000 for various positions in EPU, only two were recruited, while the rest were considered unsuitable on the basis of experience and academic performance. One successful candidate soon left.

The low level of remuneration was also seen as a cause for delays in filling vacant positions (as well as of staff leaving). Some officials felt that it has been difficult to attract highly qualified staff because of better opportunities provided elsewhere. A review of comparative salaries (among the three agencies in this study) suggests that salary levels are uneven, at least for officials on the same rank. Data gathered for this research suggest that DPM\&NEC officials are paid better that officials holding similar rank in the other two agencies. At the assistant secretary rank, for example, 
the incumbent in DPM\&NEC would be positioned between Grade 17-18, while he/she would be positioned between Grade 15-16 in DF\&T and DPM (see Table 5.1 in Chapter Five for a comparison on salary). It appears prima facie that unevenness in salary may have contributed to staff leaving DF\&T. For example, of the officials interviewed for this project in DPM\&NEC, two were ex DF\&T staff and had indicated during the interviews that their move to DPM\&NEC was partly based on better terms and conditions in DPM\&NEC.

While the need to fill vacant positions was seen as necessary, there was a strong feeling among staff that filling existing vacancies was by itself unlikely to fully enhance the capacity of the unit; an increase in staff positions, from currently 21 positions overall to about 30 was thought to be equally important. It was felt that the unit would be more capable and therefore able to respond to the demands of policy clients in a comprehensive and reliable manner if it had significantly more staff.

\section{Skills and Expertise}

All EPU officials have acquired a basic Bachelors degree - most from the University of Papua New Guinea (UPNG). Table 6.4 gives a synopsis of the qualification-mix of EPU officials from the survey data.

\section{Table 6.4: Qualifications of EPU Staff}

\begin{tabular}{lc}
\hline Qualification & No of Staff (\%) (N=8) \\
\hline $\begin{array}{l}\text { Bachelors } \\
\text { Bachelor of Economics }\end{array}$ & 75 \\
$\begin{array}{l}\text { Other Bachelors Degrees } \\
\text { Statistics/Maths, Business Economics, Public Administration } \\
\text { Development Studies }\end{array}$ & 25 \\
$\begin{array}{l}\text { Post Graduate } \\
\text { +Post Graduate Diploma in Economic Policy Analysis } \\
\text { +Masters (MBA, MA, MEC; MPhil) }\end{array}$ & \\
$\begin{array}{l}\text { Extra Skills } \\
\text { +Complementary skills (computing, data analysis, project management) } \\
\text { (various short courses (e.g., from the World Bank and IMF) }\end{array}$ & 37.5 \\
\hline
\end{tabular}

+ Indicates additional qualification or skills on top of a Bachelors degree.

The above table could be simplified by comparing qualifications by basic category in three key areas: Additional Skills, Post Graduate degree and Bachelor degree. Figure 6.5 shows that around 62 percent of staff have a post graduate qualification (they also hold a Bachelor's degree). However, key skills (data collection and 
analysis, computing, project management etc.) that are usually needed for substantive policy work are still lacking: only 12.5 percent of staff posses extra skills.

Figure 6.5: Spread of Qualification by Major Category, EPU

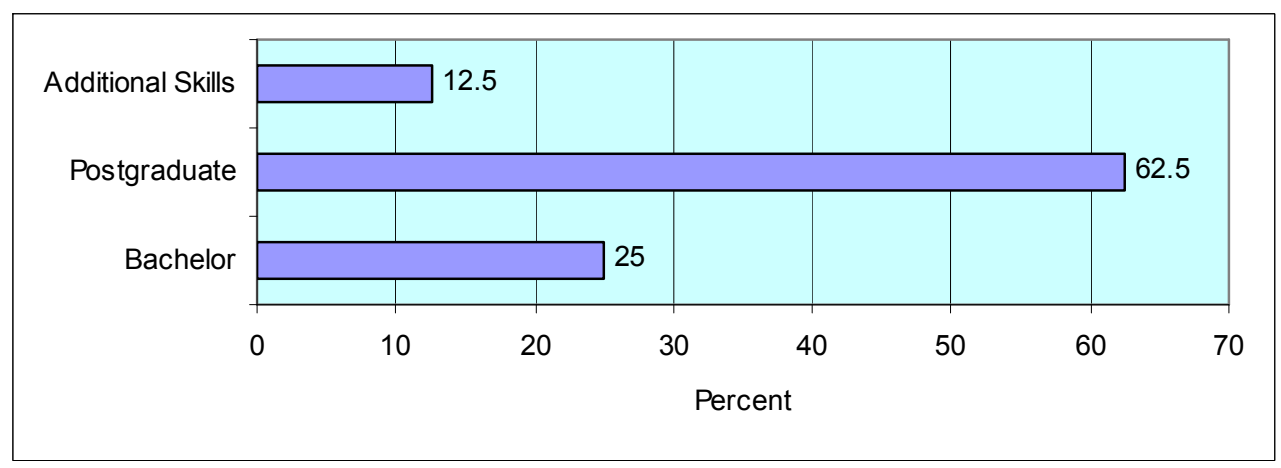

Qualifications and skills are important elements in improving the quality of analysis carried out by officials. One aspect of the interviews with policy staff was therefore aimed at soliciting the views of these officials on the adequacy of their present qualification, and the constraints preventing the use of the skills they have. Lack of experience was seen as a key constraint. This is consistent with the survey finding, which reveals that the majority of staff have no more than three years of work experience in the present position.

A significant number of EPU officials believed that the tasks encountered in their present position were more demanding than those of other branches of DF\&T. Such tasks require a good background in policy analysis, in depth knowledge of the job and its requirements, extensive knowledge of government operations and policies, and relevant experience, especially within EPU. Such a perception is reflected in the following statement:

In my branch there are only junior staff, but economic forecasting needs particular skills especially in econometrics and modelling. Although they are generally introduced to those areas in their undergraduate level, specific skills need to be honed in while they are on the job. I would say what we do here is different from what we learned in the lecture halls some years ago (senior official, excerpt from interview).

Those who had recently joined the department raised the need for more familiarisation with the exact nature of the task and the role of the EPU. A general view was that officials tended to go straight to performing their substantive roles with insufficient time given to induction. Some analysts felt that their understanding of 
economics at the undergraduate level ought to be complemented with additional knowledge of the policy processes, constitutional and legal issues, and the political context in which policymaking takes place. Others felt that a post graduate qualification particularly in economics would help them play a role at the higher level, especially in communicating policy views, negotiating policy positions and undertaking leadership responsibilities. On the whole, such problems were not new; they have been recognised and hence identified in the SWOT analysis of the weaknesses of the department (DF\&T Corporate Plan 1998-2000, SWOT Analysis: 13).

Mentoring was seen as essential especially by junior officials: there was a general feeling that junior analysts and those who join the unit were likely to get "the feel of the job" more quickly, and work more effectively if they could work under the guidance of senior and experienced analysts who could help them along the way. Despite its perceived significance, there was little mentoring in the department. This was primarily because of the limited number of senior policy officials available to nurture and develop junior or inexperienced staff. For example, of the five officials who occupy senior positions (grade 14-17), four were Assistant Secretaries already heavily occupied with the management of their respective sections of the EPU apart from their role as senior analysts.

\section{Developing Knowledge and Skills}

Knowledge and skills are vital components of capability. As observed in Chapter One, the scarcity of skills and expertise has been one of the key contributing factors to the weakening of public services in many developing countries and, has been a primary reason for many donor agencies (and developing country government) to take a renewed interest in skills development. As in other developing countries, continued emphasis in developing departmental capability through improving the skills of personnel in the public service has been a primary concern for the PNG government (see DPM, 2000).

Those interviewed saw improved knowledge and skills as an important prerequisite for building the capability of staff. For example, many officials felt that EPU's role as the lead policy advisory unit of the department is likely to be strengthened if the present knowledge and skills of the staff are improved. Moreover, there was a very strong feeling that long-term investment in knowledge and skills development is the 
best way of enhancing the present level of knowledge and skills of staff. This perception was evident in the following comment by a senior official:

We value further training; if we have the necessary resources and finance, we will ensure that all our staff are properly trained.

DF\&T plans for human resource development are comprehensive, identifying the respective training needs of staff, and slotting staff within relevant timeframes to receive the appropriate training (see DF\&T Corporate Plan, 1998-2000). Despite having a good training plan, there was a perception that the department has not always been committed to training staff. More than half of the officials indicated that they have been waiting for some time for training. In-house training, especially on short skills-based courses (e.g., data analysis and spread sheet, computing and project management) was seen as the area requiring immediate attention by the department.

There is a heavy reliance on donor agencies to fund the training for many public servants in PNG. DF\&T is no exception. For example, between 1998 and 2002, donors account for "roughly 85 percent of all major training for DF\&T staff" (senior policy official, EPU). Furthermore, "more than 95 percent of overseas training was donor sponsored" (ibid). Despite the goodwill of donors, donor-sponsored training programmes have their own drawbacks. For example, donor-sponsored training does not necessarily address the capability requirement of a department (especially when it is developed without a proper "needs-based analysis" of the types of skills needed, and with little input from the department concerned). This situation is explained by one policy official:

The need to attend a specifically defined course based on the donor's wishes can be counterproductive. Staff are trained but their training is often ill-suited for the tasks within the department. In fact, it has been the primary reason for staff leaving... when they find that their skills are unsuitable or better utilised elsewhere they move. ${ }^{38}$

Moreover, donor-sponsored training overseas only concentrates on a select few thus leaving many staff out. It has also been viewed as a less cost-effective exercise, with

${ }^{38}$ MBA training was cited by the official as an example of training that could be counterproductive. The official acknowledged that some MBA trained staff have left for private companies. As a result, the skills gap in the department has worsened or at best remained the same. 
minimal output. One senior policy official, for instance, estimated that "the cost of training a staff member overseas can cater for 15-20 staff in any one time if training is held domestically, especially on skills-based courses" - for example short courses in project management, data analysis and information technology (excerpt from interview).

Officials advanced a variety of budgetary reasons to explain the lack of increased support for skills development. Budget shortfalls, a perception largely held by senior officials, were seen as one primary cause for the lack of emphasis in skills development. Others, especially junior officials, see a combination of causes, pointing to the poor support that training has received within the department as being as much a factor as the lack of funds; and, for those years that funds were made available, a lack of cost-effective use of funds. As one policy official commented, "we see the figures, but we do not see the actual training".

On a prima facie basis financial allocations to training appear to support the above claims - indeed putting more weight to the claim by senior officials (that a lack of focused attention by the department was primarily a result of lack of adequate funding). Figure 6.6 gives an estimated distribution of the training allocation as a component of total allocations made to Goods and Other Services ${ }^{39}$ in a five-year period.

${ }^{39}$ As noted in Chapter Two, training is an item whose allocation comes under Goods and Other Services in the current system of input-based budgeting. 
Figure 6.6: Estimated Distribution of Funding to Training, DF\&T 1998-2002 (\%)

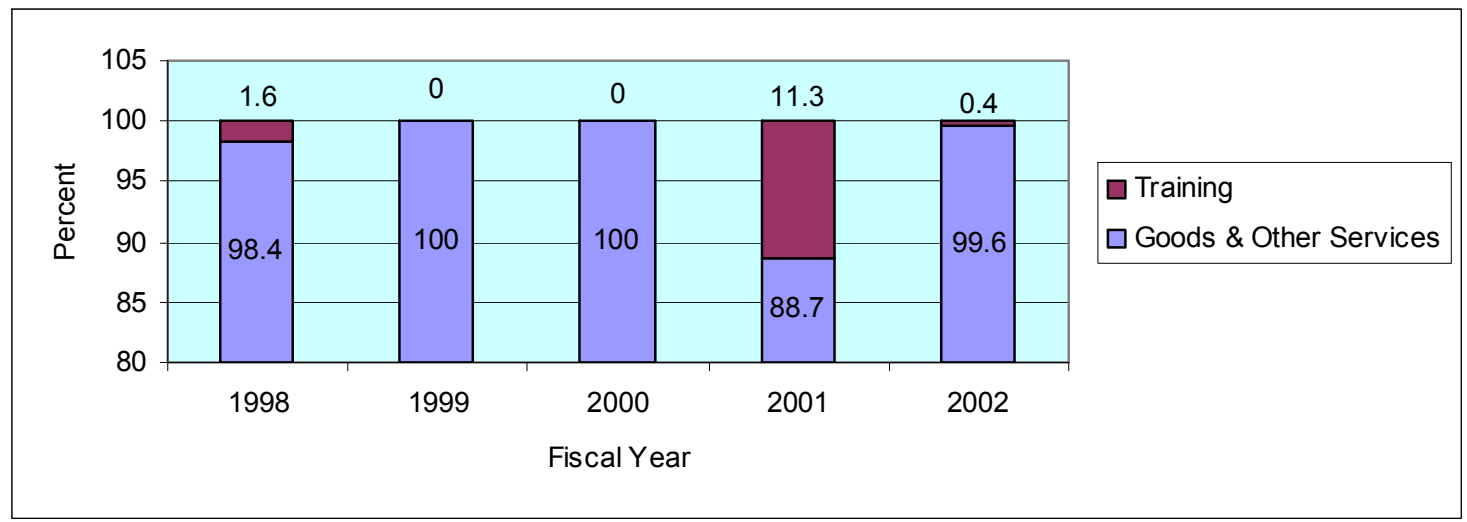

Source: Computed from Department of Finance \& Treasury, Estimates of Recurrent Expenditure 2000(Volume 2 Part 3); 2001 Budget (Volume 2 Part 1); 2002 Budget (Volume 2 Part 3).

Some senior officials have observed that financial allocations to training have not taken into account the demands for training in the department arguing that, "it has fallen far below what the department needs" (excerpt from interviews). A senior official noted that, "roughly at the minimum, five percent [of the allocations to goods and other services] is required to sustain training over a three year period if staff capability were to be maintained at some reasonable level". Using that as a crude yardstick, it can be contended that training has received less than adequate funding in the years 1998 to 2000. As noted in Figure 6.6, about 1.6 percent (of the total for Goods and Services) was allocated for training, thus falling below the projected benchmark of five percent. The allocation for 2001 and 2002 were also perceived to be inadequate (although the 2001 allocation was twice the projected benchmark estimated by the Treasury official) by an Assistant Secretary:

When you consider our budgetary allocations [for training] in the previous years, they were so insignificant. So when we received funding in the 2001 fiscal year, everything was directed to outstanding [training] commitments from the previous years. We did not really attend to our training commitments for that year and the following year.

A significant concern, as observed by the official above, relates to the effect the increasing number of staff requiring training has on the department's future training budget and, the future prospects for training. It was argued by several officials that funding difficulties only delay training and have created a "training waiting list". This situation is likely to increase the cost of training at unmanageable levels (in the 
future) and as observed by some officials, "has created frustration among officials who have to wait for their turn".

Many junior officials felt that there has been a frequent diversion of money allocated for training to fund other items. Although the extent of redirecting training funds may have been exaggerated, one senior official admitted that redirecting training funds to other areas has happened in several occasions when the department was facing a shortage of funds.

\section{Facilities for High Quality Policy Work}

Departments and their policy units require a good infrastructure to generate high quality policy work. Such an infrastructure comprises basic tools and facilities such as computers, a satisfactory information and communication network, a departmental library and support materials (such as paper and copiers). Of importance is the availability of the right kind of facilities (i.e., the need to maintain the required quantity) and the quality of such facilities (i.e., how well facilities are maintained).

A robust infrastructure was viewed as essential by virtually all the staff interviewed, as evident in the following statements by various officials:

The quality of our work will be aided by good facilities....

Without good facilities, we cannot give our best to the government

We realise that, what we need are good facilities. If we can improve our facilities, we would do a lot do a better than what we do now....

Generally, DF\&T has better facilities than the Department of Prime Minister and National Executive Council (DPM\&NEC) and the Department of Personnel Management (DPM). For example, DF\&T has a fairly modern office complex with each staff having a workstation, and in EPU virtually all the staff have a computer.

However, as the above statements indicate, the quality and quantity of the existing infrastructure were considered to be inadequate. As observed earlier, information management, and the storage and access to information fundamental to policy analysis work was rated as inadequate (both in terms of quantity and quality) by staff. The inadequacy of the present departmental library (in terms of storing up-to-date information) and a limited access to the Internet were also the focus of many 
criticisms. In EPU, for example, Internet access is limited to a few selected managerial staff. According to one official, this situation "reflects the current state of communication and information technology in many government departments" ... "for many departments having a very good Internet facility is long overdue".

Having a full research capability to mount detailed studies on policy issues, especially those of a substantive, strategic and cross-sectoral nature, was seen as essential by most policy staff. They recognised that DF\&T does not have the capability to mount in-depth research or long-range studies (including surveys) on policy issues. According to one senior official:

... government policy formulation may have been compromised over the years because of the department's inability to investigate in detail the causes and effects of policy.

Various causes contribute to this lack of research capability, many of which have already been noted - for example, problems of data management, a lack of research skills among existing staff and insufficient staff (especially within EPU) were some of the contributing causes.

Staff saw a lack of adequate funding to sustain both the quality and quantity of existing infrastructure as a key impediment. This view is reflected by the comments of a senior policy official:

Financial allocation to our unit has not been at the desirable level. We therefore value what we are given and try to utilise that as best as we could. There are many things we would like to have but unfortunately we can't have them due to the current budgetary climate.

A review of the department's spending on a prima facie basis appears to support the above observation. Table 6.5 summarises selected expenditure of the department between 1999 and 2001 in two key categories, current expenditure and capital expenditure. To use the language of the new managerial environment, such expenditures are devoted to the "purchase of inputs" perceived to be necessary in producing the relevant departmental outputs. 
Table 6.5: Selected Expenditure Items 1999-2002, DF\&T (in K’000)

\begin{tabular}{|c|c|c|c|c|}
\hline Expenditure Items & 1999 & 2000 & 2001 & 2002 \\
\hline \multicolumn{5}{|l|}{ Current Expenditure } \\
\hline Personal Emoluments & $5,851.7$ & $5,919.0$ & $7,151.3$ & $9,321.0$ \\
\hline Goods and Other Services & $10,016.3$ & $10,896.5$ & $6,859.8$ & \\
\hline Current Transfers & 529.6 & 243.2 & 462.8 & NA \\
\hline \multicolumn{5}{|l|}{ Capital Expenditure } \\
\hline Capital Formation & 733.0 & 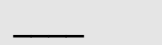 & $1,488.0$ & $1,001.1$ \\
\hline Total & $17,130.6$ & $17,058.7$ & $15,961.9$ & $19,261.3$ \\
\hline
\end{tabular}

Source: Finance \& Treasury, Estimates of Recurrent Expenditure 2001 (Volume 2 Part 1), 2002 Supplementary Budget (Volume 2 Part 3).

As mentioned earlier, the infrastructure supporting policy work is purchased from allocations under capital items. In real terms, the financial allocations for capital items as a percentage of total allocations for the entire department have fluctuated over the years (Figure 6.7). As was the case with training, some senior officials contended that allocations have not kept pace with the demands for improved infrastructure. As observed by one official, "many of our provincial treasuries are still without basic facilities".

Figure 6.7: Distribution of Funding to Capital Formation, DF\&T (\%)

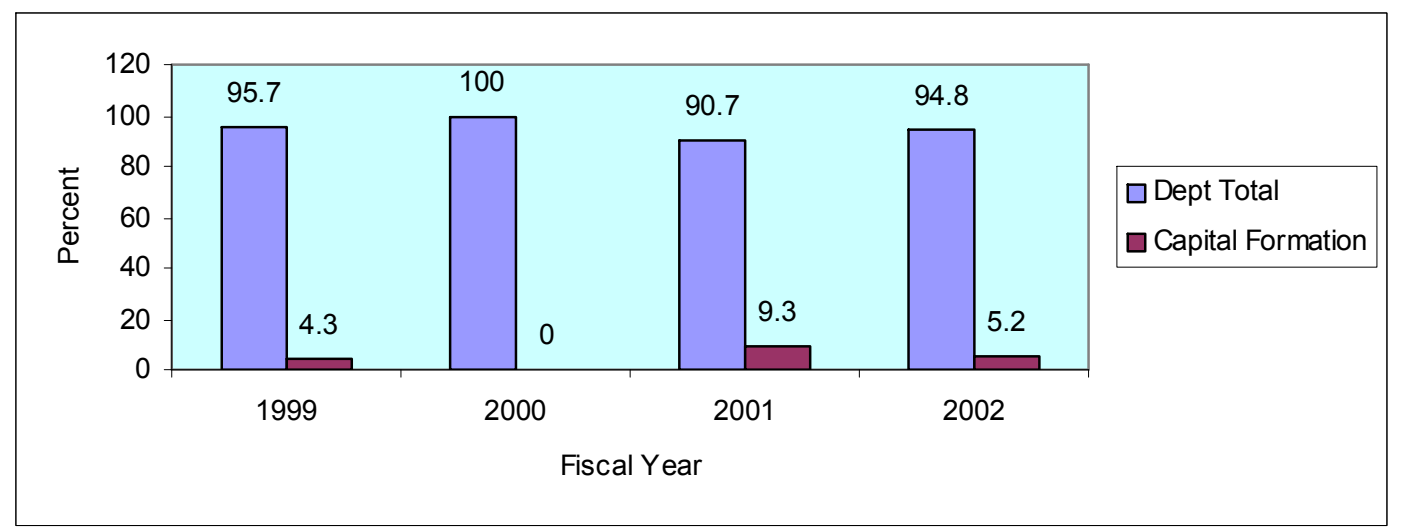

Source: Computed from Department of Finance \& Treasury, Estimates of Recurrent Expenditure 2001 (Budget Volume 2 Part 1); 2002 Supplementary Budget (Volume 2 Part 3).

Spreading capital funds too thin, which cannot adequately sustain the capability of one unit, has been a key problem facing DF\&T. Assuming for the purpose of illustration that allocations are distributed equally among the ten branches of DF\&T, the amount each branch would have received would be hardly enough to effectively sustain capital formation. For example, of the total allocations to DF\&T for capital 
formation, EPU would have received $0.42 \%$ in $1999,0 \%$ in $2000,0.86 \%$ in 2001 , and $0.52 \%$ in 2002 . The biggest allocation would have been in 2001 in which it would have received $0.86 \%$. The above figures are indicative and would be drastically reduced if funding for capital items in provincial treasuries were taken into account.

There has been a gradual rise in salaries, as shown in Table 6.5, from 34.1 percent (of total expenditure) in 1999 to 48.4 percent in 2002. Some policy officials saw this as having implications for the long-term sustainability of important facilities. One implication is that the increasing salary bill coupled with the ongoing difficulty faced by the government in raising revenue, will lead to funding cuts for important facilities. As one policy official observed, "the rising wage bill is a worry because there is a real possibility for a cut back in other areas". Some staff were of the view that outstanding commitments were likely to be left unfulfilled with some adverse consequences to the department. The sentiments expressed by a senior official in the Forecasting Section of the EPU reflect such a view:

We need the necessary software to construct economic models; but we don't seem to have money to purchase them...we do not have a comprehensive and up-to-date database for forecasting, and I must say this has affected our economic forecasts.

The real effects from the rising wage bill remain to be seen in the long run. However, if the funding for capital items for 2001 and 2002 is any indication, it shows that there has been a reduction from 9.3 percent in 2001 to 5.2 percent in 2002, the period when the salary bill was expanding. Furthermore, as shown in Chapter Two, there have been cases where departmental spending in other areas was cut as a result of the rising wage bill. Hence the fears expressed by the policy officials were not without any foundation. For example, in 19 provincial departments salary (as a component of total expenditure) had risen, from 71.3 percent in 2001 to 82 percent in 2003 with a corresponding reduction in operational spending (including the budgetary support for capital items), from 29.7 percent in 2001 to 18 percent in 2003 (DF\&T, 2002 Supplementary Budget, Volume 1).

Poor planning and a lack of prioritisation by senior management were seen as contributing to some of the inadequacies of the existing infrastructure. Some officials believed that with careful long-term planning selected facilities could be upgraded or bought over the years. Information and communication technology (ICT) improvement was cited as an example. According to one senior official, "had we 
committed funds for upgrade over a 2-3 year period, we would have a quality ICT system up and running...it would be a long process, but surely we would get there."

\section{Organisation of Policy Work}

An important tool in organising and assessing policy work within departments in the PNG public service is the corporate plan. By design, this plan is supposed to define what departments and their branches do, how they are going to achieve their intended performance targets and how they would report and account for their performance. In recent years the drive to have a good corporate strategy has been spearheaded by the DPM\&NEC and especially the DPM. For policy advice, ideally the corporate plan should be the principal instrument in which advisory outputs are planned, organised and delivered. In theory, proper planning of policy advisory outputs would have certain benchmarks against which the quantity, quality and timeliness of policy advice can be assessed.

The department uses a corporate planning process to identify its visions, goals and outputs and to demonstrate how its visions and goals are to be achieved in practice (see for example, the department's corporate plan, 1998-2000; 2001). This plan is comprehensive, describing clearly what the branches and their respective units are supposed to do and achieve.

As in other cases, the perception of staff about the usefulness of the corporate plan was gauged by their reaction to in several perception statements (P4-P6). There was a strong agreement among staff that the corporate plan is potentially a useful device for planning, organising and delivering policy advice. In general, reactions to the actual use of the corporate plan were somewhat negative. Most staff felt that it has not been effectively used as a device for guiding, reporting, and evaluating anticipated outputs in policy advisory work. For example, 62.5 percent of staff could see little benefit to policy advice in the current planning process in terms of evaluation (P8); another 50 percent did not believe that there has been any meaningful external evaluation done to assess the quality of policy advice (P9).

Although staff are guided by public service procedures, generally the work environment is informal: staff are required to use common sense and initiative; they formulate policy proposals, or comment on drafts or policy submissions using their prior knowledge of issues and best judgement. There are no set targets for policy work; rather staff take policy work "as it comes", and the expectations they have 
about policy work therefore vary from one official to another. Feedback on policy work among superiors varies; there was some mention of peer review but this was not viewed as part of the formal process of assessing policy work and therefore depends on individual initiative rather than being a standard practice. Asked whether there were any expectations of them in terms of the way they should perform as policy analysts and researchers, and whether they are held accountable for their performance on policy advisory work, many commented that they are only aware of those expectations that are set out in their Duty Statement. However, many were unaware of specific expectations for policy-related work. Neither were they aware of anyone being specifically held to account in respect of the policy work they have produced.

Disenchantment over poor leadership and organisation of policy work came out strongly from several officials. This has been evident, for example, a failure to set high performing goals and a lack of setting benchmarks to guide, monitor and evaluate the quality of policy advice. Some officials clearly felt that the standard of leadership in policy work could have been better than it is. According to one official, some officials who have been appointed to head sections or units within the department either "lacked the experience or lacked adequate skills to manage policy work".

\section{External Context of Policy Advice}

Discussion on the external political context of policy advice in Westminster systems was discussed in Chapter Three. A significant point in that chapter was that policy advice is shaped, apart from administrative and organisational factors, by the relationship the minister has with his or her department regarding the provision of policy advice. A key aspect of the relationship between official advisers and the minister involves ministerial expectation of performance of policy work. In particular, officials in any lead policy unit require clarity in ministers' statements and good policy directions so that they can organise policy work around the desired vision of the minister. In the Westminster tradition, it is the minister who communicates the expectations and desires of cabinet; public servants are generally expected to provide policy advice within the framework set by the minister. High expectations by the minister in respect of policy advice are also necessary to provide the kind of incentives staff require to produce reliable and comprehensive policy advice. Officials' rating of the extent to which the minister communicates the required 
expectations in policy advice (P2) were split, with half agreeing and another half disagreeing with the view that ministerial communication has been effective.

There was a general feeling that clarity in policy decisions and effective communication depends very much on individual ministers. The minister of finance, between 1999 and July 2002 who was also the Prime Minister, was seen to be doing a good job, whereas those before him were difficult to deal with. On balance, the general impression was that many past ministers have kept a significant distance from bureaucratic advisers; communication was poor and policy direction was lacking.

As explained in Chapter Two, PNG has a volatile political climate. There was a strong concern about the sudden decisions taken at the political level in macroeconomic and fiscal policy, which often send mixed signals to different stakeholders. Some staff mentioned that in such situations they cannot be sure of the nature of advice to be provided because the policy focus of government often changed without notice. Others mentioned that there has been a tendency for the advice of the department to be circumvented rather than DF\&T being a key participant for providing policy advice to politicians on matters of macro-economic policy. This perception is shown in the following statement made by a senior official:

There is a reason for our [EPU] existence. If certain key policies are taken without our advice, I am afraid we will have to pay dearly for those policies that are politically driven.

The demand for policy advice at short notice has often compromised the comprehensiveness, quality and reliability of policy advice. According to some officials this problem has often been made worse when there is already a high workload and fewer staff.

Virtually all the staff interviewed felt that there is a high degree of political interference generally in the public service in PNG. Equally, many did not believe that operational and management matters are shielded from politicians; rather ministers and cabinet can act capriciously and impose their wishes on departmental operations. Comments on some aspects of fiscal policy management reflect some of the tensions between politicians and bureaucratic advisers, and the difficult position staff working in lead policy units like the EPU often find themselves in. One official mentioned that sound advice on deficit reduction often fell on deaf ears because of 
the spending commitments of politicians. In several cases, decisions made to commit funds came after the formulation of the budget, and despite prior advice not to commit funds. In the comment of one staff, "it is often frustrating working under such a situation."

One area that received a lot of comment was the volatile situation facing the appointment of departmental heads. Nearly everyone interviewed in DF\&T saw this as having a negative impact on the performance of departments and their respective heads. This line of thinking is reflected in the following comment:

You know as well as I do that the constant change of departmental heads is a big issue in the country. Even though this has demoralised our public service, I don't think this will change anytime soon.

Asked whether they perceived the current situation as likely to affect their own departmental head, almost all those interviewed were of the view that their departmental head is not immune to political interference; he like others can be replaced if political masters decide to do so. Thus, there was a general perception that politicians could replace their departmental head at any time. According to one senior official:

You wouldn't want to be in a situation where constantly you are looking over your shoulders, always cautious in what you do and knowing that you can be out the next day.

There was a general agreement that offering free and frank advice is unlikely to strictly follow the classical Westminster model given the volatile political climate in which many departmental heads are placed. Some staff did not believe that departmental heads have always given advice without fear or favour. Furthermore, some did not think ministers understand and appreciate the concept of free and frank advice and its importance, and therefore are likely to view countervailing advice from their departmental heads or their department as threatening or questioning their wisdom.

Views expressed on ministerial responsibility reflect the above apprehension. Some of those interviewed saw ministerial responsibility as necessary in shielding the departmental head while the minister takes responsibility for what happens in the 
department. Equally, however, they saw that ministerial responsibility has not really been followed in practice in PNG. There was a common view that the minister is unlikely to take responsibility for the mistakes of departments and their heads, and that advice offered by the department may be questioned once decisions are taken. This may bring about a situation where departmental heads are taken to task even after the minister accepts the advice ${ }^{40}$.

\section{Conclusion}

DF\&T is the largest department of the three agencies analysed in the present study and is no doubt one of the most powerful central agencies within the PNG public service. As is the case with similar departments in other Westminster jurisdictions, its decisions permeate the entire government machinery and the advice it provides to cabinet has a significant influence on public policymaking. Such an influence has been a consequence of a variety of statutory controls, which DF\&T assumes: the most important one being its statutory control over PNG's public finances.

By comparison DF\&T is better resourced than DPM\&NEC and DPM and therefore may have an edge over the two other agencies in terms of capability. This notwithstanding, the analysis in this chapter shows many inadequacies of the department which need remedying. To some extent the issues faced illuminate the problems confronting many central agencies in the developing world discussed in Chapter One. That is, while such agencies possess immense power and authority, they cannot exercise such authority effectively because a range of problems weakens their capability to do so. In the case of DF\&T, it has been evident in this chapter that despite its overarching, statutory powers over the policymaking framework of the government, its capability is lacking in various ways. In serious doubt is the ability of department to provide quality and timely advice to policy clients in a decisive and comprehensive manner.

\footnotetext{
${ }^{40}$ The issue of who should be responsible for advice after the minister accepts is a "grey area". However, as noted in Chapter Three, ministers can accept, reject or vary advice. Further, they can ask for new advice if in their view existing advice is unsuitable. But once advice is accepted and therefore is used for policymaking purposes, the minister assumes overall responsibility and accountability for actions taken on that advice.
} 


\section{Chapter Seven: Department of Prime Minister and National Executive Council (DPM\&NEC)}

\section{Introduction}

As observed in Chapter One (and to a lesser extent in Chapter Two), the lack (or loss) of capability in the PNG public service appears to be widespread, although as noted in Chapter One, evidence showing this to be the case is largely anecdotal. Thus one objective of this study is to determine the extent of this assessment focusing on the capability of the three central agencies to provide quality policy advice. Using the perception of policy officials and measured against the key elements of capability noted in Chapter One, this chapter will explore how the provision of policy advice has weakened in the Department of Prime Minister and National Executive Council (DPM\&NEC) and the factors that contribute to it. The chapter begins with a brief profile of DPM\&NEC, discussing how the variety of roles the department performs shapes the organisation of advice.

Unlike the Department of Treasury and Finance (DF\&T) discussed in the previous chapter, the Department of Prime Minister and National Executive Council (NEC) is, as the name suggests, very closely connected with the Prime Minister and cabinet (NEC). By design, DPM\&NEC has key characteristics of many similar agencies found in the Westminster system: it serves the policy needs of the chief executive of the executive branch (the Prime Minister) and cabinet and is the chief adviser to government on all matters of policy. Combined with these is the role of the department within the PNG public service as a "lead central agency" and "the leader", responsible for "providing leadership of the central agencies of government" (DPM\&NEC, 1999:4). On this basis it can be argued, that DPM\&NEC is more powerful than the two other principal central agencies (DF\&T and DPM).

The DPM\&NEC has undergone some major reorganisations since 1999. In 2000, the cabinet (Decision No. 10/2000) directed that a specialised unit, the Public Sector Reform Management Unit (PSRMU), be established within DPM\&NEC. PSRMU structurally is part of the DPM\&NEC and reports administratively to the secretary of DPM\&NEC. It is headed by a Director General who holds an executive position at the secretary's level (Exec.6), and is assisted by programme managers, programme coordinators and a group of consultants funded by donor support. 
The department sees PSRMU as an "implementing agency" (DPM\&NEC, 2000: 12); however, in practice, it is principally a policy formulation and coordinating body, responsible for aspects of managing and coordinating the ongoing public management reforms. In terms of policy advice, it was envisaged initially that the unit would be a leader in supplying substantive and strategic policy advice to the Central Agencies Coordination Committee (CACC) and cabinet on issues of public sector reform.

The creation of the CACC by the NEC in 2000, including its empowerment as an executive committee of cabinet, is another reason why the DPM\&NEC was restructured. The powers of CACC were consolidated through the enactment of the Prime Minister Act in 2002 (see s24 of the Act). This Act provides for the composition of $\mathrm{CACC}^{41}$ and elevates the secretary of DPM\&NEC to be the Chief Secretary to Government and Chairman of CACC. The adoption of this legislation has ensured that the CACC is a key actor in policy formulation; its position as the executive committee of cabinet at the bureaucratic level has meant that nothing goes to cabinet without its approval or recommendation. Structurally, the CACC is independent, but is attached to DPM\&NEC for reasons of maintaining policy and administrative coordination in managing the government machine.

\section{Organisation of DPM\&NEC}

The Prime Minister's Department consists of a web of divisions and branches and has under its umbrella a number of secretariats and semi-independent units. Figure 7.1 outlines the organisational chart of the department, reflecting the two main divisions of the department.

\footnotetext{
${ }^{41}$ The CACC members are the Chief Secretary and Head of DPM\&NEC, Secretary of Treasury, Secretary of the Department of Personnel Management, Secretary of Provincial Affairs and Secretary of the Department of Attorney General.
} 
Figure 7.1: Organisational Chart of DPM\&NEC

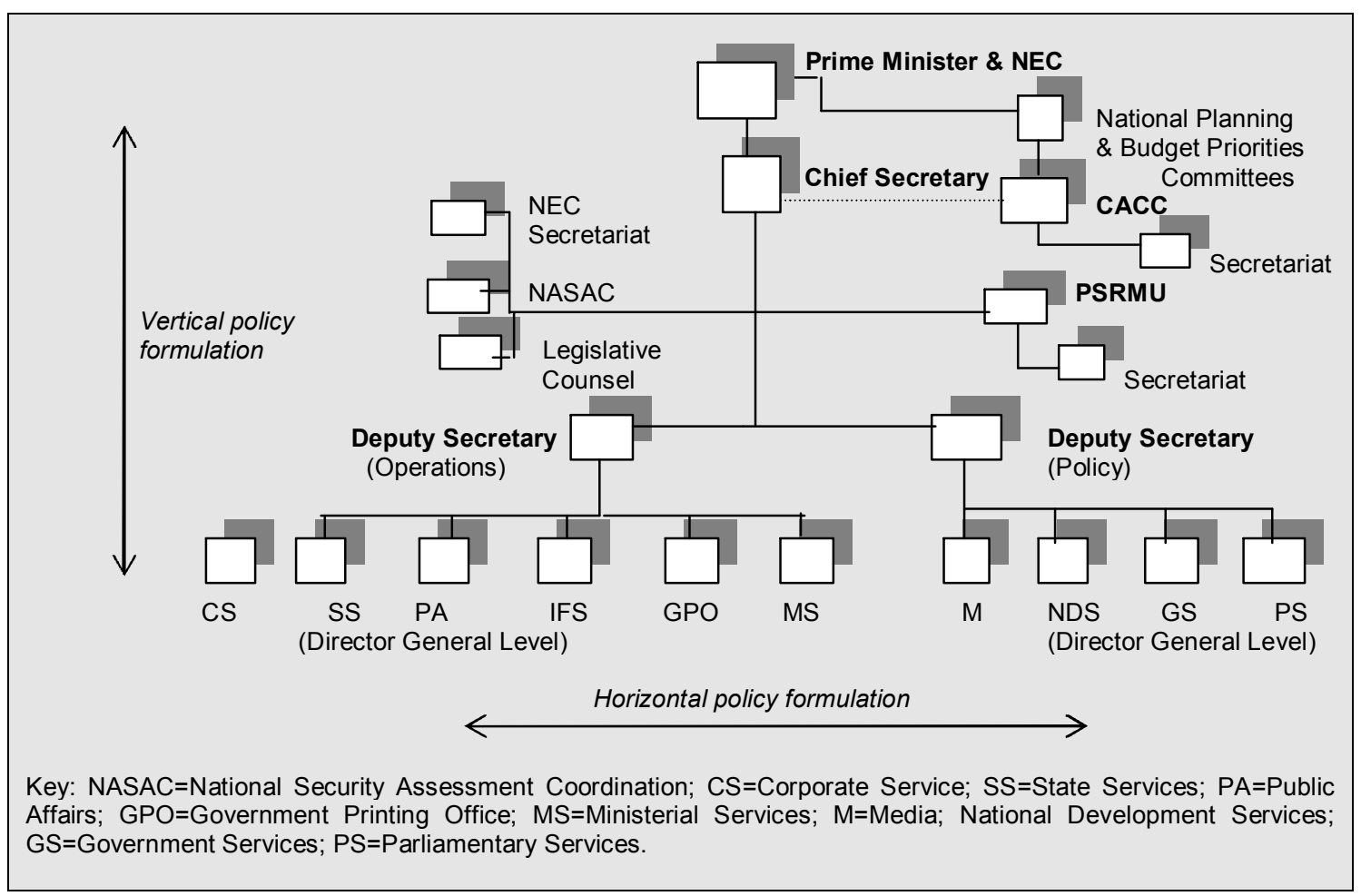

The core units of the department are the Policy and Operations Divisions, each headed by a Deputy Secretary. Policy work whether in operational, substantive and strategic policy is mostly done by the Policy Division. The Operations Division plays a support role taking care of the in-house administrative matters of the department. In addition, there are specialised units that deal with specific issues mandated by the Prime Minister and NEC, which are housed within the department and report to the Prime Minister and NEC via the Chief Secretary. These are the National Security Assessment Coordination unit (NSAC), the Legislative Counsel and the NEC Secretariat. As already explained, the PSRMU and the CACC are entities established to pursue specific policy mandates on public sector reforms and on advising NEC respectively. Although formally this is the case, they are part of DPM\&NEC and their advice is provided to the Chief Secretary who is then expected to advise the CACC and NEC accordingly.

\section{The Chief Secretary}

Under the Prime Minster Act 2002 the Chief Secretary to government is allocated a powerful role on all matters of policy. He sits on virtually every influential committee being the chairman of the CACC and the NSAC; he also oversees the NEC's secretariat. He is not only the chief adviser to the government. In practice, he 
oversees the performance of all the departmental heads including the heads of other central agencies and plays a powerful role in determining their appointment or removal (Taimbari, 2003). This role was reinforced by simultaneous changes in the Public Service Management Act (PSMA) in 2002 giving wide-ranging but specific powers to the Chief Secretary as the Chairman of the CACC. Two specific provisions in the amended PSMA exemplify the large powers vested in Chief Secretary:

The Head of State, acting on advice, given after consideration of recommendations made by the Chairman of the [CACC] in conjunction with the [Public Service Commission (PSC)], may make regulations prescribing standard criteria and procedures for the regular appraisal by the [CACC] of the performance and discipline of Departmental Heads [s24A (1)].

The Chief Secretary to Government, after consultation with respective ministers, shall, through the Departmental Head of the Department of Personnel Management, provide to the $[\mathrm{PSC}]$, in the prescribed manner, regular appraisals of the performance and discipline of Departmental Heads (other than himself) who are members of the [CACC] and the [PSC] shall take such appraisal into account in making its recommendations in relation to the appointment of such Departmental Heads [s24A (3)]. ${ }^{42}$

Particularly worthy of note is the influential statutory role of the Chief Secretary in respect of the appointment process (including termination) of departmental heads and his colleagues within the CACC. He (or she), for example, can set standards (or regulations) for the monitoring and evaluation process of departmental heads. Although the Act specifically provides for a consultative process with the PSC, to date there is neither a set process nor standards in place defining how the Chief Secretary is to discharge his responsibility for appointing or assessing departmental heads. This situation allows the consultative process to be easily circumvented, especially in situations where the PSC is slack in performing its role (as is the case currently) (see Mellam and Aloi, 2003; Sause and Aloi 2003). Also, given the current environment in which the public service is said to be highly politicised (Windybank and Manning, 2003), the consultative process between the Chief Secretary and ministers is likely to be taken advantage of to aid the partisan interest of ministers and the Prime Minister (for example, in appointing individuals who are closely associated with parties controlling the executive branch).

\footnotetext{
${ }^{42}$ Section 24A (4) provides for the PSC to carry out "regular appraisals of the performance and discipline of the Chief Secretary" in consultation with the Prime Minister.
} 


\section{The Department's Role in Policymaking}

DPM\&NEC plays a pivotal role in policymaking as the lead central agency of government and is the principal adviser to the Prime Minister and the NEC. The department's Corporate Plan notes its overarching role as, "to provide leadership and coordination necessary at the public service level for the development and implementation of government directions and policies (DPM\&NEC, 1998; 2000). A significant aspect of this role entails "providing quality advice, information and support to the Prime Minister as Head of Government and Chairman of Cabinet" (DPM\&NEC, 2000: 4). In order to do this, the plan notes that, "the department must work closely with all the public sector institutions, ministries, national and provincial departments, constitutional offices, statutory bodies, government owned commercial bodies as well as churches and private sector and community" (DPM\&NEC, 2000: 5).

As the principal department responsible for the effective operation of the government machine, DPM \& NEC is required to provide the necessary leadership in assisting the Prime Minister and the NEC in mapping out the strategic intent of government in the medium to long term. Such a responsibility not only entails working with the Prime Minister and the cabinet in defining the outcomes sought by the government but also involves liaising closely with other central agencies and line departments to ensure that the government expectations are communicated clearly and incorporated into the departmental planning process. As the premier agency responsible for advising the Prime Minister and NEC on all matters of policy the department is in a very powerful position for assessing advice (or policy submissions) coming from other departments. This position allows the department to have the last say, prior to CACC and NEC's deliberation, on virtually all advice offered to ministers.

As with analogous departments in other Westminster systems, the task of policy coordination - aimed at maintaining policy coherence across government - and managing crosscutting issues transcending departmental boundaries remain central to DPM\&NEC's many responsibilities. In administrative coordination, DPM\&NEC is responsible for ensuring that the implementation of policy by departments culminates in achieving the desired outcomes sought by government. This role also involves assessing impacts of government programmes on the community and advising government of such impacts and providing the relevant steering across the broad spectrum of government to maintain unity of action. Managing crosscutting policy involves providing the required leadership among departments to solve overarching issues that transcend departmental boundaries. This requires pulling together 
departments, determining how departments should best work together to solve the issues in question, coordinating the efforts of those who are involved, and ensuring that effective strategies are found to address such issues. This role may also require formulating advice arising from cross-departmental work to relevant authorities.

There has been a noticeable change in the role of the department since 2000, from largely a policy formulation and coordinating agency to being an agency that is responsible for a variety of implementation functions. This has been particularly evident in areas such as the increased role of the Chief Secretary in monitoring and evaluating the performance of departmental heads, the creation of the CACC and in monitoring and evaluating ongoing public sector reforms through the PSRMU.

There is what appears to be a corresponding decline in the influence of the Department of Personnel Management (DPM) in some areas. Certainly the new dominant role of the CACC and its Chairman, the Chief Secretary, in performance evaluation raises questions about the current roles of DPM (the agency traditionally vested with the function of performance evaluation) regarding the management of departmental heads - and perhaps the Public Service Commission (for further discussion see Chapter Seven).

The changes brought about by the Prime Minister Act 2002 and amendments to the Public Service Management Act 1995 have ushered in new challenges for DPM\&NEC. For example, as has been explained above, the department is required to take an active role in performance evaluation of departmental, something it has little or no experience in doing. The department is also expected to steer policy and perform its advisory function more effectively now that its head, the Chief Secretary, in the Chairman of the CACC. The small secretariat of the CACC raises questions about how the secretariat will handle its many tasks. Suck a lack of capacity of the CACC's secretariat is likely to require other units in DPM\&NEC to shoulder much of the secretariat's responsibility.

\section{The Policy Division}

Most of the policy work associated with policy analysis and the subsequent production of policy advice is concentrated in the Policy Division. Headed by one of the two Deputy Secretaries, the division is relied upon by the Chief Secretary, and until recently the CACC, on all matters of policy. Its head, the Deputy Secretary of 
the Policy Division, assumes the Chief Secretary's position when the Chief Secretary is absent.

The Division comprises four specialised units: National Development Service (NDS), Government Service (GS), Media, and Parliamentary Service. The NDS and GS are the lead policy units of the division and therefore the department, whereas the Media and Parliamentary Service units perform support and administrative roles - i.e., in media liaison and supporting the Prime Minister and NEC during parliamentary sessions.

Figure 7.2 shows the two lead policy units, the National Development Service (NDS) and Government Service (GS), responsible for much of the policy work within the department

Figure 7.2: Lead Policy Units-DPM\&NEC

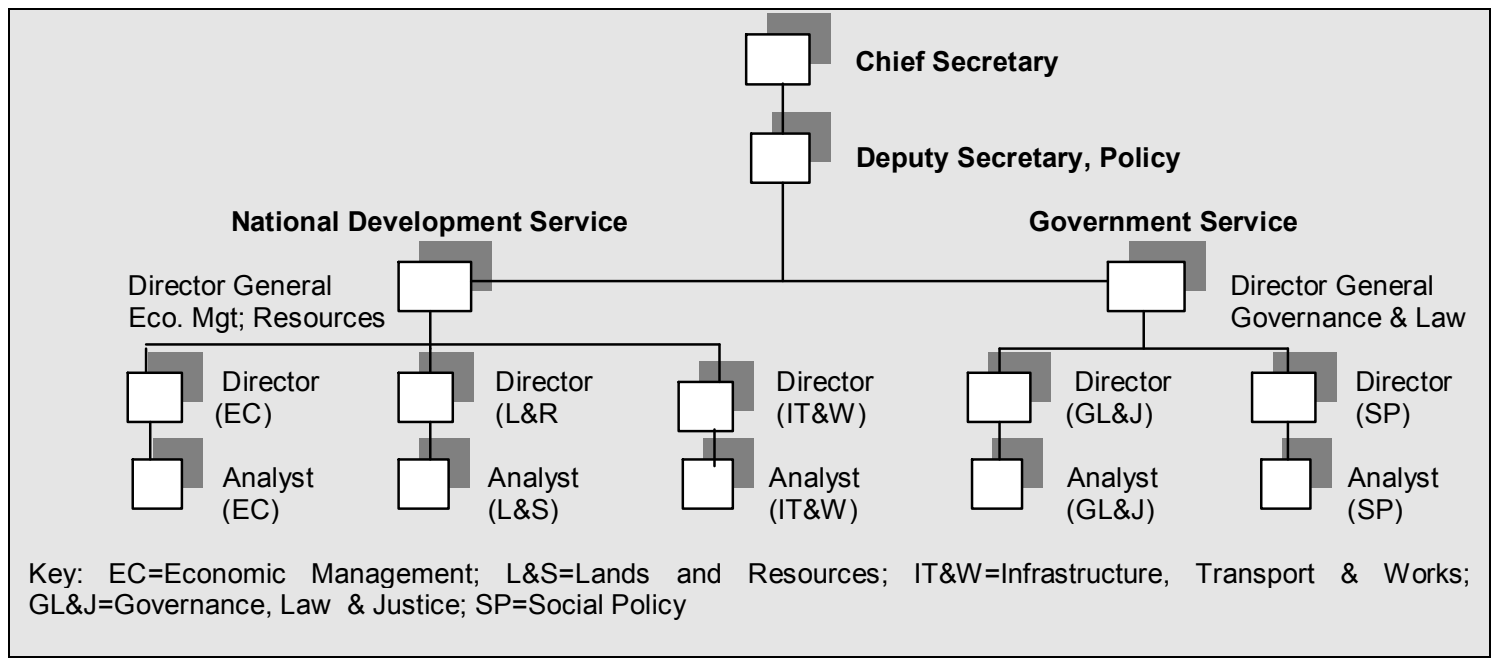

The Policy Division is responsible for coordinating policy and providing advice on key sectors including economic management, lands and resources, infrastructure, works, governance, law and justice and social policy performs its tasks both vertically and horizontally. It performs its tasks both vertically and horizontally. Vertically, other units and line agencies report to it and liaise with it on matters of policy. Its analyses of policy work and the subsequent advice are communicated to the Chief Secretary - and often NEC and CACC - via the Deputy Secretary. The delegation of duties and responsibilities follows the same vertical channel. Horizontally, it works with other divisions, branches and units, and the PSRMU and CACC secretariat within the department. It also works horizontally across departments and provincial administration to monitor and coordinate government policy. 


\section{DPM\&NEC's Performance}

There is an overwhelming belief among staff that the department is the lead central agency and therefore plays an important and strategic role in both the policymaking framework of the government and the operations of the entire government machine. For example, responses from staff in the survey to the perception statement one (P1) reveal a strong view that the department plays a vital role in providing policy advice to the Prime Minister and cabinet.

But the perceived centrality or importance of roles does not always correspond to what organisations do in practice. Thus, one of the aims of the survey was to gauge the perceptions of staff about the overall capability of the department in organising and delivering policy advice in practice. As was the case with DF\&T, this was elicited through two perception statements (P13 and P14). Perception statement 13 asked respondents to state whether there is capacity in DPM\&NEC to organise and tender policy advice in the required quantity, quality, cost and timeliness. Perception 14 asked respondents to state whether they are satisfied with the overall performance of their department in supplying policy advice.

Only a few staff believed that the department has a strong capability in organising and delivering policy advice specifically in areas of quantity, quality and timeliness. For example 28 percent had agreed that capability to provide quality and timely policy advice exists, while 72 percent had doubts and therefore disagreed or strongly disagreed. A similar response to DF\&T was received for P14 in that there were doubts expressed about the overall capability of the department. Overall, while P13 showed an overwhelmingly negative view regarding capability, P14 had registered a mixed feeling among staff about performance, but nevertheless revealed strong reservations.

It is pertinent to note that most staff acknowledged the important contribution of their department to the overall policymaking framework of government, to policy coordination, and the department's role in advising the Prime Minister and NEC. However, they also registered their belief that they are doing their work within constraints that bear heavily on their performance. 
The following statement from one of the DPM \& NEC officials reflects some of the problems encountered:

Just look at me; I have a computer here and it is not connected to the net. We have too little information and it is difficult to know what is going on within line agencies and departments, despite the fact that we are supposed to effectively coordinate government policy.

Another official had the following comment:

I am a newcomer, but looking at our minimal staff, we are stretched too thin and I don't think we can do a good job.

Some officials questioned the logic behind giving the department more responsibilities. There was a view that the new responsibilities are likely to compound existing problems of managing and coordinating policy. For example, not only is the department relatively small, which raises prima facie questions about its capacity, but its location only in Waigani means that it constantly faces logistical difficulties in dealing with isolated provinces. Unlike the Department of Finance and Treasury which has offices located in the provinces, the DPM\&NEC does not have a local presence; it therefore has to maintain contact with each provincial administration from Waigani. Also, the sheer size of the public sector has its own challenges in terms of vertically and horizontally monitoring and coordinating policy. From fewer than 15 departments at independence in 1975, the public sector has grown to 40 line departments and agencies, 20 provincial administrations and a range of semi-independent entities. As the lead central agency responsible for maintaining policy coherence, DPM\&NEC needs at one time or another to deal with all these organisations, which vary both in size and functional responsibility.

Several officials considered that the new tasks contained in the Prime Minister Act of 2002 and the creation of the PSRMU might have also posed problems of implementation. One official describes it this way:

The Act [Prime Minister Act 2002] provides for the department through the Chief Secretary to prescribe the standard criteria and guidelines for the regular appraisal of departmental heads. But we do not have that in place... and it is difficult to imagine how that will be done. 
Another official (specifically referring to the PSRMU) notes:

While over the years a variety of public sector reform initiatives have been implemented right across government, we don't know how they have progressed because we do not have the capacity to evaluate their impact. The creation of PSRMU, though a step towards the right direction, still lacks qualified personnel. I think PSRMU will face the similar obstacles [in evaluating the impact of the reforms]...one concern is, it needs to sort how it is going to coordinate the existing [reform] programmes currently being implemented....

The new role of managing the appointment and termination process of departmental heads also raises questions about how best to organise the department so that it can effectively perform its tasks. Senior officials, for example, were of the view that the existing structure was designed primarily to manage, monitor, evaluate, and coordinate overarching policies and to advise the Prime Minister and NEC accordingly: it was not designed to "manage top civil servants whose appointments are regulated by various legislations and general orders of the public service" (excerpt from interview). There was a view that the failure of the department to reconfigure its structures to accommodate its new role is likely to undermine the process of appointment rather than strengthening it. For example, without the necessary administrative support from the department the Chief Secretary is unlikely to be able to perform his role effectively. In particular, the situation pointed out by the official quoted above is likely to impede cabinet determination on the basis of integrity, experience and qualification:

If there are no relevant criteria guiding the process, the process can be abused. The Chief Secretary may recommend to NEC a particular appointee but that may be not based on merits. NEC's need for fair and honest advice may be compromised (another senior official, excerpt from interview).

The new role of DPM\&NEC (regarding the appointment of the departmental heads and head of central agencies) has also given rise to concerns among some policy officials who saw the task as moving away from the department's key role of maintaining policy coherence. Faced with myriad tasks and with inadequate capacity, the department is unlikely to be effective in discharging all its tasks. 
There was a view among officials that changes in the PSMA have created overlapping responsibilities and are likely to result in duplication and rivalry between the CACC and DPM\&NEC on the one hand and DPM on the other. For example, while traditionally such a responsibility was vested with DPM, the amended PSMA has made monitoring and evaluation a joint responsibility between the CACC and DPM (section 24(2) of the Act). Officials were not quite sure how the two different entities would perform this role. There is a potential for conflict until clear guidance (on how the joint responsibility is to be carried out) is put in place. There is some indication in 2003 that CACC is now taking charge of that role - although questions relating to its capacity (to undertake this role) and how DPM is going to fit in the picture remains.

The increasing role of the CACC is evident in a recent announcement (in March 2003) by the Chief Secretary as reported by The National newspaper:

Heads of central government agencies, departments and statutory authority bodies have been warned to start delivering results or ship out. In a firm and blunt message, Chief Secretary to Government, Joshua Kalinoe, told the top officials they have a duty to the people of this country. All heads will now be required to front up at the Central Agencies Coordinating Committee and present progress reports on policy implementation on a quarterly basis or when required starting this year. Mr Kalinoe said the all-important CACC role would now include regular monitoring (Taimbari 2003, 'Top government officials told to deliver results")

Coordination difficulties were seen by those interviewed as a key problem right across government. This has brought about difficulties in maintaining policy coherence, evaluating the impact of policy, and proposing policy intervention measures. This has, in turn, made difficult the task of advising on the progress and development of key policies. A long-standing failure by management to deal effectively with coordination problems was seen as contributing to current coordination difficulties:

Our problem has been one of cooperation among the central agencies and line departments and agencies. It has not been at a level that we expect. Now that we [DPM\&NEC] have assumed increased responsibility over the coordination of government policy, we need to increase our efforts in improving cooperation among departments (Senior official, excerpt from interview). 
Working in isolation, little exchange of information, and poor interdepartmental cooperation were also identified as contributing to the coordination problems of the department. A failure by DPM\&NEC top management to assert its steering function over the government machine was seen as the single most important factor contributing to many coordination problems encountered by the department and right across the government. A senior official explains it this way:

What is experienced today is a reflection of us losing control over the operations of the government. If we insist that departments must provide information; if we pull departments up and ask them about what they have been doing in the policies they have been implementing; if we demand and make sure departments cooperate with one another; if we pull slack departmental heads up and tell them that the Prime Minister and NEC will hear about your performance... we would solve half of our problems. We have not been doing that...you see the results are obvious...each department thinks they can do what they want.

Generally, most staff acknowledged that DPM\&NEC does not have the capability to fully maintain its functions - in strategic policy formulation, assessing and evaluating policy submissions and advice emanating from other agencies and line departments, pulling departments together to work toward achieving the desired goals of government, managing cross-cutting policies, and in monitoring and evaluating the impact of overarching policies and advising the government accordingly. Such a lack of capability has been blamed on a lack of resources and staff, poor facilities, financial constraints and inadequate skills and expertise.

\section{Policy Staff}

The department has a staff of 212 (DPM\&NEC, 2001 Budget Estimates) - this figure includes the staff of the CACC and NEC secretariats and the PSRMU. Of the 212 staff, 120 officials were working for the Policy and Operations Divisions in 2001 (DPM\&NEC, 2001). Within the National Development Service (NDS) and Government Service (GS) there were nine staff working in various capacities. All of them are positioned between grade 15 and Grade 19 (Table 7.1). 
Table 7.1: Policy Staff by Position, DPM\&NEC

\begin{tabular}{lc}
\hline Staff Category & Percent (\%) (N=9) \\
\hline Head of Policy Unit (Director General, Grade 20) & 22 \\
Section Heads (Director, Grade 17) & 56 \\
Senior Analysts (Grade 15-16) & 22 \\
\hline
\end{tabular}

The majority of staff (56\%) are at the Director's level effectively being remunerated at grade 17 , which carries a minimum base salary of K35, 000 per annum. This level of remuneration is relatively higher than earned by the incumbents of equivalent rank, that is, assistant secretaries, in the two other central agencies. ${ }^{43}$

All the positions in NDS and GS are classified at senior levels; the minimum rank is at the senior analyst level, at grade 15 . This does not necessarily mean that all the staff have a wealth of experience and are highly qualified. No doubt these factors were taken into account when they were recruited. However, the main reason why NDS and GS have relatively senior positions is because of the perceived importance placed on DPM\&NEC as the lead coordinating body and as the lead agency in advising the Prime Minister and NEC on policy matters. The justification was that those who play the advisory and coordinating role in this important department must carry a higher position and hence a higher level of remuneration, commensurate with the role they play and the standing of the department.

Survey data show that the largest category of staff $(42.8 \%)$ have between 3 to 5 years of work experience in the department. Almost half of the staff have previously held jobs in other government departments prior to taking up positions with the department. The majority of staff were aged between 31 and 35 years. A few were slightly below age 31 , and one was over 36 years of age. Overall, most policy staff were mid-career officers and generally would have finished their basic university education in the mid-1980s. Table 7.2 summarises the work experience of staff from the survey data.

\footnotetext{
${ }^{43}$ For example, at Grade 19 a Director General in DPM\&NEC would earn 11 percent more that those holding equivalent positions (i.e., First Assistant Secretary) in DF\&T and DPM.
} 
Table 7.2: Work Experience of NDS\&GS Staff, DPM\&NEC

\begin{tabular}{lll}
\hline No. of Years & \multicolumn{2}{c}{ Work Experience (\%) (N=7) } \\
\cline { 2 - 3 } & DPM\&NEC & Current Post, NDS\&GS \\
\hline $0-2$ & & \\
$3-5$ & 14.3 & 28.6 \\
$6-8$ & 42.8 & 42.8 \\
$9-11$ & 28.6 & 14.3 \\
$>11$ & 14.3 & \\
\hline
\end{tabular}

Strengthening the operational capacity of the department was identified as a key issue by virtually all those interviewed. In particular, shortage of staff was seen as a major obstacle. This problem is more acute in NDS and GS. At the time of carrying out the fieldwork (2002) NDS and GS had 15 established positions, but only nine were filled. There was a perception that the establishment of 15 positions was based on a gross underestimation of the types of functions the department (and especially the NDS and GS) is required to undertake. Increased responsibilities, the need to service the CACC, the demand for coordination across the broad spectrum of the public sector (including monitoring and assessing the impact of ongoing public sector reforms), and the need to provide advice to the Prime Minister and NEC require the department to respond effectively and in a timely fashion. One of the proposed solutions is to re-deploy staff to NDS and GS from branches and units with a smaller workload or from units the focus of which is not really on the department's core responsibilities:

The lack of capability to steer the government machine, for example, was attributed to fewer staff facing more pressing and demanding responsibilities. This is reflected by the observation of a senior official:

Part of the reason why we have lost control is because we have fewer staff. We are told to coordinate policy and give the required directions, but what can we do with only a few staff?

Inexperience of staff was also an area of concern among senior officials. Inexperience is not so much related to the lack of exposure to working in the public service; the majority of those employed have moved on from previous jobs in the public service. Rather the concern was about getting to know the changing tasks of DPM\&NEC and being able to carry out the required responsibilities in an effective 
manner. As noted earlier, this difficulty is compounded by the new roles imposed on the department by the Prime Minister Act of 2002.

According to one official, the tasks in DPM\&NEC were "more demanding" than he had initially perceived. Working to meet deadlines, providing comprehensive and reliable analysis on issues, good knowledge of government processes, and having an excellent knowledge of policy issues were some of the requirements regarded as important by those interviewed. Most of these attributes are developed through work experience for considerable periods; time can be wasted, therefore, on new staff, especially when the lead-time to get to know the job and the requirements that come with it is longer than estimated. This has been the case with some staff of NDS and GS. There is a strong concern among those interviewed that a lack of experience, especially in the crucial areas identified above, may have undermined the policy capacity of the lead units.

Concerns were also raised about the general work environment, which according to some policy analysts, should be aimed at nurturing the experience necessary to cope with the given tasks. Some analysts are still trying to find their way in their job. The big challenges therefore include the need to understand the nature of policy work within the units, how to work better and produce the expected outputs, and how to organise and coordinate policy advice with staff of other units and branches, and within line departments and agencies. Efforts to respond to these challenges, according to those interviewed are impeded by inadequate flow of information, a lack of engagement and liaison with other central agencies, and poor capacity to organise policy work.

\section{Knowledge, Skills and Expertise}

The post-graduate degree is the highest type of qualification held among staff. Among those holding a Bachelors degree, the majority were from social sciences and humanities. Figure 7.3 shows the distribution of qualifications on the basis of three broad categories_-bachelor, post-graduate and extra skills. 
Figure 7.3: Distribution of Qualification by Major Category, NDS\&GS (\%)

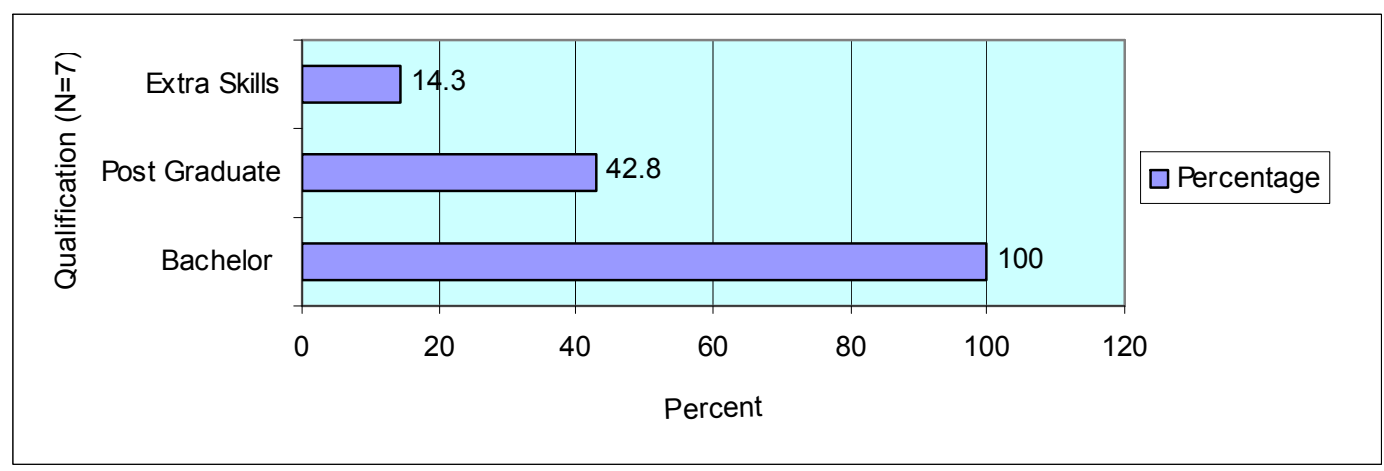

Almost everyone at the policy analyst level believed that they need extra qualifications and skills to be able to do their current work effectively. One important area, which was noted in the interviews, was the need for additional skills in research and on data analysis focusing specifically on the areas for which policy units are responsible. Most junior staff felt that their ability and confidence in carrying-out work on substantive and strategic policy would be aided if they had additional knowledge and skills in policy analysis. There was a general feeling that the basic knowledge and skills acquired from undergraduate degrees do not really provide staff with the necessary "tools" for undertaking policy work in a real and practical environment. According to one officer,

The undergraduate degree, though useful, is generic. Staff would need to reorient themselves to the specifics of the job once in the job. Often the job requires more skills than what is taught at the undergraduate level.

Getting the best results from existing qualifications and skills depends on whether these are recognised and whether there is a nurturing process that allows existing talents to be utilised to achieve their full potential. A work environment that encourages and supports the utilisation of existing skills coupled with work processes attuned to providing high quality policy advice can boost morale, organise and employ skills to their best possible use, and generally, instil confidence on staff. Furthermore, a good work environment can nurture the necessary experience in a short period and can supplement extra qualifications that staff may see as necessary. 
One area of common concern was that there was no effective guidance, and therefore to some extent control, over the way policy work is done. There was a strong feeling during the discussions that the existing pool of knowledge and skills is not appropriately marshalled in the direction and manner that would allow their constructive and maximum use. Such a perception, for example, is illustrated in the following statement made by one of the staff interviewed:

We only comment on policy briefs when we are required to. We do not really initiate things like policy research, or do serious investigation on key policy issues.

Overall, lack of positive leadership has led to a situation which some policy analysts have called "lapses in discipline". This problem may have given rise to a poor work ethic among policy staff. This perception is captured in the following statement:

If you have a look now, some of the offices are empty; some of us do not take our work seriously because there appears to be no reason to. But if you go to the buai market across the road now, a good number of those who are not here are there chewing buai. $^{44}$

It seemed also that a lack of positive leadership might have contributed to a situation where some highly qualified policy staff have felt demoralised working in an environment where their expectation of how policy work ought to be managed cannot be matched by what they are actually getting and or seeing.

The state of existing resources and support infrastructure necessary for the effective utilisation of knowledge and skills was perhaps the next biggest worry shown by staff. There was a general perception that the existing environment does not support the use of existing talents.

\section{Developing Capability through Training}

As mentioned earlier in the discussion of the Department of Finance and Treasury (DF\&T), developing training plans is an acknowledged part of departmental planning in the PNG public service. Staff rated the training plan of DPM \& NEC as either inadequate or poor, as evident in the following comment:

\footnotetext{
${ }^{44}$ Buai is the Pidgin name of the beetle nut, a nut that comes from a variant of the palm tree, and is loved and chewed by many Papua New Guineans.
} 
This has been the problem with our staff development unit [referring to lack of attention to training]. They are responsible to organise training for staff and they haven't been a good job about it.

Officials who were interviewed cannot recall being placed in a training plan or even seeing one. Those officials who have undergone further training have done so on their own initiative, applying for donor-funded scholarships when they became available, and then getting study leave once they were accepted. But scholarships are scarce, acquired through open competition among all public servants, and are available on an irregular basis.

Figure 7.4 gives selected allocation to the department on Estimates Item 136 Training as a component of allocations to "Goods and Other Services".

Figure 7.4: Selected Financial Distribution to Training by Years, DPM\&NEC (\%)

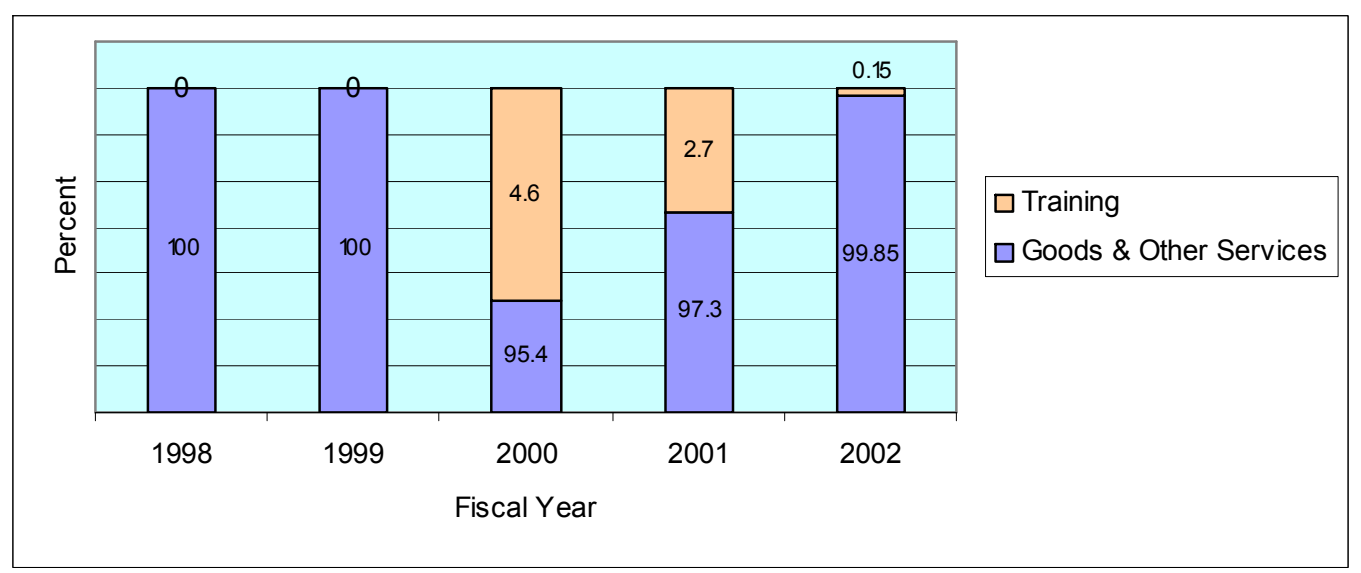

Source: Department of Finance \& Treasury Estimates of Recurrent Expenditure 2000 (Volume 2 Part 3), 2001 (Volume 2 Part 1) and 2002 (Volume 2 Part 3).

As indicated in the above Figure, training as a percentage of the allocation for Goods and Services faced a relative decline in budget support, from 4.6 percent in 2000 to 2.7 percent in 2001 and 0.15 percent in 2002 . The lack of budgetary support for training was seen by some senior officials to be the cause for the current predicament facing staff:

We can mount internal training programmes but where will we get the money to buy materials and contract trainers (senior official, excerpt from interview)?

In-house training was important to sustaining staff capability by virtually all the officials interviewed. There is a strong feeling, however, that there been little of that 
happening within the department. One Director who had undergone some form of training in his previous department had the following comment:

One thing that I find here is that there has been no internal training for staff. I don't know whether we have any training plans at all.

Some officials have commented that the standard public service six-monthly induction programme should to be actively pursued in a much more rigorous manner. This programme, by design, is intended to place new recruits to a department through a six-month induction period. However, some officials felt that the induction exercise has gone off track; it needs to be brought back to serve its original purpose. For example, newly recruited staff found that there was no mentoring and training and that, they were "required to get into their substantive duties immediately" (policy official, excerpt from interview). This situation places the department at some risk, according to several senior officials. For example, the department risks providing illinformed advice to the Prime Minister and the NEC on key issues dealt with by junior inexperienced staff. Key functions, such as in monitoring and evaluating the impact of government policies, and providing comprehensive scrutiny on policies coming from line departments are unlikely to be effectively discharged. This situation is likely to further undermine the steering role of the department within the government machine.

As is the case with DF\&T, most training in DPM\&NEC was sponsored by various donors and took place outside the country. Concerns about limited in-house training, especially in situations where funds were available, therefore, raise similar issues to those identified by the policy officials of DF\&T. There was, for example, a perception among policy officials in DPM\&NEC that funds earmarked for training were not being put into good use. Some officials felt that funds were being diverted to other areas. Others were sceptical about allocations, claiming that the actual transfer of funds from the Treasury was often less than what is shown on the Estimates.

\section{Resources}

Virtually every staff member interviewed expressed grave concern about the inadequacy of existing facilities within the department. A physical examination by the researcher of the facilities used by staff confirmed this assessment. Generally, the condition of most facilities gave a distinct impression of officials in DPM\&NEC experiencing poorer working conditions than their colleagues in DF\&T. The problem 
of storing and accessing data in DPM\&NEC was more severe than in DF\&T. Most policy officials recognised that this was one of the most important constraints inhibiting the department from maintaining coordination across government. There is no departmental library or a central repository of important information within the department - for instance crucial information derived from monitoring and evaluating key policies implemented by the government. Information is limited and kept by individual staff. This situation has made it impossible to build a good "institutional memory", for example, on how policies were devised and executed, the difficulties faced, the intervention measures taken and their impact on policy outcomes. This situation has prevented policy analysts from constructing future policies based on experience and evidence.

Of the nine staff interviewed, 77 percent are not electronically linked to the Internet and none had email facilities. Only the two Director-Generals had access to such facilities. Although virtually every staff member has a computer, most were old and used only for basic word processing. According to a senior official, "many of the computers will become obsolete if the staff were to hook up to the net...and most computers needs replacement anyway".

Access to support facilities such as printers, copiers and paper was also seen as problematic by staff. Some facilities (for example, printers and copiers) have depreciated to a point where they needed urgent replacement. The view of one official summarises a regular situation:

There is always something wrong... either the toner runs out or the copier breaks down...or we just run out of paper. Sometime we can wait for days for the toner to be replaced or the photocopier to be fixed.

Although there has been some emphasis, particularly in the PSRMU, in recent times on improving the research, monitoring and evaluation capability of the department, it was obvious during the time of this research that the department does not have such a capability. Within NDS and GS, problems mentioned above have prevented the units from building capability over the years. A lack of competent staff and foresight by the management (in concentrating resources in this area) were also seen as impediments to building the necessary competence for research, monitoring and evaluation. The lack of competence in this area has adversely affected the coordination role of DPM\&NEC and has prevented the department from monitoring, 
evaluating and proposing intervention measures in respect of key policies of the government.

As is the case with training, officials blamed lack of funds as one of the primary causes of the poor state of facilities. For example, the perception of staff (from the survey - P12) regarding funding of policy advice showed that the majority of staff felt existing financial allocations to be inadequate - the results show that 42.8 percent believe that existing funds are adequate for policy advisory work but the majority (57.1 percent) did not agree.

Review of evidence in this area (i.e., funding), which could only be tentative, supports (and also raises doubts) the claims by officials. For example, allocation to the DPM\&NEC for capital expenditure has risen from roughly K0.833 million in 1999 to K2.11million in 2002 (Table 7.3). The rise is consistent with the requirements for additional resources imposed by the new roles adopted in 2001, and especially from the creation of the Central Agencies Coordination Committee (CACC) and the Public Sector Reform Management Unit (PSRMU). If the allocations for capital expenditure had been concentrated wholly on strengthening the CACC, PSRMU, the NEC secretariat, and other units like the NSAC and State Services then it is possible that units like NDS and GS were not given the necessary allocation for sustaining their facilities. Insofar as this was the case, then there is some merit to the claims made by officials. But it is more likely that funds would be shared across all the units.

Table 7.3: Selected Expenditure of DPM\&NEC, 1999-2001 (in K’000)

\begin{tabular}{|c|c|c|c|c|}
\hline & 1999 & 2000 & 2001 & 2002 \\
\hline \multicolumn{5}{|l|}{ Current Expenditure } \\
\hline Personnel Emoluments & $11,550.5$ & $10,948.5$ & $12,562.3$ & 12,700 \\
\hline Goods and Other Services & $6,785.1$ & $7,595.2$ & $11,036.2$ & -- \\
\hline Current Transfers & 351.2 & 635.4 & 600.0 & --- \\
\hline \multicolumn{5}{|l|}{ Capital Expenditure } \\
\hline Capital Formation & 833.2 & --- & $2,112.7$ & --- \\
\hline Total & $19,520.0$ & $19,179.1$ & $26,311.2$ & 12,700 \\
\hline
\end{tabular}

Source: 2001 Budget, Volume 2 Part 1, 2002 Budget, Volume 2 Part III.

There was a perception among staff that, while financial allocations were made, these were inadequate; funds were spread too thin to have a significant impact on the support infrastructure of the lead policy units. Prima facie, this claim may have 
some merit. For example, currently DPM\&NEC has more than 30 different units in its various divisions. It is possible that spreading the amount in the above table would result in an inadequate allocation to each unit. For example, using Table 7.3 as a guide, allocation to the lead policy units (NDS and GS) for Capital Expenditure in 2001 would have been $\mathrm{K} 70,000$ to each unit. On existing practice, this amount would be spread over two years, which would mean that each unit would have roughly spent just under $\mathrm{K} 15,000$ in each year to maintain (and purchase) equipment and support materials. Poor conditions of facilities (and in some instances the lack of facilities) also appear to support the view that both the quantity and quality of critical facilities could not have been sustained at an adequate basis within the allocations the department has been receiving.

Managerial capacity to utilise funds effectively in important areas was also seen as key factor contributing to poor support facilities. Despite the evidence of capital funding, according to some officials, routine support materials and services cannot be sustained in a reliable and sensible manner which "raises the issue of whether funds have been used in a cost-effective way" (excerpt from interview). Moreover, it may support the view of some officials that funds may have been diverted to other areas.

\section{Planning and Organisation of Work}

There is no up-to-date corporate plan for the department. The only available corporate plan, on which the department appeared to rely during the time of this study (2002), was that covering the period 1998-2000.

The majority of staff did not think that the existing corporate planning framework had any use for policy advisory work. For example, when asked to give their perception of whether their performance evaluation has been based on the expected advisory targets (P8), most of the surveyed staff did not think that evaluation had taken place. Also, most policy officials did not think there has been any meaningful planning and organisation of policy advisory work. 
The majority of officials were not aware of any formal benchmarks to check their policy work. This view is reflected in the following comment:

I try my best to comment on policy briefs and submissions and use such criteria as consistency with government objectives and the costs of mounting such a policy to assess the policy that I work on. Once the comments are given to the boss, it's up to him to decide whether the brief is sufficient.

There was a feeling among some senior officials that policy advice is an opaque concept rather than something, which could be readily measured. One director had the following comment:

It has been hard to state clearly what to assess in policy advice, because policy advice is difficult to measure and depends on who is providing the advice.

The need for setting key benchmarks and observing them in policy work was, however, seen to be important by most staff. Many commented that some form of benchmarking was overdue. Some officials felt that reviewing of policy advisory work by peers would be encouraged if staff were made aware of benchmarks they are expected to observe. And, according to one senior analyst, this would reduce the bias, which senior staff often bring to assessing policy work.

\section{Political and External Factors}

As is the case with the two other central agencies in this study, the responsible minister - in this case the Prime Minister - plays an important role in setting the general framework within which policy advice is to be provided by DPM\&NEC and its lead policy units.

Results of the survey on Perception 2 (P2), on whether the minister communicates to the department his expectations on policy work, showed that the majority of DPM\&NEC staff (57 percent) were satisfied with the level of ministerial communication.

The general feeling was that communicating the expectations of ministers is a relative matter and depends very much on who is at the helm. Some senior staff felt that the previous Prime Minister (Sir Mekere Morauta) was able to communicate 
clearly the strategic objectives of government; and that there were transparent directions about what government wants. ${ }^{45}$

According to one senior official:

This has helped us in coordinating policy that comes from line agencies and departments more effectively

However, there were some who had suggested that the minister's views are not always communicated effectively within the department's internal channels by top and middle level management.

While the DPM\&NEC provides most of the policy advice to the Prime Minister and NEC, staff acknowledged that not all of it was influential. There has been a perceived tendency for cabinet to rely on outside advice provided by political staff. While this is cabinet's prerogative, some officials acknowledged that such actions may undermine effective policy formulation. There was a perceived fear that if external policy advice is not coordinated in such a way that policy staff could comment on it there may be inconsistencies with the general direction of government policies. Another concern was that advice might be incomplete, lacking adequate consideration of administrative and technical factors. Thus, political attractiveness may be the driving force behind policy formulation rather than administrative and technical feasibility. An example given by a senior policy official reinforces this view:

Some years ago, we had very serious problems with the formulation of the budget. We could have coordinated it better with Treasury and advised the government accordingly, but certain political leaders decided to rely on outside advice so that our advice was seen as unnecessary. The result was that many activities of the government were affected due to major shifts in budget priorities; some institutions were thrown out overnight.

As is the case with the EPU's officials in the Department of Finance and Treasury, there was scepticism about the utility of outside advice. The majority of those surveyed (71 percent) did not think that outside advice would make any significant

\footnotetext{
${ }^{45}$ Staff could not provide comments on the current Prime Minister, Sir Michael Somare, since he took office (in July) a few months after the interview. The last time he was Prime Minister was in 1982.
} 
difference to the quality of advice provided by professional public servants. Responses from the interviews show similar views. Staff did not think that outsourcing of policy advice is a good option, and felt that the department itself can provide better policy advice if certain impediments were removed.

There was a common view among those interviewed that the department is operating in an environment where politics matter. There was a widespread belief that political influences have been a key factor in determining the management of organisations within the PNG public service. Such influences were generally perceived to be adverse. Constant changes in government were considered unfortunate and were perceived as a key factor to changing priorities in government policy. Not only has this sent mixed signals to relevant stakeholders, but it has also made it difficult for DPM\&NEC to coordinate policy and for any government in office to fully implement its policies.

The position of the Chief Secretary remains volatile in the existing political climate, according to almost all the officials interviewed. Staff cited constant changes in department heads, often for no apparent reason, as a key factor influencing their perceptions about the security of tenure of their departmental head.

Few policy staff thought that ministerial responsibility is taken seriously in PNG (Figure 7.5). Two senior officials mentioned that there were exceptions: a few good ministers have been more likely to defend their department than shift blame.

Figure 7.5: Practice of Ministerial Responsibility, DPM\&NEC (\%)

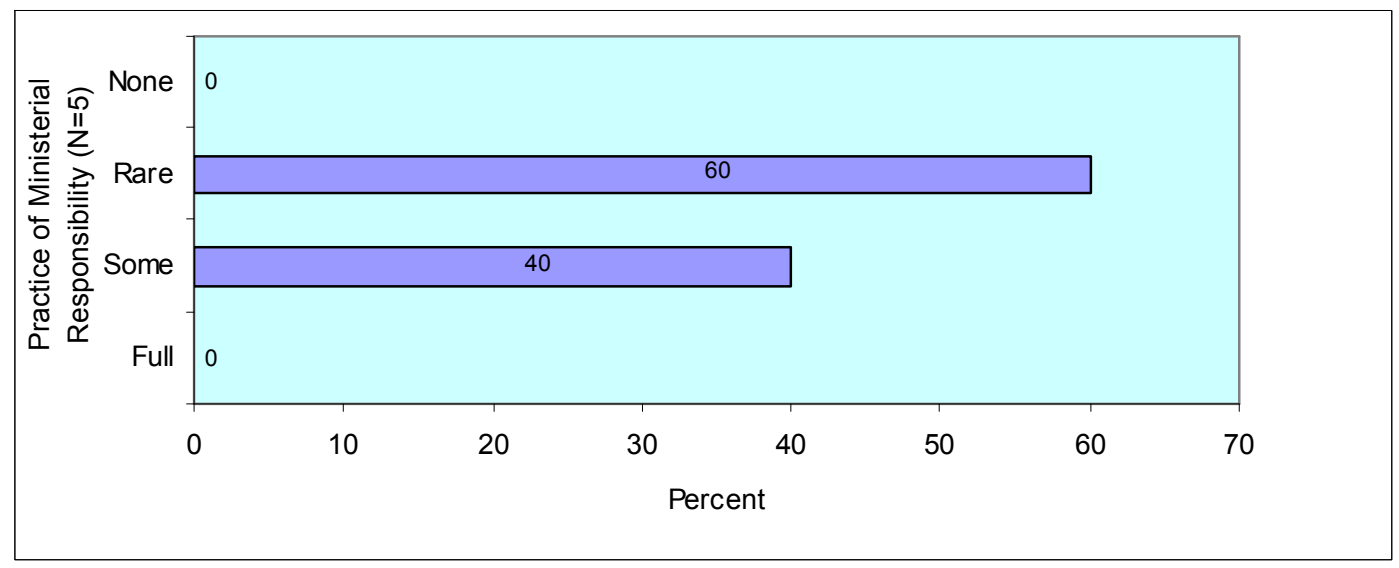

Most staff felt that the continuous threat of being blamed for what happens inhibited effective management by departmental heads. They were also of the view that policy 
advice tends to be supplied more cautiously, especially in circumstances where there is no clear responsibility over who would take the blame for what goes wrong consequent to the tendering of policy advice and the acceptance of that advice by the minister.

\section{Conclusion}

This chapter has reviewed the functions of DPM\&NEC and its capability to provide quality and timely advice. There is no question that the department is the lead central agency responsible for maintaining policy coherence across the whole of government and is also the chief adviser to the government. Its close connection with the chief executive of the government, the Prime Minister, and the NEC underlies its influence on virtually all aspects of public policy. Such a connection also makes the department the most powerful central agency within the government machine.

In an age where the powers of central agencies have been restrained ${ }^{46}-$ evident, $^{2}$ for example, in the devolution of managerial controls under the NPM-led reforms DPM\&NEC in PNG still retains a considerable influence. New responsibilities brought about by the Prime Minister Act 2002 have further consolidated DPM \& NEC's influence over the government machine. Although powerful, a review of evidence in this chapter shows that the department is facing difficult challenges in the performance of its functions.

The capability of the department to steer the government machine, for instance, appears to have been eroded over the years. As observed by one senior official, "the failure of top management to take control over the situation (i.e., to reassert its control) has created a multitude of problems" including, but not limited to, a lack of coordination of policy and poor performance of other departments. Its ability to provide strong leadership within the public service especially over crosscutting policies has also been tested by various internal problems. Thirdly, although the

\footnotetext{
${ }^{46}$ There have been some attempts to strengthen the centre of government (especially in policy coordination and managing crosscutting policy) by re-empowering central agencies, particularly the Department of Prime Minister and Cabinet (or its equivalent) in some Westminster countries (e.g. Britain and New Zealand). Such attempts have been spurred by the "hollow crown" thesis and what was perceived to be a lack of coherence from the centre caused by the "fragmentation" of government (see Weller et al, 1997 and New Zealand Report of the Advisory Group on the Review of the Centre, 2001). However, generally, these efforts have fallen short of restoring the controlling powers central agencies used to have under the "traditional" public service environment.
} 
creation of the CACC and the position of the Chief Secretary were aimed at bringing control back to the centre of government, evidence in this chapter shows that new statutory responsibilities placed on the department by the Prime Minister Act 2002 may have added further strain on the already flagging capability of the department.

Central to this chapter has been the review of evidence on how policy advisory capability has been constrained. The review of evidence shows interlocking constraints working in various ways to undermine the organisation and provision of policy advice. Although it is often easy to see inadequate public servants (particularly in developing countries) as the cause, this chapter suggests varying causes, many of which are not necessarily related to staff inadequacy - indeed, if anything, evidence here suggests that a revealed lack of skill and expertise is itself the result of other problems.

The new responsibilities allocated to DPM\&NEC have received particular emphasis in this chapter. As noted in the foregoing analysis, such responsibilities have ushered in new clients such as the CACC, redefined the role of DPM\&NEC in the provision of advice (especially to the Chief Secretary and CACC) and put in place a new process of providing policy advice. For example, all advice (particularly of substantive and strategic nature) is now furnished to the Chief Secretary and the CACC prior to NEC's deliberation. More importantly they have placed new demands on DPM\&NEC to provide a stronger and more effective advisory service capable of responding to the needs of key policy clients when required. In the next chapter, a similar analysis of the role of the Department of Personnel Management (DPM), another key central agency sharing some joint responsibilities with DPM\&NEC, is taken up. As is with this chapter, discussion is focused on key elements of capability and how these have been weakened by prevailing administrative and political problems. 


\section{Chapter Eight: Department of Personnel Management (DPM)}

\section{Introduction}

A detailed examination of the role of DF\&T and DPM\&NEC, two of the three central agencies who are the focus of this study, was provided in the two preceding chapters. This chapter is the final in the three-chapter series focusing on the experience of the three central agencies. Using a similar approach and with a similar objective, the chapter provides a detailed examination of the organisation of policy advice within the Department of Personnel Management (DPM).

DPM, unlike its two sister agencies, is a relatively new department. The department came into existence following the 1996 amendment to the National Constitution on the role and functions of the Public Service Commission (DPM, 1997). This amendment was followed by the enactment of the Public Service Management (PSMA) Act 1986 (repealed and replaced with the PSMA 1995), giving a wide range of functions to the Minister of Public Service and the Department of Personnel Management.

The amendments to the constitution and the enactment of the statute substantially eroded the power and role of the Public Services Commission (PSC) previously the sole authority on personnel management matters, relegating it to being a mere consultation and review entity, rather than a body that formulates and executes policy on personnel and organisational matters. According to Whimp (2000: 3):

...the [1995] Public Service Management Act had removed the central function of the Public Service Commission as an independent, constitutionally-entrenched body responsible for apolitical appointments and management of public servants.

Under the new changes appointments to top positions to the public service were made more political: the Public Service Minister recommends and NEC makes appointments under a confidential process. As a result there has been frequent appointment of "cronies" and appointees frequently became involved in corrupt practices marked by their close affinity to government ministers and cabinet (World Bank 1999; 2000; Whimp, 2000; Sause, 2003). 
In March 2003, after much public opposition and insistence from the World Bank (see World Bank, 2000), Parliament decided to reinstate the powers of the PSC through constitutional amendments (see The National, 17 March, 2003).

Advertising, short-listing and recommending candidates to the NEC is now the responsibility of the PSC. The effect of the changes remains to be seen, but already it has been hailed as timely: "they will ensure that [departmental heads] are appointed on merit and removed only if they fail to adequately discharge their duties" (The National, Thursday $20^{\text {th }}$ March 2003). Although these changes are important, significant power and functional responsibility over personnel matters in the public service remains with the DPM.

\section{Structure}

The Department of Personnel Management consists of two key divisions, six branches and twelve units. The branches and units are organised around the key functional responsibilities of the department. The two divisions are (a) Policy Research and Performance Management, responsible for policy formulation and therefore the provision of much of the policy advice, and (b) Implementation and Corporate Affairs, the division responsible, as the name suggests, for much of policy implementation.

Figure 8.1 outlines the organisational structure of the department showing the key divisions and the branches. 
Figure 8.1: Organisational Chart of DPM

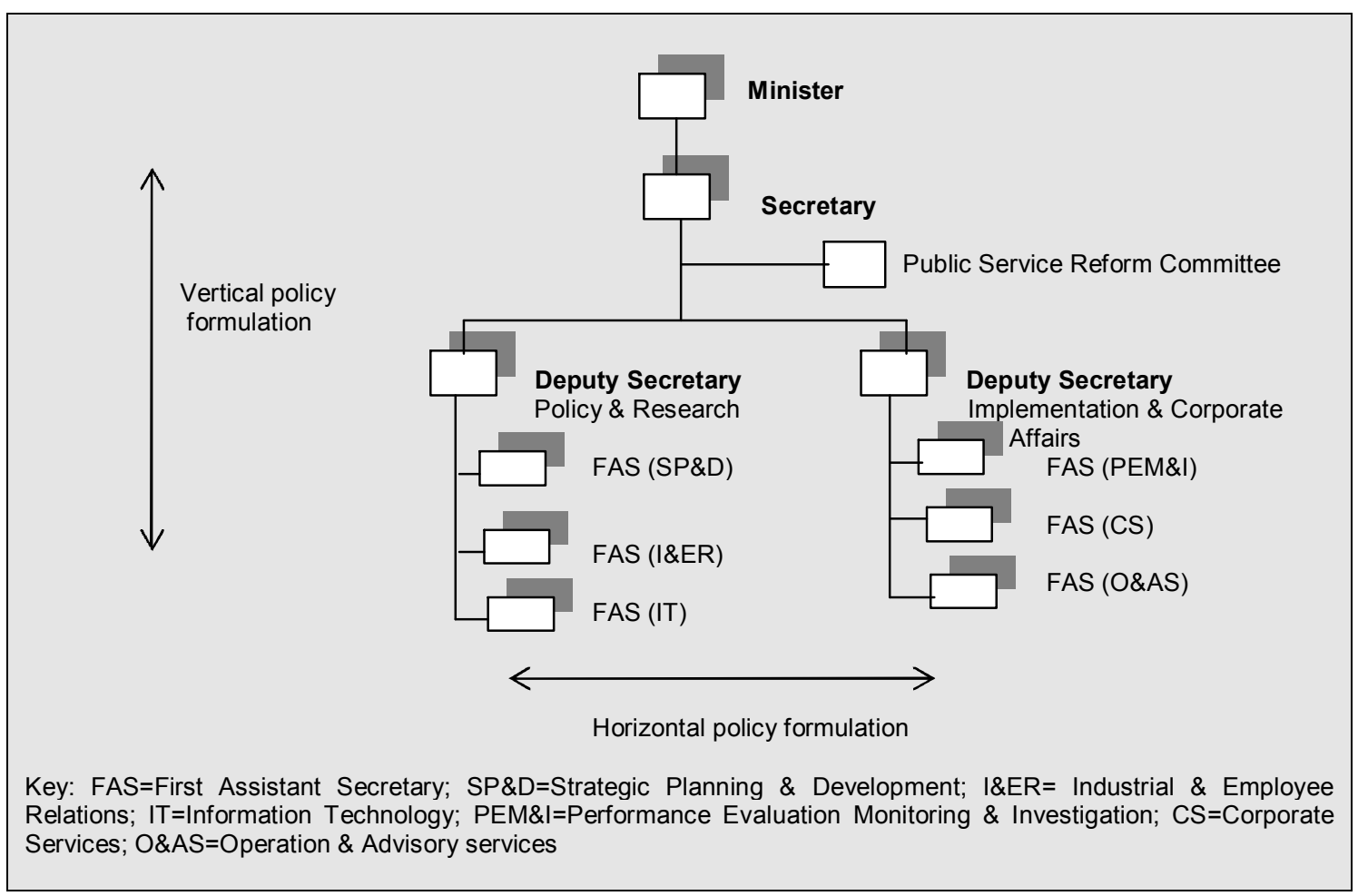

Source: Department of Personnel Management Corporate Plan, 2001-2005

A Deputy Secretary at grade 20 administers each division, while a First Assistant Secretary on grade 18 administers each branch and an Assistant Secretary on grade 16 administers a unit. There are usually two units in a branch, but there are bigger branches comprising three units. Policy work is carried out, coordinated and managed both vertically and horizontally. At the unit level where most policy work is found, assistant secretaries are responsible for ensuring that the unit's responsibility is discharged and work is channelled up through the hierarchy for certification, approval and further action. At the same time, work assignments and expectations are channelled downwards to subordinates. In policy advice this vertical flow of work ensures that the deputy secretaries and the Secretary get the required advice and in turn advise the CACC, the minister and NEC. Horizontally, divisions, branches and units exchange information and collaboratively carry out various tasks between and among themselves.

The Policy Division of DPM comprises three branches and seven specialised units (see above figure) and is responsible for most of the policy advice produced by the department. Although the Information Technology (IT) unit is part of the Division, its 
role is mostly one of delivery, ensuring that the information technology needs of the department are taken care of. However, there are signs that the government may be embarking on an information technology policy for the public service as a whole and it is expected that the IT unit would assume much of the responsibility if that should occur.

The Strategic \& Planning Development (S\&PD) and the Industrial and Employee Relations (I\&ER) Units are the core policy units of the department. However, it does appear that a large portion of the role of the I\&ER unit is focused on delivery or implementation responsibilities. These include advocacy and negotiation on industrial relations matters, providing administrative support for the Salaries, Condition \& Monitoring Committee (SCMC) and negotiating, formulating and administering and enforcing contracts for public servants under contract.

With much of the I\&ER unit devoted to policy delivery, the S\&D unit has become the lead unit of the Policy Division responsible for doing much of the policy advisory work of the department. Its specific functions, according to DPM's corporate plan, are policy research and formulation, strategic planning, and providing operational and substantive policy advice on machinery of government issues, performance management and training, organisational systems and development, and manpower planning and job placement (DPM, 2001: 14). It is estimated that these functions cover more 60 percent of the department's business.

\section{Functions of the Department}

The authority of DPM over the public service machinery and provincial departments is extensive, established by the Public Service Management Act (PSMA) 1995, and the General Orders, issued from time to time by the Secretary of the Department. The latter are quasi-legal notices and decisions, which are enforced by DPM and are designed to change administrative practice, especially at the operational level, without requiring statutory amendment. In a large measure the 1995 Act is attuned to centralised control, giving a significant authority to the department, in particular the Secretary, over the management and performance of the machinery of government.

The department carries out its policy functions and advises the CACC, the minister and NEC under its broad mandate spelt out in the PSMA. More specifically, its role is one of formulation, facilitation, management and implementation of policies relating to human resources management, machinery of government and improving public 
management systems of national and provincial departments and statutory authorities. $^{47}$ According to the department, this role has two broad and complementary objectives: (a) "to have an efficient and effective public service", and (b) to "have a lean, dynamic and responsive public service (DPM, 1997; 2001).

The exercise of functions is maintained through a variety of management, control, oversight and coordination mechanisms. Such functions and influence also make DPM the chief adviser to the CACC, the Minister of Public Service and NEC on personnel and machinery of government matters. One of its key functions relates to coordinating and approving machinery of government changes. Here, the department works with line departments and agencies in reorganising departmental structures, allocating staffing positions or what it calls "manpower planning" (DPM, 2001:8), and configuring departmental portfolios to suit the requirement of government. This role also extends to advising NEC on establishing or abolishing departments within the public service.

Another role is to formulate and promulgate personnel policies and standards across the entire public service and to ensure that such policies are adhered to. Third, the department is responsible for formulating terms and conditions of employment of civil servants through the Salaries, Conditions and Monitoring Committee (SCMC) and ensuring their application throughout the public service. By comparisons with systems elsewhere, for instance New Zealand, terms and conditions are highly centralised, even for contractual employment, and are uniform throughout the public service.

Fourth, the department is responsible for performance management across the public service, ensuring that public service organisations are effectively performing their mandated tasks and empowering them to do so. This role is performed in a number of ways. One is that DPM develops with other central agencies and line departments programmes and initiatives to improve performance. The aim is to promote an environment in which departments adopt sound and effective management practices that would have the desired effect on government outcomes. A key aspect of this has been the recent initiatives for reform of the public sector for

\footnotetext{
${ }^{47}$ Statutory authorities have been delegated managerial responsibility over many personnel matters. However, DPM still holds the reins over terms and conditions through the SCMC and, as noted earlier, retains some influence on the appointments of the heads of some statutory bodies via the CACC.
} 
which the department is responsible for providing advice on aspects of it (especially on human resource management in the public service) in consultation with the PSRMU in DPM\&NEC. Another is DPM's responsibility for ensuring that departments have the desired capability to competently undertake their designated responsibilities. This requires DPM to ensure that departments take proactive measures in investing in training and skills enhancement. It also requires DPM to work horizontally with line departments to establish appropriate training plans, and carry out training of staff (including having in place the required mentoring and induction programmes).

The fifth role is concerned with performance evaluation and accountability of public service organisations. This task is focused at two levels: one is directed at assessing the performance of departmental heads (in consultation with DPM\&NEC and through the CACC); the other is the assessment of departmental performance, which, according to DPM is concerned with a "public service performance management framework that is results-oriented" (DPM, 2001: 5). The latter role of evaluating departmental performance involves the annual appraisal of performance of all the agencies and departments in the public service. This role is presently discharged through the presentation by departments to DPM of annual performance reports.

\section{Analysis of Roles}

As is with the two other central agencies examined most staff saw the role of DPM under present centralised controls prescribed by the PSMA and various other statutes as significant both in terms of policy formulation and advice and policy implementation. In the survey, the majority (70 percent) strongly agreed to "Perception Statement 1" (P1), "my department plays a vital role in providing advice to the Minister and Cabinet".

Strong sentiments about the useful and important role of the department were also evident during the interviews. For example, several officials mentioned the empowerment role of the department especially in relation to assisting weak national (and particularly) provincial departments to improve their management systems. They felt that DPM plays an important role in this area, both in providing advice and in actually going out and helping line departments. 
The following extracts from interviews reflect the attitude of staff:

We play an important role in the public service. For example, without our monitoring of staff level, some departments will have more staff than necessary, given the climate of nepotism which we all know is rife in PNG.

We have a longstanding interest in ensuring that there are changes to the appointment of departmental heads because a lot of appointments have been political. So for the last couple of months we have been working hard on the proposed [constitutional] change and it now appears that the government has finally agreed to what we have been advising them to do. I hope parliament will pass the changes.

Despite the above sentiments, most officials felt that DPM's performance has been weak in some areas. Perhaps this is not surprising. The department has been inundated with concerns about its lack of effectiveness for many years. The failure of line departments and agencies to submit annual reports of performance and an apparent lack of action by DPM to deal with the situation is one clear example of ineffectiveness. Another is the relatively poor overall performance of the public service, which is attributed, among other factors, to lack of coordinated action by DPM to improve capability across many line departments and agencies, and a lack of robust performance evaluation with the subsequent enforcement of appropriate accountability measures (World Bank 2000; PSRMU, 2001).

Some DPM staff were of the view that individual departments could perform some of the tasks performed by the DPM. This would remove unnecessary workload on the department. More specifically, there was a perception by a few officials that many centralised controls imposed by the department are often counter-productive, inhibiting managerial freedom and therefore working against the very goals the department is supposed to achieve. For example, manpower placement - that is, the task of manpower planning, creating positions and eventually recruiting staff - is highly controlled so that many departments are finding it difficult to fill senior positions or get the extra staff to enhance their operational capability. This problem is caused by DPM delays in responding quickly to departmental submissions or its outright refusal to approve new positions despite a demonstrated requirement for them. Devolution of authority to line departments to give them greater control over recruitment would remove some of the existing constraints on departmental management. There is no evidence that this possibility is being explored at the time 
of writing (January 2004). A dilemma for the PNG public service is perhaps the fear that greater departmental freedom in personnel matters would facilitate nepotism and corruption. But there is little indication that central controls by DPM have effectively inhibited these tendencies.

A lack of a clear definition of responsibilities in the PSMA was seen as a constraint on the department performing some of its functions. The difficulty in evaluating departmental performance and in holding departments accountable was an example cited by several officials. Conditions of performance are never transparent. Although the PSMA provides for a department be managed in an "economical, efficient and convenient" manner (section 24), these benchmarks were perceived as insufficient to monitor and evaluate the performance of departments. Thus, according to one senior official:

These provisions can mean anything and could be interpreted in different ways. Under such a circumstance we find it difficult to really evaluate the performance of departments.

There was also confusion about the joint responsibility (with DPM\&NEC) in monitoring and evaluating the performance of departmental heads. Some officials questioned the logic of the 2002 amendment in the PSMA which has given rise to this arrangement. Some saw it as nothing more than "replicating the role of DPM" (excerpt from interview). There was a view that a lack of guidelines specifying how DPM and DPM\&NEC would contribute to the process may undermine the evaluation of departmental heads. In the absence of a transparent process, there is a likelihood of the Public Service Commission (PSC) getting mixed advice from the two departments. There is also a possibility of the Central Agencies Coordinating Committee (CACC) being ill-advised on the appointment (or termination) of departmental heads.

In a geographically diverse country effective coordination by one department located within central government (and especially at one location) can be a formidable task. . Unlike DF\&T, DPM does not have units operating in provinces. Matters attended to by the provincial departments are sent to Waigani and dealt with by DPM. As with DPM\&NEC, DPM has found it difficult to maintain effective coordination across the public service given its relative isolation from departments (especially provincial departments), its small size (which poses particular difficulties for the coordination of 
personnel functions across the broad range of the public service) and the poor channels of communication and exchange of information between DPM and line departments. Financial constraint was also seen as another factor preventing DPM officials from effectively maintaining coordination on all human resource matters and machinery of government issues. Officials commented that it has been difficult to help departments mount training programmes and to travel to provinces to assist provincial departments improve their capability because of financial difficulties.

Survey responses to the capability of the department to provide quality and timely advice (P13) and general confidence of staff about the overall capability of the department (P14) indicate that DPM has not been providing policy advice to key policy clients, as it would have liked to. From those surveyed, 70 percent were apprehensive about the capability of the department to provide policy advice of the required quantity, quality, cost and timeliness (P13).

Without question, most line staff spoken to in the interviews appear to be sincere and passionate about what they do, but they point to a number of administrative and organisational constraints that prevent them from being effective. The impediments cited include lack of resources, the presence of many junior staff with little experience, the failure to nurture expertise and skills, political expectations that were not technically sound, poor decisions from the top, inadequate leadership and poor work processes in policy-related tasks.

Inadequate leadership at the branch and unit levels was viewed as undermining the effectiveness of policy units. This view is reflected in the following comment:

We realise we can do more that what we presently do, but we can only be effective if our bosses are enthusiastic and provide strong leadership in our branch.

One senses from the interviews that there is a need to define the purpose of the policy units and branches, and to take a proactive approach by ensuring that staff and resources are committed to achieving the desired purpose. This requires the delegation of tasks in a transparent manner, providing necessary assistance and support, setting performance benchmarks and their expected time of achievement, following up on the assigned tasks and ensuring that these are done properly. 
Concern was expressed about the deterioration of research infrastructure, a point, which was raised time and again in the two other agencies discussed in the preceding chapters. Staff spoke about the pressing need for a departmental library, the urgent need to improve the poor state of data management in terms of compilation, storage and continuous update, and the need to have Internet access to external sources of data. Others expressed disappointment about difficulties of crosscutting policy work with many line departments and agencies because of lack of cooperation and inadequate exchange of information.

Some factors working against the effectiveness of the policy units were intertwined. For example, insufficient capability in policy research was seen as directly arising from a lack of managerial skills that could organise, plan and allocate resources to research work. Such concerns are reflected in the following comment:

I don't think the boss understands the value of [policy] research. Ask any one of us and each will tell you we don't have a defined research portfolio; we don't know what we should be carrying out research on. Our efforts in getting the boss to see the value of research, even some of the proposals we have made, have hardly received a feedback.

\section{Staff}

In comparison to the two other central agencies, DPM is a small department with a total of 127 staff. The lead policy unit (SP\&D) has 18 staff (Table 8.1). Comparatively, this makes up 14.1 percent of the total staff, which is higher than EPU within DF\&T (1.8\%) and NDS and GS within DPM\&NEC (4.24\%).

Table 8.1: Breakdown of Staff by Major Category, SP\&D (\%)

\begin{tabular}{|c|c|}
\hline Staff Category & Percent $(\%)(\mathrm{N}=18)^{*}$ \\
\hline Head of Policy Unit (Grade 18) & 5.6 \\
\hline Head of Section, and Strategic and Senior Analysts (Grade 14-17) & 38.9 \\
\hline Policy Analysts and Research Officers & 54.5 \\
\hline
\end{tabular}

*Based on actual strength rather than projected strength

Source: DPM Item 111, 2002

More than 50 percent are junior staff located between grade 8 and 13. Survey data indicates an average of three years experience in the department and less than two years of work experience in the current position in SP\&D. Most policy staff were 
therefore relatively inexperienced. The majority ( 55 percent) can be found within the age group of 25-30 years of age.

There were various reasons given to justify the high percentage of junior staff. One is that there are too few experienced people willing to take on the job. This implies that more experienced people may be seeking employment elsewhere rather than in DPM. Another possible reason is that the department is aiming to recruit people who have at least a university degree and this has restricted the range of people applying for the post, especially those at mid forties and beyond.

Policy work is as much about understanding important administrative, constitutional and policy processes of government as it is about having the necessary qualifications for policy analysis. The former is achieved through experience in the public service, the latter through education. During the interviews, many officials commented on the need to work alongside more senior staff so that they could benefit from their guidance and assistance. One junior analyst commented that half his time is wasted trying to figure out the administrative and political process so important to strategising and channelling policy work. Guidance and direction was seen as lacking from senior officials:

The truth is we don't really get a feedback on our work. We keep trying but we do not know whether we are doing the right thing. I think it would be reassuring for us and it would boost our confidence if we can get some form of feedback on what we do (Junior Official, excerpt from interview).

As was the case with the two other central agencies, the need for nurturing skills through mentoring, better guidance on policy work, and the need for well-established processes of ensuring that policy work is done properly were some of the concerns raised by junior policy officials.

The issue of filling vacancies was an ongoing concern. Despite the lead policy unit's relatively high percentage of staff relative to total departmental strength, they were still facing problems in filling vacancies when this research was carried out (February to April 2002). As mentioned earlier, because of its small size and its location, a lack of staff can add to the operational and management difficulties of the department. Figure 8.2 compares the overall vacancies of SP\&D within two of its key sections, Human Resource Planning, and Performance Management. 
Figure 8.2: Vacancies in SP\&D (DPM)

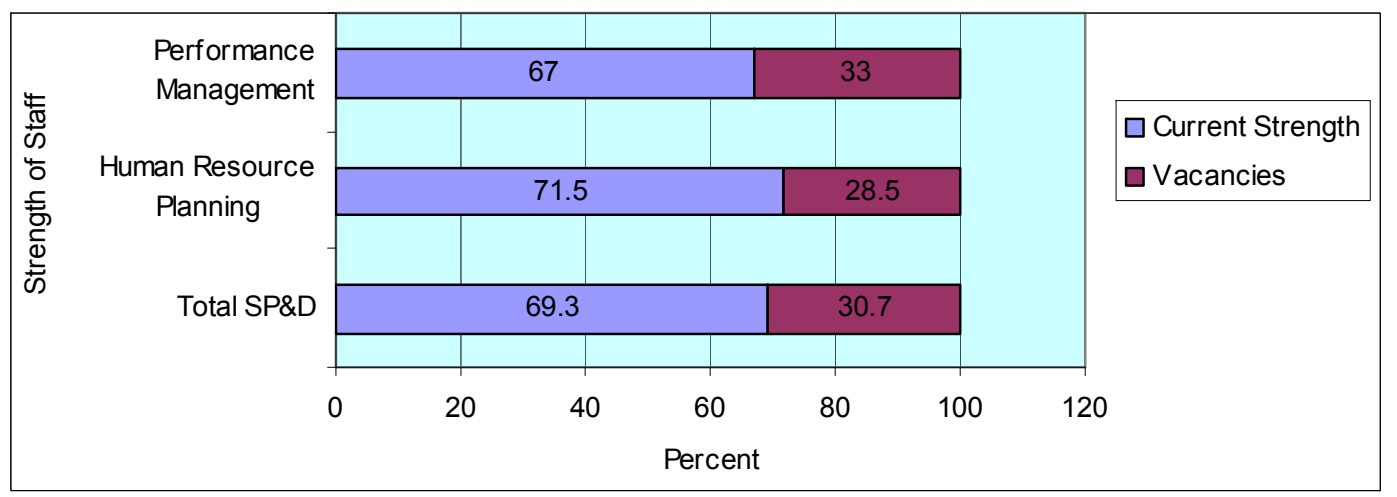

About 28.5 percent of senior analyst positions (or 2 out of 7 positions) in the Human Resources Planning section were yet to be filled. In the Performance Management section, 33 percent of senior research officers posts (or 2 out of 6 positions) were yet to be filled when the research was carried out. The estimated total ceiling of staff based on the department's record (DPM, 2001; DPM Item 111) is 26. Out of that 18 positions were filled, with 8 vacancies. Overall SP\&D has to rely on staff strength of 69.3 percent of establishment.

\section{Skills and Expertise}

All staff in SP\&D have a first degree, with a few combining their Bachelors degree with some form of skills or post-graduate qualifications (Figure 8.3). The distribution of qualifications by major category shows some disparities in the spread of qualifications skills. Those who posses extra skills are relatively few (only ten percent of staff). And, only 20 percent of staff have post-graduate qualifications.

Figure 8.3: Distribution of Qualifications by Major Category, SP\&D (\%)

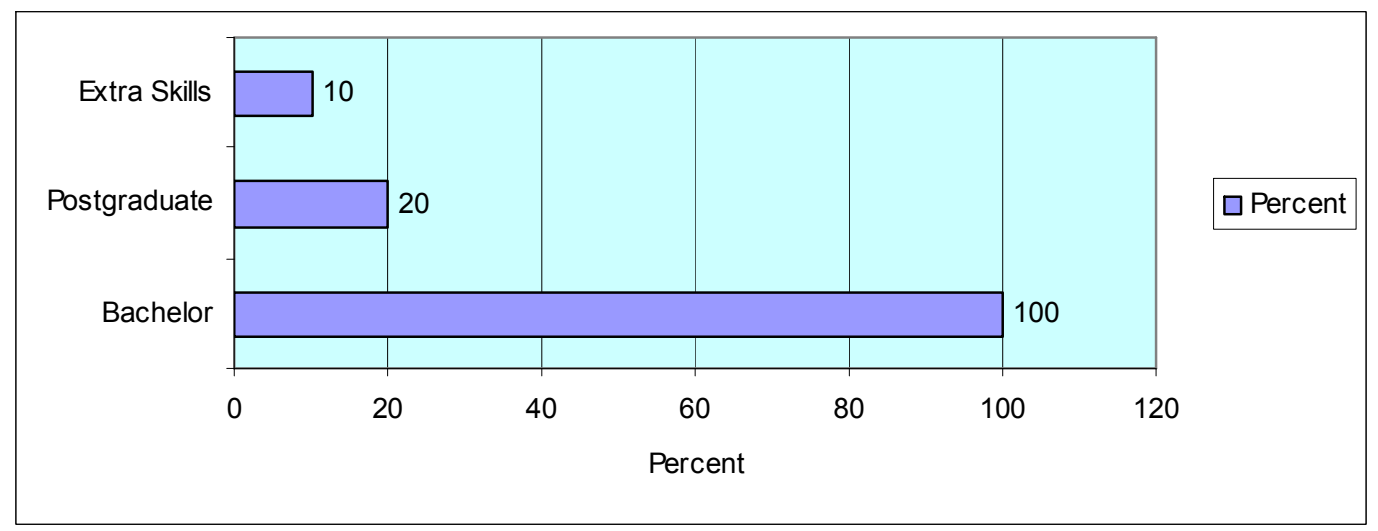


As is the case with the staff of the DF\&T and DPM\&NEC, officials in DPM considered well-developed skills and expertise to be critical to enhancing the capacity of their unit and the ability of individual staff. The following comment shows the importance placed on skills and expertise:

Most of us are junior staff with only a first degree. Our skills at this level are inadequate to effectively undertake the tasks we have before us. But if we are given opportunities to undergo further training, I am sure this will strengthen the operations of our unit and the performance of the department.

There is no question that many staff saw further training and skills-based course as necessary preconditions for improving their performance in policy related work. For example, one junior official pointed to his need to understand and get a better grasp of the operations of government, its administrative, constitutional and political contexts, and a basic knowledge of the policy process. Short in-house training courses, therefore, could readily address such needs if they are organised, funded and mounted successfully.

Some of the specific skills seen to be lacking were liaison and communication skills that would help analysts communicate better within DPM and across line departments and agencies, quantitative techniques of policy analysis, especially in statistics, skills in accessing and analysing data, and writing skills.

\section{Knowledge and Skills Development}

Investment in knowledge and skills development in DPM shows a similar trend to the DF\&T. For example, published records show that there have been fluctuations in funding since 1999 (see Figure 8.4). Of the total allocation for Goods and Services since 1999, only K2000 was allocated for training in 1999; K99, 000 for 2000; and no allocation for 2001 and 2002 respectively (see, 2000, 2002 Budgets Item 136 DPM). Moreover, as is the case with the two other central agencies, there is some evidence of funds earmarked for training and skills enhancement not being actually used for these purposes. ${ }^{48}$ This implies that funds may have been diverted elsewhere or that they may not have been released at all by Treasury.

\footnotetext{
${ }^{48}$ For example, compare the appropriated sum of K90,000 in the 1999 budget (see 2000 Estimates, Volume 3 Part 2) to the actual sum spent as recorded in the 2001 budget (see 2001 Estimates, Volume 2 Part 1). Despite a recorded projected sum of K90,000 in 1999, that amount was not spent on training according to the 2001 record of Estimates.
} 
Percentage wise, the above allocations represent only a meagre fraction of the total funds allocated for Goods and Other Services. As Figure 8.4 below demonstrates the spread of investment in training and skills development has been insignificant, almost negligible. Except for 1999 (accounting for $0.12 \%$ ) and 2000 (around 10\%), there were no allocations for 2001 and 2002.

Figure 8.4: Investment in Training and Skills Development 1999-2002, DPM (\%)

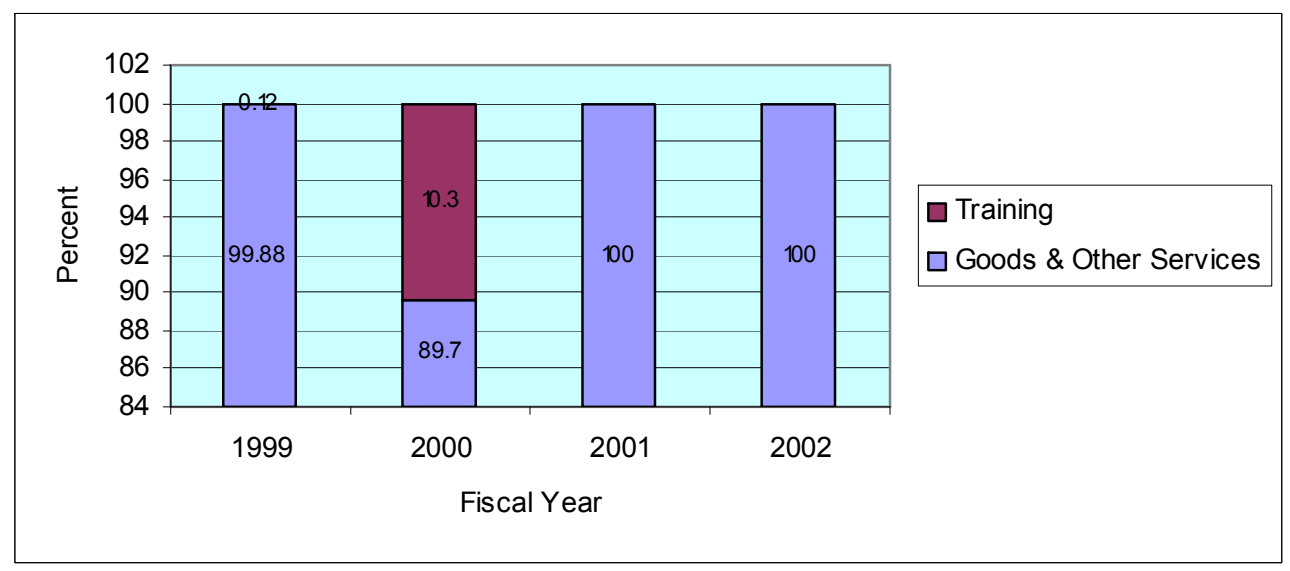

Source: Finance and Treasury Estimates of Recurrent Expenditure 2001 (Volume 2 Part 1), 2002 (Volume 2 Part 3).

Although the department had a substantial allocation in 2000 (accounting for 10.3 percent of total allocation to Goods and Services), officials pointed out that this was spent on outstanding training commitments for the previous years and was barely sufficient to cater for training cost in 2001 and 2002. A similar problem to that encountered in DPM\&NEC regarding the lack of capacity for the department to meet future training cost of staff (arising from outstanding training commitments of the previous years) was faced by DPM. Those who voice their concern on training saw consistency in annual funding to training as the key to preventing this situation from happening.

There was little evidence of actual in-house training when this research was carried out (February-April 2002). As was the case with the two other central agencies, most training in DPM was sponsored by donors and undertaken out of the country. This situation has created similar problems to those encountered in the two other central agencies discussed in the preceding chapters. For example, scholarships tend to be limited to only a few selected staff. According to one official, "the capability needs of the department are unlikely to be sufficiently met if [the department] continues to go 
by this trend". Donor funding has also created a "dependency mentality". As argued by some officials"

Donors are now primarily seen as replacing [not supplementing] the department and the PNG government in carry out training programmes (excerpt from interview).

There was a perception that this situation may have forced the DPM and the PNG Government not to take seriously their role in training staff. On a prima facie basis, the allocation to training in recent years (for instance as reflected in Figure 8.4) appears to support this claim. As one official puts it, "...perhaps we have been getting less funding for training because government tends to think that the cost will be borne by donors".

The need for adequate in-house or department-sponsored training was a major concern during the interviews. The overall perception was that training has been administered badly. For example, of the five analysts and researchers interviewed, none has been sponsored to receive further training or attended a skills-based course regularly mounted within and outside Port Moresby, despite a desire to do so. One official who had graduated from the University of Papua New Guinea (UPNG) mentioned that he has an interest in pursuing the newly introduced MBA from UPNG but his applications for departmental sponsorship and research leave have both been turned down. He is now considering resignation and then getting a bank loan to finance his education.

The lack of a proper training plan for the department was also an area of concern by officials. Unlike the DF\&T where policy officials were well aware of their future personal training plans - for example, type of training, the expected time of training, and the sponsor - those interviewed in DPM have expressed disappointment with the lack of a properly instituted training plan for the department. It was cited as one key cause for the unit's lack of pro-active approach in training its staff:

Perhaps money allocated for training is committed elsewhere, to fund the training of staff in the other units. There are no plans so there is no way of controlling who gets what in training, and when training of individual staff should occur (policy official, excerpt from interview). 
Some junior staff have also pointed out the difficulty in getting study leave for shortterm courses necessary for enhancing their skills, even if they were willing to sponsor themselves. There is always an option of resignation, but several staff mentioned that it would be counter-productive for the department, and that they intend to continue their employment with the department. While a pressing workload seems to be the main reason for approval not being given for short-term study leave, there was a common view that the management of DPM needs to take a long-term perspective about the benefits to the department. It was argued by staff that there is added value from short-term study leave (for example in improving critical skills in policy work), which could significantly strengthen the capability of the department in the years to come.

Staff discontent over a lack of investment in training and skills enhancement demonstrates to some extent the need for extra skills in policy related work. The discontent also corroborates the survey results, where 70 percent of the respondents do not believe that the department has the capacity to provide policy advice in the expected quality and timeliness (P13).

A failure to invest effectively in skills development no doubt has constrained the operational efficacy of the department in various ways. For example, the lack of capacity to mount research on machinery of government and performance issues was attributable partly to a lack of necessary skills in carrying out research work on substantive policy issues. Inadequate managerial capability at the unit level was also seen as a consequence of the passive attitude to meaningful investment in skills development. This perception is reflected in the comments from a senior official:

Training and developing managers is a challenging task, especially in a third world country like ours. There are few good managers around, so it is important that each organisation concentrate on developing its cadre of officials to the highest level, while at the same time retaining them. My view is that we have not taken this very seriously in DPM. We now have a situation where more people with little managerial ability will have to be appointed because there aren't enough good managers around.

\section{Facilities}

As is with the two other central agencies, the sustenance of high quality policy work within DPM depends on both the quality and quantity of existing facilities. Insufficient and/or poor facilities can have a detrimental effect on the performance of staff and can undermine organisational capability. 
Concern about deteriorating facilities was frequently expressed by policy officials during the interviews. A common view was that deteriorating facilities arose from the long-term neglect by the department of maintenance of critical facilities. One also gathers a sense of a lack of management foresight in either replacing or improving facilities that have depreciated.

The work environment was perceived as "psychologically depressing" by some staff. Officials being cramped together without adequate working space, sharing of computers and the occasional short supply of office materials were some of the key reasons for having such a perception.

As is with DPM\&NEC, several facilities fundamental to sustaining high quality work were missing. For instance, DPM does not have a departmental library. Storing and accessing important information, therefore, has been problematic. Electronic storage and transmission of data was also limited because of a lack of a strong information technology network. Although all the officials interviewed had access to email facilities, none had access to the Internet. The sharing of computers has also meant that their use was restricted to the times when they are available.

Funding difficulties were identified in both the survey and interviews as a key cause of deteriorating facilities. In the survey, the majority, 70 percent, did not agree that current funding for policy advice was adequate for the past four years (P12). An examination of the financial allocation to DPM (Figure 8.5) seems to reinforce the view held by officials, although as mentioned in the two previous chapters, such financial analysis can only be tentative because of the inadequacies in the published records. 
Figure 8.5: Selected Funding to Capital Formation 1999-2002, DPM (\%)

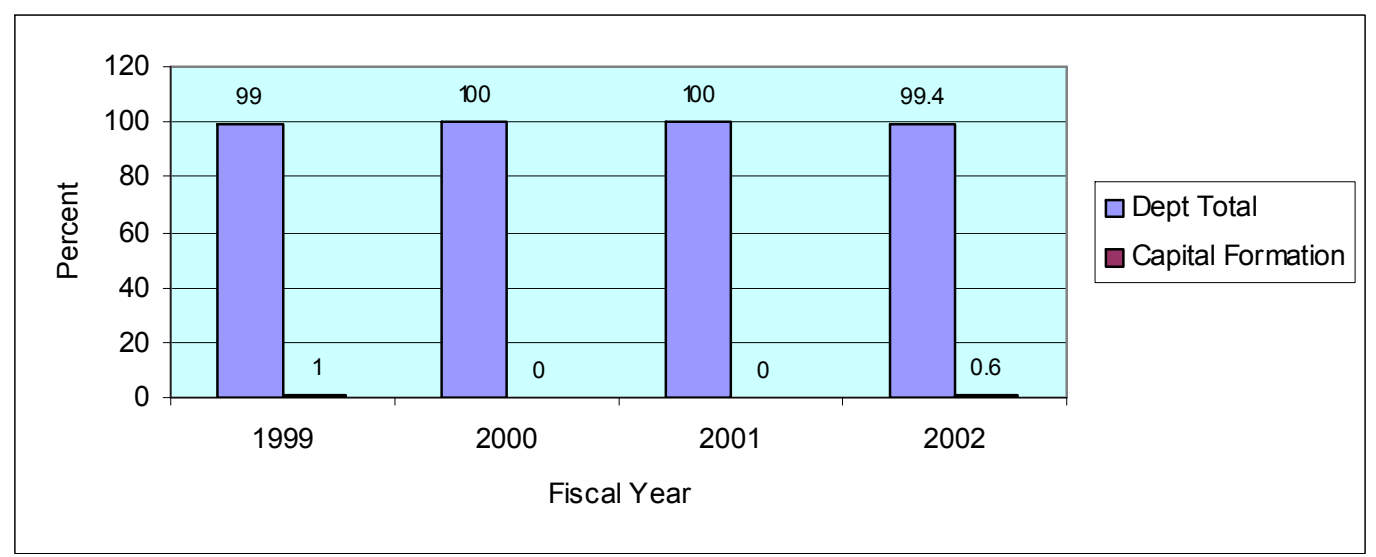

Source: Department of Finance \& Treasury Estimates of Recurrent Expenditure 2000 (Volume 2 Part 3), 2001 (Volume 2 Part 1) and 2002 (Volume 2 Part 3).

As the Figure 8.5 shows, total allocation to capital formation in 1999 represents only 1.0 percent (or K189, 900) of total expenditure, none in 2000 and 2001 and 0.6 percent (or K28, 000) in 2002. The allocation in 1999 (K189, 900 or 1.0 percent of total expenditure) was the highest allocation in that period (1999-2002), but would have been spread out for three years (1999-2001), in which case DPM would have spent on average K63,300 in each year). The allocation for SP\&D would be even smaller supposing that allocations are divided equally among the six branches of DPM. For example, it would have received K31, 552 and K4, 666 of the total allocations to capital formation in 1999 and 2002 respectively.

As evident in the above figure (and as discussed in the two previous chapters), there is a lack of consistency in allocations to capital items: fluctuations in allocations tend not to recognise the particular capability needs of departments; they tend to fall far below what was required to adequately maintain facilities. In DPM, it was evident from site observation that allocations between 1999 and 2002 were hardly sufficient to maintain both the quantity and quality of the existing facilities and to invest in new ones.

\section{Organisation of Policy Work}

Like all public service work, internal systems describing the planning and organisation of work processes are the formal means the department carries out its responsibilities in policy advisory work. As in the other two central agencies, planning and organisation of work in the department takes place using the corporate planning strategy, i.e., the corporate plan. DPM has a corporate plan (2001-2005), 
identifying its operational objectives and strategies priorities, and the means to achieve them.

The survey results on the use of the Corporate Plan as the key instrument of organising policy advisory work indicate a variety of interesting perceptions. Figure 8.6 shows the perceptions (P4-8) from the survey, on how policy staff view the expected use of the corporate plan (P4-6), and its actual use in terms of reporting performance and reviewing policy advisory work (P7-8).

Figure 8.6: Perceptions on Organising and Planning Policy Advice, DPM (\%)

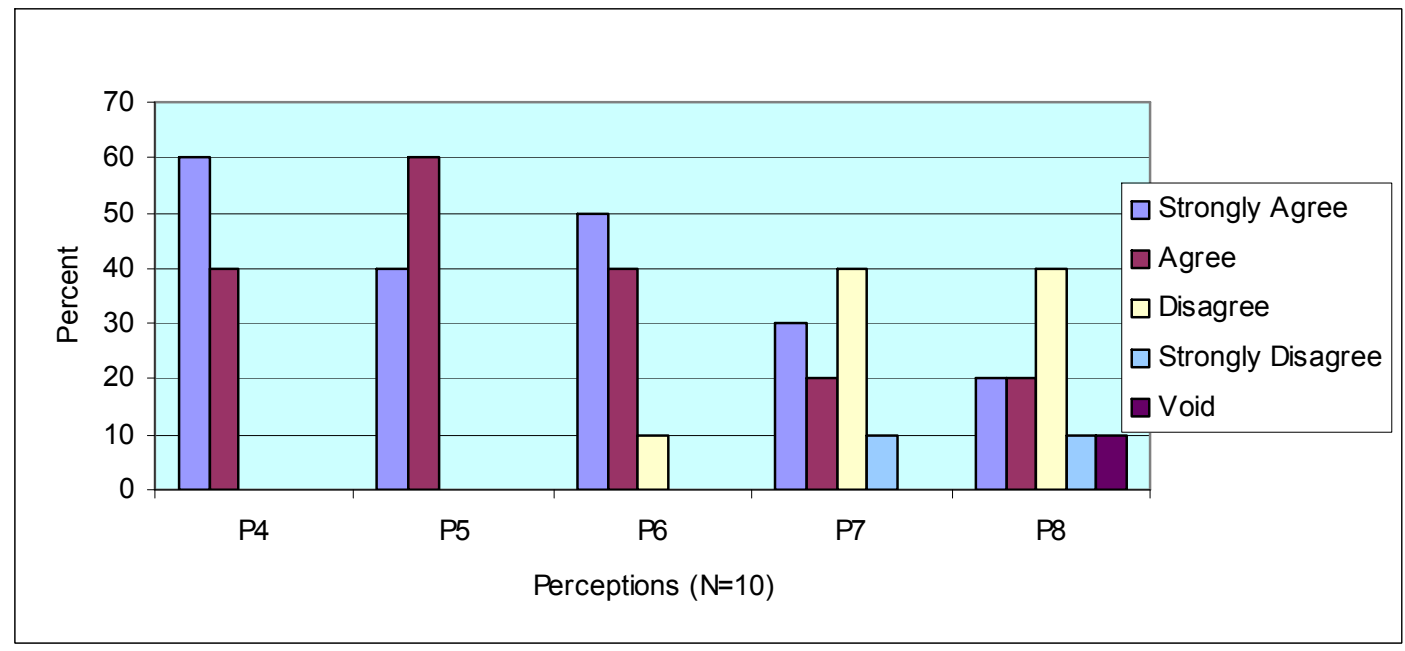

The majority of staff saw the corporate plan as a useful tool for planning and organising policy advisory work (P4-P6). But when it came to the perceptions of staff regarding its actual use especially in reporting targeted (expected) performance and using it as an instrument for reviewing policy advisory work (P7-8), a majority did not think that it has been put to effective use. As the above Figure demonstrates, perceptions tend to shift more towards the "disagree" and "totally disagree" categories.

Most officials mentioned that their work was more focused on operational advice than on substantive and strategic policy advice. Overall, policy work tends to be carried out sporadically and is largely restricted to commenting on policy briefs and responding to the demands of the superiors on specific tasks. While expected work is listed in the "Duty Statement" of each policy official such statements are general and do not specify clearly what staff are expected to do in policy advice. Most policy 
analysts tend to take their work as it comes, without conforming to certain expectations.

Views about work processes subscribing to standards of quality in policy advice vary. For example, a few senior analysts tend to have the view that policy advice is provided with due regard to ensuring that the quality of advice is maintained. But when asked to spell out clearly what they mean by "quality", most tend to leave the answer void. Others tend to refer to the standard public service appraisal that is carried out on a sixth-monthly period as the basis for maintaining quality.

The majority of policy analysts held the contrary view, pointing out that under present conditions it has been difficult to maintain any policy work to a satisfactory or quality level. Citing a range of problems, many senior analysts and policy analysts demonstrated why maintaining a work process that subscribes to producing quality policy advice has been difficult. Prominent in the interview discussions were the absence of quality assurance in policy advisory work and sporadic evaluation of policy work. This appears to corroborate the perceptions in the survey (P6 and P7).

Constructive peer review can help in ensuring quality in policy work. However, there appears to be very little peer review in DPM. It was mentioned that, this is not a formal expectation and therefore it depends on individual staff to use their initiative to ask their colleagues to review their work.

Both senior and junior analysts commented that there is no formal statement of any standard of quality or of a high expectation of performance; and of the need to account for better outputs in policy advice. Staff tend to do what they see as relevant.

A recurring issue in the interviews pertains to the management of policy work. Staff felt that there is a lack of effective leadership in setting work targets and ensuring that such targets are met. By the same token, they felt that the key portfolios of the unit have received little emphasis from those who are leading them. New staff joining the policy unit were not always sure of the precise role of the unit and how they were expected to contribute to that role.

As mentioned earlier, many policy analysts single out policy research as the activity needing urgent attention. According to one senior analyst, "there needs to be some 
life put into it". The general view was that policy managers and the management of the department need to revamp the focus of lead policy units, set appropriate research plans and targets and get staff to engage in research work. There may also be a need for more experienced senior analysts working with junior analysts to provide the necessary guidance and leadership.

As is the case with DF\&T and DPM\&NEC, managing and using information both vertically and horizontally was perceived to be problematic by a number of those interviewed: information across units is not readily shared or made available; in some instances close cooperation is absent. Staff also mentioned the need for more effective information sharing between superiors and line staff:

Most officials saw a need for specific data to be stored within the unit or somewhere within the department. This includes, reports on key changes in government policy, departmental occasional papers, specific research reports that report on selected issues, departmental annual reports, cabinet policy papers, and important international developments. This feeling underlines the need for a good information system, able to collect data, store them and make them available when needed. This is necessary if comprehensive and reliable analyses are to be carried out on policy issues.

\section{Political and External Factors}

As in the case of the DF\&T and DPM\&NEC, sound political direction is seen as important by staff of DPM. Virtually all staff acknowledged the important role of the minister in cabinet decision-making and saw the role of DPM as supporting the minister in giving him the best advice possible, and in executing government policy with respect to human resource and machinery of government issues. Overall, the views of staff were similar to those found in the two other central agencies. This should not be surprising. In PNG, the political context within which departments operate is similar: ministers reflect larger political forces that exist at the cabinet or government level. Decisions or political moves which are made within cabinet or government caucus are transmitted through ministers, and eventually affect departments.

The setting of ministerial expectations in respect of policy advice was viewed as problematic by most staff: 71.5 percent did not think there was clarity in the minister's communication of the government's anticipated policy objectives in the survey (P2). 
Such a perception was also held by most of those interviewed. There was a perception that providing technical advice (for instance on the types and nature of outputs the department should contribute to the desired outcome, the cost of producing such outputs and the likely impact such outputs would have on anticipated outcomes) has been a constant challenge as a result of a lack of clarity on the part of the minister. There was a perceived risk that this situation may lead to poor departmental planning and a misunderstanding of the policy outcomes of the government.

As was the case with the policy officials from the two other central agencies, political interference in the public service and the constant changes in the government were seen by most officials as creating a volatile political climate. There was a perception that DPM and the public service as a whole is unlikely to be managed effectively if the volatile political climate continues.

Officials expressed doubt about the security of tenure of their departmental head. Although DPM has been fairly stable in this respect the constant change in the heads of departments in the public service generally has clearly influenced the perception of the staff of DPM. A policy analyst demonstrates this view in the following statement:

Going by what happens in the public service, there is no reason to believe that departmental heads are secure in their position. And I don't think our departmental head is secure either.

Interview discussions about the concept of "free and frank advice" revealed some interesting responses. Some officials felt that the exercise of this characteristic of the Westminster-style public service principle depends on strong departmental heads. Others thought that "free and frank advice" in practice depends on how ministers choose to regard it. Encouragement from ministers would create a climate where departmental heads would feel free to give impartial advice without fear. There was a view that the insecurity surrounding the tenure of departmental heads in PNG may have forced departmental heads to provide advice on the basis of what ministers want to hear.

On ministerial responsibility, most officials felt that while it is an important convention underpinning the role of the minister in Westminster systems, it has not been really 
honoured in practice in PNG. For example, 71.4 percent of those interviewed felt that the exercise of ministerial responsibility is rare.

There were some concerns about policy advice supplied by the private staff of ministers, or to put it in one analyst's perspective, by "outside consultants". Policies decided through that process take departments by surprise, as there is no prior consultation and departmental input is not sought. One official's comment perhaps illustrates the effect outside advice can have on policy implementation:

The departments often have to cope with the implementation of policies which are clearly complex and political, and not properly planned.

There was general agreement that policy formulation would be more effective if politicians were to rely on the advice of officials rather than outsiders. Or, in cases where outsiders are influential, departmental input should also be sought so that there is balanced, contestable market in policy advice.

\section{Conclusion}

Underpinning the analysis in this chapter (as well as in the two preceding chapters) has been the need to examine how functional responsibilities shape the organisation and delivery of policy advice and how policy advice is being impacted by various organisational, administrative and political factors. As in the two preceding chapters, this chapter has sought to unravel the interlocking forces that work to weaken the capability of a PNG central agency — in this case, DPM — in providing quality and timely policy advice.

As the premier agency responsible for personnel matters and machinery of government issues, and, until recently, for managing the appointment process of departmental heads, DPM plays an influential role in the advice it provides to the government in these matters. As noted in this chapter, this influence is further strengthened by the many centralised controls that the PSMA vests in DPM.

From the various perspectives of staff analysed in this chapter, it is now evident that DPM faces apparent shortcomings in the provision of quality and timely policy advice. As is the case with the other two central agencies, such shortcomings stem form a variety of causes, most of which were inter-related. Many of the shortcomings encountered by DPM appear to be similar to those found in the two other central 
agencies, DF\&T and DPM. Common political and administrative contexts explain why such problems are found across the three central agencies. However, the commonality of the problems also touches on a significant point: that constraints encountered in the provision of policy advice are not sporadic; rather they appear to be pervasive and systemic. The next chapter, Chapter Nine, moves the analysis forward by providing a broad evaluation of the status of policy advice using the analysis in the preceding chapters. 


\section{Chapter Nine: Evaluating the Status of Policy Advice}

\section{Introduction}

The arguments for carrying out this study were extensively discussed in Chapter One. To rehearse some of the main arguments, it was argued that knowledge about the widely commented on operational deficiencies of the PNG public service was limited by the scarcity of in-depth information available, particularly from scholarly research. Although there is a long-standing perception of a lack of capability in the PNG public service, and as pointed out in Chapter One, this was largely associated with the "weak state" thesis, most evidence appear to be anecdotal in nature related largely to the weakness of the PNG state generally and the problems of governance in the country (Dinnen et al, 1997; Denoon, 2002; Windybank and Manning 2003). Moreover, there is no published evaluation to date on the role of central agencies in the provision of advice. It was observed, therefore, that substantial gaps in the literature exist, firstly with regard to a deeper understanding of the extent of capability problems in the PNG public service and, secondly (and more specifically), about the provision of policy advice.

The objective of this chapter (Chapter Nine) is to advance a broad evaluation of the status of policy advice within the three agencies, based on the discussion so far and noting in mind the objectives outlined above. The chapter begins with an evaluation of some of the central features of organising policy advice that have become apparent from the analysis in the immediately preceding chapters. The discussion then turns to identifying the key constraints on advisory capability and their various implications for policy advice in PNG.

\section{Evaluating the Central Features of Policy Advice}

\section{Diminished Influence?}

Changes internationally in various administrative and organisational arrangements for policy advice (informed by the New Public Management (NPM) approach to the pursuit of more efficient and better government), were briefly discussed in Chapter Three. An important question (against this backdrop of NPM changes) worth pointing out at this juncture relates to the influence of the three central agencies in PNG has it diminished or increased? This point is particularly significant in the light of the present discussion, since increased influence (or vice versa) of the three central agencies has important implications for policy advice and public policymaking 
generally in PNG. Here, a brief evaluation of the developments in the influence of central agencies in other Westminster countries (focused on managerial devolution) is contrasted with the three central agencies in PNG. The aim is to show, in the context of Luke's observation (Luke, 1990) noted in Chapter One - that central agencies may indeed be powerful but fail to use that power constructively - and especially in the light of the discussions in the three preceding chapters, how the influence of the three agencies might affect policymaking in PNG.

Recent public sector reforms in many countries, especially within the OECD, have focused on managerial devolution as a means of enhancing organisational effectiveness (Pollitt, 1993; OECD, 1990; 1993). According to Kernaghan (1992), the aim is to "empower" organisations and their managers by way of devolution, although his conception of empowerment is broader than mere devolution. In Australia and the United States for example, the trend to devolve organisational and managerial authority was evident in the Financial Management Initiative Programme (FMIP) (Keating and Holmes, 1990) and Performance Management Review (PMR) (Gore, 1993), respectively. In New Zealand, managerial devolution was part of the overall state sector reforms, initiated by the Fourth Labour Government in 1986 (Boston et al, 1996; Scott, 2001). In policy advice, similar developments diffusing central dominance were epitomised in the emphasis on policy contestability via multiple and alternative provider arrangements (Boston, 1994; Shaw, 2001), reduction of policy capture (Boston et al, 1991), or the need to curb bureaucratic power over policy formulation in a few powerful agencies - something which was seen increasingly as posing a challenge to the authority of politicians (Savoie, 1994; Levine, 1998).

Some evidence now appears to suggest that the diffusion of the policy advice role has had debilitating effects on central agencies, especially in their control over key policy domains (Halligan, 1995; Hart, 1998). Although there has been a recent trend to hand back some power to central agencies underpinned largely by the "hollow crown" thesis (Weller et al., 1997; Ministerial Advisory Group, Report on the Review of the Centre, 2001), the pursuit of organisational and managerial devolution has had an overall effect in reducing central agencies' influence and has contributed to shrinking policy capacities (Dunleavy, 1995a; Norman, 2002), although the nature and extent of this decline is contextual and therefore varies among countries. ${ }^{49}$

\footnotetext{
${ }^{49}$ See additional comments in Footnote 47 in Chapter Seven.
} 
In respect of policy advice, Halligan (1995:145) notes, "the trend has been towards expanding [the policy capacity] of line departments at the expense of central agencies", though he observes, central agencies may still maintain some control especially under "fiscal austerity". Patrick Dunleavy (1995a: 62) was more forthright in the case of the UK noting that, "the shrinkage of the central state machine produced by ceaseless reorganisations and efficiency savings has sadly reduced core competencies".

What has been the case in the three central agencies in PNG? Has their influence in policy advice been eroded in the same manner as their counterparts in developed jurisdictions? As observed in the three preceding chapters, unlike central agencies in the developed world (whose powers have tended to subside under various managerial reforms), the three central agencies in PNG continue to have an overriding influence on policy advice. There has been some shrinkage in DPM's authority over the appointment of departmental heads. (As noted in Chapters Seven and Eight, this has been brought about by the changes in the PSMA which have conferred an increasing role on the Chief Secretary). This, however, appears to have no significant impact on its potential influence: overall, DPM's powers over personnel management and machinery of government issues and, as observed in Chapters Two and Eight, remain intact.

For a variety of reasons discussed in the preceding chapters, the three agencies remain at the pinnacle of the government's advisory machine and continue to exercise an overriding influence on policy advice. As noted above, one of the main contributing factors is that the policy advice function has not been subjected to reform through managerial devolution and/or dismembering the power of the centre. The key statutes (PFMA 1995 and PSMA 1995 and more recently the Prime Minister Act 2002) giving substantial powers to these agencies have not been changed to such a significant degree as to pose a threat to their influence.

Second, and as observed in Chapter Three, although there has been an international trend in recent times to use a variety of external providers (who tend to compete with the traditional in-house sources of advice), this has been very slow to take root in PNG by comparison with developed jurisdictions. Evidence in the three preceding chapters (especially on DF\&T and DPM\&NEC) indicates some use of consultants, but this has been limited, pursued through counterpart funding arrangements 
between the PNG government and donor agencies. There is, therefore, no real challenge to the three agencies posed by external providers of advice.

Third, the widespread notion of expanding the internal sources of policy advice within the public service using a variety of structural arrangements (Boston, 1994; Halligan, 1995) - for example in creating specialist ministries, or specialist advisory units could have been adopted in PNG. Experience elsewhere suggests that this could potentially reduce the power of the three agencies. The reality, however, is that such changes have not taken place in PNG and there is little challenge from line departments and agencies to the central agencies' pre-eminent position in the provision of policy advice. The only significant institutional change, as noted in Chapter Two and the three preceding chapters, has been the creation of the specialised high-level advisory committee of the CACC which has the reverse effect of consolidating the power (and influence) of the three agencies.

The overriding influence on policy advice of the three agencies raises several questions at the centre of this study. How will they influence the CACC? Bearing in mind Luke's important insight recalled earlier in this chapter (of central agencies being powerful but failing to use that power constructively), will they put that influence to effective use? And, against the backdrop of weakening capability (as observed in the preceding chapters), what are the implications for the provision of operational, substantive and strategic advice - and, more generally, for public policymaking? These questions will be taken up later in the chapter.

\section{The Context for Organising Policy Advice}

As observed in Chapter Three, many governments in the Westminster tradition have opted for mixing a variety of "organisational" arrangements in the provision of policy advice. A noted shift observed in that chapter has been the supplementation of internal advice by external advice, although governments continue to rely heavily on professional public servants. Also, there have been some changes in the structural arrangements internationally for in the provision of advice (e.g., in the split between smaller policy ministries and large delivery (implementation) departments). What then is the situation in the PNG central agencies?

Policy advice in the three principal central agencies in PNG is largely concentrated in-house, produced mainly by public servants with its delivery focused on the portfolio minister and cabinet. Thus PNG conforms to the general Westminster tradition in 
which, as Halligan (1995: 143) observes, "advice is executive oriented and has placed greater emphasis on the public service". Unlike the Department of Prime Minister and National Executive Council (DPM\&NEC), ${ }^{50}$ the two other central agencies - the Department of Finance and Treasury (DF\&T) and the Department of Personnel Management (DPM) - are not solely policy-focused departments; rather they are made up of broad-based multiple functional units combining both policy formulation and delivery. Policy advice, therefore, is combined with many other functions performed by the agencies. On this basis, there are some similarities to agencies in Australia, where functions are combined (Di Francesco, 2000; Matheson, 2000). This is markedly different to the delivery split in New Zealand ${ }^{51}$ (Boston et al, 1996) and to some extent the British set-up of executive agencies versus policy departments (Oliver and Drewry, 1996). ${ }^{52}$

Within the three central agencies the responsibility to provide policy advice is centred primarily on policy branches and specific lead policy units. To use Halligan's (1995:164) phrase, the focus has been on "maintaining a professional in-house capacity" to service the needs of important policy clients within the government. The units serve as "think tanks" for each agency and perform a variety of functions. Working both vertically and horizontally within their parent agency and across the government structure, they comment on and scrutinise policy submissions originating from line departments and agencies, prepare briefs and policy submissions, coordinate interdepartmental policy work, liaise with line departments and agencies on policy formulation, and provide operational, substantive and strategic policy advice.

\footnotetext{
${ }^{50}$ Having said this, new roles assumed by the DPM\&NEC, especially after the enactment of the Prime Minister Act 2000 indicates that DPM\&NEC is moving towards performing policy implementation (delivery) roles.

${ }^{51}$ The policy delivery/split was a feature of the structural reforms in New Zealand in the 1980s and early 1990s, but there were always exceptions and more recently (2003) policy and delivery have been re-combined in some departments (e.g., Ministry of Justice and the Department of Courts).

${ }^{52}$ According to Oliver and Drewry (1996) the creation of the "executive agencies" was an important attempt in the late 1980s to split the policy and delivery functions of departments in the UK civil service. Using the "framework document" (outlining the scope of work and accountability arrangements), executive agencies were contracted by departments to perform delivery functions. Matters of policy formulation (and that of policy advice) remained with departments.
} 
The policy units within the three central agencies vary in size, and do not necessarily mirror the size of their agency. For example, the Department of Personnel Management, which is the smallest agency, has the largest policy unit with around 18 staff compared to DF\&T (14 staff) and DPM\&NEC (9 staff).

When assessed against the tasks at hand and the broader role of each central agency, especially in combining multiple functions of policy formulation and implementation, the size of each unit does hold important implications for the capacity to perform as think tanks of their respective agencies. As noted in the preceding chapters, most units tend to be operating without their full strength which has placed severe pressure on officials to perform at the required level.

\section{New Advisory Process?}

As observed in Chapter Three, the quest for better, coordinated advice, has led many governments to seek (and experiment with) new advisory arrangements. PNG is no exception. The most significant change noted in the preceding chapters has been brought about by the creation of the CACC. Whereas previously the responsible ministers were the conduits for feeding departmental advice into the NEC, advice originating from each agency and (elsewhere in the public service) will now be provided to the CACC and then fed directly into cabinet deliberation. To some extent this situation has brought about the possibility of "competing voices" (one from the minister and the other from the CACC) in cabinet debates. There is a risk that the individual voice of ministers may be overshadowed by the voice of the CACC. ${ }^{53}$ Whether this will eventuate is a matter yet to be seen. However, to the extent that CACC becomes more influential (than individual ministers), there is a likely possibility that the supremacy of ministers (in the formulation of policy) could be overshadowed by the CACC. Moreover, there is a possibility of conflicting advice. The new regime of providing advice calls for greater coordination of policy advice between CACC and

\footnotetext{
${ }^{53}$ There is an important point worth bearing in mind, particularly within the context of the Westminster system which PNG embraces (and also within the context of the discussion in Chapter Three). Generally, ministers are the principal link between cabinet and departments. In principle at least, advice emanating from the department would be furnished to the minister prior to going to cabinet. As observed in Chapter Three, this provides an important opportunity for the minister to vet the advice and decide whether it should be taken on board, varied or rejected prior to going to cabinet. CACC effectively breaks that link in that its advice can be directly injected to cabinet bypassing ministers (especially ministers of other departments who are not represented in the CACC). This holds important implications for the role of ministers in PNG. As noted above, there is a risk of public policymaking being "hijacked" by the CACC although it is an expectation that secretaries would keep their ministers informed.
} 
ministers, especially on the policy issues in which CACC and the portfolio minister have a vested interest or responsibility.

In principle, the ascendancy of CACC has some resemblance to elite executive agencies and/or committees such the Central Policy Review Staff (CPRS) in Britain in the 70s (Blackstone and Plowden, 1988), the Priorities Review Staff in Australia, and the Prime Minister's Advisory Group in New Zealand (Boston, 1980; Galvin, 1991) - that have at various times been prominent in advising the core executive. The notable difference, however, is that CACC's role is established in law. This statutory role ensures that it has a very influential position in advisory matters over the entire government machine.

Although departmental heads will continue to have an important role in policy advice, that role has become subordinate to the CACC, and perhaps the influence of the Chief Secretary, being the Chairman of the CACC. Overall, the respective heads of each agency would need to exert their influence at the CACC if they wish to influence the decision-making process at the cabinet level. The powerful role of the CACC also raises the risk of "advice capture". Advice emanating from other departments may be overshadowed by that offered by departments whose heads are the members of the CACC. This may lead to situations where NEC is ill-advised (or is led to hear one-sided advice from the CACC), particularly on policy issues on which central agencies do not have expertise. As noted in Chapter Seven, this was an issue about which some Treasury officials were fearful.

Furthermore, the CACC route implies collective effort, requiring secretaries of the three agencies to work collegially to get advice through to cabinet. This may be problematic in instances where the "silo" mentality underpins departments' operations. In Australia, for example, Di Francesco's (2000) analysis and those of others (Glenn, 1993; Weller 1996; Weller and Stevens, 1998) highlights significant differences and conflicting positions between the Department of Finance and Department of Prime Minister and Cabinet in the inter-departmental committee charged to develop ways to improve policy advice in Australia. There is some evidence emerging from the present study of "turf protection", poor exchange of information in critical areas of policy, conflicting perceptions, and in the case of DPM\&NEC, a lack of robust leadership, among the three agencies. These are likely to undermine the provision of collective advice. For the CACC to operate effectively and in unison as the key advisory body of cabinet, cooperation and exchange of 
information needs to be improved at the departmental level. Moreover, departmental secretaries would need to improve the performance of their departments and to inculcate a culture of cooperation at the departmental level, if greater collegiality is sought at the CACC level.

Last but not least, CACC risks facing an administrative overload that may cause it to lose sight of its core mandate of maintaining policy coherence and being the chief adviser to government. As observed in Chapter Two, policy coordination at the centre, for example, may be sacrificed at the cost of taking on additional responsibilities of monitoring, evaluation and accountability.

\section{External Advice}

There is some evidence of resorting to external advice, although this has been on a limited scale and perhaps of a different nature from the practice emerging in developed Westminster systems. This has been particularly the case in DF\&T. Anecdotal evidence suggests that DPM\&NEC may also be getting advice from nonbureaucratic sources. $^{54}$ In DF\&T, external policy advice was mainly provided by consultants responsible for implementing a variety of macro-economic reforms and usually working for international financial institutions such as the World Bank.

However, there are some differences in the way "contractual arrangements" are managed in the PNG agencies compared to what has been happening in other jurisdictions. There is a departure from the purely commercial arrangements often found in outsourcing generally and of policy advice (see Boston, 1994; Kakabadse and Kakabadse, 2001).

Under government arrangements with donor agencies, consultants are embedded in either a policy unit or branch of the department and therefore are seen generally as part of the unit's staff. Their salaries and allowances, however, are borne by the donor rather than the PNG government, and in cases where "counterpart funding" arrangement exist these are borne jointly by the donor and PNG government. Generally, consultants work under the direction of the head of the policy unit, perform tasks as required by the agency from time to time and are required to transfer the relevant skills to local staff. It would therefore be expected that such an arrangement

\footnotetext{
${ }^{54}$ This was mentioned in several interviews, but consultants were not attached to or working with the policy units; rather they were attached to the Public Sector Reform Management Unit.
} 
would have particular advantages in that the consultant is easily observable and where conflict exists (for instance over policy recommendations) it can be readily resolved. Further, the transfer of skills could be expected to have a strategic impact in the long term through building up capability that is currently lacking and therefore sustaining organisational effectiveness in the long run. Despite these developments, questions of accountability - for example, to whom should consultants be answerable for their performance - remain unresolved because of the dual reporting framework.

The characteristics observed above notwithstanding, generally, the experience of the three PNG agencies appears to be similar to other Westminster countries such as New Zealand and Australia where despite the use of external experts, the bulk of advice is still provided in-house. What is different is the degree in which advice is obtained from external sources: despite the public profile of international agencies PNG resorts to a lesser degree to externally provided advice than many developed governments.

\section{Tensions between Political and Policy Advisers}

The increased role of political advisers in formulation of policy advice has been a controversial one internationally, and as observed in Chapter Three one which is increasingly at odds with the classical Westminster model of separating policy advice from political or partisan advice. Evidence emerging from the three preceding chapters suggests an increasing role played by political advisers (attached to the offices of ministers) in the formulation of policy advice in PNG. This is consistent with the assessments made by King (2003) and Eichbaum and Shaw (2003) with regard to this tendency internationally.

The role played by political advisers in the provision of policy advice raises several important issues. A wider concern relates to the issue of ethical (and advisory) responsibility of political advisers whose role, as observed in Chapter Three, is ambiguous compared with their colleagues in the public service. There is no Code of Conduct for Ministerial Advisers (CCMA) (or equivalent) in PNG. This raises questions about how political advisers should go about performing their role. Because political advisers are usually closely associated with ministers (and in the case of the three agencies, powerful ministers), they may pretty much do what they want knowing that they will always be backed by the minister. Evidence provided in the three preceding chapters suggests that this might have been the case in the 
recent past. This has been evident, for instance, in policy submissions (circumventing the primary agency concern) which overlook important administrative and financial considerations. ${ }^{55}$

Secondly, there is the issue of whether political advisers are properly placed to provide competent and reliable technocratic advice. This issue is debatable. There are, however, merits to the argument that professional public servants are better placed than political advisers to provide technocratic advice. As the discussions in Chapter Three suggest, public servants (as opposed to political advisers) in providing policy advice are expected to be able to draw on institutional memory, long years of experience, in-depth understanding of policy dynamics and complex administrative and constitutional issues, and perhaps most important, their professional orientation to providing advice underpinned by technical (the merits of the case) rather than partisan considerations. It is worth bearing in mind also that the volatile political climate in PNG (of constant changes in governments and ministers) has had an adverse effect on political advisers: they have a high turn over (their tenure in office depends on the minister) and this situation tends to work against political advisers building the necessary experience and expertise on policy issues. Advice provided by political advisers (without appropriate countervailing advice, in this case from the three agencies) therefore risks overlooking important constitutional, administrative and financial implications of policy options provided to ministers (for example on the long term socio-economic benefits of the policy and the financial capacity to sustain it).

Also, the increased role of political advisers, especially without a relevant CCMA is likely to compromise or worse "mismanage" the interest of the Crown (in this case the PNG state). As observed in Chapter Three, the distinction between policy advisers (i.e., professional public servants) on the one hand and political advisers on the other has been essential (at least in theory) in shielding the interest of the Crown from partisan interests in the Westminster system: public servants (whose loyalty is to the Crown) are required to protect the Crown's interest (by being apolitical in the advice they provide), while political advisers serve the interest of their political masters; it is in their province to provide partisan advice. There is a risk in PNG of public policy (and hence the interest of the PNG state) being heavily influenced by partisan interest, especially when there is currently no code of conduct for political advisers.

\footnotetext{
${ }^{55}$ Some populist policies such as the Free Education Policy and the Electoral Development Fund or the "Slush Fund", are examples (see Mellam and Aloi, 2003).
} 
In this respect the recommendation by Eichbaum and Shaw noted in Chapter Three for a CCMA though directed at New Zealand, has some relevance to PNG.

\section{Tensions surrounding Westminster Conventions}

As observed in Chapter Three, conventions serve an important role of maintaining the integrity and reliability of policy advice provided to policy clients. Overlooking such conventions may lead to adverse consequences for the quality and timeliness of policy advice. Analysis in the prefatory part of this chapter and those of the preceding chapters has shown increasing tensions in PNG in respect of several important conventions regulating the provision of policy advice; it would appear that there are significant departures from the classical Westminster model in the application of important conventions. At this point it might be useful to recall Dorney's (1990) observation in Chapter Two that "PNG has a unique brand of Westminster parliamentary democracy". Evidence from this research (in the context of policy advice) appears to reinforce Dorney's observations.

The findings of this research suggest a public service environment constrained by a hostile political climate. The provision of free and frank advice by heads of departments (and in this case heads of the three central agencies) in particular, appears to have been inhibited by this political climate. As the evidence from this research would suggest, this environment has been shaped by a number of deeprooted problems in PNG's administrative and political system. Among them has been the lack of security of tenure of departmental heads and the constant interference in the public service by politicians. Doubts also remain about the exercise of ministerial responsibility: in most instances ministers seem unwilling to accept blame or take responsibility for advice which has already been subject to ministerial scrutiny and acceptance.

The situations highlighted above are likely to have perverse consequences on the provision of policy advice (and indeed it appears to be the case as the analysis in the previous chapters would indicate). Firstly, departmental heads are likely to compromise their position and indeed perceptions of officials would suggest that to be the case; advice may be provided on the basis of what ministers (or politicians) want to hear rather than what they need to hear. This is likely to undermine the quality of policy advice. A lack of quality advice, in turn, may lead to poor decisions on public policy issues. Secondly (and keeping in mind the lack of security of tenure and the volatile political climate in PNG), weak ministerial responsibility is likely to 
perpetuate an environment where departmental heads are unlikely to provide free and frank advice (for fear of being blamed and eventually sacked). To the extent that this happens, the PNG public service will be further politicised.

\section{Ministerial Direction of Departments}

A review of developments in developed Westminster jurisdictions in Chapter Three suggests that an increased ministerial interest (expressed through closer ministerial control and direction in the way departments should provide policy advice) has been one of the key incentives for improving the way advice is supplied to ministers. For example, this has been evident in the policy management reviews (PMRs) (spurred by increased scrutiny by parliament of the quality and timeliness of advice provided by central agencies) in Australia (Uhr and Mackay, 1996; Weller and Stevens, 1998), the development of performance benchmarks stating how advice should be provided to ministers in New Zealand (SSC, 1992; 1999; Boston et al, 1996) and the emphasis on using evidence-based analysis as a basis for providing advice to ministers in the UK (UK Cabinet Office, 1999; 2000).

Ministerial control over departments, as noted in Chapters Two and Three, has been an important feature of the Westminster system, not least in PNG. Ministers perform a significant role of being the conduit through which the executive branch exercises its "will" over the implementation of public policy. As the political heads of their department, ministers are expected to ensure that the will and intent of the executive branch is carried out and that appropriate direction is given to the department to exercise that will. Observations in the preceding chapters raise serious questions about the capacity of ministers in PNG to effectively manage the policy process and more generally to direct their departments

While ministers in PNG rely on their departments for internal policy advice, analysis in the three preceding chapters suggests that there has been little interest shown by ministers in ensuring that policy advice is supplied at a level that satisfies their expectations and those of the government as a whole. It would appear that the lack of ministerial interest in both the quantity and quality of advice may have contributed to a lowering of the quality of advice provided by officials and has provided no incentive for officials and managers to improve the internal systems and processes of advice. 
An important point regarding policy advice highlighted in Chapter Three is that departments need to know what the government intends to achieve so that they can structure the advice accordingly — for instance in advising the minister on what kind of outputs they should produce and how these outputs will contribute to achieving the desired policy objectives (outcomes) of the government (see Chapman, 1995). Ministerial communication (and direction) to officials appears be inadequate, not least in policy advice. As the review of evidence in the preceding chapters would suggest, this situation has led to confusions about the strategic intent of government in the formulation and implementation of public policy. This situation has made it difficult to organise advice in line with the government's broad vision.

\section{Lack of Strong Ownership Interest by Ministers and Government}

Ministers (and the government) play dual roles of purchaser and owner insofar as their relationship with their departments is concerned. As the purchasers of advice ministers would have an interest in getting policy advice that is comprehensive and reliable and provided in a cost-effective manner. As the owners of departments they would have an interest in ensuring that each agency is fully capable of meeting the demands placed upon it both currently and in the longer term. In the context of this study, maintaining both roles is important for ensuring a sound system of advice. ${ }^{56}$

However, the purchase and ownership roles pull the responsible minister in opposite directions often resulting in a situation where maintaining an appropriate balance on both roles becomes difficult. The ownership role, as the analysis in the preceding chapters suggests, inevitably recedes in the face of short term influence governed by allocating resources and contracting for next years' outputs. There is little evidence from the three agencies that ministers (and the government) have been vigorous in maintaining their ownership roles in the three agencies. On the contrary, the deterioration of critical facilities has been caused in part by a lack of adequate commitment of resources to the agencies over the years. Such a commitment, it is argued, is to be found at the political level where critical decisions regarding the allocation of financial resources are made.

\footnotetext{
${ }^{56}$ For example, setting a high expectation of the quality of advice and in the manner (format) advice should be provided (a purchaser role) could compel departments to provide high quality advice. On the other hand, ensuring that departments have the required resources (an ownership role) is important to maintaining the advisory capability of departments.
} 


\section{Short-term Policy Cycles}

The tendency for the short-term political imperatives of ministers (and government) to blur the long-term anticipation and planning of policy is widespread (see, for example, UK Cabinet Office, 1999; Campbell, 2001). This tendency is likely to be pronounced at times of national instability or in situations where the government has a short term in office. In PNG, political instability that impinges heavily on the activities of central agencies has been associated with the prevalence of no confidence votes in the parliament and resignation of the Prime Minister. ${ }^{57}$ Governments are short lived and as observed above there is a high turnover of ministers. An obvious tendency is that ministers and the government in the office are likely to concentrate on short-term policies thereby putting pressure on departments to concentrate on operational policy (rather than on long term policy). Within the three agencies there was some concern from the officials that the overwhelming concentration on operational policy advice may have crowded out the need for strengthening capability for substantive and strategic policy advice. The demand for instantaneous policy advice for largely short-term policy also risks compromising the need to comprehensively analyse issues and may generate short-term policy solutions instead of realistic long-term solutions. ${ }^{58}$

\section{Evaluating Policy Advisory Capability}

The need to unravel the factors that account for a lack of policy advisory capability and the effect such factors have on policy advice has been the central thrust of this study. The detailed examination of the capability of each central agency in Chapters Six to Seven has been a response to this objective. Hence, there is no need to discuss them in detail here. In what follows, a rehearsal of the main constraints is put forward followed by a summary of various policy implications arising from a lack of policy advisory capability. However, it is first necessary to make two important observations that should be borne in mind in the following discussion. First, constraints on policy advisory capability are interlocked; many are complex; and

\footnotetext{
57 The effects on the executive branch in managing policy and providing the appropriate direction to departments arising from the constant change in governments are well documented in PNG (see, for example, Saffu, 1992; Reilly, 1992; 2002a). No government since the first general election in 1977 after independence in 1975 has survived a full term in office. In total, there have been three successful votes of no confidence in the government and two prime ministerial resignations (Larmour, 2000).

${ }^{58}$ Curtain's (2000) analysis of the short-term financial solutions to PNG woes in financial management in the 1999 budget at the expense of realistic, long-term strategies in fiscal policy management illustrates this point.
} 
some create conditions for others to be nurtured. Second (and as observed in the first part of this chapter), there is a political as well as administrative and organisational dimension to the constraints. The political dimension (and its various implications) has already been treated in the prefatory part of this Chapter. The main constraints summarised here are those of the organisational and administrative dimension.

\section{Funding Difficulties}

Funding difficulties (either the absence of funds or insufficient funding) appears to have been systemic right across the three agencies for a long period and a major cause of the predicament currently faced in the provision of policy advice. Difficulties in funding are compounded by a lack of effective management of funds, and as the perceptions of officials in the previous chapters would indicate, a frequent diversion of allocations to items other than those concerned with policy work.

Funding difficulties appear to have contributed directly to a neglect of investment in knowledge and skills development, poor data for analysis, and a deteriorating office infrastructure unable to support high quality policy work.

\section{Quality of staff}

\section{Gaps in the Qualification and Skills of Staff}

In their influential book, Policy Analysis: Concepts and Practice (1999), Weimer and Vining point out that policy analysis on which policy advice is based essentially depends on the quality of skills and knowledge of policy analysts and how they use such skills and knowledge for a variety of policy assessment work. Policy staff possessing the right kind of skills and knowledge are able to provide robust "examination and interpretation of data and other information both quantitative and qualitative, to provide insights to improve the formulation of policy and delivery of services" (UK Cabinet Office, 2000:8). Put another way, possessing the requisite skills and knowledge and knowing how to utilise them allows policy staff to: (a) carry out a systematic comparison and evaluation of alternatives to contribute to solving social problems, (b) synthesise existing research and theory, including the use of evidence to predict consequences of alternative policies, and (c) be able to meet strong deadline pressures to provide the necessary advice (Weimer and Vining, 1999: 30). 
There are obvious gaps in the current level and quality of skills among policy officials in the three PNG agencies and these tend to undermine their capability to perform high quality policy work. Specific skills that were found to be lacking include a lack of information technology skills; the need for more in-depth statistical skills to be able to formulate and interpret data; the need for skills in collecting and analysing evidence including the ability to use information from various reports and studies, writing and presentation, and communication skills; and a sound understanding of the political environment.

\section{Neglect in Investing on Knowledge and Skills Development}

An enduring theme in the field of development administration regarding human resource development centres on training staff so that they can acquire the skills and expertise necessary to effectively carry out the tasks they are entrusted to do (Edoho, 1998; Franks, 1999; Kirkpatrick and Mann, 1999). Efforts in training are rightly seen as an investment because organisations reap the benefits in future if they devote their resources and time to building staff competence (SSC, 1997; Ulrich, 1998).

Gaps in the qualifications and skills across the three agencies, as this research suggests, are compounded by the lack of a consistent investment in knowledge and skills development over the years. This situation tends to lead to a long list of officials waiting to be trained and has placed heavy pressure on future training budgets. Because fewer officials are trained, the gaps in skills tend to widen over the years thus affecting the effectiveness of policy units. Various interwoven causes have directly or indirectly contributed to the lack of intensive effort in training officials. These include lack of funding, poor management capacity to formulate training plans, mount training programmes and manage training funds, and a heavy reliance on donor agencies (which according to officials has led the agencies and the government to shirk their responsibility).

\section{Gaps in Imbuing and Nurturing Knowledge in Policy Work}

It is generally expected that certain aspects of policy work can and will be learned and nurtured whilst in the job; this expectation, however, depends on a favourable work environment and work processes. In development administration, Kirkpartrick and Mann (1999: 1) refer to this as "the closer linkage between working in the organisation and learning on the course". Excellent work environments and good work process are not only "tools of developing work commitment" (Ulrich, 1998), but 
are also catalysts for imbuing staff with relevant learning and transfer of skills, and provide an alternative to formal training. In short, they are the avenues through which the generation, transfer and diffusion of new skills and knowledge takes place within an organisation.

Evidence in this study suggests that in the three central agencies there is limited accumulation and generation of an appropriate knowledge base committed to rigorous policy work where it could be easily transferable among policy staff. It has been difficult to develop and transfer relevant organisational knowledge in policy analysis work because of the current scarcity of expertise and talents to develop, accumulate, and transfer relevant knowledge and skills in policy advisory work.

\section{Experience in Policy Work}

Experience matters in policy advisory work. According to Chapman (1995: 19), "an adequate understanding of the problems 'on the ground' is hard to develop if policy advisers are too cloistered and lack a real 'feel' of how people and institutions are behaving". Experience is built and natured over time, and skills in policy analysis are dependent on the time spent on building experience-this is the reason why policy analysis is often referred to as an art developed through learning from experience (see Wildavsky, 1979, Weimer and Vining, 1999).

Lack of experience is a common problem among the three agencies. The majority of staff in the three central agencies, as the analysis in the three preceding chapters would suggest, are fairly junior officials lacking the necessary experience for sophisticated policy work, especially on substantive and strategic issues (officials have an average of three years working experience in DF\&T and DPM \&NEC, and two years in DPM in the current position, i.e., within the policy advisory unit). The time lag to develop the necessary experience is also crucial. Shortening this time can be aided by appropriate mentoring and support from senior staff — for example in on the job training or working under the guidance and supervision of senior staff in joint policy work. However, relevant support and mentoring of junior officials were seen as inadequate.

\section{Work Overload, Recruitment and Retention Difficulties}

One problem identified in the present study is that policy officials in the central agencies are overloaded with work beyond manageable levels. The mismatch between higher workloads on the one hand, and fewer staff on the other has not 
surprisingly led to situations where capacity is stretched too thin, resulting in staff being unable to cope with the demands for producing high quality policy work in a timely fashion. Evidence from this research would suggest that this situation is attributable to both recruitment and retention difficulties. These are compounded by a lack of funding and administrative foresight in filling vacant positions

\section{Level and Quality of Resources}

Advisory systems operate in an integrated fashion, requiring not only quality staff and good processes and systems, but also a level and quality of resources (other than staff) that allow staff and systems to function effectively. Although the demand for adequate resources is common across public sector organisations, policy advisory work is a specialised task requiring specific resources critical to maintaining capability. Examples are computers and database systems which help to create and sustain knowledge within an organisation (Waller, 1992; Franks, 1999; Office of the Provincial Auditor, 2000) and direct commitment by government to sustain its ownership interest through purchasing and meeting the ongoing costs of maintaining necessary assets.

This study has found that there has been deterioration (and in some instances a complete neglect) of both the quantity and quality of resources required to sustain the organisation and delivery of high quality policy advice. This has been evident in the lack of data and information necessary for rigorous policy analysis, poor management and use of data, a lack of information and communication facilities such as the use of the Internet and departmental library and the inadequacy of support materials. A key problem has been a mismatch between the demand (both in terms of quantity and quality) for resources and funding of important facilities. Neglect, and especially fluctuations in funding, has meant insufficient financial support to maintain important facilities adequately. As the analysis in the three preceding chapters would indicate, such constraints appear to have weakened the ability of policy units to respond decisively and comprehensively to the policy advisory needs of key policy clients.

\section{Organisation and Management of Policy Advisory Work}

The organisation and management of policy advisory work are critical to ensuring that the final output (policy advice) is reliable, comprehensive, timely, and presented to the satisfaction of the minister and cabinet (UK Cabinet Office, 2000). This depends on the competence of top management and the ability of the leadership of 
the policy unit to manage resources and staff, set priorities and benchmarks for policy work, communicates expectations of policy work to staff, and continue to monitor and appraise staff performance (Anderson, 1997; Bhatta, 2002). Anderson (1997: 472), drawing from the Canadian experience, observes that delivering good policy work in government is a major managerial task and requires strong leadership in strengthening policy capacity.

Evidence from the present study would suggest that the existing systems and process of organising and delivering policy advice within the three agencies are inadequate to sustain quality policy advisory work. Some of the problems discussed earlier stem directly or indirectly from the inadequacy of the existing systems and processes of organising policy advice.

\section{Lack of Effective Management of Policy Advice}

Analysis in Chapter Two and the three preceding chapters would suggest that policy units are task-specific. Their design is shaped by the need to respond to the immediate and long-term tasks of providing operational, substantive and strategic policy advice. How best the policy unit of a department responds to these tasks is not only a function of staff knowledge and skills coupled with adequate resources, systems and processes; it also depends on the knowledge and skills of the policy manager. In Wolf's (2000: 24) perspective, "policy leaders must be competent in the area in which policy advice is proffered". According to the SSC (1992), understanding the political context, being able to put issues into their right perspective, having a good ethical orientation, knowing how to consult relevant stakeholders, understanding relevant process of channelling policy advice, and being able to communicate advice in a effective manner are some of the critical skills both policy analysts and policy managers should have.

Inability to manage policy units effectively was a primary issue that emerged from the analysis in the preceding chapters. One critical area, which was found to be lacking, was "policy leadership" (Wolf, 2001). Policy managers were found to exercise weak leadership, evident in their inability to "synthesise, interpret and steer the work of policy teams", to borrow Anderson's (1997: 478) conception. As the survey of the three departments in previous chapters suggests, weak leadership tends to be reflected in poor management of staff and other key resources. 


\section{Poor Quality Assurance}

When appropriately organised, policy advice can be produced in accordance with the required standards of quantity, quality and timeliness (see Chapter One). A major trend in recent international changes in the advisory systems noted in Chapter Three and rehearsed again in this chapter has been the concentrated focus on improving the quality and timeliness of policy advice using better quality assurance processes (SSC, 1999a; UK Cabinet Office 2000; Sanderson, 2002, Bhatta, 2002). Such processes encompass level of performance or standards that define "best practice" (or a range of working practices and policies) in policy advisory work and how such standards will be constantly monitored and reviewed (Camp, 1989, Watson, 1993, Auluk, 2002). In the international experience that was reviewed in Chapter Three, it has been shown that many countries are using such assurance processes to improve the way advice has been provided to key policy clients.

The survey of the experience of PNG officials in the three preceding chapters points to the absence of any formal quality assurance process: there are no prescribed benchmarks (for instance on the quantity of advice expected, the basic protocols of analysing policy issues and the responsibilities of advisers to ministers - see Chapter Three) for guiding and monitoring policy advisory work; peer review is seldom encouraged; and there has been little monitoring and evaluation of policy advisory work.

An obvious risk is that without any formal benchmarks (for instance on how policy advice should be presented and what should be taken into account when presenting options to ministers) there is a risk that policy issues will not be comprehensively assessed taking into account the available evidence, views of parties concerned and, most important, the possible implications of a lack of concrete action by the government (in situations where the government is unlikely to respond) or the range of options available (if government chooses to respond) (Davies et al, 1999; Leicester, 1999; Sanderson, 2002). The lack of clear ministerial expectations about policy advice (an issue discussed earlier) is also likely to exacerbate this risk. Furthermore, an absence of prescribed public service standards for policy advisory work is likely to inculcate a poor work ethic among analysts: officials who know that their work is not going to be subject to scrutiny may well not take their work seriously. Overall, the lack of benchmarks for ensuring the quality of advice is likely to compromise the comprehensiveness and reliability of advice to the ministers and 
NEC and may lead to situations where ministers and the NEC are ill advised on policy issues.

\section{Conclusion}

This chapter has presented a broad summary evaluation of the status of central agency policy capability in PNG building on the analysis of the previous chapters. Discussions on the political dimension of the status of policy advice in the first part of this chapter have raised several key points. One is that there have been some fundamental shifts in the conventions regulating the provision of advice, and that this has given rise to various tensions. For example, there has been an increased tendency for political advisers to be involved in the provision of policy advice in PNG. This raises the question of whether they are suitably positioned to provide policy advice and also has implications for the separation of policy advice from political advice. As the analysis in the prefatory part of this chapter suggests, the increased involvement of political advisers has brought certain risks to the formulation of advice including the likelihood of partisan interests influencing advice and the subsequent formulation of public policy, and, as a consequence, ministers and the NEC being inadequately or wrongly advised.

There are also increased tensions surrounding the principles of free and frank advice and of ministerial responsibility (certainly the exercise of those principles has shifted away from those in the classical Westminster model): departmental heads may well not provide free and frank advice given the hostile political environment and the likelihood that ministers will not accept blame and responsibility for the actions they have taken on advice. Both of these tendencies, as noted in the foregoing discussion, are likely to undermine the role of professional public servants in providing policy advice.

A fundamental recent shift in the policy advisory process has seen the statutory dominance of the CACC. An important point worth restating here is the likelihood of the competition between the voice of "the minister" (particularly the minister whose head of department is not a member of the CACC) and the "voice of the CACC" given that CACC will now inject advice directly to cabinet level debates. It would appear that this situation was not considered when the role of the CACC was defined. And, as noted earlier, to the extent that CACC becomes dominant the primacy of ministers over policy formulation, a key feature of the Westminster tradition, could well be further weakened. 
Although there has been a consolidation of power in the collectivity of the three central agencies (primarily through established statutory provisions and especially the creation of the CACC) there are doubts about the overall capability of the three agencies to provide quality and timely policy advice on operational, substantive and strategic policy issues. As noted in this chapter, problems arising from the political dimension coupled with funding difficulties, problems relating to the quality of staff, inadequacies in both the quantity and quality of resources, and the poor organisation and management of policy advisory work have placed strain on the capabilities of the three agencies. This situation raises several important implications.

First, there are implications for the operational effectiveness of the three agencies. A central operational feature of departments in PNG (and the three agencies) as observed in Chapter Two and especially in Chapter Five is the primacy of the policy units on nearly all matters of policy. As noted in Chapter Five:

[Policy] units do much of the work in both the formulation and implementation of policy; they are the linchpins of the policy advice process, providing nearly all the in-house advice to their parent department and the government. Officials from these units comment on most policy briefs and submissions; they carry out most research work within central agencies; and are responsible for devising most policy proposals originating from central agencies. .... in circumstances where policy work is required at short notice, or involves collaboration with other departments, lead policy units usually attend to such demands.

On the basis of the existing evidence, there can be no doubt that the capability of the policy units have been weakened, and that this situation is likely to affect the operational efficacy of the three central agencies. For example, key functions such as those relating to maintaining coherence and conformity to various policy guidelines on a diverse range of policy and management issues and monitoring and evaluating performance are likely to be undermined. Overall, there is a risk of the centre of government losing its ability to control and steer the government machine.

Of primary concern is the likely effectiveness of the CACC as the primary advisory committee of cabinet. The weakness of the policy advisory capability of the three individual agencies is likely to reduce the ability of the CACC to provide comprehensive and reliable advice to cabinet. This, in turn, may weaken the executive branch's effectiveness in policy formulation. At risk also are the other 
functions of the CACC. As noted elsewhere in this study, apart from advising the NEC, CACC gets much of its advice and support from the three agencies to perform its other core functions - of maintaining policy coordination and coherence across government, evaluating the performance of departments and their heads, and providing scrutiny on policy submissions and advice emanating from the public service. The inherent weaknesses in the capability of the three agencies raise doubts as to whether the three agencies can provide the necessary support (and advice) to the CACC to effectively discharge these functions.

There are also important implications for the role of the minister. As the analysis in Chapter Two demonstrates, ministerial direction of departments in PNG is maintained by a vertical command-control relationship between the minister and the department on the one hand, and, on the other, the minister and the NEC. Ministers exercise control and oversight (on behalf of the political executive) over departments and advise the NEC on the basis of departmental advice. If a lack of capability in the central agencies affects adversely the quality of their advice to the minister his or her advice to cabinet is, in turn likely to be inadequate. 


\section{Chapter Ten: Strengthening Policy Advisory Capability - Some Policy Lessons}

\section{Introduction}

Analyses in the preceding four chapters show a weakening policy capability arising from varying and often complex causes. Measures considered for strengthening the advisory capability of the three agencies, and generally within the centre of government in PNG, would need to take into account these various causes. At another level, measures would need to focus on strengthening the broader political environment and the organisational and administrative context within which advice is provided. The aim of this chapter (Chapter Ten) is to consider, against the insights of new institutionalism and especially the policy transfer literature discussed in Chapter Four and bearing in mind the particular constraints identified in the preceding four chapters (Chapters Six to Nine), the case for adopting various policy lessons (policy intervention measures) from the experiences of developed Westminster countries. ${ }^{59}$ The primary objective of this exercise would be to strengthen the agencies' capability (and more broadly that of PNG's central government) in providing quality and timely policy advice.

Two areas are given particular attention in the chapter: (a) how the transfer of policy lessons might take place, and (b) the consideration of relevant lessons of reform. The former clarifies the process by which lessons might be transferred from developed Westminster models to PNG. It focuses on some of the key issues and questions of lesson drawing found in the literature, especially those highlighted by Dolowitz and Marsh (2000). The latter identify policy lessons and demonstrate how they might apply to strengthening policy advice. To avoid some of the pitfalls of lesson drawing identified in the literature — for example, those arising from mimetic isomorphism, and the copying of lessons based merely on their perceived superiority without actually assessing their viability - the chapter uses prospective evaluation ${ }^{60}$ (Rose, 1993) to evaluate and predict the viability of policy lessons. However, before proceeding it is necessary to make an important point that should be borne in mind in

\footnotetext{
59 There is undoubtedly scope for PNG to draw from the experience of other developing countries. This study has focused on lesson drawing from the developed Westminster jurisdictions not only because of the comparatively much greater amount of information available but also because the process of diffusion through multilateral agencies and consultants tends to transfer lessons from developed to developing countries.

${ }^{60}$ For a discussion of "prospective evaluation" see Chapter Four.
} 
the following analysis. Lessons suggested in this chapter are by no means exhaustive; nor should it be assumed that the lessons proposed are adequate to address all the capability gaps identified in this study. Indeed, the multifaceted nature of many of the problems leading to a loss of capability would mean that lessons suggested may not be adequate on their own and that policy actors should take a long term and holistic approach (i.e., addressing capability problems consistently over the years bearing in mind this interlocking nature).

\section{Institutional Change and Lesson Drawing}

Discussions in Chapter Four raise important points about the dynamics of institutional change, what accounts for it and the resultant effects of such changes. Against the context of the discussion in Chapter Four, this prefatory part of Chapter Ten briefly analyses the institutional pathways of policy advice and the positive effects these pathways will have on lesson drawing. It places particular emphasis on the role of the executive branch, the public service and ministers in effecting change in the existing policy advisory arrangements.

As mentioned in various places in this thesis, advisory arrangements in PNG's central agencies follow the Westminster tradition although there are variations. The role of parliament and more specifically cabinet is critical to introducing changes to the existing arrangement of policy advice. Parliament's scrutiny of the executive branch's policy decisions will be crucial in changing the way policy advice is sought by the executive branch because of the presumption that executive branch decisions will normally be based on advice. Thus configurations in the demand for advice plus the quality of advice received - changes which will clearly alter the "customs and practices" of existing advisory arrangements - are more likely to happen if parliament steps up its scrutiny role.

As is the case with other Westminster systems, cabinet plays a powerful role in the structure of advisory arrangements in central agencies. In improving policy advisory capability, cabinet will need to consider the prevailing advisory arrangements - that is, where it receives advice, how advice is crafted and tendered, and the quality assurance required. - and make the necessary changes in the way advice is provided by the three central agencies. Any successful adoption of lessons therefore will require cabinet's support in carrying out the necessary changes in the advisory arrangements. 
The role of ministers as agents for change is also crucial in reinvigorating the fledgling capability for policy advice within central agencies. Ministers are the most important clients for policy advice and they receive advice almost on a daily basis. And as alluded to elsewhere in this thesis, the demand for high quality policy advice must come from ministers. Change in the existing advisory arrangements is unlikely to be effective if ministers are unwilling to tackle the way advice is produced and delivered by their individual departments.

On the bureaucratic front, the CACC will need to play an important role in precipitating change that will ensure improvement in the advisory capability of the three central agencies. Like the cabinet, CACC will have to improve its scrutiny of advice and perhaps reconfigure the way it receives and "reconstructs" advice for presentation to cabinet. Being a powerful committee, CACC will need to concur with proposals for wider reforms on the advisory arrangements and ensure that these reforms take effect. Without CACC's commitment, moves to transfer policy lessons to improve policy advisory capability in PNG are likely to fail.

While Cabinet, ministers and the CACC are important agents for introducing institutional changes in the provision of advice, their "buy-in" will not be sufficient by itself. As observed in Chapter Four, institutionalised systems and processes - and in this case the systems and processes of policy advice - are shaped by the exogenous environment in which they are located. In PNG the political environment (and to a lesser extent, the bureaucratic environment) is critical. Hence any meaningful institutionalised improvement in the provision of advice will require a change in the wider political environment that shapes the way advice is tendered. In that regard, several changes will be necessary. For example, the Westminster conventions governing the provision of policy advice will have to be taken seriously and practised. Also, the electoral system's encouragement of the tendency to opt for the provision of short-term advice (against long-term substantive advice) will need to be looked at seriously. On the bureaucratic side, the system of appointment and tenure of office of departmental heads will need to be modified to foster stability and continuity. This in turn will have a positive effect on the provision of free and frank advice. Finally, ministers and senior public servants will need to be grounded in strong ethical principles underpinning the discharge of their responsibilities with integrity and honesty. For example, ministers should give preference to sound technocratic advice rather than allowing themselves to be strongly influenced by self- 
interest (rational choice institutionalism). By the same token, public servants will need to provide advice without fear and favour, untainted by political imperatives and self interest.

\section{Lesson Drawing Process}

Comparing and contrasting political jurisdictions and organisations for lesson drawing purposes can be a difficult exercise (Rose, 1991; 1993; Bennett, 1997). As shown in Chapter Four, questions arise about the form of the transfer process, which policy actors will get involved, what lessons are to be borrowed and what type of lesson drawing will be considered. A key issue pertains to the compatibility of transactions between jurisdictions; that is, whether jurisdictions, institutions and organisations that appear incompatible - for instance, developed and developing countries - can borrow policy lessons from each other. One particular danger is that if the lesson drawing process is not clearly specified, contentions can arise as to the feasibility of the process itself. For example, the copying method (Rose, 1993; Bennett, 1997) is often criticised because it fails to consider contextual differences (see Schick, 1998; Pollitt, 2001).

Schick's (1998) caution to developing countries not to try New Zealand's model of contract-type management in their public sector because of differences in market institutions is illustrative of the "argument of incompatibility". He contends that incompatibility exists in the regulation of the market and therefore market type reforms will fail in developing countries if the rule of law (especially, the protection of property rights) is not strengthened and enforced. However, a key point omitted in Schick's analysis is that developing countries can draw inspiration from the innovative changes in New Zealand and devise their own reform programme shaped by their particular context (see Bale and Dale, 1999; Boston, 1999). Or they can emulate rather than copy aspects of contract type management since it is already in existence in developing countries - for example in public construction, works and infrastructure development. 
As Rose (1993: 118) mentioned:

We cannot expect programmes to be completely fungible, transferring easily from one government jurisdiction to another, equally we cannot expect total blockage. The fact that a programme is in effect somewhere else demonstrates that it is not inherently impossible to implement.

Dolowitz, in a recent article (2003: 101), hails the merits of lesson drawing, even between political jurisdictions that seem to be far apart:

... two of the most important lessons a policy-maker can learn are, first, that foreign political systems often offer interesting laboratories of policy innovation, and second, that it is often possible to use the work done in these laboratories in the development of policies within a policy-maker's own political system.

Describing the transfer process helps to unravel perceived confusion surrounding the transfer of lessons.

\section{Similar Problem(s) and Goal(s)?}

A key question in policy transfer that justifies the consideration of drawing policy lessons from other jurisdictions is whether a similar problem(s) is being encountered in the country or organisation that aims to "import" the lessons being considered (Rose, 1993; Mossberger and Wolman, 2003). Also, policy lessons that attempt to achieve similar goals are often seen as another justification for policy transfer. The aim is not just to see whether the jurisdiction that aims to adopt particular lessons has a similar problem, but rather to go beyond that and see whether borrowed lessons will serve similar policy goals at their point of application. In the case of the three PNG central agencies, there can be no question that both conditions hold. For example the problem of poor quality of policy advice has been similarly confronted in many developed jurisdictions and has subsequently triggered initiatives aimed at improving the quality and timeliness of policy advice (Halligan, 1995; Boston et al, 1996; Uhr and Mackay, 1996; Anderson, 1997; Sanderson, 2002; UK Cabinet Office, 2000).

Furthermore, the aims of the reform (directed at tackling the problem) are broadly similar, though the initiatives may differ in degree and kind. In New Zealand, for example, the quest for improved policymaking capacity (and improved policy advice) has been evident, inter alia, in the policy/advisory split of departments (Scott, 2001) 
and the ongoing work of the State Services Commission seeking improvement in the capability of line departments and agencies in the provision of advice (SSC, 1999; 1999a). In the UK, this was evident in the quest for evidence-based analysis and effective policy formulation where emphasis has been placed on the need for public service organisations to improve the quality of policy analysis, and the split of departments into policy ministries and executive agencies responsible for delivery (UK Cabinet Office, 1999; Flinders, 2002; Wilson and Barker, 2003). In Australia, this was demonstrated in various attempts to improve the policy advisory process at the federal level (Waller, 1992; 1996; Weller and Stevens, 1998; Di Francesco, 2002).

It can be said that the nature of the problem, namely the perceived inadequacy of the quality and timeliness of policy advice, has been similarly confronted in virtually every political jurisdiction embracing the Westminster model of government and therefore is a universal problem in such systems (see Halligan, 1995; Andeweg, 1999; Weller and Stevens, 1998; SSC, 1999; UK Cabinet Office, 2000; Provincial Auditor, 2000). Factors accounting for the poor quality of advice often, however, differ among countries. In the case of PNG there is a clear problem of a deteriorating capability in the provision of advice, a problem that has been similarly confronted in developed Westminster countries where expectation of the quality of policy advice have not been met. This similarity in the problem therefore justifies the consideration and adoption of appropriate policy lessons from developed Westminster models that have attempted to improve their systems and processes of policy advice through a variety of reforms.

\section{Types of Transfer}

Voluntary adoption of lessons is proposed in the case of PNG. This type of lesson drawing entails the active engagement of those who adopt lessons (usually policy makers) in identifying relevant lessons, assessing their merits and considering how they should apply in the setting where the lessons are going to be adopted (Dolowitz and Marsh, 2000). The essence of this type of lesson drawing is based on the personal volition of policymakers because of the obligation to fix a perceived policy problem.

The technique(s) of transfer employed tend to determine whether the transfer of lessons will be successful or not. For example, copying which entails the transfer of the exact policy lesson from one setting to another can have a particular drawback in 
that lessons might not suit contextual settings (for instance they might be at odds with prevailing political and institutional structures). As a result transferred lessons might not have the desired impact at the point of adoption. The lessons proposed in this study would involve a combination of transfer methods encompassing emulation (lessons adjusted to particular settings), inspiration (development of novel lessons as a result of stimulus elsewhere), copying (transfer of the same lessons and/or policies) and synthesis (combination of policy lessons and where relevant modifications of such combinations) (see Rose, 1991). It is posited that the types of transfer will be determined by the nature of the problem and/or constraint addressed and, more significantly, whether the mode of transfer will create a positive impact in the point of their application.

\section{Who will be involved?}

It is argued that any meaningful transfer to reinvigorate policy advisory capability in PNG would need a concerted and cooperative effort of four key categories of actors: (a) cabinet and ministers who politically manage the three agencies and therefore can influence reform at the political level, (b) respective departmental secretaries who can initiate change at the top management level, (c) policy managers who can initiate change at the policy unit level, and (d) senior policy analysts and policy analysts who can initiate change in their immediate work environment.

\section{What Lessons are to be drawn?}

Experience in developing new methods of improving policy advisory capability in developed Westminster models, as well as innovations in improving the performance of the public sector as a whole, provides a myriad of useful policy lessons. Copying, emulating, synthesising and drawing inspiration from such developments therefore can assist in enhancing the quality of policy advice generally, and more specifically of the capability of the three agencies.

Lessons considered in this chapter could be policy ideas waiting to be borrowed and utilised; they could be actual policies that are in place elsewhere; or they could be policies (ideas) that have been tried but abandoned. Discussions in this chapter will generally focus on both negative and positive lessons (Rose, 1993). As pointed out in Chapter Four, the former entails those lessons that are not worth copying because of their lack of feasibility or negative impact. Such lessons serve as "signposts" warning policymakers of the dangers about borrowing such lessons. Positive 
lessons on the other hand are worth considering because of their perceived favourable impact on policy once applied.

\section{Applying Policy Lessons: Broader Considerations}

\section{Policy Awareness and Policy Learning}

Any meaningful and sustained reform in improving the quality and timeliness of policy advice in PNG must begin with a wider and comprehensive awareness of the central importance of policy advice to policymaking generally and the significant role of policy advice in ministerial and cabinet deliberations. Such awareness is necessary as it is the first step to policy learning, and makes the subsequent drawing of policy lessons easier (Rose, 1993; May, 1999). An essential ingredient is an appreciation of the task of reforming advisory systems and the dangers that poor organisation and delivery of policy advice pose for the centre of government.

In many developed Westminster systems awareness of the need to reinvigorate policy advisory capability has been one element of the wider process of reform concerned with improving the effectiveness and efficiency of the public sector. In the UK, this has been evident in the Modernising the Government agenda (UK Cabinet Office, 1999; 1999a; 1999b), a key initiative of the Blair government, which seeks not only to improve public service delivery, but also constantly to revise and upgrade the quality of public services as deemed necessary by the recipients of government services. A similar initiative, but with a different policy focus and emphasis, can be seen in the New Zealand Treasury's documents - Economic Management (1984) and Government Management (1987) — which identified key problem areas in the economy and public service and proposed measures for reform. In Australia too the National Audit Office (ANAO) is calling for good corporate governance and for the definition and communication of the benchmarks of good corporate governance (Edwards 2002: 53). According to Edwards (2002: 54), the task:

[... of the ANAO] is not to simply define the elements of sound corporate governance, but to ensure that all the elements of good corporate governance are effectively integrated into a coherent corporate approach by individual organisations [departments] and are well understood and applied throughout those organisations.

Awareness of the problem is a necessary but not a sufficient condition; concerted efforts are required, focusing on specific policy domains and pinpointing precisely the 
problems and emphasising the urgent need to tackle them (including highlighting the serious consequences that might occur as a result of inaction). Awareness also should be focused on the stakeholders who matter most in the particular policy domain - for example, public servants and politicians who are responsible for ensuring that the reform takes place. In policy advice, the best example can be seen in the UK case. Concerned with the need to improve the quality of policy making, the Blair government established the Performance Innovation Unit (PIU) in 1998 and other "cross-cutting units" within the Cabinet Office to "address strategic and crosscutting issues and promote innovation in the development of policy..." (Flinders, 2002: 60). As part of the Modernising Government effort, the PIU together with the Cabinet Office initiated a comprehensive and broad awareness campaign through the development and dissemination of critical policy documents. These were intended not only to make departments and agencies aware of the importance of improving policy, but also to communicate the vision and policy objectives of the government. In policy advice, two key documents - Professional Policy Making for the Twenty First Century and Adding It Up: Improving Analysis and Modelling in Central Government - were indicative of this wider effort to convey a serious message to public servants and other stakeholders about the immediate need to reinvigorate policy advisory capability if the government is to tackle complex policy problems in the Twenty First century (see Sanderson, 2002; Flinders, 2002).

A similar approach in creating policy awareness could be seen in other initiatives to improve performance such as the Best Value Framework (BVF) aimed at improving policymaking and the quality of service delivery of local government (Boyne et al, 1999; Martin, 1999; Auluk, 2002; McAdam and Walker, 2003. According to Martin (1999: 58):

... almost from day one, ministers and their envoys have embarked on a punishing schedule of national speaking engagements and visits to individual councils designed to generate bottom-up support for change.

In fact, the UK Government has gone a step further in its attempts to foster greater policy awareness among key stakeholders within and outside of the government, and in developing cutting-edge solutions. Whereas in countries like New Zealand the pattern has been to lift awareness through central agencies like the State Services Commission (SSC), the UK Government created a specialised learning and policy development agency within the Cabinet Office - the Centre for Management and 
Policy Studies (CMPS), the principal purpose of which is to educate and train ministers and civil servants in the virtues of effective policymaking ${ }^{61}$ and how best the quality of public services can constantly improved. The role of the CMPS for example, is reflected in a recent report by the Cabinet Office, which observes that:

... training of new Ministers and for senior civil servants run by the Centre for Management and Policy Studies should emphasise the importance of analysis for evidence-based policy (UK Cabinet Office, 2000: 5).

Thus CMPS, apart from the PIU, is being used as a conduit for normative isomorphism, disseminating policy ideas through a professional network (in this case comprising ministers and civil servants) throughout the public sector (see Auluk, 2002).

A key problem in PNG is that key stakeholders (ministers especially) appear oblivious of the importance of improving policy performance. If they have concerns they have shown little indication of them - for example, the analysis in Chapters Six to Eight indicates that the demand for good analysis is weak especially at the ministerial level. In Australia and New Zealand, on the other hand, Ministerial dissatisfaction with the quality of policy advice and a requirement for its improvement triggered much-needed reforms (Weller and Stevens, 1998; Bhatta, 2002). This problem tends to be shown as well at the departmental level in PNG. For example, the limited efforts devoted to sustaining the quality of policy advice at the managerial level suggest that policy managers and departmental heads are not really aware of the central contribution of quality policy advice to effective policymaking.

Reforms in the three PNG central agencies could emulate the UK's experience. In particular, there are lessons worth considering in the techniques of running awareness strategies, formulating the objects of reform initiatives, and in deciding who should be involved in the awareness and development of policy ideas. In PNG the Public Sector Reform Management Unit (PSRMU) within DPM\&NEC could take charge of the exercise because it was primarily set up for that task; it has some implementation capacity because of the support it has been receiving from bilateral and multilateral donors in providing consultants to help perform its tasks. In developing an approach to the dissemination of ideas, the PSRMU could synthesise

${ }^{61}$ The UK Cabinet Office refers to "policy analysis" as "policymaking" in its various policy documents. 
or emulate the UK's approach in which key documents, reports, training and seminars are the conduits for policy awareness and initiation of much needed reform. Provided that key policy officials and ministers are well informed by the PSRMU, and therefore understand the existing problems of policy advice and new reform initiatives, they in turn could carry back to each central agency the ideas for improving policy advisory capability.

\section{Managing the Change Process}

A key question directly applicable to developing countries like PNG which seek to reform the organisation and delivery of policy advice (and for that matter any other aspect of public management) is whether agencies should do it alone — or do they need a broader support from government to initiate the change process? The reality is that departments and agencies in PNG do not have the capability to initiate the change process needed. The present study has demonstrated this to be the case in the three central agencies. To propose policy lessons based on experience elsewhere on the presumption that departments can adopt them without any assistance is unrealistic.

Experience in some developed Westminster models reveals different approaches. In New Zealand for example, while the SSC produces most of the policy documents and develops standards of improving policy advice (see SSC, 1992; 1999, 1999a, 1999b), much is left to individual organisations to take the initiative within the broad framework devised by the SSC to start the change process in their organisations. Most departments, building on the awareness and initiatives created by the SSC, have taken measures to improve their policy advisory capability, though much work remains in improving policy advisory capability (SSC, 1999b, 1999c).

A quite different approach can be seen in the UK's case. Here, the government has built a wide network to support the Modernising Government initiative of the Blair government. This network was not only responsible for creating awareness among those who are responsible to implement the Modernising Government programme, but was also used to develop ideas, run training programmes, provide the necessary leadership in pulling departments and agencies together, coordinate the reform strategies, monitor and evaluate aspects of the reform, and feed performance information back to the reform process for continuous improvement (UK Cabinet Office, 1999; 2000; Ling, 2002). For example, both the PIU and the CMPS were instrumental in coordinating the various efforts to improve policymaking; they set the 
required performance standards and ensured that departments worked to improve their capability. As mentioned earlier, the CMPS was also used in training ministers and senior civil servants in the techniques, approaches and process of reforms (see Cabinet Office, 2000; Flinders, 2002). In the case of the BVF for local governments the Audit Commission for Local Authorities and Health Service for England and Wales has established the Best Value Inspectorate whose role is to evaluate the implementation of BVF, suggest necessary improvements and, where possible, to help local councils to improve delivery and quality of services using various performance information derived from evaluation exercises (Boyne et al, 1999; McAdam and Walker, 2003; Kelly, 2003).

It can be argued that two different premises underpin the different approaches taken in New Zealand and Britain. In New Zealand, there was an understanding that generally departments would have the required trained manpower and resources, and that minimal external guidance in implementing the change process is needed once general frameworks are established. In the case of the UK, the opposite appears to hold. The overall approach was shaped by the presumption that reformers within departments and agencies need effective guidance and where necessary they ought to be trained and assisted in implementing reform initiatives. Furthermore, coordinating such efforts and feeding information back to the process was seen as crucial to the success of the reforms.

A similar approach to the UK, but relying on the use of an interdepartmental committee (IDC) system can be seen in the Australian experience. Weller and Stevens (1998) note that when the central agencies came under pressure from Parliament to improve the quality of policy advice the issue was addressed by a task force, an interdepartmental committee comprising the officials from four central agencies - Prime Minister and Cabinet, Treasury, Finance and the Public Service Commission. The aim was to develop a process through which advice could be improved, and more importantly, evaluated. Inputs from performance evaluation then can be fed back to the advisory process to improve it. Overall the Australian experience departs from the New Zealand and British experiences in that the central agencies came together to devise and implement a strategy to improve the quality of the policy advisory process. $^{62}$ This requires that the central agencies, despite

\footnotetext{
${ }^{62}$ More recently, and with a wider mandate than policy advice the three key New Zealand central agencies (Treasury, State Services Commission and Department of Prime Minister and Cabinet) have worked closely together in the review of the centre.
} 
differing approaches and policy differences, have the capacity to mount a change process within their internal systems to achieve a desired goal.

\section{Building a Broad-Based Support System}

Particular constraints faced by the three central agencies in PNG — in particular their inability to mount, coordinate, improve and monitor any meaningful change process as a result of lack of skills, ineffective administrative and leadership capacity and a lack of resources - does mean that any drawing of lessons is likely to fail if the necessary support environment is not established to help the three central agencies initiate, manage, and implement the change process. So the experiences of the three developed Westminster models mentioned above are worth considering in the case of PNG. Overall, the Australian and New Zealand approaches are unlikely to ensure a meaningful change process if they were to be emulated (because they were based on the underlying belief that key central agencies (or departments) concerned have the required capability).

The UK's experience of building an external support base to help the central agencies mount the reforms is worth considering. In the UK's case, a variety of organisations were established, each specifically responsible for key aspects of managing the change process - namely, the CMPS whose role was to train civil servants and ministers, and the Audit Commission which was to develop and communicate reform strategies and evaluate, and to monitor and inject lessons back to the reform process (see, UK Cabinet Office, 2000; Kelly, 2003).

Copying a similar strategy in PNG would depend on whether the PNG government has enough resources to support existing and new organisations responsible for specific aspects of the change process. A key question in PNG is whether a new organisation is required to mount and sustain a reform of policy advice capability or whether the existing PSRMU and DPM\&NEC would be capable of carrying this responsibility. Analysis in the previous chapters has shown that DPMC\&NEC lacks the capability to effectively undertake its tasks, and it is not clear that PSRMU can effectively discharge this function given the problems it currently faces. There is a risk of the change process being managed poorly if DPM\&NEC were exclusively charged with that responsibility.

One possible way forward would be to create a special elite unit within the DPM\&NEC, similar to the PIU, to assist the PSRMU. Such a unit, could not only be 
tasked to develop the blueprint of reforms by drawing on relevant lessons from other countries, but could assist the three central agencies to implement the reforms (for example in training staff) as well as in monitoring its implementation and feeding performance information back into the change process so as to continuously improve it. The establishment of such a unit, however, would require a clear delineation of its functions in relation to PSRMU and DPM\&NEC to avoid duplicating tasks, followed by a shift in the allocation of scarce resources reflecting the new functions. The strategy (of creating additional elite units), however, should be approached with caution, as experience in the UK has shown that problems do arise. For example, Flinders (2003: 57) notes that in the UK's case, "such moves are not substituting old structures with new but, on the contrary, are imposing new layers and mechanisms upon existing frameworks" (Flinders, 2003: 57). This implies problems of communication, coordination, and conflict resolution. A particular benefit of learning from the UK's experience is that alternative administrative structures such as elite agencies can have particular shortcomings (i.e., negative lessons). The challenge for PNG, if it were to adopt the elite agency model, is to note those shortcomings and to devise appropriate containment measures.

Another possibility is for the PSRMU to take charge of the reforms aimed at in improving capability. However, as it is, PSRMU would be unable to discharge the task competently. For example, it has a small staff (currently numbering eight) and a lack of expertise and knowledge in reforming the machinery of government and maintaining coordination across the public sector. A significant strengthening of PSRMU's capability in terms of resources and skilled manpower would be required before the PSRMU could effectively take charge of reforms to strengthen the advisory capabilities of the three agencies. At some point, the use of special advisers provided by donor agencies (for example, AusAID) would need to be considered. This could be done through a twinning arrangement and with a specific purpose of transferring skills (see separate discussion in this chapter).

\section{Extending the Scope of the Multiple Provider Arrangement}

As discussed in Chapter Three, there has been a tendency for governments particularly in the developed world to resort to a multiple provider arrangement (as opposed to relying on the public service) for policy advice (Boston, 1994; Kakabadse and Kakabadse, 2001). This has been done for a variety of reasons including the perceived relative efficiency of outside providers and the cost-effectiveness of this strategy (see Boston, 1994). Fundamental to this change is the outsourcing of policy 
advice function to a range of providers in the "policy advisory market" (Ayres, 1998; 2001). This usually (but not necessarily) involves a process of competitive bidding in which different parties and organisations would compete for policy advisory work based on the standard of service they are willing to offer at a given price - often in competition with the traditional public service departments (see Boston, 1994). Among the other arguments advanced to support a multiple provider arrangement have been the reduction of policy capture, improvement in the quality of policy advice (or quality of service generally), better value for money and filling in the gaps created by lack of skills and expertise (OECD, 1997; Kakabadse and Kakabadse, 2000; 2001).

Should the outsourcing arrangement be actively encouraged in PNG? There are some merits in adopting this option through emulation. It must be first mentioned, however, that such an arrangement would not be a wholesale substitute for the existing arrangements; rather, as has been the experience in the other Westminster systems, this option would complement existing departmental provision of policy advice. To the extent that outsourcing is extensively used, the three central agencies can outsource the provision of particular advice to external (and other public service) sources. A major point raised in Chapter Nine relates to the possibility of advice being influenced by the interests of the three agencies that make up most of the CACC membership. Resorting to alternative providers at some point is likely to reduce the possibility of advice capture. Moreover, NEC may also get better advice through that process (for instance, NEC is likely to be better informed by countervailing advice provided by a variety of sources rather than relying exclusively on the CACC).

Although there are merits to the outsourcing option, its adoption should be taken cautiously. Except for the provision of specific technical advice - for instance, in the area of Information and Communication Technology (ICT) development (see Kakabadse and Kakabadse, 2001) - there has been no concrete evidence to indicate that the quality of policy advice has been significantly enhanced through outsourcing — indeed, evidence appears to be mixed (see OECD, 1997). In New Zealand a survey by the SSC (SSC, 1999b) in connection with its project on improving policy advice found that departments had outsourced 12 percent of their policy work to external contractors and consultants. 
A key finding of the survey was that:

In-house policy analysis was of better quality, more responsive and more immediately useful than that provided by the consultants" (ibid: 9 ).

A larger study (Kakabadse and Kakabadse, 2001) conducted by the Cranfield School of Management comparing outsourcing in public services across the USA, UK, and continental Europe, arrived at similar conclusions to the SSC survey of experience in New Zealand. According to Kakabadse and Kakabadse (2003: 401):

A greater proportion of public servants maintain that outsourcing has done little to enhance public service provision.

On the other hand, the outsourcing of specific financial services and information technology services was found to have added value to the performance of public organisations.

Given the mixture of results from outsourcing, emulating the multiple provider arrangements in the provision of advice cannot be considered solely on the grounds of improving the quality of service. A more compelling reason for emulating international experience in outsourcing advice in countries like PNG is found in particular problems, notably of the lack of skills and expertise and administrative overload. As demonstrated in this study, the provision of substantive and strategic policy advice has been unsatisfactory as a result of a lack of relevant skills and expertise. It therefore makes sense to consider the outsourcing of policy advice in areas where policy expertise and/or competence is clearly lacking within the three central agencies.

The feasibility of applying policy lessons from one setting to another, as noted in Chapter Four, is determined, among other considerations, by the particular context offered by the country that imports the lessons. If the local context is unsuitable to nurture the success of imported lessons then transferred lessons are likely to fail (see Schick, 1998; Dolowitz and Marsh, 2000). In the case of PNG (and especially the central agencies) three important points need to be considered if outsourcing of policy advice is to be successful. First, fostering a multiple provider environment would require institutional support from the government. One major obstacle to be overcome is the existing public service culture, which relies almost entirely on in- 
house arrangements, serviced largely by policy units. This culture has been characterised by a tendency not to question the suitability and efficacy of traditional arrangements; it appears to inhibit innovation in the PNG public service. There is a need to break away from that and the government should actively encourage departments and agencies (and in this case the three agencies) to seek outside suppliers of advice whom they think would give the best possible advice and at a cost-effective price. Also, ministers should be encouraged to escape from the traditional mindset in which the public service is seen as the only provider of policy advice and to seek policy advice from external sources that are capable of providing the advice sought. A guideline on outsourcing policy advice developed by government and specifying the scope of and key benchmarks for outsourcing advice would be necessary. This should not only create the necessary awareness among departments and agencies, but it would also set the necessary parameters within which outsourcing should take place, and the criteria against which departments' outsourcing activities are to be assessed.

The experience in countries that have outsourced many public service activities shows that the success of outsourcing depends partly on the extent in which managerial authority is devolved to allow managers to manage their departments in ways that would bring the best returns. Greater managerial flexibility backed by appropriate accountability mechanisms allows departments to manage effectively the outsourcing of departmental activities (OECD, 1997; Kakabadse and Kakabadse, 2000). A known obstacle to effective outsourcing that needs to be addressed in PNG pertains to the present stringent centralised controls restricting resort to the outsourcing option. Strict financial regulations inhibit departmental managers' authority to issue tenders for policy advisory work. Spending caps placed on expenditure which require the authorisation of the Secretary of Finance (and depending on the amount of expenditure, the Minister of Finance) restrict departments' ability to determine the quantity and quality of suppliers of policy advice as and when the need arises. For example, most tendering is managed and controlled by the Central Supplies and Tenders Board - a centralised body that does all the tendering work for the public service. Also, getting approval for spending has been a key problem encountered by departmental managers in PNG; departments often wait for months for the necessary approval. In addition, if the outsourcing of policy advice is to be realised, the current strict controls over personnel matters should be eased and greater flexibility given to departmental managers, especially in the recruitment of staff. For example, the present centralised 
controls imposed by the Public Service Management Act do not allow departments to recruit short-term candidates (expertise) for specialised policy work for relatively short periods. This recruitment function is maintained by DPM.

There is a final important point about outsourcing policy advice. A key ingredient is the ability of departments and agencies to manage contracts. This is a complex task involving placing tenders, assessing bidders, specifying the tasks to be done, placing the relevant benchmarks for performance, negotiating the terms and conditions of contracts, and monitoring and evaluating performance. In the cross-national survey of outsourcing practice in the USA, UK and continental Europe mentioned earlier (Kakabadse and Kakabadse (2001), it was found that managers in the public service require skills that would (a) "integrate different ways of working between their organisation and external suppliers; (b) prepare the organisation to be outsource ready; (b) manage the outsource commitment; and (c) motivate staff and lower-lever management in the host organisation to meet the outsourcing challenge" (ibid: 408).

Without a proper understanding of and ability to manage public service outsourcing departments (and in this case the three agencies) may open themselves to a number of risks, which according to Boston (1994: 1), include "a greater risk of opportunistic behaviours by suppliers of advice, higher agency costs and transaction costs", and problems of vertical and horizontal coordination of advice. As the analysis in Chapters Six to Nine suggests, lack of skills and expertise and managerial capacity is a key problem confronting the three central agencies. Hence, any meaningful contracting out of policy advice would first require some strengthening of the organisational and managerial capacity of the central agencies.

\section{Stronger Policy Intervention Measures at the Political Level}

As observed elsewhere in this study, ministerial control over departments and the strong traditional nexus between policy formulation and execution in Westminster systems means that the external political environment remains important and affects the way policy advice is organised and delivered within departments. Policy awareness (as suggested earlier) is necessary but not sufficient. It needs to be accompanied by concrete political action to strengthen the enabling environment within which policy advice is provided. Creating the necessary changes in the enabling environment can, however, be difficult; it may require fundamental changes in the political system, in the behaviour of ministers and how they relate to their departments, and the political priorities of the government of the day. Also 
fundamental weaknesses in the political system may be a consequence of constitutional and administrative law; others may be embedded in the prevailing political culture and are therefore are difficult to change within a short period.

\section{Creating an Enabling Environment through Streamlining Key Legislation}

One area that needs close attention by politicians in PNG is the "streamlining" of key enabling statutes in order to: (a) do away with many bottlenecks that undermine departmental performance; and (b) give greater managerial latitude to departmental managers to manage their departments. In the case of the three central agencies, the objective would be to allow managers to make and implement important decisions regarding the optimal use of resources, particular in sustaining the quality and timeliness of policy advice. As mentioned earlier, reforms in this regard would require devolving managerial authority and responsibility in two key statutes: the Public Finance Management Act 1995, and the Public Service Management Act 1995. Such a move would be consistent with international trends - for example as seen in the enactment of the State Sector Act 1988 and Public Finance Act 1989 in New Zealand - whereby key legislation was enacted to give greater latitude for managers to run their departments, but within a performance framework emphasising the achievement of results and greater accountability. There is a need of caution though (a negative lesson). Compliance costs pertaining to monitoring and maintaining accountability can put extreme pressure on the budget (see Boston, 1994), especially for a developing country like PNG. There can be high compliance costs when responsibilities are devolved from the centre because of the need to observe, monitor and evaluate their impact. Thus, there has to be a balance between what is devolved and the capacity to hold costs of compliance, if PNG were to venture into devolving managerial authority. Such a move would need to be based on an assessment of the benefits of greater managerial latitude against the costs of maintaining an output-based management system. ${ }^{63}$

\footnotetext{
${ }^{63}$ For example, while it is often argued that greater managerial latitude is necessary to maintain results-oriented performance, over-emphasis on results could be counter-productive. In New Zealand the review carried out by Professor Allen Schick (1996) on the state sector reforms found that the output-based management system had perpetuated a culture in which the purchaser role of the government was overly emphasised to the detriment of its ownership interests (also see Ormsby, 1998). A similar conclusion was reached in the Review of the Centre Report (2001) (see Robinson, 2002). This has led to the deterioration of departmental capability is some areas as the government had expected more from departments without an equal effort being devoted to sustaining their capability.
} 


\section{Concerted Efforts in Policy Learning at the Political Level}

On the issue of short-term policy cycles - and hence the generation of politically motivated, short term, policy advice - proposing a straightforward remedy is more difficult; the behaviour of ministers and the government is determined by diverse factors including the electoral cycle and the term of government in office as well as political instability created by a range of unstable coalition partners in government and a fluid party system (Reilly, 2002). Despite such difficulties a number of initiatives could be taken to strengthen the enabling policy environment in PNG using experience elsewhere. New Zealand offers some examples worth considering and emulating. For example, it was found that the short-term policy focus of ministers, and, often the government, is endangered by a three-year electoral cycle, which according to some observers is too short for any meaningful strategic planning (see for example Schick, 1996; SSC, 1999b; Campbell, 2001: 258).

One attempt at solving the problem has been through various policy learning efforts and development of policy solutions carried out especially by the SSC — for example through an earlier review by Professor Allen Schick (1996) and the Commission's various publications under the Review of Accountability and the Capability, Accountability and Performance Project (CAP) - and more recently through the recommendations of the Review of the Centre Report (2001) commissioned by the Ministers of State Services and Finance. Through these efforts the government and especially ministers are informed of the dangers of a short-term focus on policy and the need for more robust, comprehensive and long-term analysis of strategic policy including an emphasis on a clear development of government outcomes (Review of the Centre, 2001). The overall emphasis has been to focus more on long-term strategic policy and to engage the active involvement of ministers in mapping strategic policy outcomes of government (Robinson, 2002). Although the full impact of such initiatives remains to be seen, anecdotal evidence appears to show some positive developments. For example, following the recommendations of the Review of the Centre Advisory Group, the New Zealand Cabinet in December 2001 decided to improve the departmental Statement of Intent (SOI) - a rolling three-year strategic planning document, which is revised annually and serve as the basis for, inter alia, strategic policy development and implementation - in which ministers are required to get more involved in strategic policy, especially in communicating and guiding departments on the key expectations (outcomes) of government in the threeyear period (see Robinson, 2002). Preliminary evidence coming from some 
departments (of the fifteen that initially experimented with SOI) shows good progress, although firm conclusions would not be available for some years (see Casey, 2002; Middlemass, 2003).

The experience of New Zealand (and as variously noted, of the UK) suggests that a proactive bureaucracy plays a key role in initiating reviews, identifying and illuminating key problems, and proposing new reform initiatives. There is also evidence of the important roles played by key ministers (e.g. Ministers of State Services and Finance) in advancing policy learning and policy intervention measures. In PNG any meaningful awareness and policy intervention measures at the political level require proactive action by the three central agencies - especially their departmental heads and senior managers - and key ministers who have a broader understanding and appreciation of existing problems. Moreover, CACC would need to play a greater role than at present in making cabinet aware of the role of ministers in strategic policymaking, the dual responsibility of ministers as purchasers and owners of departments and the adverse consequences stemming from short-term policy cycles.

\section{Strengthening Internal Capability}

To this point the discussion has focused on setting the stage for carrying out reforms strengthening advisory capability in the central agencies and adopting policy lessons aimed at changing the external political environment in which policy advice is provided. While essential these are not sufficient. There has to be an emphasis also on improving the organisational and administrative capability of the three agencies. In this section consideration is given to those areas important if the agencies' capability to organise and supply quality and timely policy advice is to be enhanced.

\section{Building Effective Managerial Systems}

A key problem identified in the earlier chapters is the shortage within the three central agencies of competent policy managers who are able to take charge of their relevant policy units. Policy managers lack appropriate skills and expertise in policy work and have not been demonstrating effective leadership in their policy units. An important challenge for policy makers in PNG therefore is to consider how to resolve this issue and to strengthen existing managerial systems. A key issue prior to any training effort would be to strengthen the broader managerial environment in which policy managers operate and to provide the necessary impetus for managers to perform effectively. Some of the measures have already been mentioned elsewhere in this 
chapter and include greater ministerial interest in and expectation of the quantity and quality of policy advice; effective formulation and communication (in terms of both content and clarity) of government strategic intents to the central agencies; removal of unnecessary centralised controls; and devolving greater managerial authority to departments.

\section{Strengthening Managerial Competence using Performance Incentives}

One of the core elements of public management reforms in developed Westminster countries has been the focus on a clear specification of results, the monitoring and evaluation of their achievement, and strong accountability frameworks ensuring that managers deliver what is expected of them (Boston et al, 1996; Peters and Savoie, 1998; Peters and Pierre, 2003). A particular lesson that has emerged from the experience of developed Westminster models - and one which should be a source of inspiration to PNG - is that sustained and effective reform aimed at improving managerial (and departmental) performance in policy advice is unlikely to take place - let alone be supported - unless there is broader reform aimed at strengthening results-oriented performance across the whole of government. Any sustained success in improving managerial systems in policy advice in the three central agencies in PNG (and the public service as a whole) requires a commitment to performance-based management systems in which policy managers operate within a framework aimed at achieving results, evaluating such results and rewarding (or sanctioning) performance. A possible solution would be to emulate (and where relevant modify and synthesise) lessons of reform in performance-based management from developed Westminster models in the ongoing public sector reforms in PNG. Specific measures in strengthening managerial capability in policy advice - for example, by setting performance benchmarks, monitoring and evaluating advice, and in setting ministerial expectations - could then be incorporated through such an emulation exercise.

\section{Specialised Managerial Training}

Emulation of lessons of results-oriented performance of itself is, however, not sufficient to ensure quality policy advice. Greater latitude to policy managers to work within a performance framework needs to be accompanied by the transfer and development of relevant managerial skills. An effective performance management system, therefore, has to be backed by policy managers who are not only skilled in policy analysis work, but are also skilled in managing and directing the work of policy units. Policy analysis skills including those of statistics and economics, and 
quantitative and qualitative analysis need to be complemented by broader skills in communication and presentation, managing complex relationships, managing performance; understanding the broader context of government and managing risks.

The key option - perhaps the most feasible at this stage - would be to invest in training programmes aimed at strengthening managerial competence. In this vein a useful lesson can be found in the current emphasis of the UK government's "joinedup" approach spearheaded by the CMPS (Ling, 2002; Flinders, 2002). As mentioned earlier, training programmes aimed at ministers and senior civil servants are mounted by CMPS; this has served as a useful way of improving managerial aptitude (UK Cabinet Office, 1999; 2000). In PNG this idea can be emulated with the PSRMU taking a lead role. However, PSRMU does not necessarily need to be the delivery agency. Using synthesis (copying the principle but refining it with a combination of different ideas) PSRMU could consider adopting various delivery methods to train managers. For example, PSRMU could contract with external providers such as the PNG Institute of Public Administration (IPA) or the University of Papua New Guinea (UPNG) to deliver tailor-made course addressing areas such as those spelt out briefly earlier. The role of PSRMU would be to manage and coordinate the process of training, rather than developing materials and mounting courses.

There are also other lessons worth considering. For example, the concept of a Senior Executive Service (SES) in which a cadre of officials is trained and rotated in the public service to eventually take the reins of departmental management is a concept worth considering (see Boston et al, 1996; Halligan, 2003). In New Zealand, for example, it was observed that:

[T] he SES would provide a focus for management development, a source of talent to meet particular government objectives, and a vehicle for chief executive succession planning (Boston et al, 1996: 117-118).

However, experience with the SES concept has been mixed. For example, in the decentralised departmental structure of New Zealand the scheme initiated in 1988 was never fully implemented and in 2003 legislation removing the statutory provisions was introduced. Also, remunerating managers at parity with executives of the same rank in the private sector has not been fulfilled (see Ingraham, 1993; Boston et al, 1996; Halligan, 2003). The concept, however, should not be solely dismissed on the negative experience of some countries. The lack of managerial 
skills within the three agencies means that the SES concept is worth considering, especially in its core emphasis on training and rotating a cadre of managers across the public service.

\section{Strengthening Staff Competence}

Improving training via twinning arrangements

One way of strengthening staff competence is through "twinning arrangements". A scheme of twinning arrangements is a common development strategy used by aid agencies and foreign governments and entails pairing similar departments and agencies (e.g., departments of finance) in two countries and exchanging staff and resources (Jones and Blunt, 1999; Proctor, 2000). The primary emphasis is the exchange of staff in which skilled staff in the developed (donor) country are seconded to specific departments and agencies in the developing country either to help implement particular policies or to transfer specific skills and expertise in various training programmes or through policy learning during the implementation of specific policies.

This has been a common strategy employed by the Department for International Development (DFID) and the Canadian International Development Agency (CIDA) in their various development programmes in Africa (Dearden et al., 1999; Proctor, 2000). In Australia, this has also been evident in AusAID's efforts in twinning arrangements with governments in the Pacific islands. However, the Australian experience in PNG - discussed in the context of the Economic Policy Unit (EPU in Chapter Seven - demonstrates an overwhelming focus on project implementation with little emphasis on transferring skills.

The training of policy staff in PNG can be greatly aided by copying or emulating lessons from twinning arrangements in Britain and Canada. This requires, however, some fundamental shifts in development policy of key partners such as New Zealand and Australia. In this case New Zealand (through NZAID) and Australia (through AusAID) could play a key role in which emphasis on training (which currently is largely done in both countries) is undertaken simultaneously through in-country twinning programmes. Although Australia is involved in some twinning arrangements with PNG, their scope should be widened concentrating on internal training and transfer of skills and competence across the three agencies and focusing less on bringing external (Australian) consultants. For example, training programmes could extend across the three agencies, instead of what appears to be an over 
concentration in DF\&T (specifically in the EPU). This means, for example, that seconded Australian Treasury officials would be stationed across the three agencies.

The twinning approach is also useful for strengthening managerial systems in policy advice. For example, Australian staff who are seconded to one central agency such as the DF\&T to manage a project or a specific programme could be utilised in training policy managers across the central agencies. Different strategies could be synthesised with the twinning approach. For example, managers in DPM and DPM\&NEC could be seconded to DF\&T and attached to programmes that are being supervised by staff from Australia (or New Zealand if it were to be involved) the overall aim of which is to facilitate policy learning and transfer skills.

\section{Training Using the Concept of "Joined-up Government"}

Another lesson in training from the UK that could be emulated in PNG would be to foster the idea of interdepartmental management of crosscutting policies in which an emphasis on interdepartmental utilisation of resources becomes the driving force. This has been advanced in the UK under the "joined-up government" and evidencebased policy initiatives (see Ling, 2000; UK Cabinet Office, 2000). In its present form, this approach is novel even ambitious, because it involves fundamental shifts in departmental budgeting - for instance, towards inter-agency budgets that cross departmental boundaries. A key tenet of joined-up government is the pooling of resources by a number of departments and their subsequent utilisation on crosscutting policies or common problems. The benefits from such arrangements include: the cost-effectiveness of departmental undertakings arising from sharing costs; the deflection of unnecessary and unfair (free riding) costs on the lead or coordinating agency; increased cooperation; and the interdepartmental transfer of skills through collaborative work. Edwards (2002: 57) observes that this idea has also emerged in New Zealand under the rubric of "horizontal management" and in Australia under "integrated or collaborative government".

Given the budgetary problems faced by each central agency in PNG, existing gaps in the policy competence of staff could be addressed by the pooling of training funds and running training programmes attended by staff of each agency. This should reduce the cost to individual agencies, while at the same time seeking to maintain a balance of skills among the three agencies. Some of the training strategies discussed earlier could be blended in with such a "pooling of resources" approach. For example, the three central agencies could utilise common funds in managing and 
coordinating training programmes, or external providers could be contracted directly using "common funds" to mount training of staff.

\section{Improving Funding and Infrastructure}

Inadequate funding and poor infrastructure to support high quality policy work have been two key constraints identified in the present study. Addressing funding and infrastructure problems would require the adoption of many of the lessons already suggested - for example, more emphasis on the ownership role of ministers; outsourcing policy advice; removal of bottlenecks and some latitude to managers to allow them to decide on the best resource mix together with adequate resources; twinning arrangements; and the sharing of common funds for training. Twinning arrangements, and sharing common funds in training, if applied correctly, could result in significant savings. A similar approach could ease pressure on infrastructural assets - for example, in the joint use of research facilities and equipment such as computers.

\section{Collaborative Research}

When considering budgetary and infrastructural problems, two important areas collaborative research and knowledge pool — offer possibilities for savings. The best analysis of joint work in policy research comes from Canada, although the UK's approach in improving analysis and modelling in central government (PIU, 2000) has similar features. The Canadian experience suggests that policy competence can be strengthened through a range of collaborative efforts in which government organisations and institutions have come to "join forces" in policy research with external institutions (Bakvis, 2000). Such efforts for example are exemplified in the collaborative efforts that the Canadian Centre for Management Development (CCMD) - the Canadian government's flagship training and research facility — and non-profit think tanks such as Canadian Policy Research Network (CPRN) have with academic institutions and public and private sector organisations. In 1996 the Canadian government launched the Policy Research Initiative (PRI) which pooled researchers and resources across government departments, research institutes and private think tanks, the aim of which is to carry out joint initiatives to provide valuable data in key policy areas (see also UK Cabinet Office, 1999: Chapter Seven). Supported by the Policy Research Council its data is disseminated through a data network and through conferences and seminars. 
Bakvis's account of the Canadian experience shows that not all collaborative efforts were successful. Some did not achieve their desired goals - most failures did not arise from the idea itself but from the process through which collaboration was pursued. Generally, however, the idea of collaborative efforts in research clearly has merits - in fact the British government has applauded Canada's PRI and refers to it as a model for emulation in its ongoing quest to improve policy analysis (UK Cabinet Office, 1999: Chapter Seven).

Canada's experience could be emulated but modified to suit PNG's context. For example, the three central agencies could enter into collaborative analytical work on substantive and strategic policy with the few existing universities and research institutes in PNG or with overseas organisations. Project teams could be employed in which academics and policy staff of central agencies embark on joint research on specific projects - for example, on crosscutting policy issues such as on poverty alleviation and crime prevention - and propose relevant policy options to decision makers. Incentives for greater cooperation such as the utilisation of government data and facilities, acquisition of public service knowledge and the option to publish results should be explored, and where possible, should be incorporated into joint research protocols. In the UK, for instance, the approach of the McKinsey consultants' (one of the largest consulting firms in the world) in managing and sharing data has been proposed for emulation in which there is to be "a development of a culture that rewards sharing and learning from others' experience" (UK Cabinet Office, 1999: Chapter Seven). There are several benefits from this arrangement.

First, existing gaps in research and data analysis skills can be filled — for instance by academics acting as team leaders guiding the team's efforts and in the production of the report. Secondly, joint collaboration in research can cut down the cost of mounting research individually through the sharing of resources and personnel. Finally, in the long term, such collaborative efforts in research provide opportunities for professional dialogues, creation of knowledge partnerships, meaningful cooperation and mutual dependence, and transferring critical skills and knowledge for example, in designing and leading successful research projects; in gathering, organising, and analysing data; and in written communication (especially in report writing). 


\section{Creating a knowledge pool}

While information is perhaps the most important ingredient for policy advice (in terms of its use in quality and evidence-based analysis), it is often scattered, patchy and/or inaccurate. Departments bear significant costs in compiling, synthesising, and utilising information. Also, the capacity for data acquisition and management varies: some departments clearly do not have capacity to compile and utilise information; in some situations robust data, for instance from longitudinal studies, in specific policy areas are lacking. Often the "silo" mentality of departments prevents agencies from sharing vital information necessary for evidence-based analysis (Edwards, 2002: 56). Most of these problems, as noted in previous chapters, are evident in the three central agencies in PNG.

The idea of a knowledge pool, which has been advanced in the UK's government evidence-based policy initiative (UK Cabinet Office, 1999; 2000) and floated in Australia and Canada (see Edwards, 2000; Office of the Provincial Auditor, 2001), could provide answers to some of the problems of data management and access identified in this study. The purpose of creating a knowledge pool is to harness information from many sources, place it in a central locality, and disseminate it to those who need it (UK Cabinet Office, 1999; 2000). The key to this effort is cooperation, contribution, exchange and sharing of information and vital data through a one-stop shop - although the coordination and management (and often collection of crucial data) would be the responsibility of one or few agencies. The UK government has placed particular emphasis on pooling data from "longitudinal studies, pilot trials and small area data" (using the CMPS and the Office of the eEnvoy as central locations) as means of filling in the data gap and improving evidence-based analysis (Edwards, 2000). Longitudinal studies for example, are long-term studies seeking to determine the impact of that which is being observed, while "pilots allow evidence of the effects of a policy change to be tested against a genuine counterfactual" (UK cabinet Office 2000: 18). The UK government has also gone as far as putting into trial a financial incentive fund, "Seed-Corn Fund", to stimulate research and generation of data especially on crosscutting issues (UK Cabinet Office, 2000: 28-29). It is expected that data derived from research supported by the fund would be injected into the data pool and used across government. 
Copying the idea of a knowledge pool is imperative in PNG and would help address some of the pressing difficulties pertaining to unavailability and poor quality of data. Other added benefits include the potential for cutting down costs through sharing and exchanging information; enhancing interdepartmental cooperation; bringing a sense of commitment to improving the whole of government (that is, an emphasis on crosscutting and substantive and strategic policy issues; and an improvement in the quality of policy analysis arising from the better access and, therefore, use of data.

The DPM\&NEC could spearhead efforts to create a knowledge pool by coordinating inter-agency efforts and drawing resources from the three central agencies and other institutions such as universities and research institutes. Key support for this should come from the CACC. Where possible, creating a knowledge pool could be synthesised with collaborative work in research in which data from joint research are made available through the knowledge pool and hence become accessible to the whole of government. One of the cost-effective and most straightforward methods is through the use of information and communication technology (ICT). The knowledge pool approach could use of specific websites that carry reports of studies and critical data, and can be accessed by those who participate. Again, examples of this can be seen in the CMPS and the UK cabinet office websites; or in New Zealand, the State Services Commission (SSC) website. ${ }^{64}$ First, however, it would be necessary to improve present ICT infrastructure within the three agencies - for example, in enhancing both computing hardware and software and getting policy units and their staff have access to the Internet.

\section{Strengthening planning and financial management}

There is a compelling case for urgent attention to be given to strengthening budgetary planning and financial management in PNG. An appropriate way forward is for DPM to carry out a "needs assessment" to prioritise key areas needing financial support. In the short term the government should concentrate on supporting those areas in which capability is critically lacking - for example, in improving databases, equipment like computers, libraries, and information and communication technology (ICT). And, where relevant, policy lessons proposed earlier in this chapter (for example, knowledge pool, collaborative research and inter-agency budgeting) should be considered with the aim of adopting the best mix of lessons from other countries.

\footnotetext{
${ }^{64}$ For example, for the SSC see http://www.ssc.govt.nz; for the UK Cabinet Office and sites of various advisory units see http://www.cabinet-office.gov.uk
} 
Meaningful and long-term improvement in both budgetary and infrastructural support is, however, more likely to come about within a context of a fundamental shift in departmental planning and operations, from input-based to an output-based management system. In the case of the three central agencies in PNG, budget and infrastructural support for policy advice has been problematic because this critical activity has never been treated as an output in budget outlays. This has led to the poor planning and financial support for policy advice.

The adoption of an output based management system such as in New Zealand (and elsewhere in developed Westminster systems) provides a framework within which departments plan and organise their outputs - currently through mechanisms such as Output Plans and Statements of Intent (SOI) - in which policy advice is defined as a specific output to be purchased (funded) (see Scott, 2001; Robinson, 2002). Financial resources, through the estimates formulation (budgetary) process, are then committed to meeting the cost of producing and delivering policy advice by departments and agencies. There is added value in this arrangement. First, it recognises the vital role policy advice plays in good policymaking and therefore places a serious emphasis on its organisation and delivery. Second, it is able to link policy advice and the costs of producing it. This allows departmental managers to plan and organise the delivery of policy advice in a more transparent and effective manner. Third, it places responsibility and accountability for policy advice clearly on policy managers and the departmental heads (for example, policy managers and departmental heads can more directly be held to account for the advisory outputs produced by their department).

There are merits in emulating the output-based management system. Drawing inspiration from the Output Plans and SOI approaches, the three PNG central agencies could incorporate more robust financial planning for policy advice into their corporate planning process, and in negotiating and formulating estimates with Treasury. However, as mentioned earlier there has to be a whole of government approach to this matter.

Although the output-based management approach treats policy advice seriously and allows for effective planning in resource use, its pitfalls (negative lessons) are worth noting. For example, Schick (1996) observes that a tight specification of outputs can be counter productive as departments tend to concentrate on producing what is contained in Outputs Plans or SOI without having a strategic mindset or broader view 
of issues relevant to their portfolio and of concern to the whole of government. This problem has received some attention in the New Zealand Review of the Centre Report and is further analysed in a recent article by Robinson (2002). One problem implied in Robinson's (2002; 6) assessment of "old" SOI requirements has been that departments were not able to provide advice in line with the broad objectives of government, and that there was little focus on outcomes by managers and staff. This problem appears to have arisen from the tight focus on outputs observed by Schick in his 1996 assessment of New Zealand's state sector reform. The lesson here is that if policy advice is to be planned as an output, it needs to be aligned with the broader goals of government. In other words, policy advice must be useful, being able to contribute solutions that would create the desired impact (outcome) on the community or else its funding and support would be wasteful, even if departments were required to produce it within a performance framework. This approach requires effective exchanges and dialogues between departments and ministers in the formulation of outcomes and the development of advisory outputs consistent with the achievement of such outcomes.

\section{Establishing Best Practice in Policy Advice}

A key problem identified in this study relates to the deficiencies in process of organising and delivering advice in the three central agencies. This bears adversely on the quality and timeliness of policy advice. Some policy lessons suggested earlier (for example, the shift to a output-based management framework, improved managerial and staff competence, strengthening planning and financing of policy advice, and strengthening the quality and use of data) are directly relevant to the work of policy units. However, there is also a need to institute best practice in policy advice if the quality and timeliness of policy advice are to be improved. This requires the authoritative establishment of the desired standard of performance or a range of working practices and policies against which policy advice is delivered and measured. Three important, interrelated areas need to be given specific attention: (a) setting high performance goals and expectations (b) high quality analysis emphasising the utilisation of data and evidence and effective consultation and (c) the monitoring and review of policy work.

\section{Setting Performance Benchmarks}

There are plenty of lessons from developed Westminster countries about the setting of high performance goals, though all have their own limitations. The BVF initiative of the UK government mentioned earlier uses various best practices as performance 
benchmarks for maintaining the quality of service in local governments (see Nutley, et al, 1999; MacAdam and Walker, 2003). The UK's Modernising Government White Paper also proposes the use of benchmarks in a range of government functions and has launched the Public Sector Benchmarking Programme to promote the use of Business Excellence Model across the public sector (Auluk, 2002: 109).

Management systems built around the notions of outputs and outcomes in setting performance standards in different functional domains of government are now widespread (Aucoin, 1994; Ormsby, 1998; Peters and Savoie, 1998; Campbell, 2001). Service delivery (including policy advice) is provided in respect of outputs, which in turn are expected to create the desired impact on outcomes. For a department, outputs are the benchmarks upon which performance is to be guided, and, eventually judged. In New Zealand's output-based performance framework focusing on policy output classes, "ministers are asked every three months to indicate the level of satisfaction with the relevance and quality of advice they receive" (Boston et al, 1996: 131). And as mentioned earlier, there has been recently an emphasis on the new SOI framework focused on improved linkages between outputs and outcomes, and an added emphasis on policy advice provision, especially on its relationship to (and hence impact on) government outcomes (see Robinson, 2002).

Work on performance indicators and quality characteristics for policy advice began in New Zealand as early as 1992 under the SSC Policy Advice Initiative (SSC, 1992) and has since been refined in subsequent work in 1998 and 1999 (see SSC 1999; 1999a). At the ministerial and departmental level, ministers and departmental heads require their departments to provide policy advice based on four key performance indicators:

- Quantity (number of policy advisory outputs expected)

- Quality (how well such outputs are to be produced)

- Timeliness (when expected outputs should be given to ministers) and

- Cost (whether advice is purchased at the relevant cost) (see Boston et al, 1996: 131-132).

The quality characteristics focus on how well advice is delivered, setting out key benchmarks policy managers and policy analysts should be aware of and in assessing the quality of the 'product'. 
To this end, there have been seven quality benchmarks employed (SSC, 1992; Boston et al, 1996: 132):

- Purpose (clarity in the objective/aims of advice)

- Logic (assumptions underpinning advice are clear and the arguments advanced are logical, supported by facts)

- Accuracy (consideration and accuracy of all facts)

- Options (the need to set out all options together with their merits and demerits)

- Consultation (the need to consult as widely as possible especially with all stakeholders)

- Practicality (consideration of all implementation issues and technical feasibility of policy) and

- Presentation (the formulation of advice on a clear and consistent format so that it can be understood).

Recent developments in the UK also show the use of "best practice" in ensuring the quality of policy advice (UK Cabinet Office, 2000; Sanderson, 2002). While there are similarities between New Zealand and the UK, there are also differences. The UK model emphasises the use of broad standards (rather than specifically-defined criteria as found in New Zealand's model) as a way of improving the quality of policy advice. Policy advice to be "forward looking; outward looking; innovative and creative; evidence-based; inclusive; joined-up; and subject to review and evaluation" with an emphasis on continuous improvement based on information injected from review and evaluation (see UK Cabinet Office, 1999).

In Canada a review of policy advisory arrangements by the Provincial Auditor of Manitoba (Office of Provincial Auditor, 2001), proposes emulation of many of the benchmarks used in New Zealand. It emphasises the adoption of best practice that would guide the policy development process - a more effective approach to issue identification and issue analysis; robust generation of solutions; effective consultation; and need for performance monitoring. The quality benchmarks used in assessing policy advisory output are derived largely from New Zealand, focusing on the seven benchmarks used in defining the quality of policy advice (see above).

Establishing best practice in policy advice in PNG is likely to bring much-needed direction on policy advisory work, to provide incentives for staff at both the managerial and staff levels to perform better, and to improve the process and quality 
of policy advice through rigorous analysis of policy issues in the three central agencies. Some of the ideas discussed above seem worth considering for possible emulation. For example, a statement of "best practice", which sets out principles and policies aimed at improving the process of analysis, could be considered for emulation. A synthesis of various ideas could be developed. For example the characteristics of the quality benchmarks in New Zealand and Canada could be emulated combined with some ideas found in the UK - for example, using more evidence-based analysis and a continuous refinement of policy based on evaluation.

\section{Greater Utilisation of Data and Evidence and More Effective Consultation}

As noted in Chapter Three, providing policy advice is subject to many pitfalls. But some can be overcome by a more sophisticated use of data and effective consultation with key stakeholders. One key policy lesson that PNG could learn from developed Westminster models is the importance placed on the use of data and evidence and good consultation processes. As previously mentioned, the UK provides the best example in this regard, especially in the use of pilot trials. Pilot trials have provided scope for observing policy implementation, to learn from it and then inject critical data into new, similar policy initiatives. "Learning from experimenting" reduces the risk of trial and error. The insistence on evidence-based analysis (that is, "what works is what counts" (see UK Cabinet Office, 2000)) using a knowledge pool and networking partners via joined-up government is also useful. Such ideas provide useful insights into the effective utilisation of evidence from a central point and how different stakeholders can meaningfully consult each other on policy issues. Some of the policy lessons considered earlier, for instance on data pools and collaborative research are also useful. Mere availability of useful data is, however, unlikely to improve the quality of policy advice in the three PNG central agencies. Critical is the integration of data utilisation into policy work, greater use of evidence and effective consultation; the aim of which is to inculcate a culture of evidence-based analysis built on best practice in the three agencies.

\section{Evaluation and Review}

Evaluation and review is widely recognised as an important aspect for improving the quality and timeliness of policy advice in developed Westminster jurisdictions (see IPU, 2000; Bhatta, 2002; Sanderson, 2002). A primary reason is the need to establish confidence in existing delivery mechanisms - that is, whether the current system of policy advice, to quote Waller (1992: 440), "meets fully the required standards of rigour, honesty, relevance and timeliness". For example, the 
introduction of the policy management reviews (PMRs) in Australia discussed earlier was triggered by the need to ensure that central agencies were providing the right kind of advice to their political masters (Weller and Stevens, 1998; Di Franceso, 2000). The other reason is the need to introduce more robust intervention measures into the process of policy advice (for instance, in new ways of treating data and presenting options to minister) so that the quality of policy advice can be improved. Evaluation and review seeks to identify shortcomings or constraints on existing policy advice process by comparing it to predetermined standard of performance or best practice. Information from evaluation exercises is then used to formulate more effective corrective measures to address known shortcomings. In the case of the UK, the emphasis on pilot trials, as noted earlier, takes evaluation and review one step further by making evidence on the ground more readily available when future policy intervention measures are being considered. The final justification for evaluation and review is the need for greater accountability for performance. To the extent that policy advice is an output that is carefully planned and funded - as is the case in an output-based management environment - accountability instruments are required to ensure that ministers (and the government) get value for money from government funding of policy advice. A rigorous accountability regime also provides the impetus for policy managers and policy staff to be aware of and to adhere to established best practice or performance standards in policy advice.

A key step forward in PNG would be to incorporate evaluation as part of the best practice in policy advice within the three central agencies. Several options may be emulated in this regard. One would be to allow an "increased openness in presenting evolving ideas to outsiders and to subject the ideas to rigorous scrutiny" (Bhatta, 2002: 102). Another would be to encourage an environment of management and peer review in which policy work is given to managers, peers and colleagues within a policy unit for constructive comments. Both review methods may rely on best practice (for instance, using the quality characteristics similar to the New Zealand model) as a basis for evaluation; they may use ex ante specifications highlighting the key benchmarks upon which the review is to be carried out. Suffice to note that these options are already common (or proposed) in countries like New Zealand, Australia and Canada (see SSC, 1999a; Office of the Provincial Auditor, 2001; Sanderson, 2002). The final option is to mount formal evaluation exercises focusing on ex post evaluation in which an assessment is carried out in respect of advice provided on specific policies. PMRs in Australia and the pilot trials and 
longitudinal studies in the UK fall in this category. The aim is to acquire evidence and critical data to be used for developing future policies.

\section{Conclusion}

The analysis in this chapter has been a response to the last of the three key questions guiding this study advanced in the Chapter One (How can the capability of the three agencies in organising policy advice be strengthened?). Using the insights of the policy transfer literature discussed in Chapter Four, the aim of this chapter has been to consider various ways to strengthen the policy advisory capability of the three PNG central agencies and generally that of the PNG public service.

The prefatory part of the chapter was devoted to explaining how the transfer of lessons might take place between developed Westminster countries (where policy lessons originate) and PNG (the importer of policy lessons). To rehearse the key points, it was argued that countries that seem miles apart (in this case PNG and the developed Westminster models) could borrow lessons from each other (and indeed the policy transfer literature observed in Chapter Four provides significant insights on how this could be done). In the context of this study, similarities in problems and goals pertaining to policy advice do mean that PNG could consider lessons from developed Westminster models. It was also argued that to the extent that the drawing of policy lessons takes place this would be voluntary involving key actors such as ministers (and other politicians), departmental heads and policy managers and policy officials in policy units, and that the drawing of policy lessons would involve a combination of methods including copying, emulation and synthesis. A key point advanced in the discussion is that, useful as it may be, policy lessons do not necessarily need to be actual lessons that have been put into practice; they could be ideas and suggestions which have either been abandoned or suggested but have never been employed in practice. However, the transfer (and applications) of such ideas would need to take into account the administrative and political context of PNG and their perceived weaknesses.

The discussion has been wide ranging and encompassed a diverse range of policy lessons. Consistent with the multidimensional nature of capability advanced in the study, the lessons considered in the first part of this chapter have been devoted to strengthening the external political environment within which advice is provided. As noted, creating robust systems and processes of policy advice within the three agencies is unlikely to have any significant impact if the external political environment 
is not strengthened. A significant point noted in that part of the discussion is the need for greater awareness by policymakers to initiate much-needed reforms and the need to create the support base necessary to carry forward the reforms in policy advice. The second part of this chapter has been devoted to consideration of the adoption of policy lessons that would strengthen the internal capability of the three agencies. Without the necessary strengthening of the capability of each agency, it would be difficult to achieve the desired aim of improving the quality and timeliness of policy advice. The lessons considered for strengthening the internal capability of the three agencies have been diverse and again reflect the multidimensional nature of capability building advanced in Chapter One. To end this chapter it is pertinent to recapitulate the argument advanced in the introductory section, viz., that lessons proposed here are by no means exclusive; there is a need for the PNG government to make a long-term commitment to strengthening capability; and there is scope for the PNG government to come up with novel, home-grown ideas rather than relying entirely on lessons from developed Westminster countries. 


\section{Chapter Eleven: Conclusion}

This has been a study of the state of policy advice within three key central agencies located at the pinnacle of the advisory machine within PNG's central government. These agencies are the Department of Finance and Treasury (DF\&T), Department of Prime Minister \& National Executive Council (DPM\&NEC) and the Department of Personnel Management (DPM). The main thrust of the study has been to provide an in-depth examination of the constraints that undermine the three agencies' capability to provide policy advice and to determine the effects of such constraints on the quality and timeliness of policy advice. Such an examination is informed primarily by the perceptions and views of policy officials in the lead policy units of each agency.

In seeking to account for the constraints on policy advisory capability, this study takes a broad approach to the notion of capability as encompassing various elements - personnel, resources, systems and processes of organising policy work and the wider political environment which shapes the operations of departments - which require to be present and well-integrated if agency performance is to be satisfactory. This broad view forms the basis of the evaluation in the empirical chapters (Chapter Six to Nine).

Chapters One and Two provide the context within which the study has been carried out. An appreciation of the analysis in the entire study requires a clear understanding of the purpose of the study, the concepts used and the key political and administrative forces that shape the operations of the public service in PNG. Chapter One introduces the key arguments constituting the thrust of this study and introduces the two principal concepts, "quality policy advice" and "capability".

A key point of departure and of difference pointed out in Chapter One, and one which has significantly influenced this study, relates to how quality and timely policy advice is conceived. Whereas improving the quality and timeliness of policy advice is often seen as primarily dependent on improving the comprehensiveness and quality of rational analysis (SSC, 1999; Waller, 1996; Sanderson, 2002; Butterworth and Horne, 2003), the present study argues that this view tends to gloss over the reality in many developing countries where the lack of resources and skills is the key constraint on the administrative capability of the public service.

Chapter Two sets out the historical, societal, political and administrative contexts for the study. Here, the operational features of the PNG public service (and of 
departments) and the problems departments face are extensively discussed. The chapter sets the context for more in-depth discussions in the later part of the study especially in the empirical chapters (Chapters Six to Nine).

Chapters Three and Four provide a review of the literature that is significant to the study. Insights provided in these chapters underpin the analysis in the subsequent chapters. The operational dynamics of policy advice discussed in Chapter Three have been particularly significant for the evaluation in Chapter Nine. The discussion in Chapter Three provides insights into the concept and nature of policy advice, its political and administrative dimensions (especially in relation to important conventions in the Westminster system), the variety of institutional arrangements that have been used for providing policy advice, and various international developments in the quest to improve the quality and timeliness of advice. To rehearse some of the key points, providing policy advice is a complex issue: advice is intensely a political as well is an administrative (technocratic) matter. Politicians will have their own say and preference about the advice they receive and, it is possible that what is "good" advice to a politician may not be necessarily feasible from a technocratic point of view. Also the task of providing policy advice is technically challenging, for a host of reasons including the need to provide a "cocktail" of operational, substantive and strategic advice and to ensure that such advice is reliable and comprehensive; the increased tensions brought about by the shift in important Westminster conventions regulating advice; and the domestic and, in many jurisdictions, international pressures to improve systems and processes of policy advice. Chapter Four discusses the theoretical insights of two strands of thinking on lesson drawing (new institutionalism and policy transfer). This chapter provides the essential building blocks for considering policy lessons in Chapter Ten.

The methodological foundation for this study is provided in Chapter Five. As explained in that chapter, perceptions and views of policy officials acquired through a survey questionnaire and in-depth interviews form the primary sources of data in this study. The use of this method is justified by a number of reasons the key one being the need to acquire first hand information which would allow an informed assessment of the capability of each agency.

Chapters Six, Seven, Eight contain the empirical analysis (or the gist of the study) providing a detailed examination of each agency. The overall aim of these chapters has been to provide answers to the two important questions posed in Chapter One 
proceeding from the presumption that there has been deterioration in capability: How has policy advisory capability weakened in each agency? What are the key constraints faced by the three agencies in organising and supplying quality and timely policy advice? The main finding has been that policy advisory capability has indeed been weakened in the three individual agencies and that this is attributable to a range of problems (causes) linked, as observed in Chapter Nine, to the political dimension on the one hand, and the administrative and organisational dimension on the other. Many of the prevailing constraints are interwoven and interlocked: the existence of one or several has often led to the creation or nurturing of others (for example, financial constraints have been the primary cause of a deterioration of resources in policy units and this in turn affects the way policy officials carry out analyses of issues).

The main constraints that have been identified in this study can be summarised as follows. From the political dimension are the unstable (and hostile) political climate - which tends to generate short term policy cycles, lack of consistency in the policy signals provided to departments (in this case the three agencies) and more specifically a high turn over of ministers - a lack of ownership interest shown by ministers (and the government collectively) in ensuring that three agencies have the required capability, weak ministerial direction of departments especially in the area of policy advice, and the lack of security of tenure of departmental heads created by a hostile political environment. The organisational and administrative constraints identified in this study have been funding difficulties; existing gaps in the qualifications and skills of staff; gaps in nurturing and imbuing knowledge in policy advisory work; neglect in investing in knowledge and skills development; lack of experience in policy advisory work, work overload, recruitment and retention difficulties; a deteriorating infrastructure (both in terms of its quantity and quality), a lack of effective management in policy advisory work and poor quality assurance in the advice process.

It is pertinent to note that while the shared political and administrative contexts explain why such constraints have been common to the three agencies, their existence underlines an important point: that constraints encountered in the provision of policy advice in PNG are not sporadic; rather they appear to be pervasive and systemic. This observation holds important implications for the "weak state" thesis and some of the broader arguments advanced in the Chapter One about the PNG 
state and the capability of its public service. A discussion of these implications will be returned to later.

Chapter Nine provides a broad evaluation of the status of policy advice in PNG and has various implications for the provision of advice derived from the analysis in the three preceding chapters (Chapters Six to Eight). Several significant points providing insights to the provision of advice and the management of the PNG public service in that chapter are worth recalling. First, while there has been an active engagement by governments elsewhere (see Chapter Three) to supplement internal advice with external advice (primarily through contracting out of the advice function), there has been no significant advancement in this area in PNG (except in a limited sense through the use of overseas consultants in a variety of aid-related work). Advice is largely internal provided by professional public servants. It has also been observed that while important changes have been made in other countries to improve the quality and timeliness of policy advice (from instance through different delivery arrangements and quality assurance processes), change in this area has been slow in PNG. There is a case for much-needed reforms, as is argued in Chapter Ten.

Second, there has been a consolidation of the power and influence of the three central agencies mainly through the amendment to the PSMA and the creation of the Prime Minister Act in 2002. This change is quite the opposite of what has happened in most developed countries where the control functions of central agencies have experienced a general decline. An important part of this consolidation process in PNG has been the creation of the CACC and the change in the advisory process which allows the direct injection of policy advice by the CACC into cabinet level debates.

Third, changes can be detected in the key Westminster conventions governing the provision of advice. A key observation in Chapter Nine has been that providing free and frank advice has been difficult given the lack of security of tenure of departmental heads. Also, there is a perceived lack of ministerial responsibility: ministers are unlikely to accept blame or take responsibility for actions taken on the advice that they have scrutinised and accepted.

Fourth, and most importantly, developments in the policy advisory process and the inherent weaknesses of the three agencies create a variety of risks not only in the provision of quality and timely policy advice, but also for the role of departmental 
heads, ministers and the effectiveness of the government machine as a whole. Some of these risks include the likelihood of a pervasive and systemic weakening of free and frank advice, which may lead to the provision of policy advice on the basis of what ministers want to hear rather than what they need to hear; a further politicisation of the PNG public service as a result of ministerial (or political) pressure for departmental heads to provide politically correct advice; the possibility of usurping the authority of ministers in policymaking by CACC, especially in situations where CACC is dominant in cabinet level debates; and the weakening of the CACC's effectiveness as a result of the inability of the three agencies to provide CACC with the required support. At the centre of all of this is the risk of ministers, CACC and cabinet of being ill advised on key policy issues.

There are important implications also for the effectiveness of the three agencies in maintaining their core functions. A key argument advanced in Chapter Nine is that a weakening of capability of the agencies' lead policy units will have severe repercussions for the effectiveness of these agencies as a whole because of the primary role policy units play in both policy formulation and implementation. At risk are the three agencies' core responsibilities of maintaining policy coherence, policy coordination, oversight and control and policy monitoring, evaluation and filtration (functions which have been briefly outlined in Chapter One and in more detail in Chapters Six to Eight). On the basis of the evidence provided in this study, it is doubtful whether these core functions will be maintained effectively without an improvement in capability. Steering and controlling from the centre is likely to be problematic. As variously observed elsewhere throughout this study, the lack of policy competence at the centre (Weller, et al, 1997; Bakvis, 1997; New Zealand Government Review of the Centre Report, 2001) fuelled in part by a fragmentation in government and managerial devolution appears to be common. Although loss of policy capacity has been driven by a different set of circumstances in developed countries, in PNG it is likely to arise from a loss of capability of the central agencies. Both Davis (1997) and Rhodes (1995) see central agencies as part of the core executive because of the essential role central agencies play in ensuring that the government machine functions according to the intents and purposes of the core executive. This situation is no less true in PNG. A loss of capability of the three agencies (as this study suggests) has serious implications for the executive branch's ability to govern. 
There is a case for strengthening policy advice systems and processes in PNG. Chapter Ten addresses that possibility. Using the theoretical insights of the policy transfer literature provided in Chapter Four, Chapter Ten explores various policy lessons for adoption in PNG. The lessons are mixed bearing in mind the multidimensional nature of capability. They focus on both the political and the administrative and organisational dimensions.

\section{The Weak State, Capability and Rational Analysis}

\section{The Weak State Thesis}

Chapter One provides some of the key arguments for carrying out this study. First there is the weak state thesis which has provided the launching point for this study. Found in the works of Joel Migdal (1998), Mann (1984) and Polidano, (2000) more generally in the third world, and in various commentaries on PNG (Dinnen, 2001, Denoon 2002; Curtin, 2000; 2002; Windybank and Manning, 2003), the key argument advanced under the weak state thesis is the inability of the state in developing countries to perform its tasks competently. This has been observed in various contexts including but not limited to the ability of the state to penetrate society and ensure that its decisions are carried out (Mann, 1984), the ability of the state to regulate social behaviour and its capacity to extract resources (Migdal, 1988) and within the bureaucratic context the policy capacity and implementation authority of the public service (Polidano, 2000). As observed in Chapter One, there is a tendency for various assessments of the PNG state to draw broad conclusions about the inefficacy of the public service from general observations about the problems of politics and governance.

To some extent, this study has sought to contribute to an understanding of the weak state thesis in a different dimension. It has attempted to shift away from using the general problems of politics and governance as a basis for drawing conclusions on the capability of the public service and instead has directly examined the public service's capability (in this case the capability of three central agencies). From such an examination on the ground observations can be made about the weak state thesis. On the basis of the evidence provided in this study, it can be argued that indeed the weak state thesis holds true for certain functions and key agencies in the public service. In the case of the three central agencies, it has been found that their performance has been adversely affected by the inherent weaknesses stemming from both the political and the organisational and administrative dimensions. There is, however, a point of departure and difference here. While some analyses of the 
weak state thesis would indicate that general political and governance problems are the cause of the public service lack of capability (see for instance Mann, 1988; Grindle, 1997), this study attempts to show that while this is a contributing factor it is not the only cause: problems of governance (especially the executive branch's ability to govern) are likely to be exacerbated by the lack of capability of the public service (in this case the three agencies). Indeed, the findings of this study confirm the fact that weaknesses in the PNG state's ability (and by extension the ability of the public service) to deliver services to its citizens are derived from political and governance problems. What has also been shown, however, is that there are multiple causes to the weakening of the state; political and governance problems constitute some of these causes. An important cause can also be a weak public service unable to perform its functions because of a lack of capability, broadly defined, as shown in the case of the three central agencies in this study.

\section{Loss of Capability?}

Has capability been lost or was it simply not there in the first place? A broad observation made in Chapter One, and one on which this study was premised, was the perception that there has been a gradual loss of the capability of the PNG public service. Inherent in this argument is that the PNG public service had the required level of capability once but that this has deteriorated over the years. The World Bank's judgement earlier cited is again pertinent:

It was not so long ago that Papua New Guinea could take pride in its effective and expanding public services. During the self-government and early post-Independence period, primary schools and basic public facilities were constructed throughout the country. Enrolment rates were rising, while infant mortality declined. New roads were built. Old ones were maintained... National agencies helped set the direction and standards for these services...the budget was almost balanced and made prudent use of resource-based revenue... (World Bank, 1995: 1).

In the light of the evidence reviewed in this study and against the context of the broad observations such as that above, what then can be the general conclusion? To the extent that the PNG public service once had the required capability, the findings of this study would suggest that there has been a loss of capability. Has the loss of capability been widespread and systemic as perceived by donors such as the World Bank and other observers of PNG? Any concrete answer to that question would depend on in-depth scholarly research covering the full breath of the PNG public 
service. At least from the experience of the three central agencies it would appear that capability problems are pervasive and systemic. As the analysis in Chapters Six to Eight shows, similar problems are encountered through out the three central agencies. Generally, this study adds weight to the observation recorded in Chapter One:

The quality of public sector management in PNG has deteriorated over the past decade. As strongly emphasised by the Government, poor governance is the root cause. The public sector's capacity for designing and implementing sound policies and to manage its responsibility has been eroded. A broad consensus has arisen that the situation must be reversed (Prime Minister, Sir Mekere Morauta quoted in the ADB News Release 192/01, 12 December 2001, p2).

\section{The Way Forward: An Organic Approach}

Influenced by the development administration literature, the argument put forward in Chapter One presents a model of advisory capability that encompass a variety of elements including (but not limited to) skills and expertise, infrastructural assets, administrative systems and process, the use of rational analysis emphasising better process of assessing policy, and the political environment in which departments operates. As Chapter One suggests, this approach appears to be at odds with a common view found in the public policy literature which posits that the key element (if not the only element) that matters in policy advice is the adoption of improved techniques of rational analysis (Parsons, 1995; Howlett and Ramesh, 1995 Weimer and Vining, 1999).

The analysis in this study has confirmed that capability in the provision of policy advice is a function of a variety of interlocking factors many of which are interwoven and complex: competence in rational analysis is but one aspect. In the context of developing countries such as PNG this observation is an important one, since focusing solely on improving techniques of rational analysis is unlikely to make a significant impact on the quality and timeliness of policy advice. On the whole, the analysis in Chapters Six to Eight would appear to show that strong advisory capability is organic: it depends on a combination of high quality people, effective leadership, robust organisational systems, and work structures and processes which facilitate high performance, coupled with an external political environment which drives and encourages organisational systems and policy staff to provide high quality advice. This observation is consistent with several analyses in the literature that view 
such factors as critical for effective performance of organisations in fulfilling their given mandates (for example, Casio, 1998; Ulrich, 1998; Waller, 1992; Lindquist, 2001).

PNG faces large challenges. The performance of the public service will be critical to successfully meeting these challenges. A crucial element in lifting that performance will be strong central agencies capable of providing advice, coordinating public sector activity and ensuring that good policies are effectively implemented. 


\section{Postscript}

Around September 2003, PNG was put on notice by its closest friend and ally, and the largest aid provider, Australia, that she risked having her programme and budgetary aid cut if she were not more careful in spending Australia's annual budgetary aid (around A\$ A333.6 million in 2002/3). ${ }^{65}$ Canberra also made it clear that new stringent accountability measures would be put in place to safeguard the use of Australian taxpayers' money in PNG. Australia's concerns included bureaucratic and political corruption, inefficient and ineffective spending of Canberra's annual budgetary support by government agencies and a failure to account fully for the Australian funds (see Australia's Foreign Minister's speech of 12 December 2003 quoted below).

From a broader perspective, there was an Australian perception that a lack of capability in the PNG government and its agencies has led to a situation where no tangible benefits to the PNG populace have been achieved and that Australian taxpayers' money was being wasted. Indeed, Australia's perception was consistent with the long-held view of other donor agencies, for instance the World Bank, that there had been a declining capability of the public service (as discussed in the present study). PNG, through Prime Minister Somare, quickly hit back sending a strong message to the Australians that problems in PNG were overstated. Somare was reported later to have told the Australians to "get their money and go" (Post Courier, Friday $17^{\text {th }}$ October 2003). Underlying PNG's response was a view that the capability of PNG's state machinery (including the public service) has not been lost to a significant degree. This appears to contradict the perception of Somare's predecessor, Sir Mekere Morauta, quoted earlier in Chapter Eleven and those of other donors and observers discussed in Chapter One.

Prior to the "aid row" between Australia and PNG two influential reports (Windybank and Manning, 2003; Hughes 2003) released by the influential Australian think tank, The Centre for Independent Studies, had painted a broad picture of PNG's public policy failures (that by Hughes had extended to providing assessments on other Pacific Island countries). These reports have been briefly referred in various places in this study, especially Chapter One. Against the backdrop of the weak state thesis, the reports provided broad analyses of the socio-economic and political problems of PNG, problems which, in the view of this researcher, are well known in PNG, but

\footnotetext{
${ }^{65}$ For more information see http://www.ausaid.gov.au/country/papua.cfm
} 
seldom reported locally in such concise and vigorous fashion as they have been in the two reports. The more damning of the two, the Windybank and Manning (2003) report, painted a stark picture of PNG and called for more proactive and concerted action by Australia.

The report, for instance, comments:

Democracy has been hijacked by those responsible for and benefiting from the 'systemic and systematic' corruption of public institutions. Some exemplary prosecutions of corruption would help restore the legitimacy to the government, but the legal system seems incapable of bringing either small or large crooks to justice.... This decline is accelerating. In the past, PNG has always muddled though despite grim economic conditions and dire prognoses because people could fall back on subsistence farming. But this social safety net now appears to be disintegrating....

The emergence in PNG of what are regarded as the attributes of the 'failed state' suggests that Australia should rethink its relationship with PNG now to avoid high costs in the future. The alternative is the prospect of Solomon Islands style collapse, but on a much larger scale. The dilemma is that Australia's capacity to influence PNG's future is no substitute for genuine and sustained commitment to reform from the country's leaders. Australia's advice and pressure are not always welcomed, but ultimately both countries share important common interest that overrides what was dubbed the 'colonial overhang'. A renewed focus is needed on how Australia can encourage and support change from within (Windybank and Manning, 2003: 2).

While the Windybank and Manning report had confirmed the capability problems (and generally the problems arising from the weakness of the state), the response from the PNG leaders was initially one of denial. Mike Manning the co-author of the report and head of the PNG Institute of National Affairs (PNGINA) was summoned before the Parliamentary Privileges Committee and asked to explain the contents of the report (this obviously arose from what was perceived by members of parliament as a gross misreporting of the "facts").

In a significant policy shift from its previous stance (partly influenced by the above reports and through direct consultation with Canberra by leading ministers of the PNG cabinet), Australia made an additional commitment (i.e., additional to its \$A333.6 million annual budgetary aid) to provide $\mathrm{K} 2$ billion (\$A800 million) to PNG to be spent over five years (2004-2009). 
The essence of the commitment by Canberra is captured by the Post Courier of 12 December 2003 as follows:

Australia is to pour and additional K2 billion (\$A800 million) into Papua New Guinea. This is "to prevent the country descending into anarchy and corruption" (quoting Australian Foreign Minister, Alexander Downer).... [Under the plan] nearly 20 Australians will be posted to PNG's law and justice agencies, including the position of Solicitor-General and five prosecutors in the Prosecutors Office.... The Federal Treasury and the Finance Department will provide the bulk of 36 Australians to work in key economic, finance and spending agencies.... ${ }^{66}$

Sir Rabbie Namaliu, PNG's Foreign Minister, put the issue succinctly insofar as improving capability is concerned:

The measures had a strong focus on capacity building in the public sector - the police force, law and justice agencies and departments responsible for financial management, planning and public sector administration.... The secondment of [Australia's] skilled and experienced officers and officials will be accompanied by training programmes for our [PNG] public servants and our police, with some training to be provided in Australia through the attachment of our officials to [Australian] federal and state departments and agencies. ${ }^{67}$

Problems pertaining to a lack of capability in the public service do appear to be pervasive and systemic as the brief account of recent events in this Postscript shows, although at various times PNG leaders have denied the existence and widespread nature of the capability problems. Moreover, there is some evidence giving credence to the application to PNG of the weak state thesis: clearly the PNG state cannot adequately perform many of its critical roles, for instance in enforcing rules (this is evident by the escalating law and order problems). Namaliu, in reference to the "departments responsible for financial management, planning and public sector administration" and the measures to exchange officers between the two administrations, underlines the position taken in this study: that strong capability is crucial to the performance of the PNG Government.

\footnotetext{
${ }^{66}$ See http://www.postcourier.com.pg/20031212/news01.htm

${ }^{67}$ Quoted in the Post Courier, Tuesday 16 December 2003. Online at http://www.postcourier.com.pg/20031216/news02
} 


\section{List of Appendixes}

\section{Appendix 1: Political Map of Papua New Guinea}

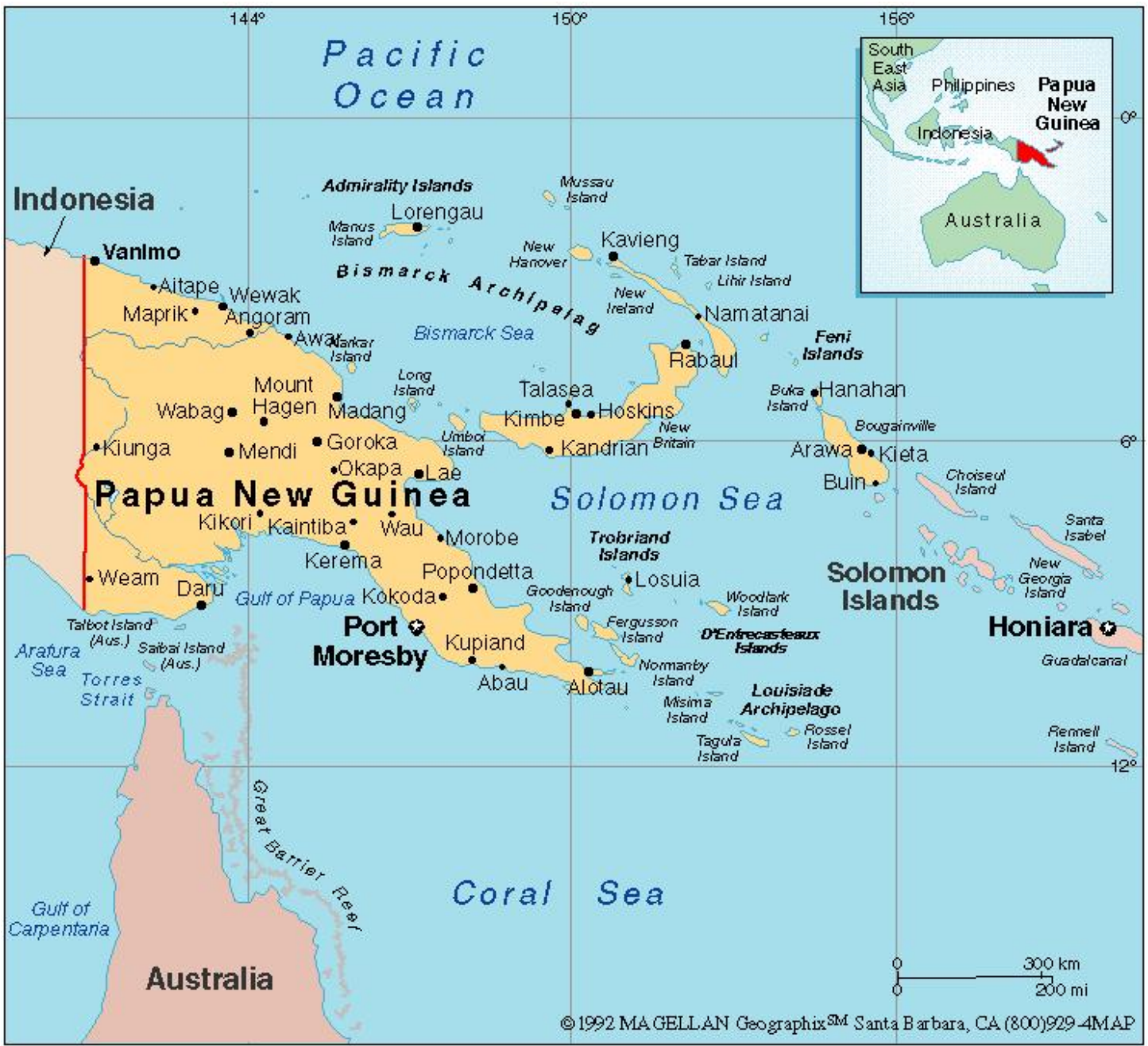




\title{
Appendix 2: Information Sheet
}

\author{
Victoria University of Wellington \\ School of Business \& Public Management *
PhD Topic: Policy Advisory Capability in Papua New Guinea's Central Government

\section{Information Sheet}

Thank you for reading the Information Sheet. This research is being undertaken for a $\mathrm{PhD}$ work in the School of Business \& Public Management under the supervision of Prof. Claudia Scott and Mr. John Martin. The researcher is Lawrence Sause, who is being sponsored by the New Zealand Government under the NZODA Scholarship administered by MFAT. The research has two parts: Part $A$ is the Survey and is anonymous. Part $B$ is the Open-ended Interviews and is confidential.

\section{Please return your filled Survey Questionnaire in the self-addressed envelope to L. Sause, the researcher.}

\section{The Study Objective}

This study evaluates the capability of three key central agencies within central government (Departments of Finance and Treasury, Prime Minister and National Executive Council, and Personnel Management) to provide quality and timely policy advice to Ministers and the NEC. The aim of the study is to identify the constraints on policy advisory capability, assess the implications arising from such constraints and propose policy intervention measures. The two principal methods for gathering data for this study is outlined below.

\section{Part A: The Survey}

The survey (in the form of structured questionnaires) is part of the above research and is focused on Policy Analysts and Policy Managers - the officials in central agencies who are at the centre of doing policy analysis work and providing advice to numerous clients including the relevant Minister and Cabinet. It is aimed at gathering information about current arrangements in policy advice. Responses (data) from the survey will aid the understanding of the researcher about present policy advice arrangements as well as identifying the constraints that impact on policy advice. .

The responses to the survey are anonymous and voluntary. There is no way of knowing the participants and therefore they will not be identified in the thesis by their name or specific title. They will be referred to in their generic name, 'policy analyst', and 'policy manager'. Raw data from the survey will be kept under security storage (in the form of locked storage and password excess to computers), to be accessed by the researcher and the supervisor only. The data will be destroyed after the duration of the study (30 July 2003).* 


\section{Part B: Open-ended Interviews}

This will include open-ended interviews with policy officials in lead policy units. Complementing the survey, the open-ended interviews are aimed at gathering additional information about current arrangements in policy advice.

The interviews will be confidential and participants will not be identified in the report by their name and title. In maintaining that confidentiality, raw data will be kept under security storage (in the form of locked storage and password excess to computers) to be accessed by the researcher and the supervisor only until they are destroyed after the duration of the study (30 July 2003). Given the face-to-face interviews (and therefore lack of anonymity), a Consent Form will have to be signed by participants prior to the interviews.

While the $\mathrm{PhD}$ thesis is the main avenue for reporting the results, conference/seminar/journals are also possible avenues for reporting the results. However, results may be released to interested participants upon request.

Should you have any questions, or require further information, please contact Lawrence Sause (researcher) Tel: (04) 4636929 / e-mail: Lawrence.Sause@vuw.ac.nz or Mr. John Martin (supervisor) Tel: (04) 3858213 / e-mail: irmartin@paradise.net.nz

Thank you for your time.

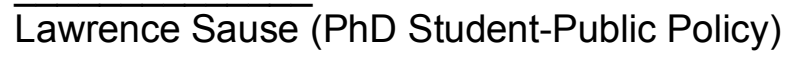

School of Business \& Public Management

Victoria University of Wellington

PO Box 600

Wellington

New Zealand

${ }^{*}$ The School of Business and Public Management was split into two separate Schools in 2003. The Public Policy "strand" in which the researcher was a PhD student became the School of Government. 30 July 2003 was the original anticipated time of finishing the PhD Programme. The Programme was extended to 31 January 2004. 


\title{
Appendix 3: Questionnaire Survey
}

\author{
ORGANISATION AND DELIVERY OF POLICY ADVICE IN CENTRAL \\ AGENCIES - PAPUA NEW GUINEA \\ STRUCTURED QUESTIONNAIRES \\ $S Q$ No. \\ (for Office Use only)
}

Thank you for taking the time to fill out this questionnaire. Please read the Information Sheet prior to filling it.

This research constitutes part of the data acquisition process for a PhD Thesis: Policy Advisory Capability of Three Central Agencies in Papua New Guinea: Analysis and Proposition of lessons. The study examines the manner and extent in which policy advice is being constrained in three key agencies: Departments of Finance and Treasury (DF\&T), Prime Minister and National Executive Council (DPM\&NEC) and Personnel Management. Open-ended (face to face) interviews on some respondents will be carried out at a later time to follow up on the responses to this survey.

The aim of the survey is to acquire information about current policy advice arrangements in PNG as a basis for comparison, analysis and drawing of lessons. Information requested may be factual, or may be based on what you see as the existing situation. Responses are anonymous and therefore participants will not be identified in the report by name or specific title. Responses obtained will be securely kept and accessed only by the researcher and his supervisor. They will be destroyed securely after the end of the PhD Programme.

This research project is conducted by Lawrence Sause (PhD Student in Public Policy), School of Business \& Public Management, Victoria University of Wellington, PO Box 600 Wellington; and complies with the guidelines of VUW Human Ethics Committee. If you have any queries, please contact:

Lawrence Sause, tel. (04) $4636929 \quad$ OR Mr. John Martin (Supervisor) (04) 3858213

Email. Lawrence.Sause@vuw.ac.nz John.Martin@vuw.ac.nz

\section{SECTION A: DATA PROFILE}

Department/Agency:

Position. Please tick one only. Assistant Secretary (Policy) Others (Specify) Year (s) of experience in current post:

Year started work in the Dept:

Age. Please tick 25-30

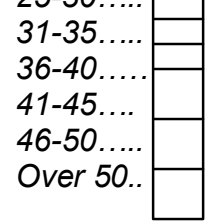

Level of qualification and discipline. Please tick and indicate discipline along side the tick.

Certificate/Diploma

Bachelors

Masters

PhD

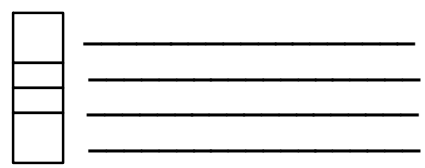

Others (e.g. Professional qualification). Please specify:

Specify other relevant work experiences in policy work (e.g. private sector management; on secondment to another organisation; previously assistant Secretary etc.). 
SECTION B. GENERAL PERCEPTIONS

Please tick the appropriate box in response to each of the following views.

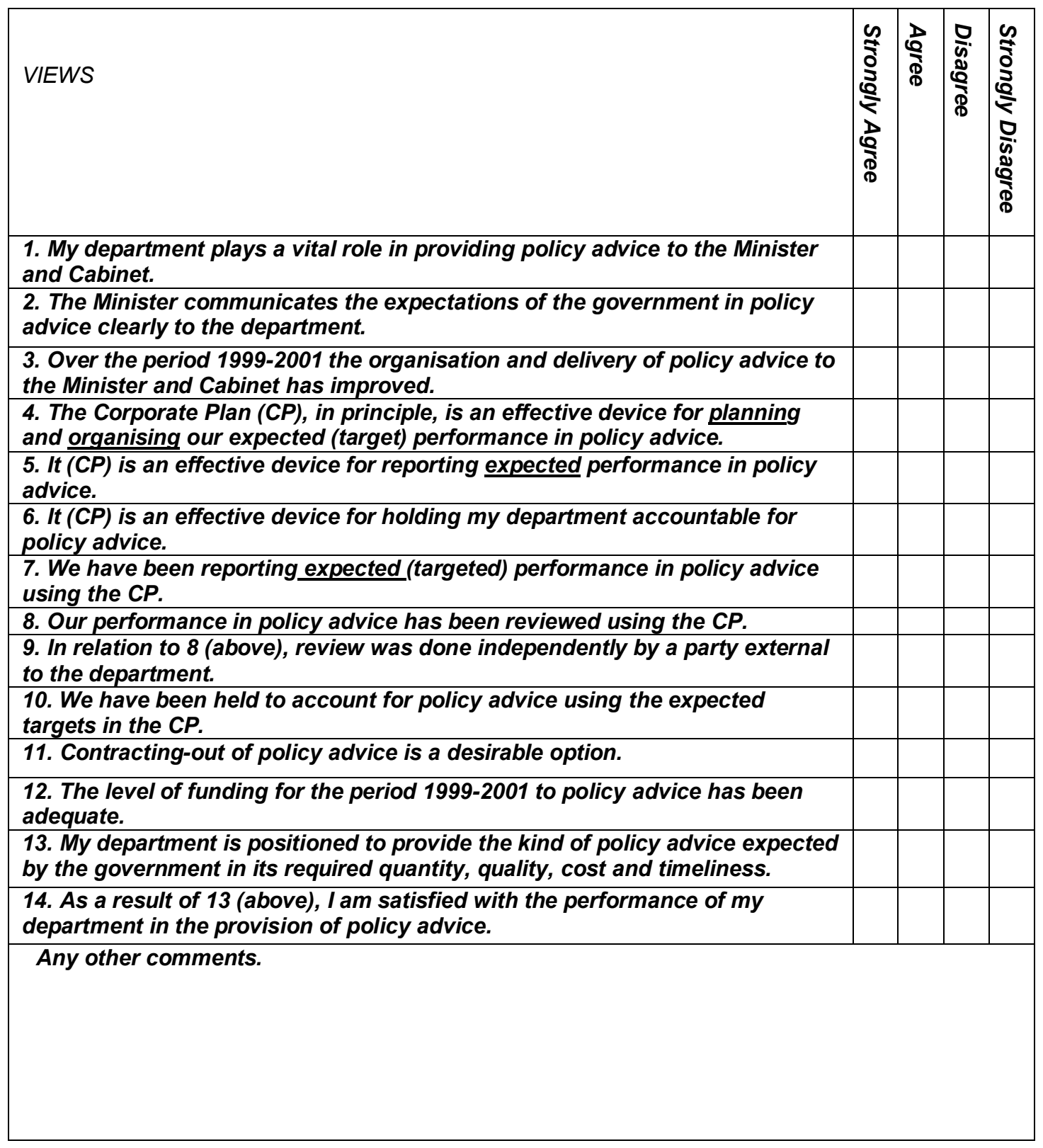




\section{SECTION C: POLICY ANALYSIS AND POLICY ADVICE}

15. How adequate do you consider the structural arrangement for policy advice (e.g. organisation of work, reporting, accountability relationships etc.) within your unit/branch? Please tick

Excellent ( () ) Very good $\left(\_\right)$Good ( $)$Fair $\left(\_\right) \quad$ Poor $\left(\_\right)$

16. How would you describe the type of policy you analyse and/or provide advice on? Please tick which ever is applicable.

Strategic (_) Substantive (_) Operational (_) Others (_) Please specify

17. Which key policy areas do you provide advice on (e.g. Trade, fiscal policy etc.)? Please specify.

18a. Is your work subject to review? Please tick.

Yes (_) No (_) If yes, is it on a regular $\left(\_\right)$or irregular basis? ( $)$

18b. If Yes, who does the review? Please tick which ever is applicable.

Peer ( _ ) Superior (e.g., Assist. Secretary, supervisor) (_) External parties ( $)$ )

Others (_) For external parties and others please specify:

19a. Does the review takes into account certain measures of performance? Please tick.

Yes (_) No (_)

19b. If Yes, what measures of performance you are aware of that are being used in reviewing your work. Please specify.

20a. Does the review takes into account any quality characteristics? Please tick.

Yes ( $\square$ No (

20b. If Yes, what characteristics are being used? Please specify.

21a. Do you liaise or interact with other line departments and agencies in policy advisory work? Please tick. Yes ( ${ }^{\prime}$ No $(\square$

221b. If yes, explain briefly the nature of that liaison or interaction (e.g. whether in providing policy advice, commenting on policy proposals/briefs, identify inter-sectoral implications etc.). Explain briefly the expectations that are brought to bear upon you as a result of that liaison or interaction. 
22a. Have you had the experience of working with colleagues in other central agencies Departments of Treasury, Prime Minister \& National Executive Council and Personnel Management- in providing advice on inter-sectoral policies or policies that require co-ordination across central agencies? Please tick.

Yes ( $\quad$ No (

22b. If Yes, what is your view on the following when working on policies of such nature? Please tick.
i. Co-operation Excellent (
co-ordination Excellent ( () Very good (
iii. Strength of leadership of the lead agency
Good (
Fair (
Poor ( ()
Excellent (_) Very good ( $\square$ Good

Fair ( Poor (

22c. If in your view improvements are required, what should be done? Please explain.

23a. Have you liaised, interacted or worked with the Minister or a Cabinet Committee in policy advisory work? Please tick.

Yes ( $)$ No (

23b. If Yes, what was expected of you as a policy analyst? Briefly explain.

24. How do you assess the Minister in terms of the following. Please tick.

24a. Understanding of the broad policy outcomes of government Excellent $(\square$ ) Very Good (_) Good ( $)$ Fair ( $($ ) Poor ( $)$

24b. Ability to communicate the Government desired policy outcomes Excellent ( $\longrightarrow$ Very Good ( $($ ) Good ( $($ ) Fair ( $($ ) Poor ( $)$

24c. Expectations over quality work in policy advice Very High (_) High (_)

Low ( ) Very Low (

25a. Have you liaised, interacted or worked with a Cabinet Committee in policy advisory work? Please tick.

Yes ( $($ ) No

25b. If Yes, what was expected of you as a policy analyst? Briefly explain.

26a. Are political expectations (or pressures) brought to bear on policy advisory work in your unit? Please tick

Yes ( ) No ( )

26b. If Yes, briefly explain.

27. Any additional comments about the organisation and delivery of policy advice in your department or in central agencies. 
POLICY ANALYST/OTHER POLICY STAFF STOP HERE; ASSISTANT SECRETARY TO CONTINUE TO SECTION D

\section{SECTION D: MANAGING POLICY ADVICE}

28. How many policy staff do you have in your unit/branch? Please indicate the number in the brackets.

Analysts ( $\quad$ Support Staff $(\square$

29. How do you regard the adequacy of the structural arrangements of policy advice (e.g. organisation of work, reporting, and accountability relationships etc.) within your unit/branch? Please tick

Excellent ( $($ ) Verygood ( $($ ) Good ( $)$ Fair ( $)$ Poor ( )

30. How do you rate your policy staff in terms of their quality of work? Please tick.

Excellent (_) Very Good ( ) Good ( ) Fair ( ) Poor ( )

31a. Is review on performance in policy advisory work an important consideration in your work? Please tick.

Yes ( 1 No (

31b. If Yes, is reviewing done regularly or on an ad-hoc basis? Please tick Regularly (_) Ad-hoc basis (

32a. Do performance reviews take into account any measures of performance? Please tick. Yes ( 1 No (

32b. If Yes, please briefly explain these measures.

33a. Does the review takes into account any quality characteristics? Please tick. Yes ( 1 No ( )

33b. If Yes, please briefly explain these characteristics.

34. Have you managed or co-ordinated policy advisory work that has been contracted out? Please tick.

Yes ( $\quad$ No (

35. If Yes, what is the value of the work contracted out in the following: Please indicate costs. 36a. 1999? 36 b. 2000 ? 36c. 2001?

36. What have been the reasons for contracting-out policy work? Please briefly explain.

37a. Using over-arching goals such as Key Priority Areas of Government (KPAG) or the EightPoint Plan (EPA) in guiding and over-all provision of policy advice to government is a good idea. Please tick.

Strongly agree (_) Agree (_) Disagree (_) Strongly Disagree (_)

37b. We have been using KPAG/EPA or their equivalent as bases for organising and delivering advice to the government. Please tick.

Yes ( ) No (

37c. If Yes briefly explain how this is done in your department. 
38. How would you rate you department's performance in providing policy advice (as an output) if you were to judge performance by comparing your intent to actual delivery of policy advice in the period 1999-2001? Please tick.

$\begin{array}{llll}\text { 38a. 1999: Excellent }(\square) & \text { Verygood }(\square) \text { Good }(\square) & \text { Fair }(\square) & \text { Poor }(\square) \\ \text { 38b. 2000: Excellent }(\square) & \text { Verygood }(\square) \text { Good }(\square) & \text { Fair }(\square) & \text { Poor }(\square) \\ \text { 39c 2001: Excellent } \square) & \left.\text { Verygood }(\square) \text { Good }()_{1}\right) & \text { Fair }(\square)\end{array}$

40. Any additional comments you would like to make as the Assistant Secretary for Policy 


\title{
Appendix 4: Sample of Interview Request Letter
}

\author{
VICTORIA UNIVERSITY OF WELLINGTON \\ Te Whare Wananga o te Upoko o te Ika a Maui
}

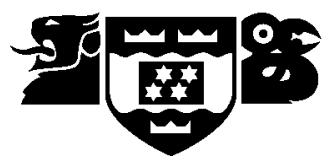

01 November 2002

Mr. Peter Tsiamalili, Secretary

Department of Personnel Management

PO Box 519, Waigani

NCD

Fax: 006753276201

Dear Secretary Tsiamalili,

\section{Subject: Approval for Interviews with Selected Members of Policy Branch}

My name is Lawrence Sause and I am a member of staff at UPNG. I am currently doing research work on central agencies in PNG for a PhD thesis. The work examines how policy advisory capability of central agencies can be improved using viable lessons from New Zealand, the country acclaimed to have introduced some of the novel and cutting edge ideas in reforming public management within the OECD.

In the beginning of the year I administered a survey questionnaire, soliciting responses from several staff of your policy unit. This time I would like to follow that with brief interviews with selected members of your policy staff and therefore ask for your kind permission. The sessions will not take more than 30 minutes. In my previous liaison with your department, I have sent out an Information Sheet briefly giving details of the research. The same Information Sheet can be produced once I am in Port Moresby. My stay in Port Moresby will be very brief (between 9-29 November) and therefore I would be most grateful for your prompt response so that I can initiate the interviews as early as possible.

Best wishes to you and I look forward to your response.

Your Sincerely

$\overline{\text { Lawrence Sause }}$

Port Moresby contact: Dept of Public Policy \& Management, UPNG. Tel: 3267190

E-mail: Isause@yahoo.com 


\section{Appendix 5: Interview Consent Form}

\section{Policy Advisory Capability in Papua New Guinea's Central Government \\ For Open-ended Interviews Only}

Thank you for your time. If you are satisfied with the information provided in the Information Sheet and would like to participate in the interview please complete this Consent Form.

I understand that aggregate results of this research will be reported in the PhD thesis, and possibly in conference/seminar and journal presentations. I also understand that where references are made individually to me, these will only be made after my express permission.

I understand that raw data in the interview including transcripts of interviews will be kept under security storage until 30 July 2003 (the duration of the research) and destroyed securely at the end of that time. I also understand that the data will only be available to the principal researcher (Lawrence Sause) and the PhD supervisor supervising him.

I understand that care will be taken in storing and processing the data where it will be stored and processed in a protected electronic environment and accessed only by the researcher and his Supervisor.

I am interested in getting the feedback of the interview and research and may do so upon request (please tick): Yes No

I understand that participation is voluntary and I am neither obliged to contribute nor to provide explanation for withdrawing my responses from consideration at any stage until the 30 July 2003 (the termination date of participating).

Name:

Signed:

Date:

Lawrence Sause

School of Business \& Public Management

Victoria University of Wellington,

PO Box 600, Wellington

New Zealand

E-mail: Lawrence.Sause@vuw.ac.nz

Fax: (04) 4635084. 


\section{Appendix 6: Interview Guide}

Questions used with the policy officials in the interview.

\section{Role of the Department and Policy Units}

1. How would you describe the role of your department?

2. How would you describe the role of your policy unit in analysing issues and providing policy advice?

3. Does your department have the required capability to perform its role?

4. What are the key problems and/or constraints preventing your unit from providing reliable and comprehensive advice?

\section{Human Resource Issues}

5. What would you consider as the three most important human resource development issues facing your department and policy unit?

6. Lack of skills and expertise is seen as a major problem affecting the PNG public service. What particular skills are lacking in your unit?

7. Briefly describe the staff development and training plan in your department. Do you consider your training plan as adequate? What areas of the training plan need improvement?

\section{Management Issues}

8. The way your policy unit is managed is important to the effectiveness of your policy unit. How would you describe the management of your policy unit?

9. Would you consider the financial allocations to your unit as adequate in sustaining good policy work?

\section{Infrastructural Support}

10. Do you consider the existing facilities as being adequate in supporting the work of your unit? What are the areas that need attention?

\section{Organising Policy Advice}

11. Could your briefly describe the way policy advice is organised within your unit?

12. Is there any established protocol or benchmark that is used in guiding and evaluating policy advisory work in your unit? 


\section{External Political Environment}

13. Thinking about the existing political climate in PNG, what would be your views on (a) the political direction and control by the minister of your department, (b) the security of tenure of your departmental head, and (c) your head of department providing free and frank advice to the Minister? 


\section{Appendix 7: List of Interview Participants}

\begin{tabular}{|c|c|c|c|c|}
\hline No & Name & Dept \& Unit & General Position & Date \\
\hline A1 & & $\begin{array}{l}\text { Prime Minister \& NEC } \\
\text { Policy Division }\end{array}$ & Senior Policy Official & 20.11 .02 \\
\hline $\mathrm{A} 2$ & & $\begin{array}{l}\text { Prime Minister \& NEC } \\
\text { Policy Division }\end{array}$ & Senior Official & 20.11 .02 \\
\hline A3 & & $\begin{array}{l}\text { Prime Minister \& NEC } \\
\text { Policy Division }\end{array}$ & Policy Analyst & 20.11 .02 \\
\hline A4 & & $\begin{array}{l}\text { Prime Minister \& NEC } \\
\text { Policy Division }\end{array}$ & Senior Policy Official & 21.11 .02 \\
\hline A5 & & Prime Minister \& NEC & Senior Policy Official & 21.11 .02 \\
\hline A6 & & $\begin{array}{l}\text { Personnel Management } \\
\text { Policy, Research \& Dev. } \\
\text { Division }\end{array}$ & Policy Analyst & 21.11 .02 \\
\hline A7 & & $\begin{array}{l}\text { Personnel Management } \\
\text { Policy, Research \& Dev. } \\
\text { Division }\end{array}$ & Policy Analyst & 21.11 .02 \\
\hline A8 & & $\begin{array}{l}\text { Personnel Management } \\
\text { Policy Research \& Dev. } \\
\text { Division }\end{array}$ & Policy Analyst & 21.1102 \\
\hline A9 & & $\begin{array}{l}\text { Personnel Management } \\
\text { Policy Research \& Dev } \\
\text { Division }\end{array}$ & Policy Analyst & 21.11 .02 \\
\hline A10 & & $\begin{array}{l}\text { Personnel Management } \\
\text { Policy, Research \& Dev. } \\
\text { Division }\end{array}$ & Policy Analyst & 21.11 .02 \\
\hline A11 & & $\begin{array}{l}\text { Personnel Management } \\
\text { Policy Research \& Dev. } \\
\text { Division }\end{array}$ & Policy Analyst & 21.11 .02 \\
\hline A12 & & $\begin{array}{l}\text { Treasury } \\
\text { Economic Policy Unit }\end{array}$ & Senior Policy Official & 25.11 .02 \\
\hline A13 & & $\begin{array}{l}\text { Treasury } \\
\text { Economic Policy Unit }\end{array}$ & Senior Policy Analyst & 25.11 .02 \\
\hline A14 & & $\begin{array}{l}\text { Treasury } \\
\text { Economic Policy Unit }\end{array}$ & Senior Policy Analyst & 25.11 .02 \\
\hline A15 & & $\begin{array}{l}\text { Treasury } \\
\text { Economic Policy Unit }\end{array}$ & Senior Policy Official & 25.11 .02 \\
\hline A16 & & $\begin{array}{l}\text { Treasury } \\
\text { Economic Policy Unit }\end{array}$ & Senior Policy Official & 25.11 .02 \\
\hline A17 & & $\begin{array}{l}\text { Treasury } \\
\text { Economic Policy Unit }\end{array}$ & Senior Policy Official & 25.11 .02 \\
\hline A18 & & $\begin{array}{l}\text { Planning, European } \\
\text { Union (EU) Programme } \\
\text { Unit }\end{array}$ & Senior Policy Analyst & 26.11 .02 \\
\hline A19 & & $\begin{array}{l}\text { Treasury, Aid } \\
\text { Coordination Division }\end{array}$ & Senior Analyst & 26.11 .02 \\
\hline A20 & & $\begin{array}{l}\text { Planning, Monitoring and } \\
\text { Evaluation Division }\end{array}$ & Policy Analyst & 26.11 .02 \\
\hline A21 & & $\begin{array}{l}\text { Monitoring and } \\
\text { Evaluation }\end{array}$ & Senior Policy Analyst & 26.11 .02 \\
\hline A22 & & $\begin{array}{l}\text { Planning, Policy } \\
\text { Monitoring and Research }\end{array}$ & Policy Analyst & 26.11 .02 \\
\hline A23 & & $\begin{array}{l}\text { Treasury, Economic } \\
\text { Planning Unit }\end{array}$ & Senior Policy Official & 27.11 .02 \\
\hline
\end{tabular}




\section{Bibliography}

Aberbach, J.D. et al. (1991) Bureaucrats and Politicians in Western Democracies. Cambridge, Mass., Harvard University Press.

Albrow, M. (1970) Bureaucracy. London, Pall Mall Press.

Allison, G.T. (1971) Essence of Decision: Explaining the Cuban Missile. Crisis Boston MA, Little Brown.

Andamolekun, et al. (1997) Political transition, economic liberalisation and civil service reform in Malawi. Public Administration and Development 17(2): 209-222.

Anderson, G. (1997) The New Focus on the Policy Capacity of the Federal Government. Canadian Public Administration 39(4): 469-488.

Anderson, P.A. (1983) Decision Making by Objection and the Cuban Missile Crisis. Administrative Science Quarterly 28: 201-222.

Andeweg, R. (1997) Collegiality and Collectivity: Cabinets, Cabinet Committees and Cabinet Ministers. In Weller, P. et al. (eds) The Hollow Crown: Countervailing Trends in Core Executives. London, Macmillan.

Andeweg, R. (1999) Advising Prime Ministers. Public Money \& Management 19(2): 13-17.

Asian Development Bank (2000) Country Operations Report: Papua New Guinea. Manila, Asian Development Bank.

Aucoin, P. (1990) Assessing Managerial Reforms. Governance 3(2): 197-204.

Aucoin, P. (1994) Prime Ministerial Leadership: Position, Power and Politics. In Mancuso et al. (eds) Leaders and Leadership in Canada. Toronto, Oxford University Press.

Auluk, R. (2002) Benchmarking: A Toll for Facilitating Organisational Learning? Public Administration and Development 22: 109-122.

AusAID (1999) The Economy of Papua New Guinea, Macroeconomic Policies: Implications for Growth and Development in the Informal Sector. Canberra, AusAID.

Axline, W.A. (1986) Decentralisation and Development Policy: The Provincial Government and the Planning Process in Papua New Guinea. Waigani, IASER.

Ayres, R. (1998) Policy Markets in Australia: Evidence and Analysis. Paper presented to the Australian Political Studies Association Annual Conference 28-30 September 1998 University of Canterbury Christchurch, New Zealand.

Ayres, R. (2001) Policy Markets in Australia. PhD Thesis, University of Canberra.

Bakvis, H. (1997) Advising the Executive: Think Tanks, Consultants, Political Staff and Kitchen Cabinets. In Weller et al (eds) The Hollow Crown: Countervailing Trends in Core Executives (1997). 
Bakvis, H. (2000) Rebuilding Policy Capacity in an Era of Fiscal Dividend: A Report from Canada. Governance 13(1): 71-103.

Bale, M. \& Dale, T. (1998) Public Sector Reform in New Zealand and Its Relevance to Developing Countries. The World Bank Research Observer 13(1): 103-121.

Bank of Hawaii (2000) Papua New Guinea: Economic Report, February 2001 online at http://www.boh.com/econ/nav-econ 010402ahk.asp [15.2.03].

Bank of Papua New Guinea (1998) Money and Banking in Papua New Guinea. Port Moresby, BPNG.

Bank of Papua New Guinea (1990-2000) Quarterly Economic Bulletin (various). Port Moresby, BPNG.

Bennett, C.J. (1988) Different Processes, One Result: The Convergence of Data Protection Policy in Europe and the United States. Governance 1(4): 415-445.

Bennett, C.J. (1991) How States Utilize Foreign Evidence. Journal of Public Policy 2(1): 31-54.

Bennett, C.J. (1991a) Review Article: What Is Policy Convergence and What Causes It? British Journal of Political Science 21: 215-233.

Bennett, C.J. (1992) Regulating Privacy: Data Protection and Public Policy in Europe and the United States. New York, Cornell University Press.

Bennett, C.J. (1997) Understanding Ripple Effects: The Cross-National Adoption of Policy Instruments for Bureaucratic Accountability Governance 10(3): 305-329.

Bennett, S. \& Mills, A. (1998) Government Capacity to Contract: Health Sector Experience and Lessons. Public Administration and Development 18: 307-326.

Berry, G. \& Harris, B. (2002) Leadership for Quality in the Papua New Guinea Public Service Reform. Labour and Management in Development Journal 2(8): 1-33.

Bhatta, G. (2002) Evidence-based Analysis and the Work of Policy Shops. Australian Journal of Public Administration 61(3): 98-105.

Blackstone, T. \& Plowden, W. (1988) Inside the Think Tank. London, William Heinemann.

Boston et al. (1996) Public Management: The New Zealand Model. Auckland, Oxford University Press.

Boston, et al. (1991) Reshaping the State: New Zealand's Bureaucratic Revolution. Auckland, Oxford University Press.

Boston, J. (1989) The Future Role of Central Agencies: What Changes are required? Unpublished Paper, Victoria University of Wellington.

Boston, J. (1980) High Level Advisory Groups in Central Government: A comparative Study of the Australian Priorities Review Staff and the New Zealand Prime Minister's Advisory Group. MA Thesis, Canterbury University. 
Boston, J. (1991) The Theoretical Underpinnings of the Public Sector Restructuring in New Zealand. In Boston et al. (eds) Reshaping the State: New Zealand's Bureaucratic Revolution (1991).

Boston, J. (1992) The Problems of Policy Co-ordination: The New Zealand Experience. Governance 5(1): 88-103.

Boston, J. (1992) The Treasury: Its Role, Philosophy, and Influence. In Gold, H. (ed.) New Zealand Politics in Perspective. Auckland, Longman.

Boston, J. (1994) Purchasing Policy Advice: The Limits to Contracting Out. Governance 7(1): 1-30.

Boston, J. (1999) New Zealand's Model of Public Management: The Promise and the Reality. NIRA Review 6(2): 15-18.

Boston, J. (2000) The Challenge of Assessing Systematic Change: The Case of Public Management Reform. International Public Management Journal 3: 23-46.

Boston, J. (2001) New Zealand: cautionary tale or shinning example? In Rhodes, P.A.W. \& Weller, P. (eds) The Changing World of Top Officials: Mandarins or Valets? Buckingham, Open University Press.

Bouma, G.D. (2000) The Research Process. Melbourne, Oxford University Press.

Boyne et al. (1999) Competitive Tendering and Best Value in Local Government. Public Money \& Finance 19(4): 23-29.

Braybrook, D. \& Lindblom, C.E. (1963) A Strategy of Decision: Policy Evaluation as a Social Process. New York, Free Press.

Bridgman, P. \& Davis, G. (1998) Australian Policy Handbook. St Leornard NSW, Allen \& Unwin.

Brinkerhoff, D. \& Goldsmith, A. (1992) Promoting the Sustainability of Development Institutions: A Framework for Strategy. World Development 20: 369-383.

Brinkerhoff, D.W. (1991) Improving Development Programme Performance: Guideline for Managers. Boulder CO., Lynne Reinner Publishers.

Brinkerhoff, D.W. (2000) Democratic Governance and Sectoral Policy Reform: Tracing Linkages and Exploring Synergies. World Development 28(4): 601-615.

Brinkerhoff, D.W. (1996) Process Perspective on Policy Change: Highlighting implementation. World Development 24(9): 1335-1401.

Brown, R.G.S \& Steel, D.R (1978) The Administrative Process in Britain. London, Methuen.

Butterworth, R. \& Horne, N. (2003) Policy advice: a practical perspective. International Journal of Public Sector Management 16(3): 219-299.

Caiden, N. \& Wildavsky, A. (1974) Planning and Budgeting in Poor Countries. New York, John Wiley \& Sons. 
Camp, R.C. (1989) Benchmarking: the search for industry best practices that lead to superior performance. London, Quality Press.

Campbell et al. (1989) Afterward on Policy Communities: A Framework for Comparative Research. Governance 2: 86-89.

Campbell, C. \& Szablowski, G.W. (1979) The Super-Bureaucrats: Structure and Behaviour in Central Agencies. Toronto, Macmillan.

Campbell, C. (1987) Canada. In Plowden, W. (ed.) Advising the Rulers. Oxford, Basil Blackwell.

Campbell, C. (1988) Review Article: The Political Roles of Senior Government Officials in Advanced Democracies. British Journal of Political Science 18: 243-72.

Campbell, C. (1993) Governments Under Stress: Political Executives and Key Bureaucrats in Washington, London, and Ottawa. Toronto, University of Toronto Press.

Campbell, C. (2001) Juggling Inputs, Outputs and Outcomes. Search for Policy Competence: Recent Experience from Australia. Governance 14(2): 253-282.

Campos, N.F \& Nugent, J.B. (1999) Development Performance and the Institutions of Governance: Evidence from East Asia and Latin America. World Development 27(3): 439-452.

Carter, E.E. (1971) The Behavioural Theory of the Firm and Top-level Corporate Decisions. Administrative Science Quarterly 16: 413-428.

Casey, K. (2002) Capability, Accountability and Performance Pilot: Department of Corrections. Public Sector 25(3): 5-7.

Casio, W. (1998) Managing for Organisations Intellectual Capital. Human Resources, April: 7-11.

Chand, S. \& Stewart, R. (1997) Economic Reforms and Structural Change in Papua New Guinea: progress, Performance and Prospects. Pacific Economic Bulletin 12(1): 53-69.

Chapman, R. (1995) Improving Policy Advice Processes: Outcome Definition, Policy Evaluation and a Competitive Market. Public Sector 18(2): 16-21.

Chapman, R.A. (1997) The Treasury in Public Policy-Making. London, Routledge.

Chin, J. (2002) Papua New Guinea in 2001: Election Fever Begins. Asian Survey 42(1): 801-806.

Clifford et al. (1984) Law and Order in Papua New Guinea (Clifford Report). Port Moresby, Institute of Applied Social and Economic Research.

Clifford, C. (2000) Administering the Summit: The British Prime Minister's Office. In Peters et al. (eds) Administering the Summit: Administration of the Core Executive in Developed Countries. London, Macmillan. 
Cohen et al. (1972) A Garbage Can Model of Organisational Choice. Administrative Science Quarterly 17: 1-25.

Cohen, J.M. (1992) Foreign Advisors and Capacity Building: The Case of Kenya. Public Administration and Development 12: 493-510.

Cohen, J.M. (1995) Capacity Building in the Public Sector: A Focus Framework for Analysis and Action. International Review of Administrative Science 61: 407-422.

Colebatch, H.K (1996) Comments on John Uhr, "Testing the Policy Capacities of Budgetary Agencies: Lessons from Finance." Australian Journal of Public Administration 55(4): 135-136.

Colebatch,H. K. (1998) Policy. St Leonard NSW, Allen and Unwin.

Considine, M. \& Painter, M. (eds) (1997) Managerialism: The Great Debate. Melbourne, Melbourne University Press.

Corban, J. (1994) The Provision of Strategic Advice to Government. MPP Thesis, Victoria University of Wellington.

Cosier, R. \& Schwenk, C. (1990) Agreement Consensus and Thinking Alike: Ingredients for Poor Decisions. Academy of Management Executive 4: 69-74.

Craswell, E. \& Davies, G. (1994) The Search for Policy Coordination: Ministerial and Bureaucratic Perceptions of Agency Amalgamation in Federal Parliamentary Systems. Policy Studies Journal 22(1): 59-74.

Crosby, B.L. (1996) Policy Implementation: The Organisational Challenge. World Development 24(9): 1403-1415.

Curtin, T. (2000) A New Dawn for Papua New Guinea's Economy? Pacific Economic Bulletin 15(2) 1-35.

Curtin, T. (2000a) Public Sector Reform in Papua New Guinea and the 1999 Budget. Labour and Management in Development 1(4): 1-26.

Curtain, T. (2002) Budgeting in a weak state: the new Somare government's first attempt. Pacific Economic Bulletin 17(2): 1-4.

Davies et al. (1999) Editorial: What Works? The Role of Evidence in Public Sector Policy and Practice. Public Money \& Management 19(1): 3-5.

Davis, G. (1997) Executive Co-ordination Mechanisms. In Weller et al. (eds) The Hollow Crown: Countervailing Trends in Core Executives. London, Macmillan.

Dearden et al. (1999) Icitrap-an experimental training exercise for examining participatory approaches to project management. Public Administration and Development 19: 93-104.

Denoon, D. (2002) Papua New Guinea's Crisis: Acute or Chronic? World Affairs 64 (Winter): 115-122. 
Department of Finance \& Treasury (1998) Corporate Plan 1998-2000. Waigani, DF\&T.

Department of Finance \& Treasury (1990-2000) Monthly Economic Monitor (various). Waigani, Department of Treasury.

Department of Finance \& Treasury (2000) Estimates of Revenue and Recurrent Expenditure, Volumes 2 Parts I \& II. Waigani, DF\&T.

Department of Finance \& Treasury (2001) 2001 Estimates of Revenue and Recurrent Expenditure, Volume 2 Parts I \& II. Waigani, DF\&T.

Department of Finance \& Treasury (2002) Treasury Economic Monitor 3/2002 Waigani, DF\&T.

Department of Finance \& Treasury (2002a) 2002 Supplementary Budget, Volume 2: Recurrent and Development Expenditure. Waigani, DF\&T.

Department of Finance \& Treasury (2002b) 2002 Estimates of Development Expenditure Volume 2 Part 3. Waigani, DF\&T

Department of Health (DoH) (1996) National Health Plan 1996-2000. Waigani, DoH.

Department of National Planning \& Monitoring (1996) Medium Term Development Strategy 1997-2002. Waigani, Department of National Planning \& Monitoring.

Department of National Planning \& Monitoring (PNGDNP\&M) (1999) Papua New Guinea Human Development Report, 1998. Waigani, PNGDNP\&M.

Department of Personnel Management (2000) Corporate Plan 2001-2005. Waigani, DPM.

Department of Personnel Management (2002) 2002 Estimates of Salaries and Allowances - Item 111. Waigani, DPM.

Department of Prime Minister \& National Executive Council (1998) Corporate Plan 1998-2000. Waigani, DPM\&NEC.

Department of Prime Minister \& National Executive Council (2000) 2001 Budget Estimates: Submission to the CACC. Waigani, DPM\&NEC.

Dexter, L.A. (1970) Elite and Specialised Interviewing. Evanston, III., North Western University Press.

Di Franceso, M (2000) An Evaluation Crucible: Evaluating Policy Advice in Australian Agencies.Australian Journal of Public Administration 59(1): 36-48.

Dinnen et al., (eds) (1997) Challenging the State: The Sandline Affair in Papua New Guinea. ANU Canberra, Research School of Pacific and Asian Studies.

Dinnen, S. (2001) Law and Order in a Weak State: Crime and Politics in Papua New Guinea. Honolulu, University of Hawaii Press.

Dolowitz, D.P (2000) Introduction. Governance 13(2): 1-4. 
Dolowitz, D.P. (1997) British Employment Policy in the 1980's: Learning from the American Experience. Governance 10(1): 23-42.

Dolowitz, D.P. (2003) A Policymaker's Guide to Policy Transfer. The Political Quarterly 71(4): 101-108.

Dolowitz, D.P. \& Marsh, D. (1996) Who Learns What from Whom: a Review of Policy Transfer Literature. Political Studies XLIV(II): 341-357.

Dolowitz, D.P. \& Marsh, D. (2000) Learning from Abroad: The Role of Policy Transfer in Contemporary Policy-Making. Governance 13(1): 5-24.

Dorney, S. (1990) Papua New Guinea: People, Politics and History since 1975. Sydney, Random House.

Duncan, R. \& Temu, I. (1995) The Need for Fiscal Discipline. Pacific Economic Bulletin 10(1): 14-18.

Dunleavy, P. (1995) Reinterpreting the Westland Affair: Theories of the State and Core Executive Decision Making. In Rhodes, R.A.W \& Dunleavy, P. (eds) Prime Minister, Cabinet and Core Executive. London, Macmillan.

Dunleavy, P. (1995a) Policy disasters: explaining the UK's record. Public Policy and Administration 10 (2).

Easterly, W. \& Levine, R. (1997) Africa's Growth Tragedy: Policies and Ethnic Divisions. World Bank Working Paper, World Bank, Washington DC.

Edoho, F. (1998) Management Capacity Building: A Strategic Imperative for African Development in the Twenty-First Century. In Udoh, V.F. (ed.) Capacity Building in Developing Countries. London, Praeger.

Edwards, G. (2000) Clarifying the Status of Policy. Australian Journal of Public Administration 59(2): 109-114.

Edwards, M. (1991) Evaluating Policy Advice: A Comment. Australian Journal of Public Administration 51(4): 447-449.

Edwards, M. (2002) Public Sector Governance - Future Issues for Australia. Australian Journal of Public Administration 61(2): 51-61.

Edwards, M. \& Hulme, D. (1996) Too Close for Comfort? The Impact of Official Aid on Non-governmental Organisations. World Development 24(6): 961-973.

Eisenhardt, K.M. \& Zbaracki, M.J. (1992) Strategic Decision Making. Strategic Management Journal 13: 17-37.

Eichbaum, C. \& Shaw, R. (2003) A Third Force? Ministerial Advisers in the Executive. Public Sector 26(3): 7-13.

Flinders, M. (2002) Governance in Whitehall. Public Administration 80(1): 51-75.

Franks, T. (1999) Capacity Building and Institutional Development: Reflections on Water. Public Administration and Development 19: 51-61. 
Garnaut, R. (1995) Monetary Stability or More Devaluation? Pacific Economic Bulletin 10(1): 19-23.

Ghai, Y. (1993) Establishing a Liberal Political Order through a Constitution: The Papua New Guinea Experience. Development and Change 28(2): 303-330.

Ghai, Y. \& Reagan, A. (1989). Decentralisation and Intergovernmental Relations in Papua New Guinea. Waigani, IASER.

Giddens, A. (1979) Central Problems in Social Theory. London, Macmillan

Glenn, G. (1993) Report on the Evaluation of the Policy Development of the 1992-93 Carers Package. Canberra, DPMC.

Goldering, J. (1978) The Constitution of Papua New Guinea. Sydney, The Law Book Company.

Goldsmith, A.A. (1996) Strategic Thinking in International Development: Using Management Tools to see the Big Picture. World Development 24(9): 1431-1439.

Goodin, R.E. (1982) Political Theory and Public Choice Chicago, Chicago University Press.

Gregory, J. (1982) Understanding Public Bureaucracy. Public Sector 4(2/3)

Gregory, R.J. (1989) Political Rationality or "Incrementalism"? Charles E. Lindblom's Enduring Contribution to Public Policy Making. Theory Policy and Politics 17: 139-53.

Gregory, R.J. (2000) Getting Better but Feeling Worse? Public Sector Reform in New Zealand. International Public Management Journal 3: 107-123.

Griffin et al. (eds) (1979) Papua New Guinea: A Political History. Melbourne, Heinemann Educational Australia.

Grindle, M. \& Thomas, J. (1990) After the Decision: Implementing Policy Reform in Developing Countries. World Development 18 (8): 1163-1183.

Grindle, M.S. (1997) Divergent Cultures? When Public Organisations Perform Well in Developing Countries World Development 25(4): 481-495.

Hall, P.A \& Taylor, R.C.R (1996) Political Science and the Three New Institutionalisms. Political Studies XLIV: 936-957

Halligan, J. (1987) Reorganising Australian Government Departments. Canberra Bulletin of Public Administration 52: 40-47.

Halligan, J. (1995) Policy Advice and the Public Service. In Peters, B.G. \& Savoie, D.J. (eds) Government in a Changing Environment. Montreal, McGill-Queens University Press.

Halligan. J. (2003) Leadership and the Senior Service from a Comparative Perspective. In Peters, B.G. \& Pierre, J (eds) Handbook of Public Administration. London, Sage.

Hannan, M.T. \& Freeman, J.H. (1977) The Population Ecology of Organisations. American Journal of Sociology 82: 929-964. 
Hart, J. (1998) Central Agencies and Departments. In Peters, B.G. \& Savoie, D.J. (eds) Taking Stock: Assessing Public Sector Reforms. Montreal, McGill-Queen's University Press.

Haveman, H.A. (1993) Follow the Leader: Mimetic Isomorphism and Entry into New Markets. Administrative Science Quarterly 38(4): 593-628.

Hawke, G. (1993) Improving Policy Advice. Wellington, Institute of Policy Studies.

Heclo, H. (1978) Issue Networks and Executive Establishment. In King, A. (ed.) The New American Political System. Washington, American Enterprise Institute.

Heeks, R. (2002) i-Development not e-Development: Special Issues on ICTs and Development .Journal of International Development 14: 1-11.

Hennessy, P. (1986) Cabinet. Oxford, Basil Blackwell.

Hennessy, P. (1988) Demystifying Whitehall: the British Civil Service Debate, 1980s Style. In Campbell, C. \& Peters, B.G., (eds) Organising Governance, Governing Organisations. Pittsburgh, University of Pittsburgh Press.

Hensley, G. (1995) Free and Frank Advice to Ministers: Reappraising Ethical Fundamentals. Public Sector 18(3): 21-23.

Hilderbrand, M.E. \& Grindle, M.S. (1995) Sustainable Capacity in the Public Sector: What can be done? Public Administration and Development 15(5)

Horberg, G. (1991) Sleeping with an Elephant: The American Influence on Canadian Environmental Regulation. Journal of Public Policy 2(1): 107-132.

Hogwood, B.W. \& Gunn, L.A. (1984) Policy Analysis for the Real. World New York, Oxford University Press.

Howlett, M. \& Ramesh, M. (1995) Studying Public Policy: Policy Cycles and Policy Subsystems. Toronto, Oxford University Press.

Howlett, M. (2000) Beyond Legalism: Policy Ideas, Implementation Styles and Emulation-Based Convergence in Canadian and US Environmental Policy. Journal of Public Policy 20(3): 305-329.

Hughes, H. (2003) Aid has failed the Pacific. Sydney, Centre for Independent Studies.

Hughes, O.E. \& Samaratunge, R. (2001) Development and New Public Management: Partners in the New Century? Working Paper 54/01 Department of Management, Monash University.

Hulme, D. (1992) Enhancing organisational effectiveness in developing countries: the training and visit system revisited. Public Administration and Development 12: 433445.

Hunn, D. \& Lang, H. (1989) Review of the Prime Minister's Office and Cabinet Office Wellington, State Services Commission. 
IMF (1990-2000) International Financial Statistics (various). Washington DC, IMF.

Ingraham, P. (1993) Of Pigs in Pokes and Policy Diffusion: Another look at Pay. Public Administration Review 53(4): 348-463.

Irwin, T. (1996) The Psychology of Judgement and the Practice of Policy Advice. Public Sector 19(3): 20-22.

Jacobs, K. \& Barnett, P. (2000) Policy Transfer and Policy Learning: A Study of the 1991 New Zealand Health Services Task Force. Governance 3(2): 185-213.

James, S. (1992) British Cabinet Governments. London, Routledge.

Jenkins, W.I. (1978) Policy Analysis: A Political and Organisational Perspective .London, Martin Robertson.

Jepperson, R.L. (1991) Institutions, Institutional Effects and Institutionalism. In Powell, W.W. \& DiMaggio, P.J (eds) The New Institutionalism in Organisational Analysis. Chicago, University of Chicago Press.

John, P. (1998) Analysing Public Policy. London, Pinter.

Jones, C.O. (1970) An Introduction to the Study of Public Policy. Belmont, Wadsworth.

Jones, G.W (1975) Development of the Cabinet. In Thornhill, W. (ed.) The Modernisation of the British Government. London, Pitman.

Jones, G.W. (1987) The United Kingdom. In Plowden, W. (ed.) Advising the Rulers .Oxford, Basil Blackwell.

Joseph, P. (1993) Constitutional and Administrative Law in New Zealand. Sydney, Law Book Company.

Kakabadse, A. \& Kakabadse, N. (2000) Outsourcing: A Paradigm Shift. Journal of Management Development 19(6): 668-728.

Kakabadse, A. \& Kakabadse, N. (2001) Outsourcing the Public Service: A Comparative Analysis of Practice, Capability and Impact. Public Administration and Development 21: 401-413.

Kaul, M. (1996) Civil service reforms learning from Commonwealth experience. Public Administration and Development 16: 131-150.

Keating, M. \& Holmes, M. (1990) Australia's Budgetary and Financial Management Reform. Governance 3(2): 169-185.

Kelly, J. (2003) The Audit Commission: Guiding, Steering and Regulating Local Government. Public Administration 81(3): 459-476.

Kelman, S. (1981) Regulating America, Regulating Sweden. Cambridge, MIT Press.

Kemp, P. (1990) Next Steps for the British Civil Service. Governance 3(2): 187-195. 
Kernaghan, K. (1992) Empowerment and Public Administration: Revolutionary Advances or Passing Fantasy? Canadian Public Administration 35(2): 194-214.

Kibria, R. (2001) The Political Economy of Reform: Designing, Initiating and Sustaining Public Sector Reform in Developing Countries. Paper presented at the Commonwealth Advanced Seminar on Transforming Public Organisations, Wellington.

King, S. (2003) Regulating the Behaviour of Ministers, Special Advisers and Civil Servants University College London, The Constitution Unit

Kirkpatrick, C \& Mann, P (1999) Knowledge, training and development: an overview. Public Administration and Development 19: 1-3.

Knapman, B. \& Saldanha, C. (1999) Reforms in the Pacific: An assessment of the Asian Development Bank's Assistance for Reform Programs in the Pacific. Manila, Asian Development Bank.

Knill, C. (1999) Explaining Cross-National Variance in Administrative Reform: Autonomous versus Instrumental Bureaucracies. Journal of Public Policy 19(2): 113139.

Kolehmainen-Aitken, R. (1992) The Impact of Decentralisation on Health Workforce Development in Papua New Guinea. Public Administration and Development 12: 175-191.

Korac-Kakabadse et al. (2000) Information Technology and Development: Creating IT Harems, Fostering New Colonialism or Solving 'Wicked' Policy Problems? Public Administration and Development 20: 171-184.

Larmour, P. (2000) Explaining Institutional Transfer in Melanesia. Pacific Economic Bulletin 15(2): 143-151.

Larmour, P. (2002) Westminster Constitution in the South Pacific: A "Policy Transfer" Approach. Asian Journal of Political Science 10(1): 39-54.

Larmour, P. (2002a) Conditionality, Coercion and Other Forms of 'Power': International Financial Institutions in the Pacific. Public Administration and Development 22: 249-260.

Lasaro, I. (1998) Budget Speech. Waigani, Department of Finance \& Treasury.

Leddy, P.D. (1989) Practical Research: Planning and Design. New York, Macmillan.

Leechor, C. (1995) Fiscal Relations and Service Delivery. Pacific Economic Bulletin 10(1): 31-39.

Leicester, G. (1999) The Seven Enemies of Evidence-Based Policy. Public Money \& Management 19(1): 5-7.

Levantis, T. (2000) Crime Catastrophe - Reviewing Papua New Guinea's Most Serious Social and Economic Problems. Pacific Economic Bulletin 15(2): 130-140.

Levine, C.H. (1988) Human resources erosion and uncertain future of the US civil service: from policy gridlock to structural fragmentation. Governance 1(2): 115-143. 
Lindblom, C.E. (1959) The Science of "Muddling Through." Public Administration Review 19: 79-88.

Lindblom, C.E. (1980) The Policy Making Process. Englewood Cliffs NJ, PrenticeHall.

Lindblom, C.E. \& Cohen, D.K. (1979) Usable Knowledge: Social Science and Social Problem Solving. New Haven, Yale University Press.

Lindquist, E.A. (2001) Building Policy Capacity in Government: Evaluating Recruitment Strategies. Public Sector 24(2): 8-20.

Ling, T. (2002) Delivering Joined-Up Government in the UK: Dimension, Issues and Problems. Public Administration 80(4): 615-642.

Lowndes, V. (1996) Varieties of New Institutionalism: A Critical Appraisal. Public Administration 74(Summer): 181-197.

Luke, D.F (1990) Central Agencies, State Capacity and the Current Structural Adjustments in Sub-Saharan Africa. International Review of Administrative Sciences 56(3): 431-446.

Machin, H. (1987) Advice on Economic and Foreign Policy. In Plowden, W. (ed.) Advising the Rulers (1987).

Maclennan, D. \& More, A. (1999) Evidence, What Evidence? The Foundation for Housing Policy. Public Money \& Finance 19(1): 17-23.

Majone, G. (1991) Cross-National Sources of Policy-Making in Europe and the United States. Journal of Public Policy 2(1): 79-106.

Mann, M. (1984) The Autonomous Power of the State: Its Origins, Mechanisms and Result. Cited in Polidano, C. Measuring Public Sector Capacity World Development 28(5): 805-822.

Mann, P. (1999) Can we make development training development? Public Administration and Development 19: 105-116.

Manning, M. (2000) Privatisation in Papua New Guinea: Where At and Where To? Pacific Economic Bulletin 15(2): 91-105.

March, J.G. \& Olsen, P.J. (1984) The New Institutionalism: Organisational Factors in Political Life. American Political Science Review 78: 734-749.

March, J.D. \& Olsen, P.J. (1996) Institutional Perspectives on Political Institutions. Governance 9(3): 247-264.

Marsh, D. \& Stocker, G. (ed.) (1995) Theory and Methods in Political Sciences. New York, St. Martin's Press.

Martin, J. (1991) Public Service and the Public Servant. Wellington, State Services Commission. 
Martin, J. (1996) The Impact of MMP on Policy Development and Advice. Public Sector 19(2): 17-22.

Martin, S. (1999) Visions of Best Value: Modernising or Just Muddling Through? Public Money \& Management 19 (4): 57-61.

Matheson, C. (1997) The Premises of Decision-Making within the Australian Public Service. Journal of Public Administration 56(1): 13-24.

Matheson, C. (2000). Policy Formulation in Australian Government: Vertical and Horizontal Axes. Australian Journal of Public Administration 59(2): 44-5.

McAdam, R. \& Walker, T., (2003) Evaluating the Best Value Framework in UK Local Government Service. Public Administration and Development (forthcoming).

McCarthy, S. (1998) Just What's it Like to Work Here? Human Resources, April: 1214.

McKinnon, M. (2003) Treasury: The New Zealand Treasury, 1840-2000. Auckland, Auckland University Press.

Mellam, A. \& Aloi, D. (2003). National Integrity Systems TI Country Report: Papua New Guinea: 2003. Port Moresby, Transparency International and Institute of National Affairs.

Meyer, J.W. (1983) Institutionalisation and the Rationality of Formal Organisational Structures. In Meyer, J.W. \& Scott, W.R. (eds) Organisational Environments, Ritual and Rationality California, Sage.

Middlemass, M. (2002) Statement of Intent: The Education Review Office Experience. Public Sector 25(3): 8-9.

Migdal, J.S. (1988) Strong Societies and Weak States: State-Society Relations and State Capabilities in the Third World. Princeton, Princeton University Press.

Miller, R. (ed.) (2001) New Zealand Government and Politic.s Auckland, OUP.

Ministerial Advisory Group (2001) Report of the Review of the Centre, New Zealand. Wellington, State Services Commission and Treasury.

Minogue, K. \& Biddis, M. (eds) (1988) Thatcherism: Personality and Politics. London, Macmillan.

Moore, N. (2000) How to Do Research: The Complete Guide to Designing and Managing Research Projects. London, Library Association Publishing.

Mossberger, K. (2000) The Politics of Ideas and the Spread of Enterprise Zones. Washington DC, Georgetown University Press.

Mossberger, K. \& Wolman, H. (2003) Policy Transfer as a Form of Prospective Policy Evaluation: Challenges and Recommendations. Public Administration Review 63(4): 428-444.

Mouzelis, P. N. (1967) Organisation and Bureaucracy. London, Routledge and Kegan Paul. 
Mulgan, R. (1997) Politics in New Zealand. Auckland, Auckland University Press.

Mutahaba, G. \& Balogun, M. (1992) Enhancing Policy Management Capacity in Africa. West Hartford, Kumarian Press.

Nairne, P. (1996) Mandarins and Ministers: A Former Officials View. In Barberis, P (ed.) The Whitehall Reader. Buckingham, Open University Press.

Nelson, H. (1972) Papua New Guinea: Black Unity or Black Chaos? Victoria, Penguin Books.

Nicholson, T. (1994) Institution building: Examining the fit between bureaucracies and indigenous systems. In Wright, S. (ed.) Anthropology of Organisations. London, Routledge.

Nielsen, K. (2001) Institutionalist Approaches in the Social Sciences: Typology, Dialogue; and Future Challenges. Journal of Economic Issues 35(2): 505-516.

Norman, R. (2003) Obedient Servants? Management Freedom and Accountabilities in the New Zealand Public Sector. Wellington, Victoria University Press.

Norman, R. (2001) Letting and Making Managers Manage: The Effect of Control System on Management Action in New Zealand Central Government. International Public Management Journal 4: 65-89.

OECD (1995) Public Management Developments: Update 1995. Paris, OECD.

OECD (1996) Occasional Papers No.12: Building Policy Coherence: Tools and Tensions. Paris, PUMA-OECD.

OECD (1997) Choice of Policy Instruments. Paris, PUMA-OECD.

OECD (1999) Issues and Development in Public Management Survey 1996-1999 Paris, OECD.

OECD (2000) Strategic Governance and Policymaking: Building Policy Coherence. Online at http://www1.oecd.org/puma/strat/coherence.htm [24.12.02).

OECD (2000a) Strategic Governance and Policymaking: Managing Cross-cutting Issues. Online at http://www1.oecd.org/puma/strat/coherence.htm [24.12.02).

OECD. (1998) Contracting Out Government Services: Best Practice Guidelines and Case Studies: Public Management Occasional Papers No. 20 Paris, OECD.

Office of the Provincial Auditor (2001) A Review of Policy Developments Capacity within Government Departments. Manitoba, Office of the Provincial Auditor.

Oliver, D. \& Drewry, G. (1996) Public Service Reforms: Issues of Accountability and Public Law. London, Pinter

Ormsby, M.J. (1998) The Provider Purchaser Split: A Report from New Zealand. Governance 11(3): 357-387. 
Painter, M. (2001) Policy Capacity and the Effect of New Public Management. In Christensen, T. \& Laegreid, P. (eds) New Public Management: The Transformation of Ideas and Practice. Aldershot Hampshire, Asgate.

Parsons, W. (1995) Public Policy: An Introduction to the Theory and Practice of Policy Analysis. Gloucester, Edward Elgar.

Perrow, C. (1986) Complex Organisations: A Critical Essay. New York, Random House.

Peters et al. (eds) (2000) Administering the Summit: Administration of the Core executive in Developed Countries London, MacMillan Press.

Peters, B.G. \& Pierre, J. (eds) (2003) Handbook of Public Administration London, Sage.

Peters, B.G. (1997) Policy transfers between governments: the case of administrative reforms West European Politics 20(4): 71-89.

Peters, B.G. \& Anthony, B. (eds) (1993) Advising West European Governments: Inquiries, Expertise and Public Policy. Edinburgh, Edinburgh University.

Peters, B.G. \& Pierre, J. (1998) Institutions and Time: Problems of Conceptualisation and Explanation. Journal of Public Administration and Theory 8(4): 565-583.

Philemon, B. (2002) Budget Speech. Delivered to the National Parliament on the Occasion of the 2002 Supplementary Budget. Waigani, Port Moresby.

Plowden, W. (1991) Providing countervailing analysis and advice in a careerdominated bureaucratic system: the British experience, 1916-1988. In Campbell, C. and Wyskomirski, M.J. (eds) Executive Leadership in Anglo-American Systems. Pittsburgh, University of Pittsburgh Press.

Plumptre, T. (1987) New Perspectives in the Role of the Deputy Minister. Canadian Journal of Public Administration 30: 376-398.

Plumptre, T. (1988) Beyond the Bottom Line: Management in Government. Halifax, IRPP.

Ombudsman Commission (2000) Report to Parliament: January 1995-December 1998. Port Moresby, PNGOC.

Poister, T.H. \& Streib, G.D. (1999) Strategic Management in the Public Sector: Concepts, Models and Processes. Public Productivity \& Management Review 22(3): 308-325.

Polidano, C. (2000) Measuring Public Sector Capacity. World Development 28(5): 805-822.

Polidano, C. \& Hulme, D. (1999) Public Management in Developing Countries: Issues and Outcomes. Public Management 1(1): 121-132.

Pollitt, C. (1993). Managerialism and the Public Services. Oxford, Blackwell Publishers. 
Pollitt, C. (1995) Management Techniques for the Public Sector: Pulpit and Practice. In Peters, B.G. \& Savoie, D.J. (eds) Governance in a Changing Environment (1995).

Pollitt, C. (2001) Convergence: the Useful Myth? Public Administration 79(4): 933947.

Powell, W.W. \& DiMaggio, P.J. (1991) The Iron Cage Revisited: Institutional Isomorphism and Collective Rationality in Organisational Fields. In Powell \& DiMaggio (eds) The New Institutionalism in Organisational Analysis. Chicago, University of Chicago Press.

Powney, J. \& Watts, M. (1987) Interviewing in Educational Research. London, Routledge and Kegan Paul.

Public Sector Reform Management Unit (2000) Making the Public Sector Work: A Medium Term Plan of Action for Public Sector Reform in Papua New Guinea, 20002003 Port Moresby, Department of Prime Minister \& NEC.

Pugh, D.S. (1990) Organisation Theory: Selected Readings. London, Penguin Books.

Pusey, M. (1991) Economic Rationalism in Canberra: A Nation Building State Changes Its Mind. Cambridge, Cambridge University Press.

Radaelli, C.M. (2000) Policy Transfer in the European Union: Institutional Isomorphism as a Source of Legitimacy. Governance 13(1): 25-43.

Reilly, B. (1997) The Alternative Vote and Ethnic Accommodation: New Evidence from Papua New Guinea. Electoral Studies 16(1): 1-16.

Reilly, B. (2000) Democracy, Ethnic Fragmentation and Internal Conflict: Confused Theories, Faulty Data, and the Crucial Case. International Security 25(3): 162-185.

Reilly, B. (2002) Back to the Future? The Political Consequences of Electoral Reform in Papua New Guinea.Journal of Pacific History 37 (2): 239-53.

Reilly, B. (2002a) Economic decline and political reform in Papua New Guinea. Pacific Economic Bulletin 17(2): 134-140.

Rhodes, R.A.W \& Dunleavy, P (eds) (1995) Prime Minister, Cabinet and Core Executive. London, Macmillan.

Rhodes, R.A.W. (1994) The Hollowing-Out of the State: The Changing Nature of the Public Service in Britain. Political Quarterly 65(2): 138-51.

Rhodes, R.A.W. (1995) Introducing the Core Executive. In Rhodes, R.A.W. \& Dunleavy, P. (eds) Prime Minister, Cabinet and Core Executive. London, MacMillan Press.

Rhodes, R.A.W. (1997) Understanding Governance: Policy Networks, Governance, Reflexivity and Accountability. Buckingham, Open University Press.

Rhodes, R.A.W. and Weller, P (eds) (2001) The Changing World of Top Officials. Buckingham, Open University Press. 
Richards, D. and Smith, M. (2002) The Paradoxes of Governance and Policy Coordination: Britain - A Case in 'Joined-Up-Government. Paper Presented at the Structure and organisation of Government Conference, IPSA, Melbourne University, Melbourne, Australia, June 3-5, 2002.

Roberts, J. (1987) Politicians, Public Servants \& Public Enterprise. Institute of Policy Studies Wellington, Victoria University Press.

Robinson, M. (2002) The Public Service and Statement of Intent. Public Sector 25(1): 6-9.

Robson, C. (1993) Real World Research: A Resource for Social Scientists and Practitioner-Researchers. Oxford, Blackwell Publishers.

Rockman, B.A. (1998) The Changing Role of State. In Peters, G. \& Savoie, P. (eds) Taking Stock: Assessing Public Sector Reforms (1998).

Rondinelli, D.A. (1993) Development Projects as Policy Experiments: An Adaptive Approach to Development Administration. London, Routledge.

Rose, R. (1991) What is Lesson-Drawing? Journal of Public Policy 2(1): 3-30.

Rose, R. (1993) Lesson-Drawing in Public Policy: A Guide to Learning Across Time and Space. New Jersey, Chatham House.

Rose, R. \& Davies, P.L. (1994) Inheritance in Public Policy: Change Without Choice in Britain. New Haven, Yale University Press.

Saffu, Y. (1996) Continuity and Change in Electoral Politics. In Saffu, Y. (ed.) The 1992 Papua New Guinea Election: Change and Continuity in Electoral Politics. Canberra, Australian National university.

Sanderson, I. (2002) Evaluation, policy learning and evidence-based policy making. Public Administration 80(1): 1-22.

Sause, L. (2002) Policy Transfer and Policy Learning: The Case of Public Management Reforms in Papua New Guinea. Paper presented at the Policy Network Conference Hobart, University of Tasmania.

Sause, L. (2003) Problems of Policy Transfer in Public Management Reforms. Labour and Management in Development Journal, 2(7): 2-17.

Sause, L. \& Kinkin, E. (1997) Managing Decentralisation in Local-Level Governments: Papua New Guinea. Pacific Economic Bulletin 12(2): 45-53.

Sause, L. \& Aloi, D. (2003) Public Sector Reform in Papua New Guinea: Stalemate or Progress? Pacific Economic Bulletin 18(1): 67-78.

Savoie, D.J. (1994) Thatcher, Reagan, Mulroney: In Search of a New Bureaucracy. Pittsburgh, Pittsburgh University Press.

Schick, A. (1996) The Spirit of Reform: Managing the New Zealand State Sector in a Time of Change. Wellington, The State Services Commission. 
Schick, A. (1998) Why Most Developing Countries Should Not Try New Zealand's Reform. World Bank Observer 13(1): 123-131.

Schweiger et al. (1989) Experimental Effects of Dialectical Inquiry, Devil's Advocacy and Consensus Approaches to Strategic Decision Making. Academy of Management Journal 32: 745-722.

Scott, C. (1992) 'Review of Purchase of Policy Advice form Government Departments. Public Sector 15(2): 19-24.

Scott, G. (2001) Public Management in New Zealand: Lessons and Challenges. Wellington, New Zealand Business Roundtable.

Self, P. (1977) Administrative Theory and Politics: An Enquiry into the Structure and Processes of Modern Government. London, Allen \& Unwin.

Self, P. (1995) Government by the Market. Boulder CO., Westview Press.

Selznick, P. (1957) Leadership in Administration. Illinois, Row \& Peterson.

Sender, J. (1999) Africa's Economic Performance: Limitations of the Current Consensus. Journal of Economic Perspectives 13(3): 89-114.

Seymour-Ure, C. (1987) Institutionalisation and Informality in Advisory Systems. In Plowden, W. (ed.) Advising the Rulers (1987)

Shaw, R. (2003) Advisers and Consultants. In Miller, R. (ed.) New Zealand Government and Politics. Melbourne: Oxford University Press.

Simon, H. (1957) The Models of Man. New York, John Wiley and Sons.

Simon, H, (1996) Decision-Making in Organisations: Hebert, A. Simon. In Pugh, D.S. \& Hickson, D.J. (eds) Writers on Organisations. London: Penguin Books.

Simon, H. (1991) Bounded Rationality and Organisational Learning Organisation Science 2(1): 125-134.

State Services Commission (1991) Review of the Purchase of Policy Advice from Government Departments. Wellington, State Services Commission.

State Services Commission (1992) The Policy Advice Initiative: Opportunities for Management. Wellington, State Services Commission.

State Services Commission (1995) The Senior Public Servant. Wellington, State Services Commission.

State Services Commission (1995a) Working Under Proportional Representation. Wellington, State Services Commission.

State Services Commission (1999) Essential Ingredients: Improving the Quality of Policy Advice, Occasional Paper No. 9. Online at http://www.ssc.govt.nz [8.11.02]

State Services Commission (1999a) High Flyers: Developing High Performing Policy Units', Occasional Paper No. 22. Online at http://www.ssc.govt.nz 
State Services Commission (1999b) Minds over Matter: Human Resource Issues Affecting the Quality of Policy Advice, Occasional Paper No. 8. Online at http://www.ssc.govt.nz [15.10.02].

State Services Commission (2000) Building Advice: The Craft of the Policy Professional, Working Paper No.7. Online at http://www.ssc.govt.nz [12.08.02].

Stacey, R.D. (1995) The Science of Complexity: An Alternative Perspective for Strategic Change processes. Strategic Management Journal 16: 477-495.

Steinmo, S. (2001) The New Institutionalism. In Clark. B \& Foweraker. J (eds.) The Encyclopedia of Democratic Thought. London: Routlege.

Stewart, J. (1999) 'Researcher Note: Purchaser-Provider: Are the Purchasers Ready for It? Australian Journal of Public Administration, 58(4): 105-111.

Stone, D. (1996) Capturing the Political Imagination: Think Tanks and Policy Process. London, Frank Cass.

Stone, D. (2000) Non-Governmental Policy Transfer: The Strategies of Independent Policy Institutes. Governance 13(1): 45-62.

Taylor, A. (2000) Hollowing Out or Filling In? Taskforces and the Management of Crosscutting Issues in British Government. British Journal of Politics and International Relations 2: 46-71.

Thain, C. \& Wright, M. (1992) Planning and Controlling Public Expenditure in the UK, Part I: The Treasury's Public Expenditure Survey. Public Administration 70(Spring): 3-24.

Thain, C. \& Wright, M. (1992a) Planning and Controlling Public Expenditure in the UK, Part II: The Effects and Effectiveness of the Survey. Public Administration, 70(Summer): 193-224.

Thelen, K (1999) Historical Institutionalism in Comparative Politics. American Review of Political Science. 2: 369-404.

Toonen, T.A.J. (1992) Europe of the Administrations: The Challenges of '92 (and Beyond). Public Administration Review 52 (2): 108-118.

Transparency International (2002) 'Corruption Perception Index (CPI). Online at http://www.transparency.org [31.10.02].

Turner, M \& Hulme, D. (1997) Governance, Administration and Development: Making the State Work. London, MacMillan Press.

Turner, M. (1990) Papua New Guinea: The Challenge of Independence. Victoria, Penguin Books.

Udoh, J.V. (1998) Building the Capacities of Developing Nations through Empowerment. In Udoh, J.V. (ed.) Capacity Building in Developing Countries. London, Praeger.

Uhr, J. (1996) Testing the Policy Capacities of Budgetary Agencies: Lessons from Finance. Australian Journal of Public Administration 55(4): 124-134. 
UK Cabinet Office (1999) Modernising Government: Action Plan. London, Cabinet Office

UK Cabinet Office (1999a) Professional Policy Making for the Twenty First Century. London, Cabinet Office.

UK Cabinet Office (1999b) Civil Service Reform: Report to the Prime Minister from Sir Richard Wilson, Head of the Home Civil Service. London, Cabinet Office.

UK Cabinet Office (2000) Adding It Up: Improving Analysis \& Modelling in Central Government. London, Cabinet Office.

UK Cabinet Office (2000a) Wiring It Up: Whitehall Management of Cross-cutting Policies and Services. London, Performance and Innovation Unit, Cabinet Office.

Ulrich, D (1998) Intellectual Capital $=$ Competence $\mathrm{x}$ Commitment. Sloan Management Review Winter. 15-26.

UNDP (1999) Human Development Report. New York, Oxford University Press.

UNDP (1999-2000) Human Development Reports, 1999, 2000, 2001. New York, Oxford university Press.

UNDP (1999a) Fighting Corruption to Improve Governance. New York, UNDP.

UNDP (2001) Human Development Report 2001. Oxford, Oxford University Press.

Voyce, E. (1997) Providing Free and Frank Advice to Government: Fact or Fiction? Public Sector 20(1): 9-17.

Waller, M. (1992) Evaluating Policy Advice. Australian Journal of Public Administration 51(4): 440-449.

Waller, M. (1996) The Changing Environment of Policy Advising. In Uhr, J. \& Mackay, K. (eds) Evaluating Policy Advice: Learning from Commonwealth Experience Federalism Research Centre Canberra, Australian National University and Commonwealth Department of Finance.

Wallis, J. \& Dollery, B. (2001) Understanding Cultural Changes in an Economic Control Agency: The New Zealand Treasury. Journal of Public Policy 21(2):191-212.

Walter, J. (1986) The Minister's Minders: Personal Advisers in National Governments. Melbourne, Oxford University Press.

Watson, G.H. (1993) Strategic Benchmarking. How to Rate your Company's Performance against the World's Best. Chichester, Wiley.

Weimer, D.L. \& Vining, A.R.(1999) Policy Analysis: Concepts and Practice. New Jersey, Prentice-Hall.

Weiss, L. \& Hobson, J.M. (1995) States and Economic Development: A Comparative Historical Analysis. Cambridge, Polity Press. 
Weller et al. (eds) (1997) The Hollow Crown: Countervailing Trends in Core Executives. London, Macmillan.

Weller, P. \& Bakvis, H. (1997) The Hollow Crown: Coherence and Capacity in Central Government in Weller et al. (eds) The Hollow Crown: Countervailing Trends in Core Executives (1997)

Weller, P. \& Stevens, B. (1998) Evaluating Policy Advice: The Australian Experience. Public Administration 76: 578-589.

Weller, P. (1987) Types of Advice. In Plowden, W. (ed.) Advising the Rulers (1987).

Weller, P. (1987a) Australia. In Plowden, W. (ed.) Advising the Rulers (1987).

Weller, P. (1996) Commonwealth State Reform Processes: A Policy Management Review. Australian Journal of Public Administration 55(1): 95-110.

Weller, P. (2001) Australia's Mandarins: the Frank \& the Fearless? Sydney, Allen \& Unwin.

Whimp, K. (2000) New Public Management and Its Application in Developing Countries: The Case of Papua New Guinea. Unpublished Paper Waigani, Department of Prime Minister \& NEC.

Wildavsky, A. (1979) Speaking Truth to Power: The Art and Craft of Policy Analysis. Boston, Little Brown and Company.

Wilson, K.G, \& Barker, A. (2003) Bureaucrats and Politicians in Britain. Governance 16(3): 349-372.

Windybank, S. \& Manning, M. (2003) Papua New Guinea on the Brink. Sydney, Centre for Independent Studies.

Wintringham, M. (1999) Occasional Papers: Improving the Quality of Policy Advice. Wellington, State Services Commission.

Wintringham, M. (2002) Annual Report of the State Services Commissioner. Wellington, State Services Commission.

Wolf, A. (2000) Building Advice: The Craft of the Policy Professional. Wellington: State Services Commission.

Wolman, H. (1992) Understanding Cross-National Policy Transfers: The Case of Britain and the US. Governance 5(1): 27-45.

World Bank (1989) World Development Report. Washington DC, World Bank.

World Bank (1990) The World Development Report. Washington DC, World Bank.

World Bank (1995) Papua New Guinea: Delivering Public Services: Volumes I \& II. Washington DC, World Bank.

World Bank (1997) World Development Report 1997: The State in a Changing World. Washington DC, World Bank. 
World Bank (1999) Country Assistance Strategy of the World Bank Group for the Independent State of Papua New Guinea. Washington DC, World Bank.

World Bank (1999a) Papua New Guinea: Improving Governance and Performance. Washington DC, World Bank.

World Bank (2000) Papua New Guinea: Country Assistance Evaluation. Washington DC, World Bank.

World Bank (2000a) Reforming Public Institutions and Strengthening Governance: A World Bank Strategy. Washington DC, The World Bank.

World Bank (2002) World Development Report 2003: Sustainable Development in a Dynamic World. Online at http://econ.worldbank.org/wdr/wdr2003 [8.1.03].

World Bank (2002a) Chapter 7: Strengthening National Coordination. In World Bank (ed.) World Development Report: Sustainable Development in a Dynamic World. Online at http://econ.worldbank.org/wdr/wdr2003 [8.1.03].

Yin, R. (1994) Case Study Research: Design and Methods. Thousand Oaks, Sage Publications.

\section{News Articles}

Asian Development Bank News Release 192/01, 12 December 2001. Online at www.adb.org/Documents/news/2001/nr201192.asp.

Gomez, B. (2003) 'PNG, a power in the Pacific. Online at http://www.thenational.com.pg/0204/nation19.htm [2.4.03].

Hriehwazi, Y. (2003) Corruption Chocking PNG to Death: Sinclair. Online at http://www.thenational.com.pg/1028/opinion13.htm [29.10.02].

Taimbari, C. (2003) Top government official told to deliver results. Online at http://www.thenational.com.pg/0203/nation4.htm [2.3.03].

The National, 'Exchange Rates. Online at

http://www.thenational.com.pg/0131/currency.htm [31.1.03].

The National, 'Financial crisis looms, warns BPNG', online at http://www.thenational.com.pg/0802/nation2.htm [8.2.02].

The National, Education Reports. Online at http://www.thenational.com.pg/0203/opinion2.htm [3.2.03].

The National, Financial crisis looms, warns BPNG. Online an http://www.thenational.com.pg/0802/nation2.htm [8.2.02].

The National, Government warned over appointments. Online at http://www.thenational.com.pg/108/nation17.htm [18.10.02].

The National, Monday $16^{\text {th }}$ November 2000

The National, Monday $24^{\text {th }}$ April 2001 
The National, TI urges Govt to stop 'jobs for the boys', online at http://www.thenational.com.pg/1028/nation4.htm [29.10.02].

Post Courier, Adjustments hit spending, online at http://www.postcourier.com.pg/20021024/news06 [10.24.02].

Post Courier, Jude: Prosecute contract abusers, online at http://www.postcourier.com.pg/20021024/news15 [24.10.02].

The Post Courier, Tribunals set to roll, online at http://www.postcourier.com.pg/20030207/news10

Post Courier, Friday $22^{\text {nd }}$ June 2001

Post Courier, Wednesday $13^{\text {th }}$ June 2001

Post Courier, online at http://www.postcourier.com.pg/20031212/news01.htm

Post Courier, online at http://www.postcourier.com.pg/20031216/news02

\section{Papua New Guinea Laws}

Constitution of the Independent State of Papua New Guinea

Organic Law on the Integrity of Political Parties and Candidates 2001

Organic Law on provincial and Local-Level Governments 1995

Public Finance (Management) Act 1995

Public Service (Management) Act 1995

Prime Minister Act 2002 